Fall 2020

\title{
2020 Miracle Yearbook
}

Cedarville University

Follow this and additional works at: https://digitalcommons.cedarville.edu/yearbooks

Part of the Higher Education Commons, Organizational Communication Commons, and the Public Relations and Advertising Commons

\section{Recommended Citation}

Cedarville University, "2020 Miracle Yearbook" (2020). Yearbooks. 101.

https://digitalcommons.cedarville.edu/yearbooks/101

This Book is brought to you for free and open access by DigitalCommons@Cedarville, a service of the Centennial Library. It has been accepted for inclusion in Yearbooks by an authorized administrator of DigitalCommons@Cedarville. For more information, please contact digitalcommons@cedarville.edu. 

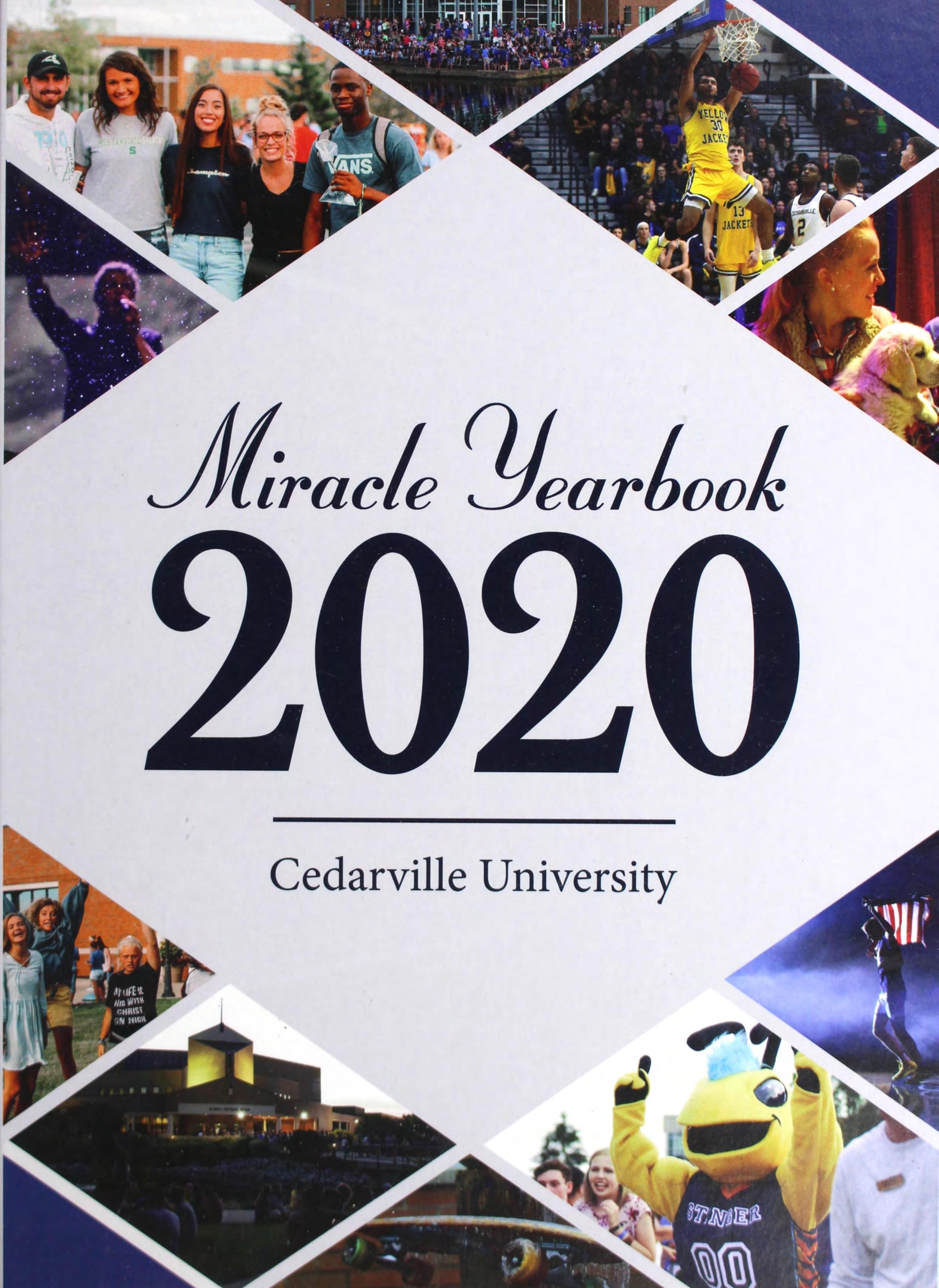


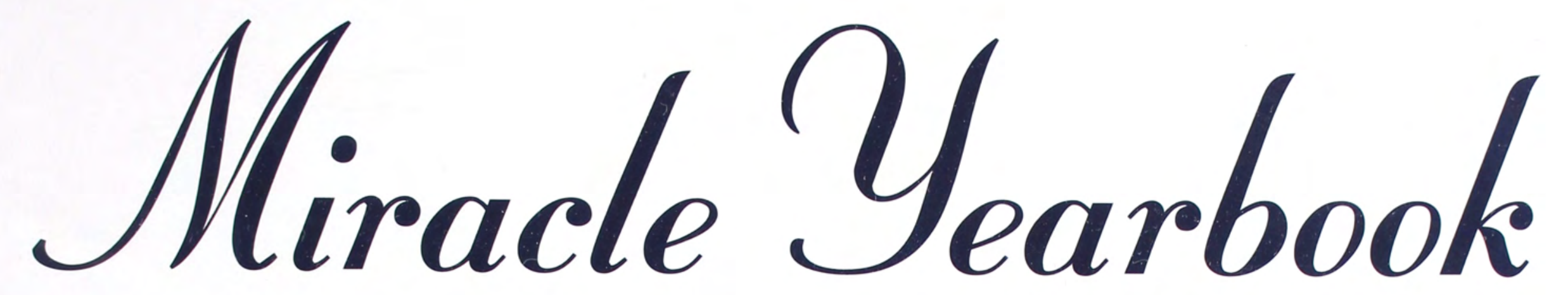

2019-2020 | Cedarville University | Volume 66 | 251 N. Main Street Cedarville, OH

Opening............................................... 02

Dedication.................................................... 03

Fall..................................................... 04

Winter.................................................... 14

Spring..................................................... 24

Student Life........................................... 32

Global Outreach...................................... 48

Sports.................................................... 54

ICC Students.......................................... 72

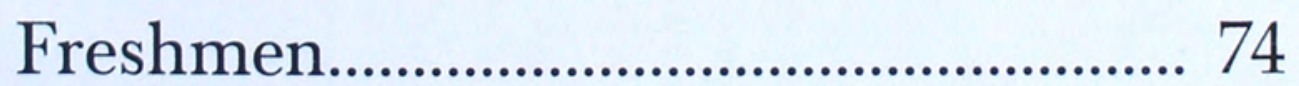

Sophomores.......................................... 82

Juniors....................................................... 86

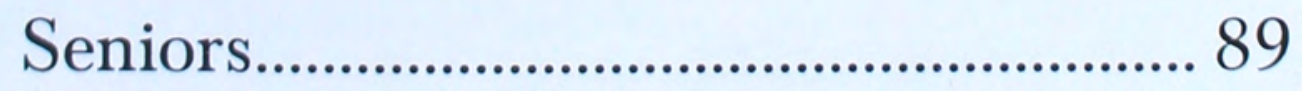

Faculty and Staff.....................................104

Senior Celebrations.................................110

Yearbook Staff........................................114

Letter from the Editor............................116

Colophon................................................. 117

Closing...................................................... 118

Index......................................................119 


\section{Opening...}

Ask pretty much anyone at Cedarville what their favorite thing is about living here, and they'll spit out the same answer: "It's the community." It comes across as borderline comedic when you're an incoming freshman; how can everybody have the same favorite thing, and what does "community" mean anyway? But since we've joined the Cedarville family and then stuck around for a year, we've realized exactly what they meant.

Over the course of this school year, we learned about what it means to live in community with one another. We gathered in Chuck's and Stinger's, saving our spots with our wallets as if we'd just come home. We went on group camping trips with people from our dorms. In the morning we gathered as a student body in chapel to praise God. In the afternoon we met for one-on-ones with friends at Rinnova to discuss our hardships and triumphs and how Christ was getting us through it all. We even gathered together to eat dinner at our professors' houses. Community started as a vague concept to us, but by the end of the school year, it had been shown to us so clearly that we were then able to live it out as we loved others.

Our goal in creating this book was to show exactly what community means to us. We wanted to capture this intangible concept through words and pictures. Our goal was to give it a concrete representation we can look back on in twenty years to remember the beginning of our understanding of true, deep Christian community. Our hope is that it would serve as a reminder of not only everything this year was, but also portray the undercurrent of Christ's love and the fellowship that comes from being family through Him. 


\section{Dedication}
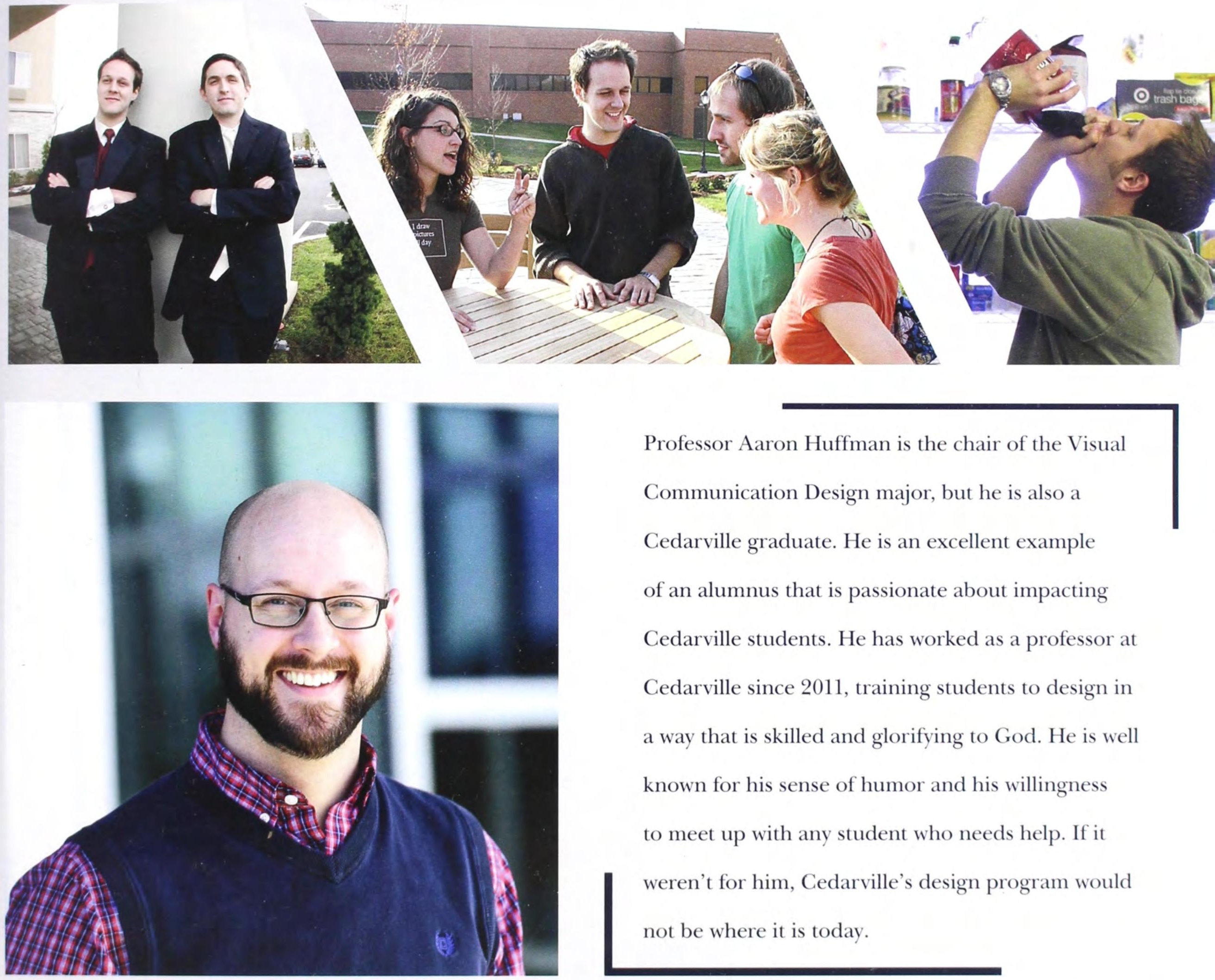

Professor Aaron Huffman is the chair of the Visual

Communication Design major, but he is also a

Cedarville graduate. He is an excellent example

of an alumnus that is passionate about impacting

Cedarville students. He has worked as a professor at

Cedarville since 2011, training students to design in

a way that is skilled and glorifying to God. He is well

known for his sense of humor and his willingness

to meet up with any student who needs help. If it

weren't for him, Cedarville's design program would not be where it is today.

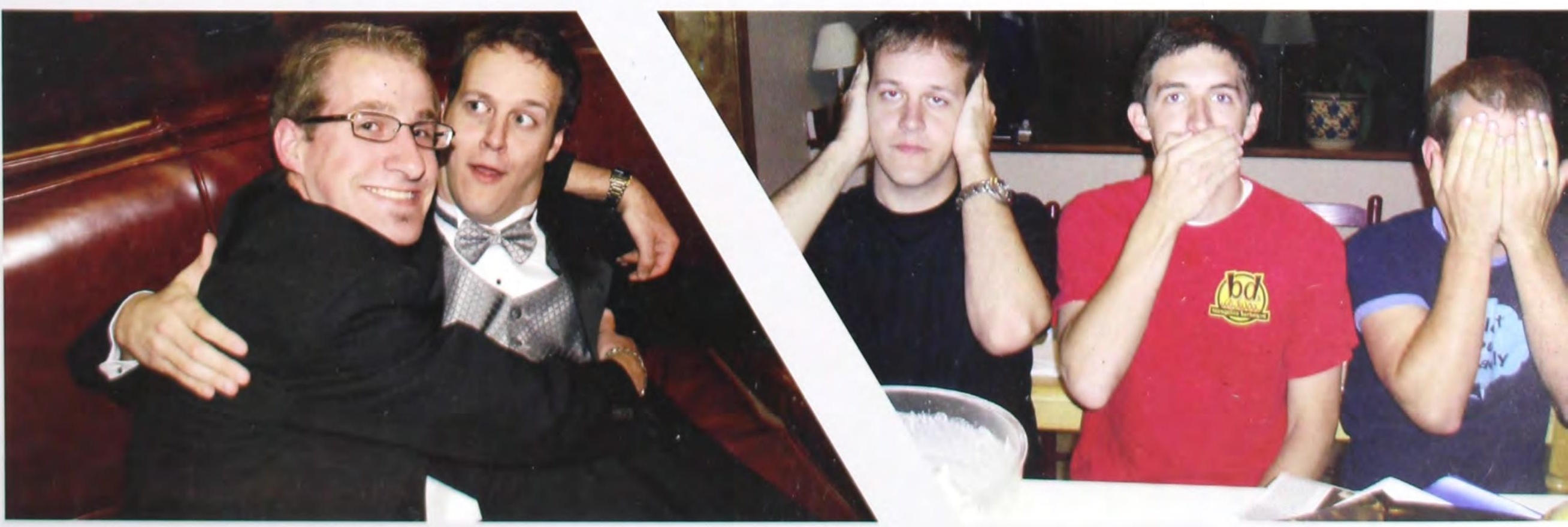




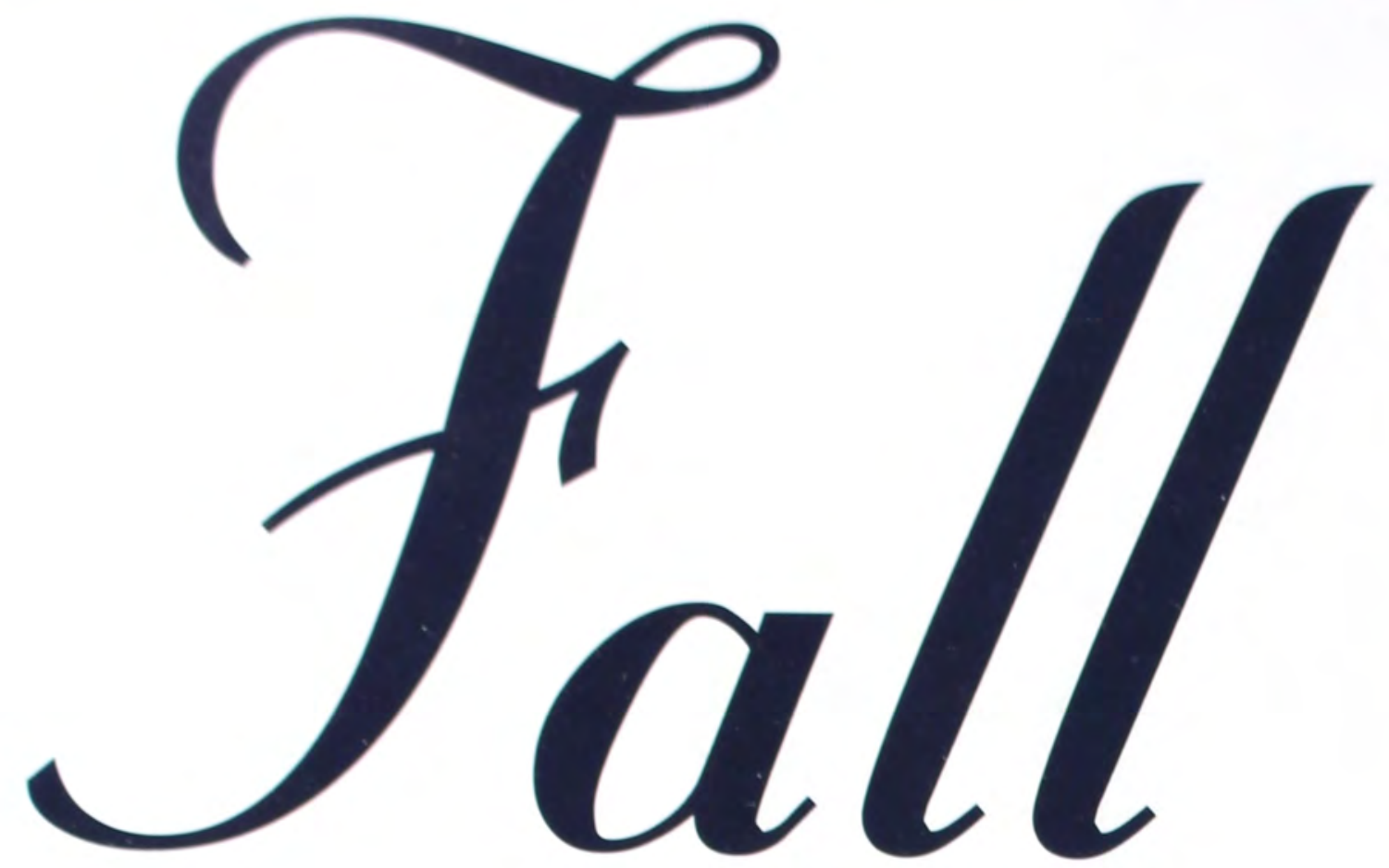

Autumn brought us new friends and new opportunities. Every activity, from

campus-wide events like Getting Started, Bible Conference, the Involvement Fair,

and Homecoming to smaller bro/sis events like speed dating and worship nights,

helped us cultivate a Christ-centered community. We met new friends, kicked

things off, and began our journey of understanding what it meant to live, work,

and worship with our brothers and sisters in Christ.

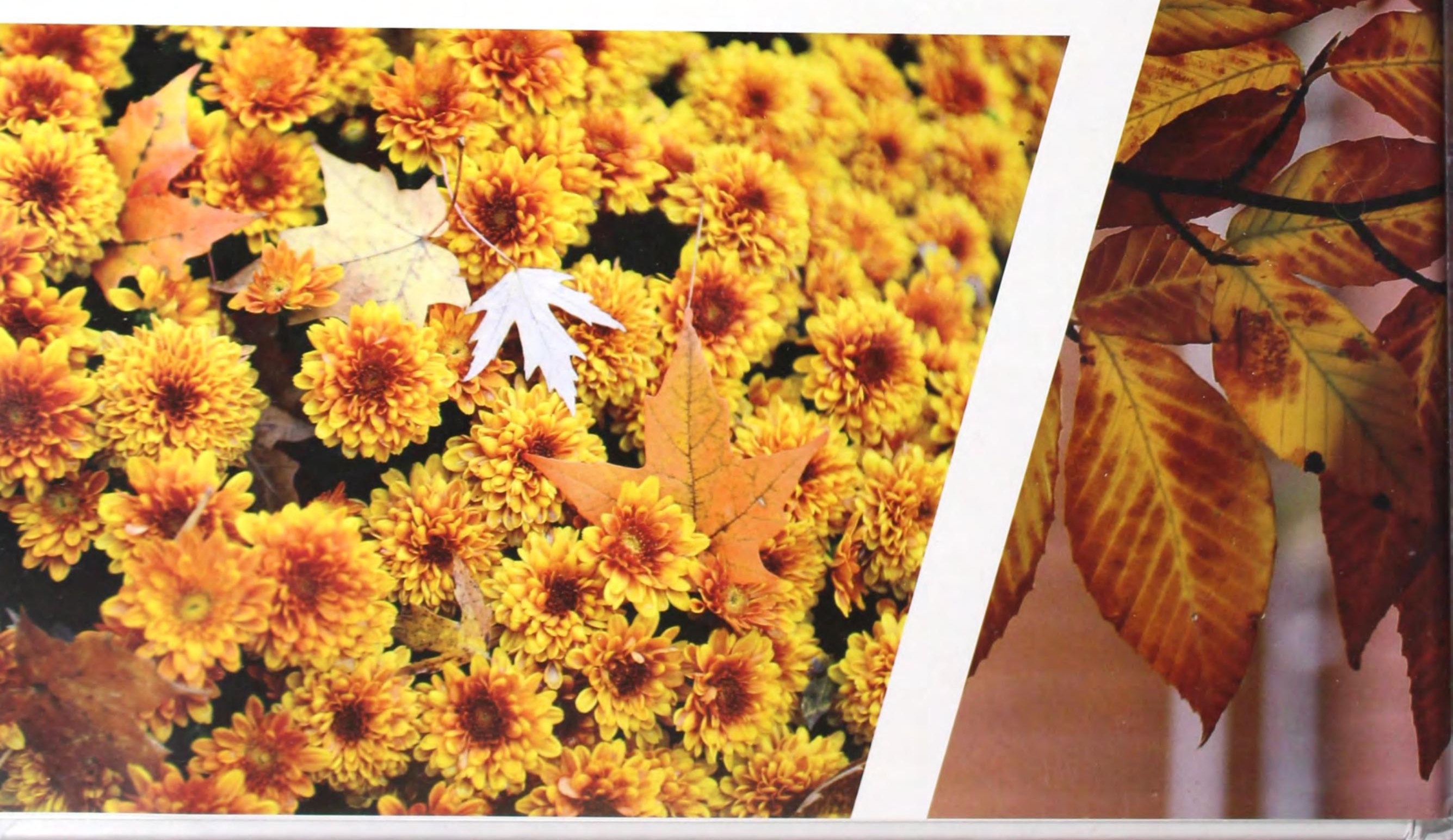




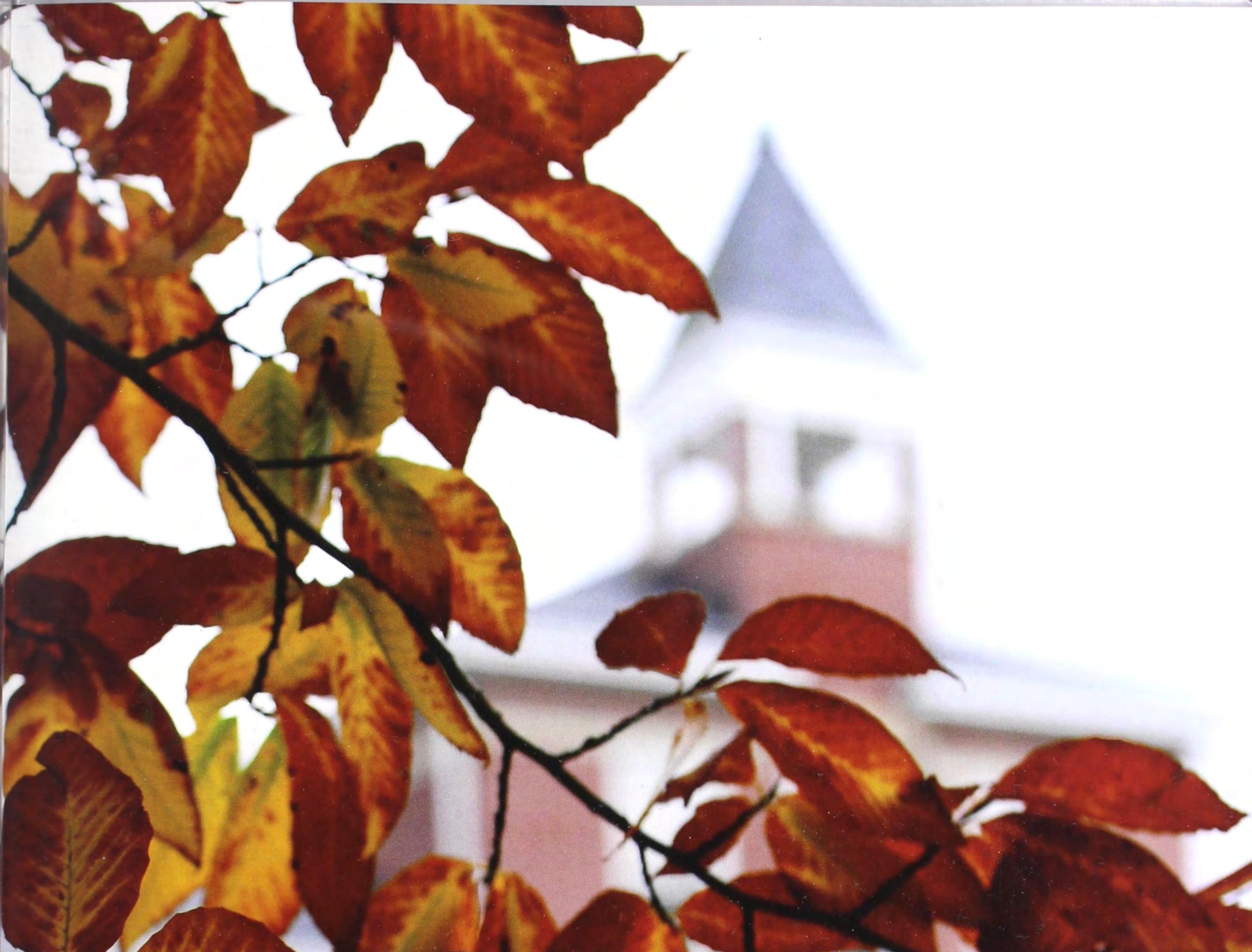


1. Todd Landis walks through a group of cheering STING Leaders during Getting Started weekend. This was an annual tradition for incoming freshmen.

2. Gabby Gagarinas, Lydia Switzer, Abby Burr, and Makayla Riley welcome students to campus during move in. The STING Leaders and RAs moved in all the incoming freshmen during this weekend.

3. After the freshman class photo, Stinger leads the way in the Jacket Jaunt.

4. A STING group gets to know one another during the Jacket Fest event. This event allowed new students to develop lasting relationships during their first weekend on campus.

5. A group of students play nine square in the air during Jacket Fest. This party was a great opportunity for students to make memories before classes started.

6. Alec Mathisen cheers with STING Leaders during a Getting Started event. Getting Started Weekend was an exciting time for incoming students as well as returning

7. RAs Anna Ward, Brooke Bailey, Isabella Schaffer, Jenna Hedlund, Allison McClean, Abbie Hintz, Grace Watkins, Olivia Dayeart, Emma Smith, Torri Wick, Charlotte Burcham, and Lydia Nordquist pose for a picture during Getting Started Weekend.
Getting Started weekend was a bittersweet time for

families. Parents were dropping off their students for

the first time, new students were moving into the dorms

for the first time, and returners were excited to get

back into the swing of college life. RAs on campus had

the special privilege of interacting with parents while

moving new students into the dorms. "My favorite part

about Getting Started is getting to see the reaction of

the parents," Anna Ward, a junior RA, said. "Typically

the students are really upbeat and excited, so it's really

fun to be able to make them more excited, but the

parents are kind of apprehensive." Even though many

parents were nervous, Ward enjoyed helping parents

and students acclimate to campus. "Getting Started is

a huge ministry to parents because we are able to show

them that Cedarville is a special place," Ward said.

"Some of these parents might not be saved, so we are

able to serve them as well and show them the love of

Jesus. Plus, it's always fun to see the parents get excited and [give] high fives on the way in."

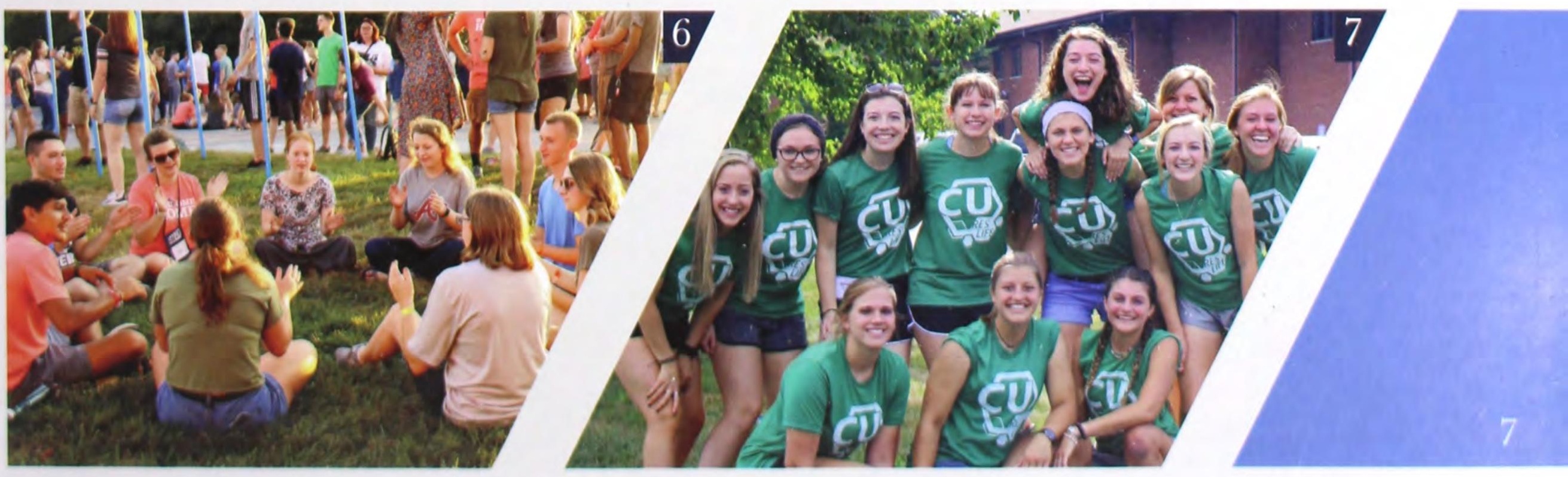



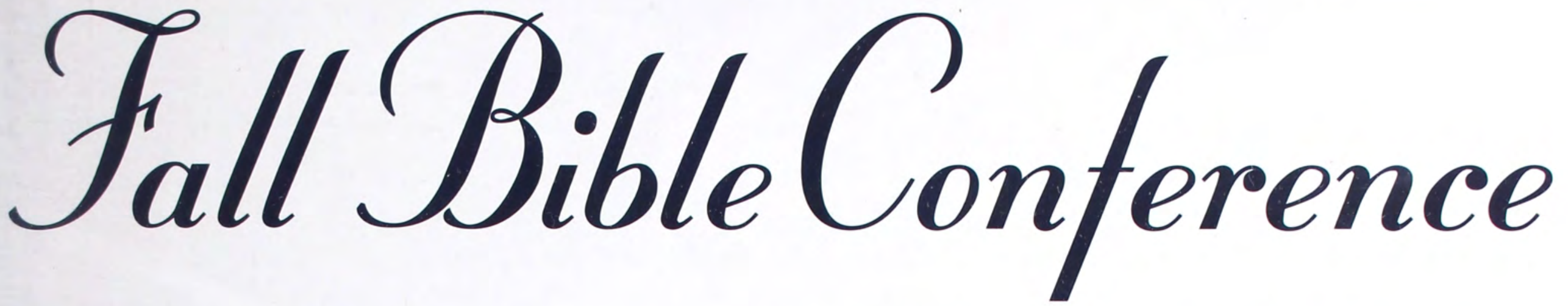

Students came together as a body of believers to start the semester focused on the Lord. Before classes even began, the entire student body joined together for Fall Bible Conference. They joined in worship together, and Dean Inserra encouraged them to prioritize Christ.

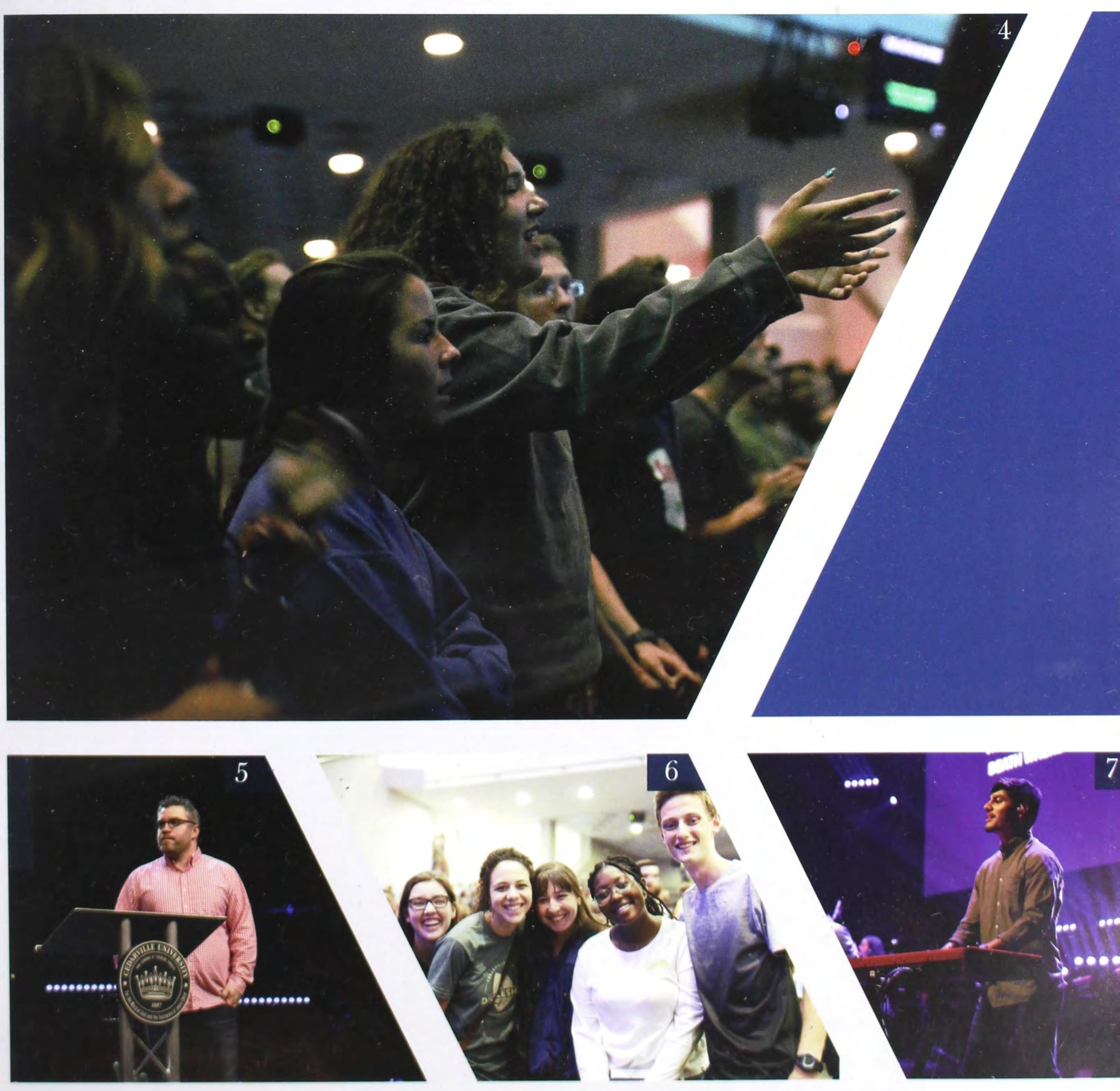


This fall, Cedarville took a different approach to a

Shakespeare classic, "Comedy of Errors," by giving it a unique twist: basing it in the 60's. Abigail Shaffer had the opportunity to play Dromio of Ephesus, and she loved playing this role in the new take. "Our version was unique in a lot of different ways - most notably the time period change, of course (amazing costumes from the 60 's), and also the fact that the two Dromio characters were now female instead of male," Shaffer said. "This gave us a lot of opportunities to play with the material and explore different ways to make the show come to life for the audience." Before this show, Shaffer had not participated in theatre, but she has always been a theatre enthusiast. She enjoyed getting to know new friends while preparing for the performance and loved the opportunity to participate in this play.

"I've never enjoyed working on any big project as much as I enjoyed working on this show..." Shaffer said. "As a homeschooled military kid, I was never able to do theatre in high school, so this was a huge surprise and blessing."
1. Two guards (Rachel Terrell and Kristin Klimek) apprehend Antipholus of Ephesus (Joey Evans). Dr. Pinch (Carl Weaver) observed the arrest.

2. Beth Oldham as Dromio of Syracuse and Hunter Johnson as Antipholus of Syracuse back away from the Courtesan in fear.

3. Rachel Terrell as the Second Merchant and Lauren Jacobs as Angela the Goldsmith demand a chain and ducats from Hunter Johnson as Antipholus of Syracuse. Beth Oldham as Dromio of Syracuse observes, confused.

4. Joey Evans as Antipholus of Ephesus, Abby Schaffer as Dromio of Ephesus, Beth Oldham as Dromio of Syracuse, and Hunter Johnson as Antipholus of Syracuse take their final bows.

5. Beth Oldham (Dromio of Syracuse) observes Hunter Johnson (Antipholus of Syracuse) as he stares in disbelief at a chain he did not request.

6. Beth Oldham (Dromio of Syracuse) and Abby Schaffer (Dromio of Ephesus) stand face to face for the first time as through they are looking in a mirror.

7. Lauren Jacobs (Angela the Goldsmith) is threatened by Joey Evans (Antipholus of Ephesus) for not bribing him.
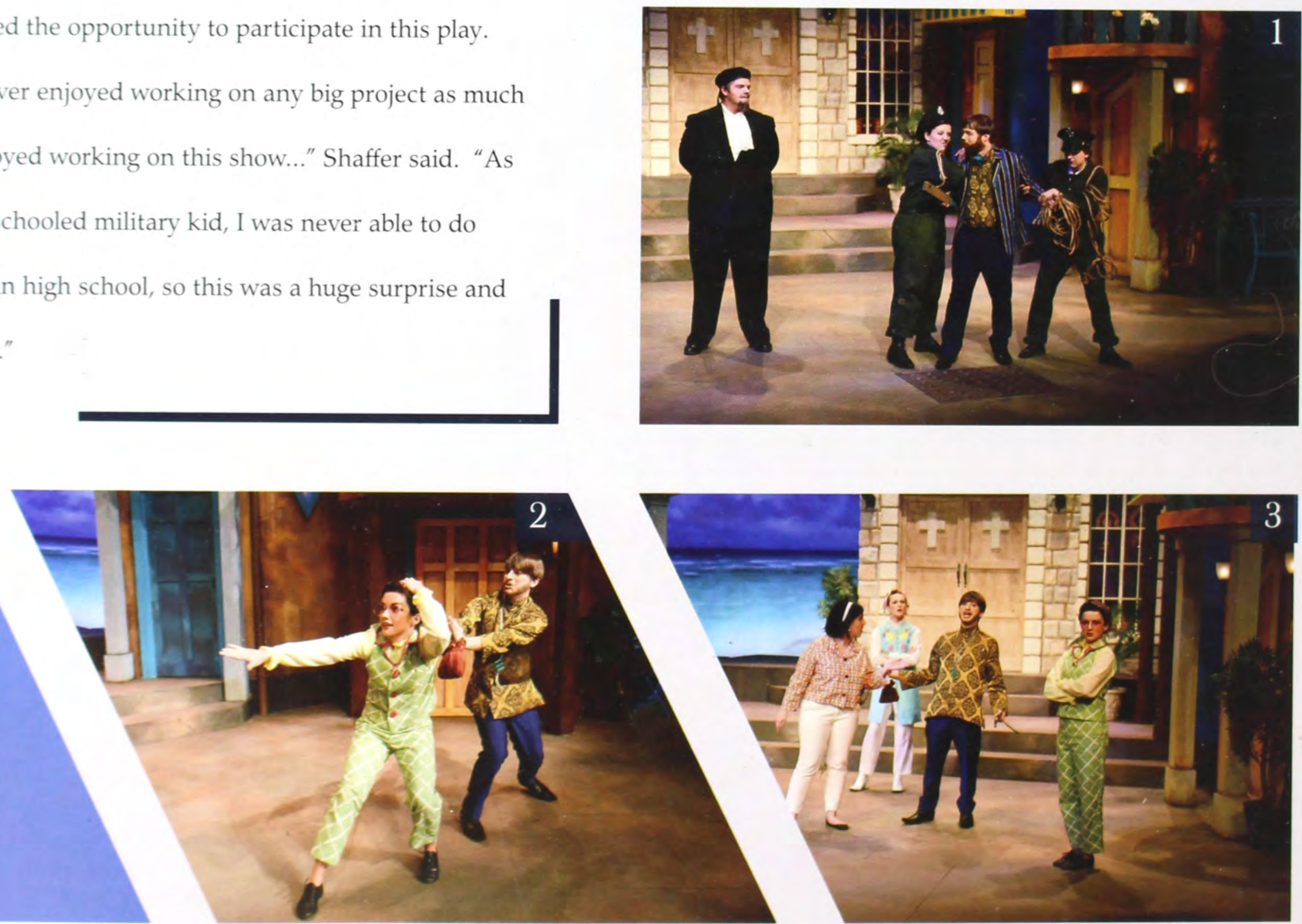

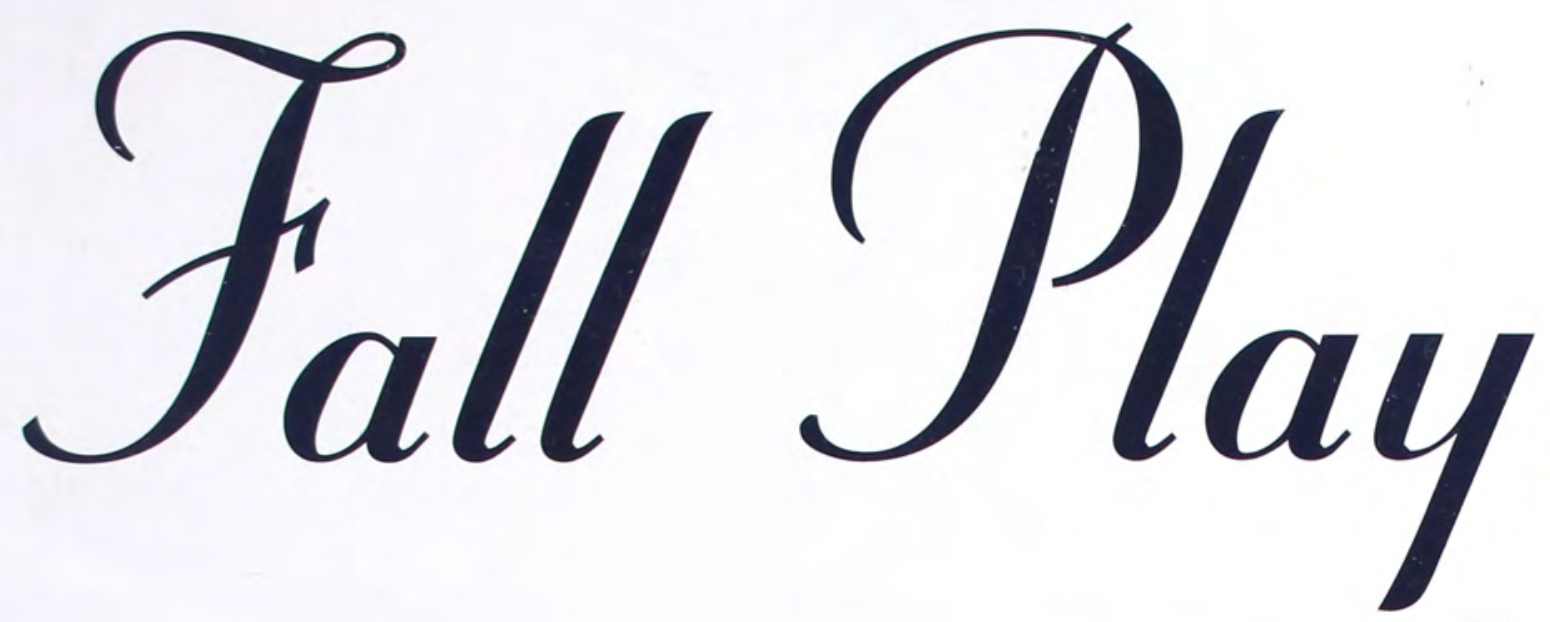

The Department of Art, Design, and Theatre performed an adaptation of "Comedy of Errors" that was changed to take place in the 1960's. Although the script remained consistent with the original Shakespeare play, the director, Diane Merchant, altered the costumes to resemble 60's fashion to add a fun twist.
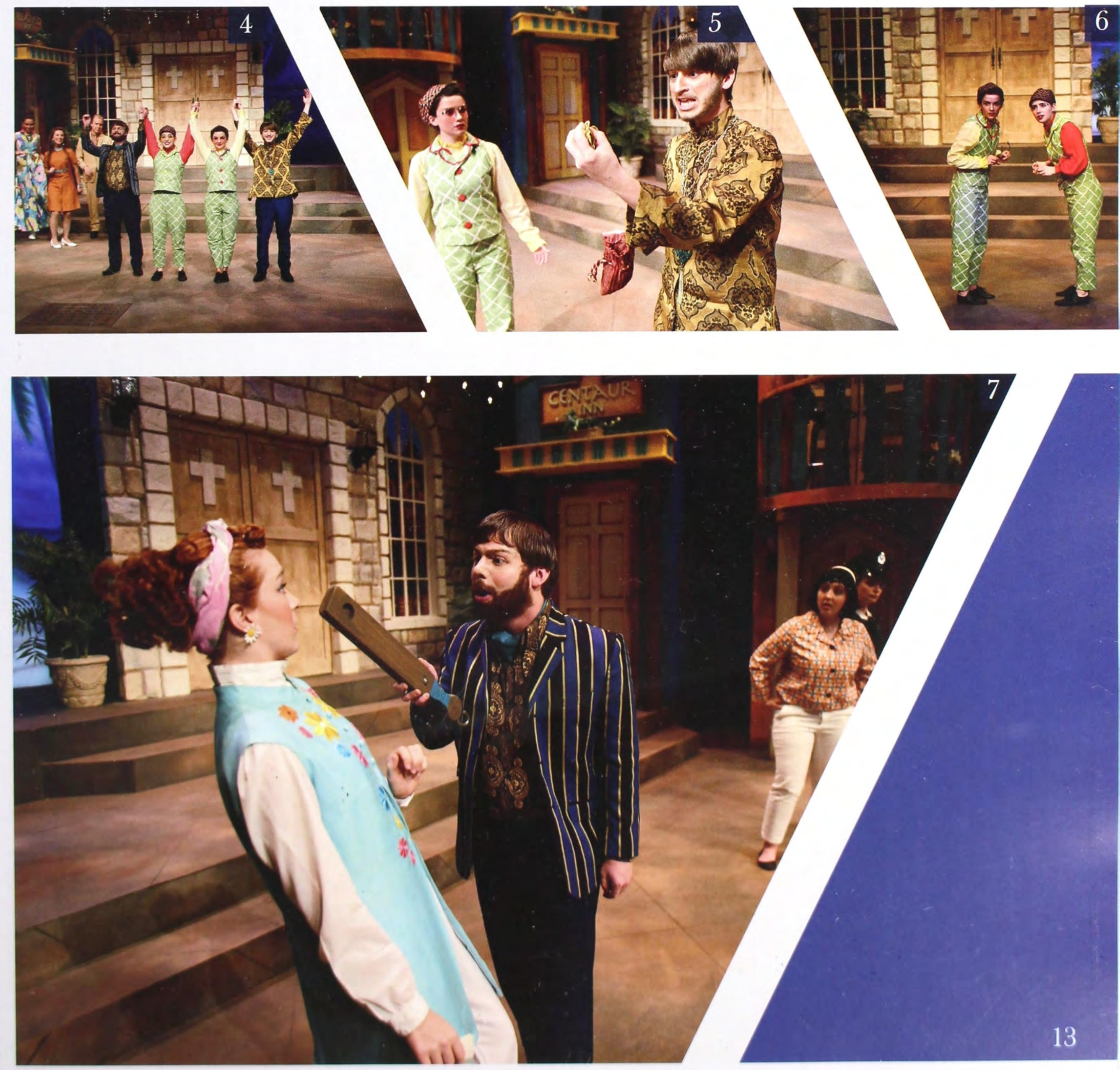


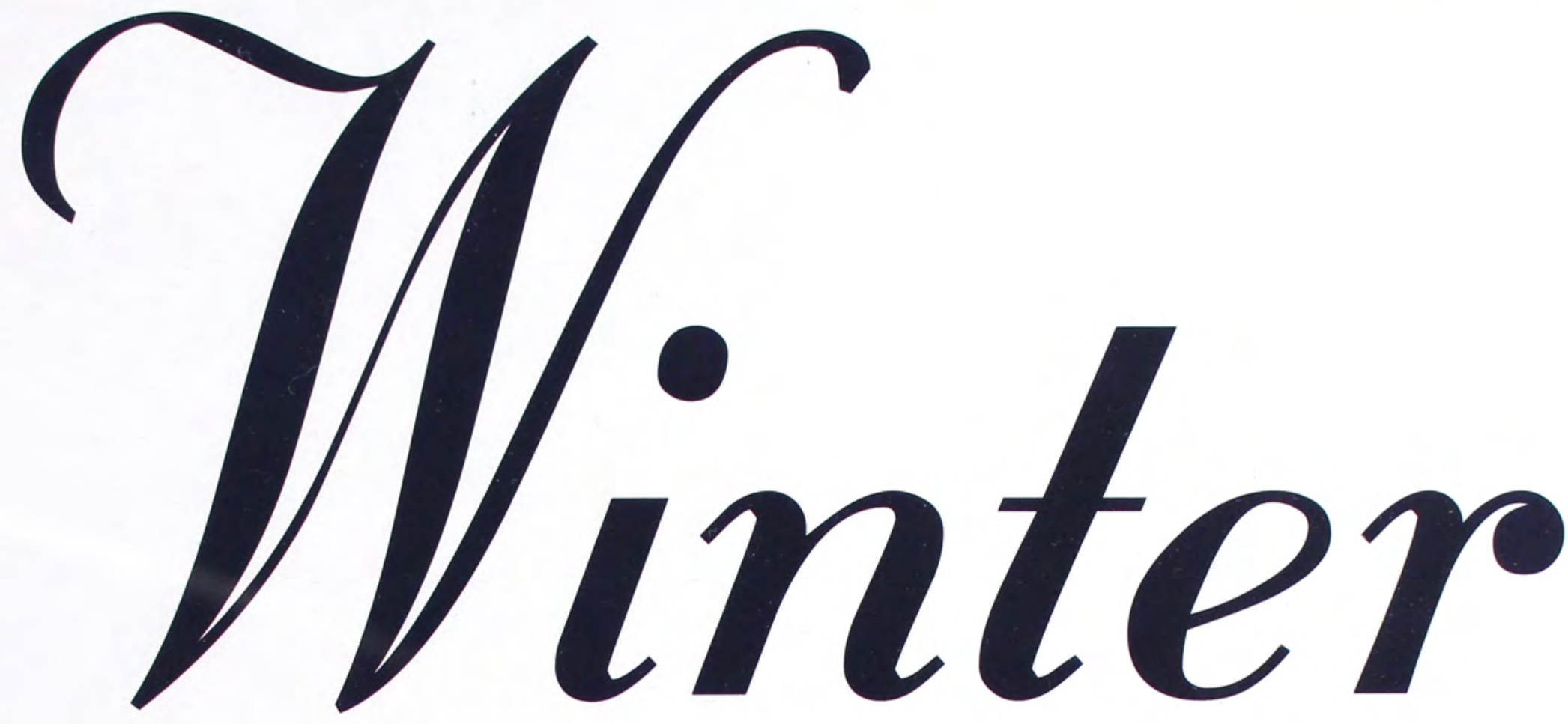

Everything got real when winter rolled around. We created little worlds inside our dorms for Campus Christmas, went on break, and then received new syllabi. We prayed with our D-groups as we trudged through snow, finals, and the beginning of a new semester. We said goodbye to one year and hello to new beginnings. Getting through the winter together helped us forge a deeper form of community than we had when we first arrived on campus.

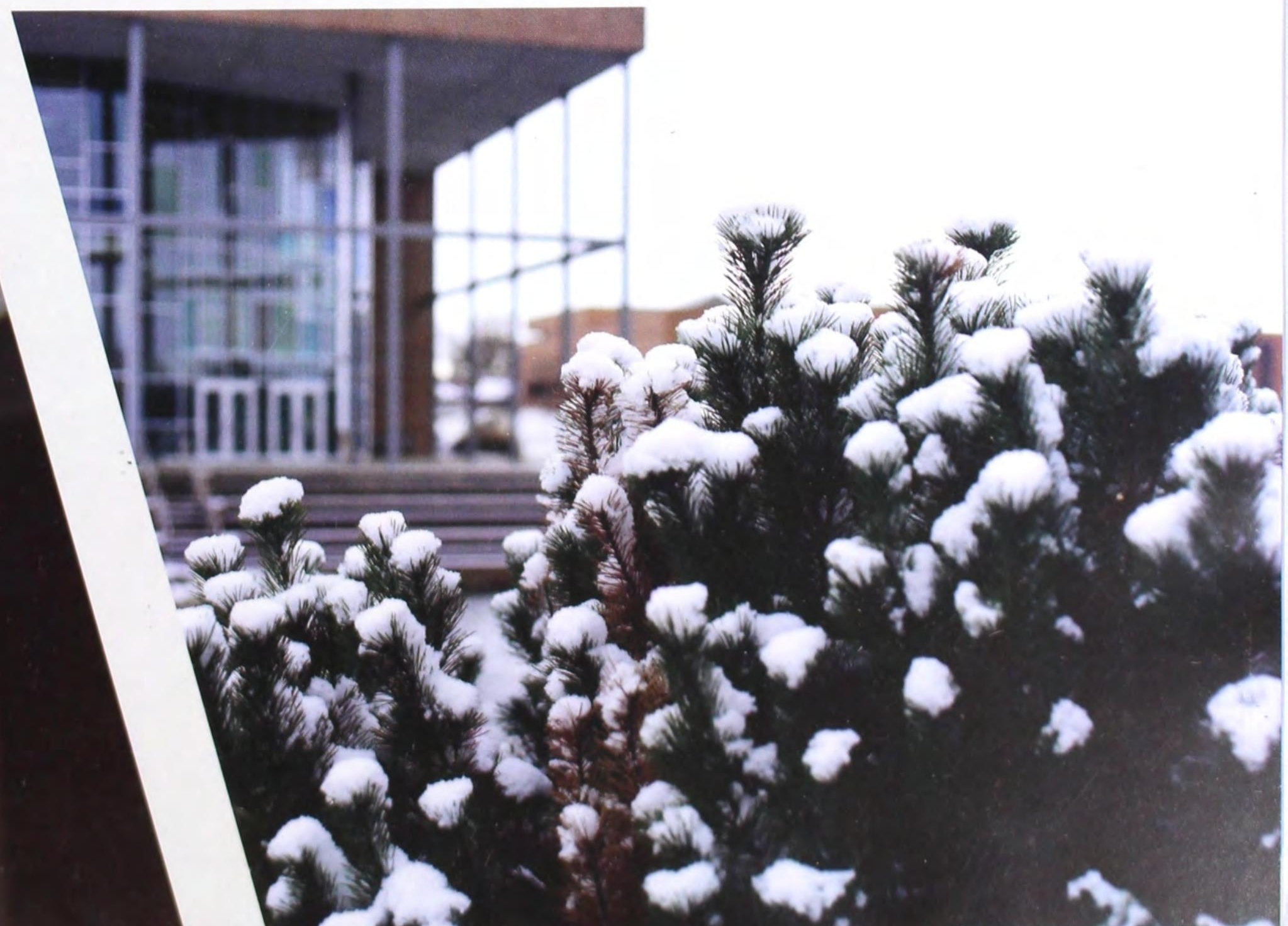




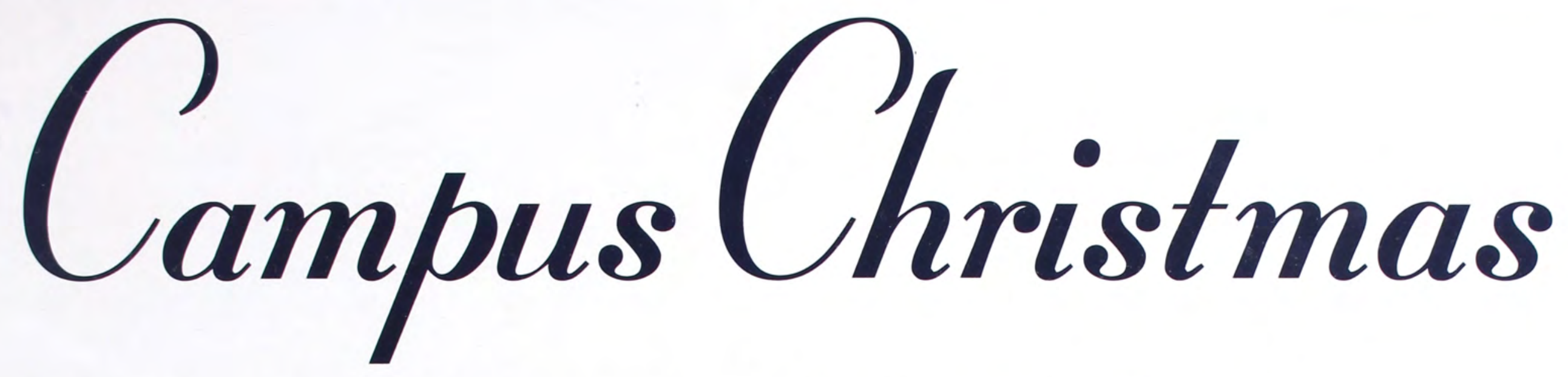

The Alumni Association hosted the University's first annual Christmas tree lighting this year to celebrate donors. They celebrated the event with Christmas carols, hot chocolate, cookies, and a reading of the Christmas story.

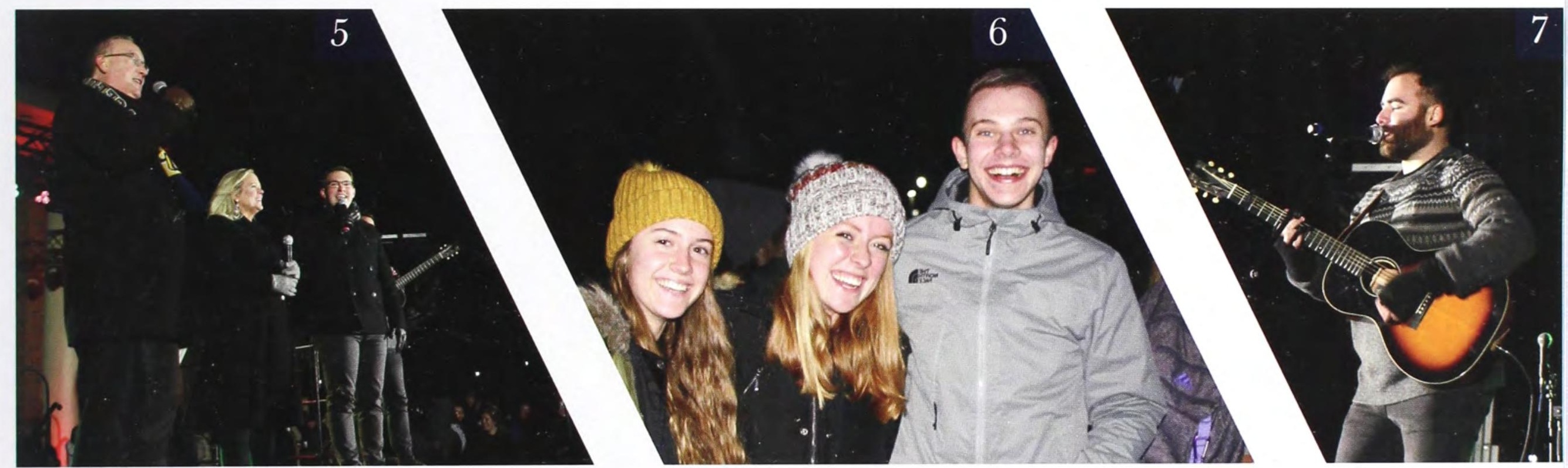

1. Matt Gillis is introduced during the event. Moonlight Madness allowed students to get to know more about each of the players through their introductions.

2. A group of friends attends Moonlight Madness. This year students were given spirit towels for participating in the event.

3. The coaching staff walks onto the court. This helped students recognize the coaches before the start of the season.

4. Nick Mantis dunks the ball during Moonlight Madness. Players had the opportunity to hype up this year's

basketball season.

5. Rick Melson, Kim Ahlgrim, and Jonathan Lyons announce the beginning of the tree-lighting ceremony.

6. A group of friends pose in front of the Christmas trees in the SSC for Campus Christmas.

7. Chris O'Mara leads the community in Christmas songs.

8. The first Cedarville Christmas tree glows outside the SSC. This year, the alumni association set up a tree and hosted a tree-lighting ceremony with Christmas carols, hot chocolate, cookies, a reading of the Christmas story, and an opportunity for students to decorate the tree. They intend

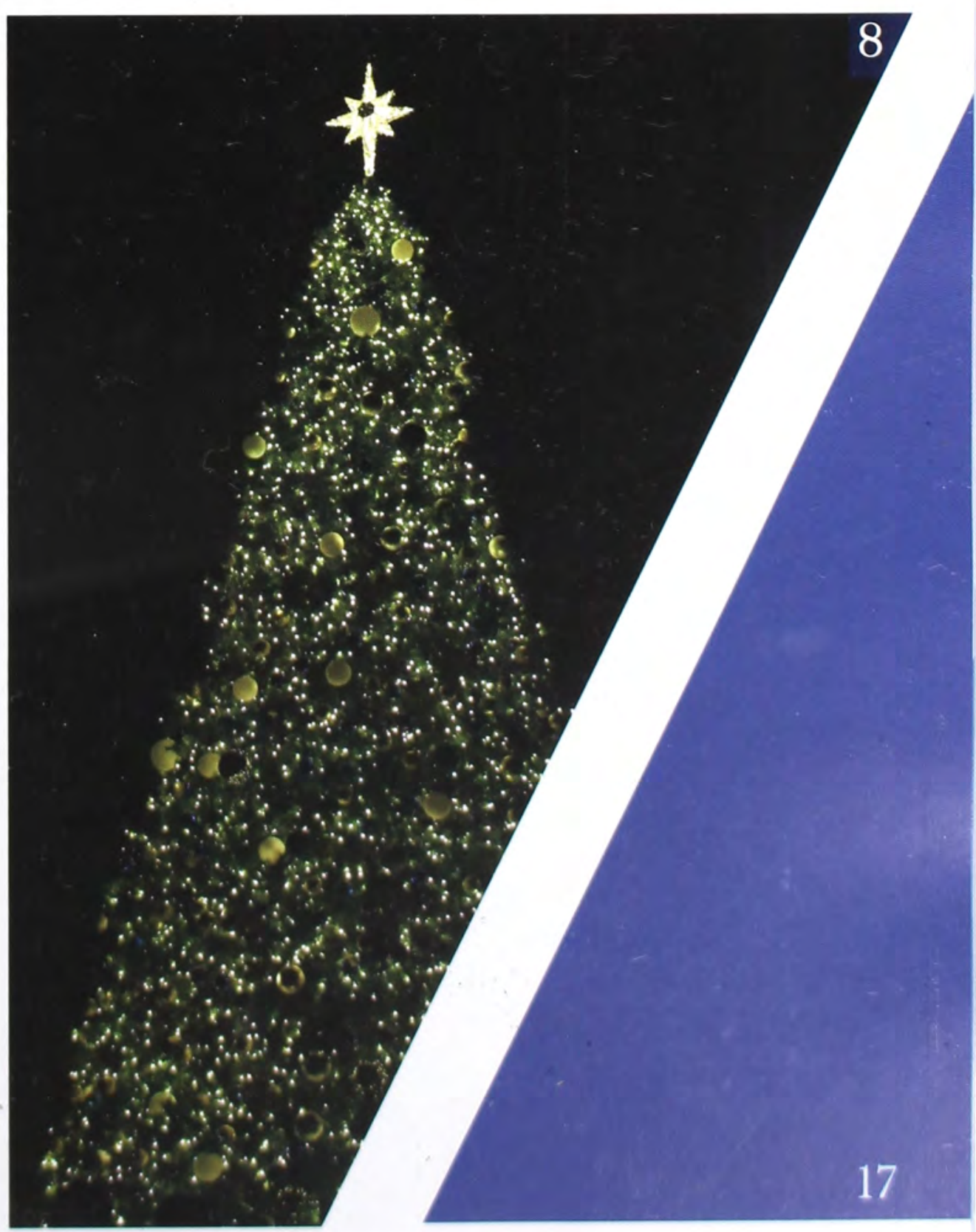


2. Isaac Gagarinas and Beka Colon act as a couple from a

Hallmark movie during Johnson's open dorms.

3. Presley Peyton Shemelia and Danae Dray ride the train in Chuck's.

4. Students slide down the Christmas slide in the upper SSC.

5. Julianna Mitten gives a speech at the beginning of her hall's skit during Campus Christmas open dorms.

6. KT Machia, surrounded by friends, holds up the ornament she made in Stinger's.

7. Girls take students' Chick-Fil-A orders during their skit during Campus Christmas open dorms.
Campus Christmas has always been a time for the community of Cedarville to shine. Along with all the regular events, like open dorms and late night Chuck's activities, Cedarville introduced a new tradition: the lighting of a 32 -foot Christmas tree outside of the lower SSC. This tree doubled as a decoration and a representation of Giving Tuesday. Melanie Edris, an Alumni Office employee, said, "The ornaments that decorated the big tree represented someone who had given a financial gift to the university on Giving Tuesday.

Their name was written on the ornament as a small way to thank them for their generosity." The tree lighting was a special event, with a performance by the Inversions, a Christmas sing-along, and a reading of the Christmas story. "Students, faculty,
staff, and Cedarville community members were all incredibly supportive and eager to be a part of this new tradition that will take place for years to come...It was such a fun opportunity to celebrate the Christmas season...” Edris said.
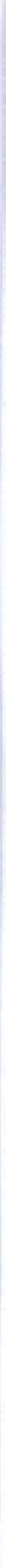

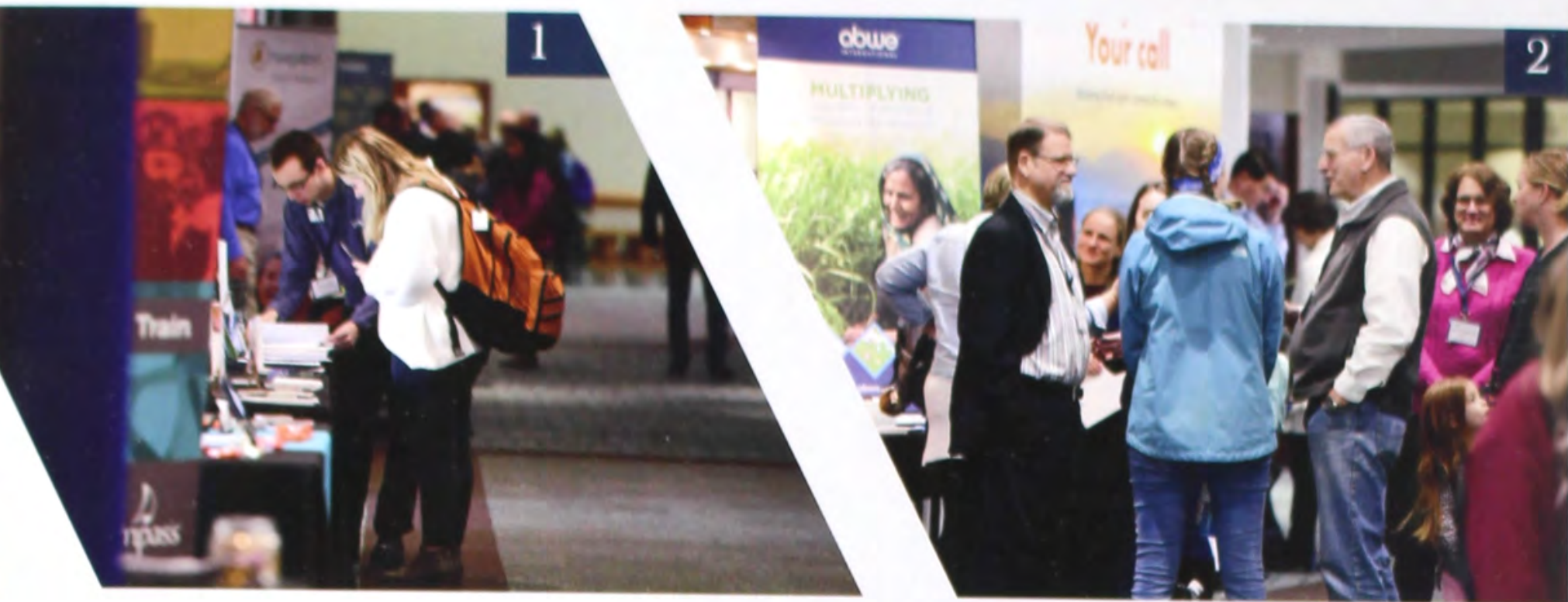

The Missions Conference happens every spring, but this year the Lord used it to lead David Kauffmann to consider full time missions work. "I have always loved missions conferences, and this year was no different," Kauffmann said. "I came away from that chapel feeling even more compelled to go and be willing to give my life for the sake of the Gospel if

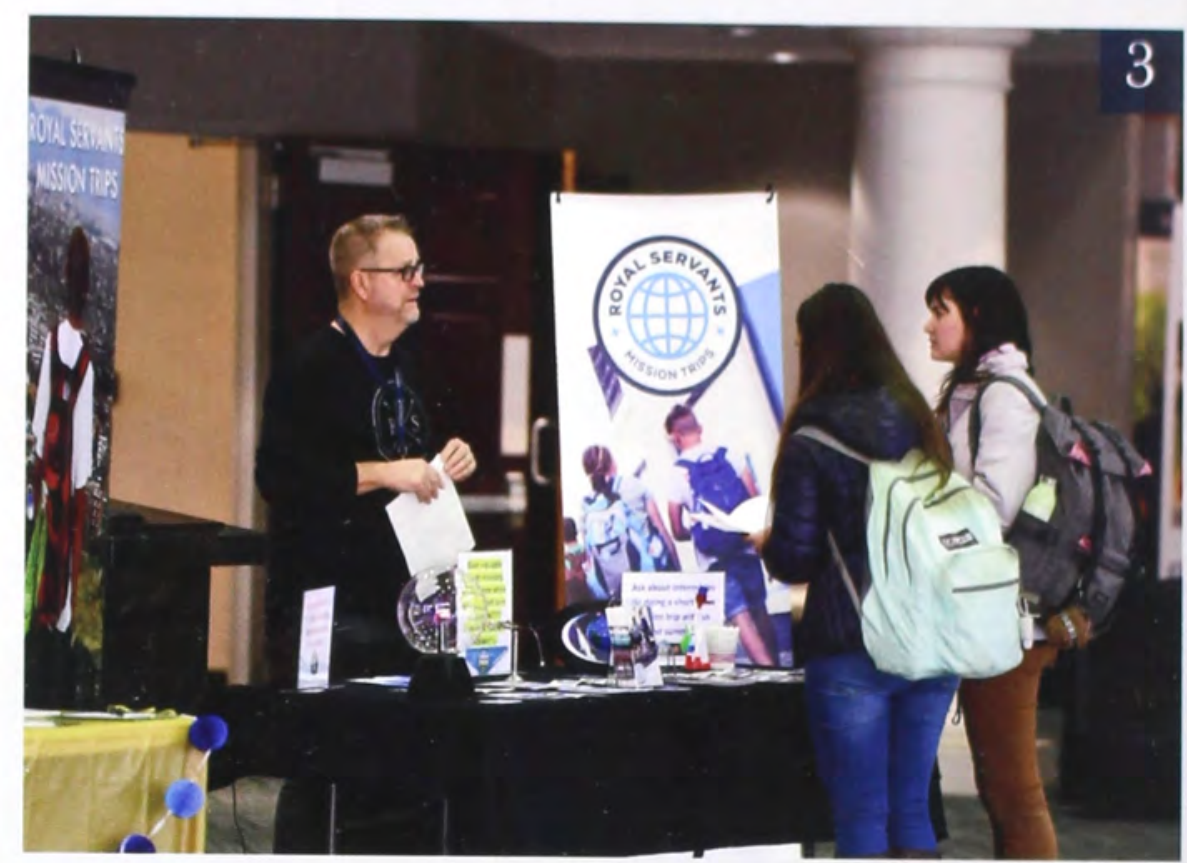
that is the path God has laid out for me." After this conference, Kauffmann felt led to use his degree in a country like Guatemala or Brazil. "The most ideal situation would be taking my accounting degree and training others in less fortunate countries,"

Kauffmann said. "However, if I am unable to help train others in that, I know I am able to help start churches and strengthen them." The Lord has used this experience to help guide him to this dream.

"I have found that having gone on a missions trip helped fuel my desire to go overseas and serve the Lord," Kauffmann said. "I was able to see firsthand the poverty, but deep and sincere happiness the kids and parents have with so little."

1. Students peruse the missions booths at Missions Conference.

2. ABWE missionaries explain what $\mathrm{ABWE}$ is doing to reach the nations with the Gospel.

3. A representative of Royal Servants Mission Trips converses with students about the opportunities RSMT offers.

4. Lauren Penner reads the Bible passage for the night.

5. Danny Akin preaches at Missions Conference.

6. Ayja Robinson and Stephanie Dickson follow along as Danny Akin reads the Bible passage for one of the main sessions.

7. Students stand and read their Bibles during Missions Conference. 

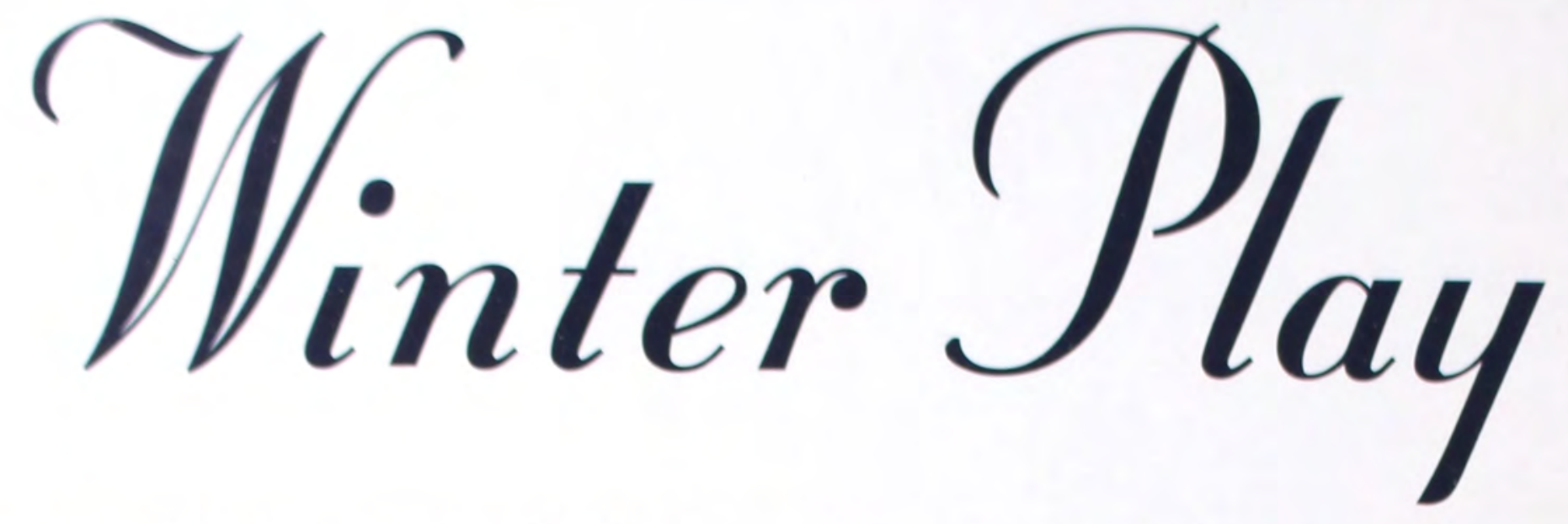

This winter, the Department of Art, Design, and Theatre put on "The Heiress." The cast came together to tell this story of a man trying to woo a young woman to get her family's money.
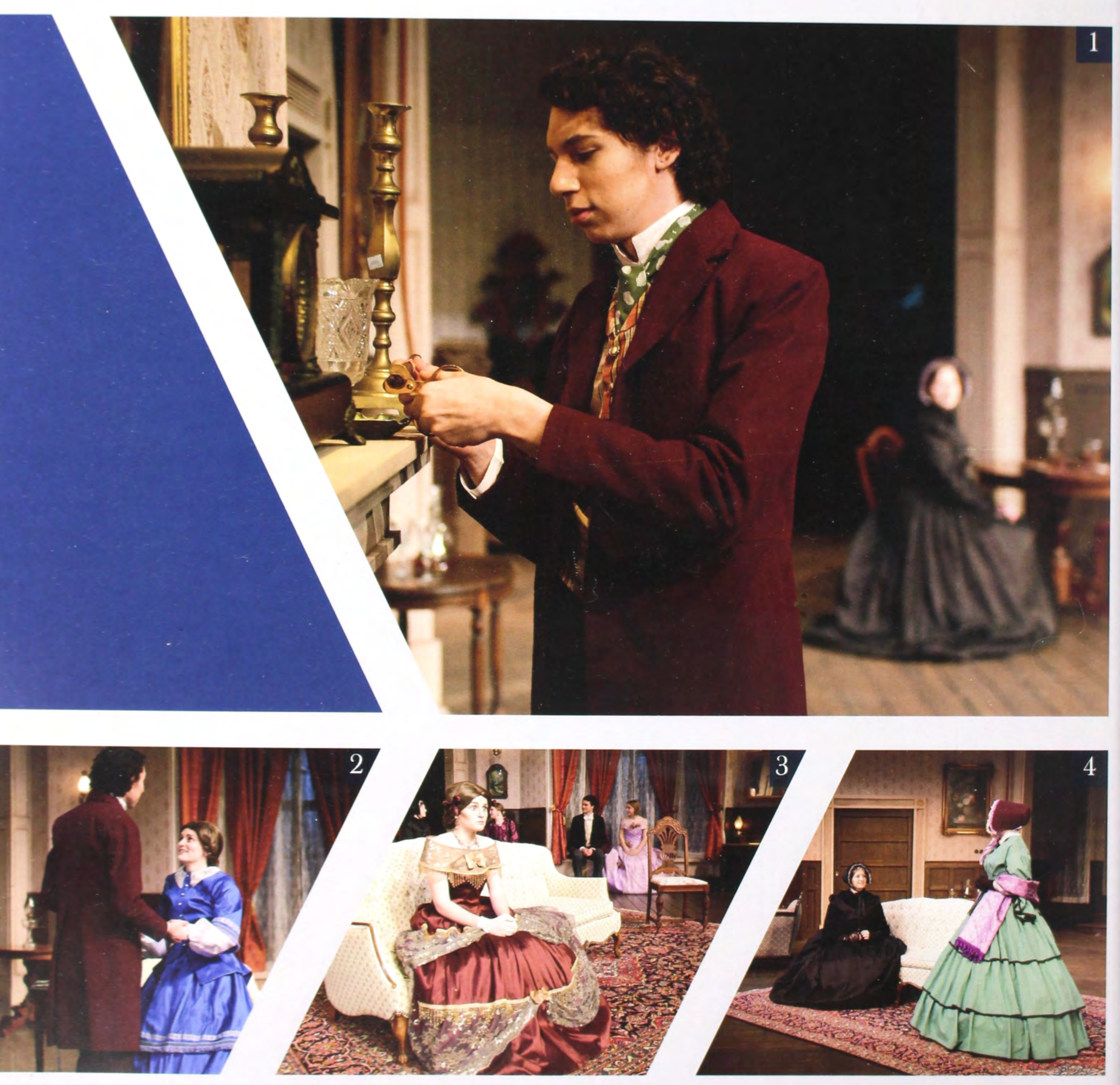
In mid-January, Dr. William Lile, a pro-life

OB-GYN, spoke in chapel about his mission

to preserve the lives of the unborn. It was an

informative but heavy message, as Lile showed the audience graphic images of life inside the womb and presented the science behind a new procedure that can reverse the $\mathrm{RU}-486$ abortion pill. This was coupled with challenging statements, such as the fact that America protects unborn sea turtles more than it protects unborn babies. One student, Lydia Bradley, was especially moved by Dr. Lile's presentation. "We live in a society today where pro-life and pro-choice is a political statement, and I think that is really scary," Bradley said. "That is a child...and should have the same rights as me; it is just human morality at that point." Since Dr. Lile's message was based in scientific fact, Lydia said it ultimately helped her see that pro-life versus prochoice is not just a religious debate, but a scientific one as well, and now she feels confident to use what she learned to share with others
1. Brothers Ben and Dan Graeff speak to Dr. Jon Wood during the "Prayer for the Nations" chapel. The Graeff brothers had the opportunity to share about persecution they experienced as children on the mission field.

2. A student holds his Bible during a chapel service. At the beginning of the year, Dr. White encouraged students to bring their own copy of the Word to chapel daily.

3. Dr. Randy McKinion preaches in chapel. He was able to remind students that they have a living hope in Christ.

4. SGA chaplain Isaac Dye preaches about 1 John.

5. Anna Ward, Emily Mattocks, and Emily Winchester pray together during a prayer chapel. This experience allowed students the opportunity to pray for themselves, others, and the nations.

6. Keith Minier, the Lead Pastor of Grace Fellowship in Pickerington, Ohio, speaks in chapel. Minier had the opportunity to share about the importance of seeking | to serve.

7. Hannah Quandt, Jenny Powell, Connor Seals, Ella Young, and Elisabeth Blank stand for the reading of God's Word.
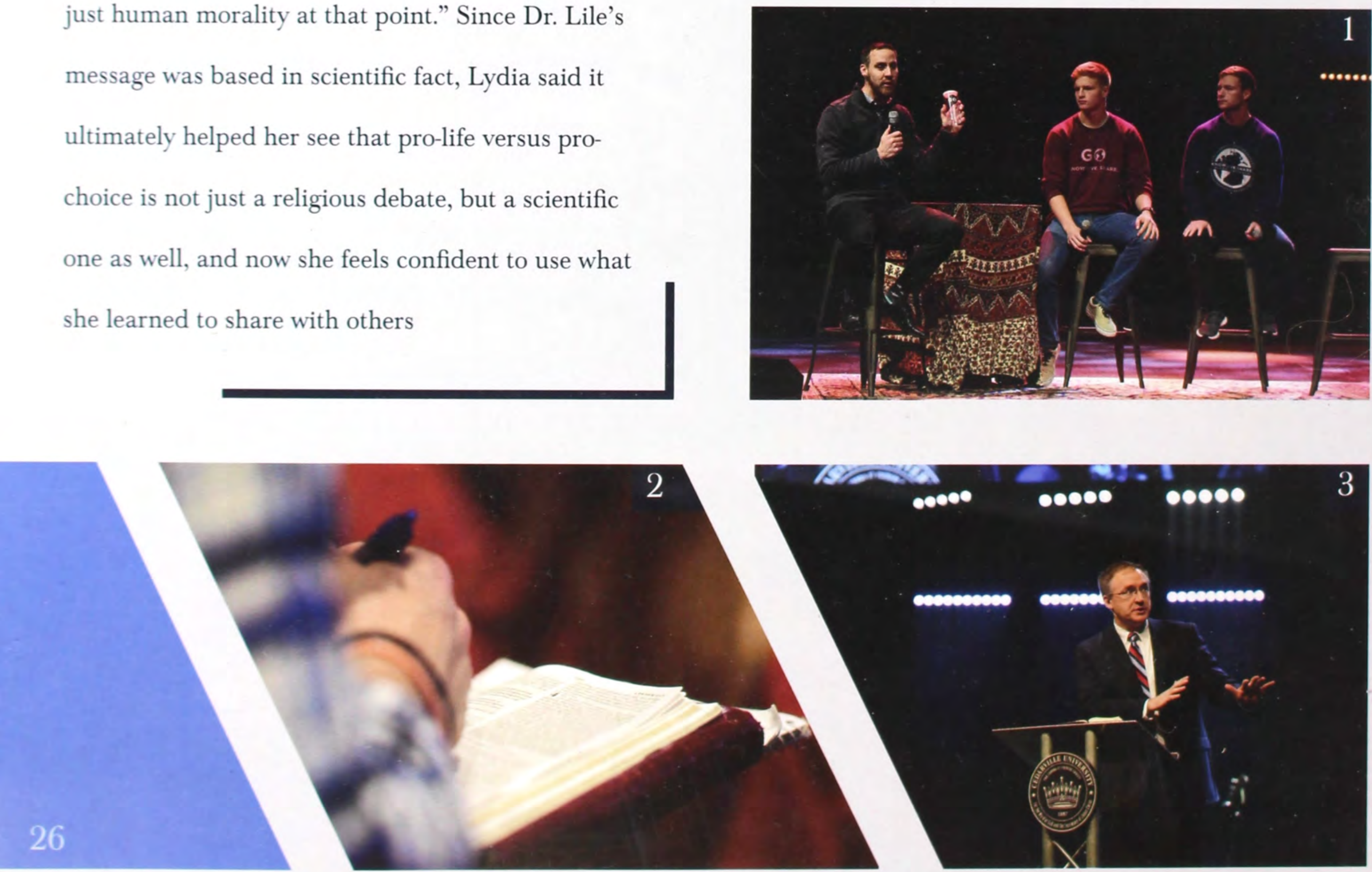


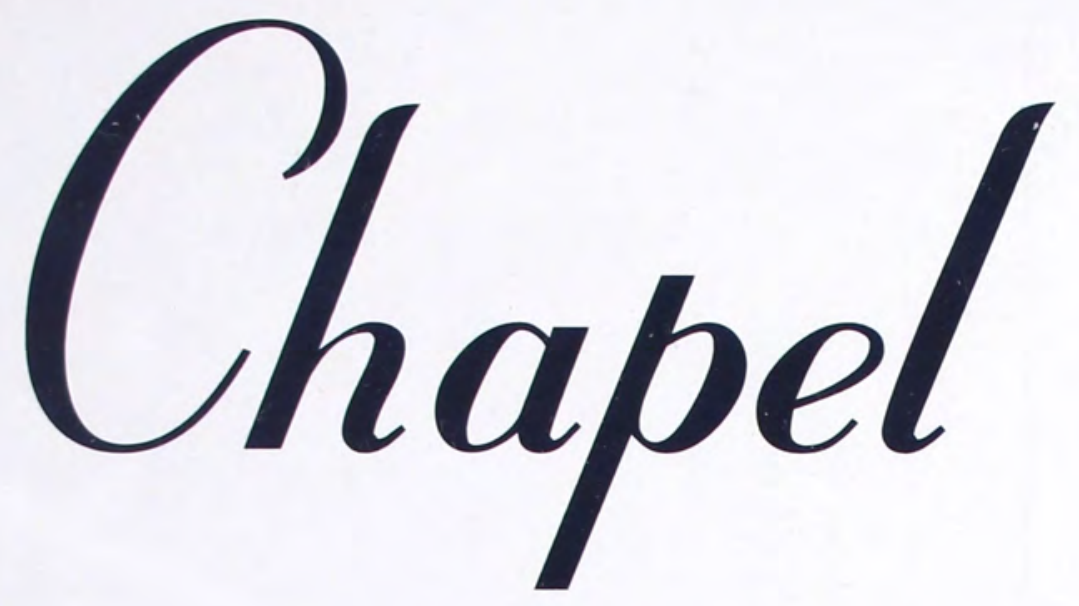

Every day Monday-Friday, all of campus would gather together at 10am to worship God through music and by learning about His Word. Chapel speakers came in from all over the world to share about their ministries and teach solid doctrine.
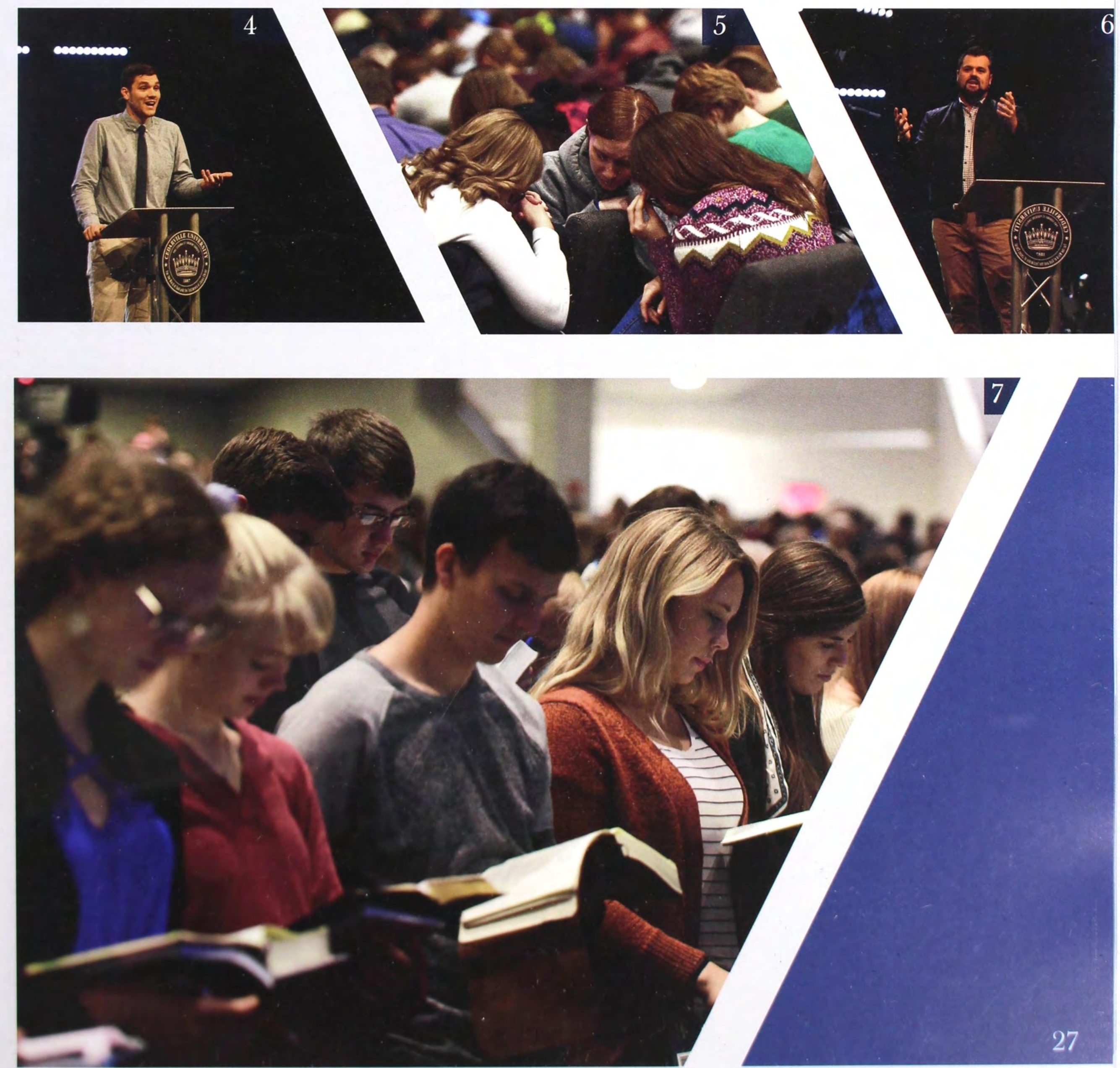
2. Stinger's remains empty because students are no longer on campus. The restaurant closed when students were originally sent home for the first two weeks off.

3. The benches that line campus sit empty for the second half of the semester. The majority of students moved out of the dorms in the middle of the spring semester

4. Dr. White speaks to an empty chapel. During the time of COVID 19, Cedarville continued to provide new chapel content online every Monday, Wednesday, and Friday.

5. JT Thompson and Gabe Boggs hug in the Lawlor parking lot. Because of the abrupt ending of the semester, it was difficult to say those last goodbyes to friends.

6. The Cedarville basketball stadium sits empty for the second half of the semester. Many student athletes were unable to finish their seasons this year.

7. The 1,000 days lounge is empty during the last few weeks of the semester. Many of the 1,000 days this semester were spent taking classes online from home.
The spring semester will be memorable for years to come because students completed almost half the semester remotely due to COVID-19. While this transition was difficult for all students involved, the senior class was most impacted by the situation.

"So as far as this semester, COVID has made it more difficult with classes and actually staying up to beat with them," Anthony Mummert said. "Also it's made it harder for the last goodbyes with our

friends and stuff like that as we are moving on and graduating." Mummert is a senior nursing major, and this transition has made the job hunt more difficult. "The fact that they are doing so many hiring freezes right now has put additional stress along with our crazy exams that we are trying to just work into the whole system," Mummert said.

While this time has been stressful, there have been a few unexpected blessings involved in the situation as well, and the university family continued to maintain community - especially through Zoom.

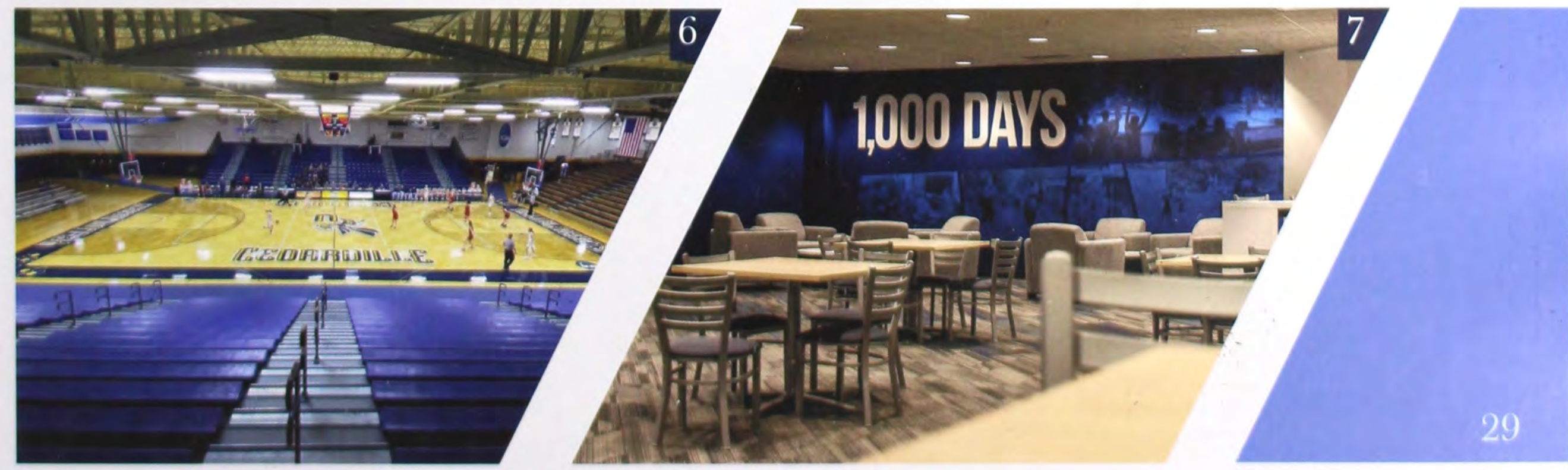




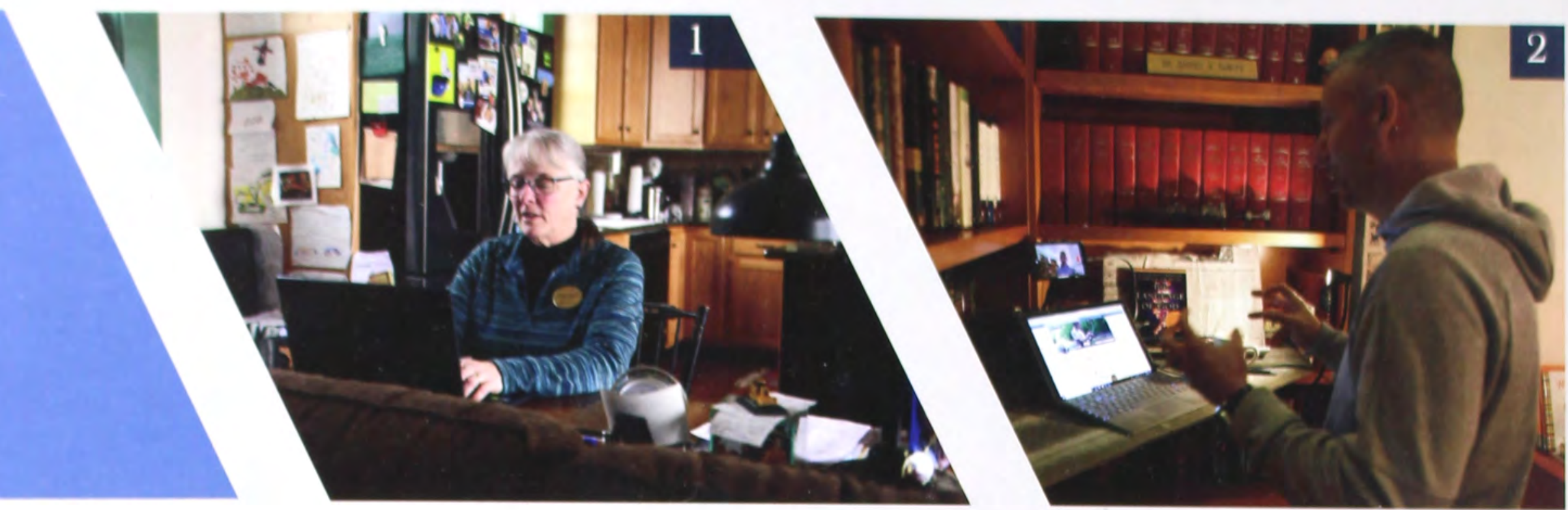

On March 11, Dr. White announced to the student body in chapel that Cedarville University would be shutting down due to COVID-19. The news then was simple: students had two days to evacuate the dorms, they would have no classes until the following Monday, and then they would have two weeks of online school. The announcement occurred three days after spring break, and many students joked about going on "Corona-cation" with cheap airline tickets. For the next four days, professors scrambled to make their courses compatible with remote learning. March 20 brought more news: the entire rest of the semester would be online. Students were required to come back on staggered days to unpack their rooms to avoid contact with each other. This was especially significant for seniors like Delaney Yutzy, as the move to online meant losing the rest of their final year at Cedarville. "I never expected my senior year to end like this, completely online," Yutzy said. "I never expected to miss out on JS, Elliv, Senior Chapel, and graduation. It's been a hard pill to swallow in a lot of ways. But I'm also thankful for the time spent with my family, and the ways I've communicated with friends through letters, texts, and FaceTime calls."

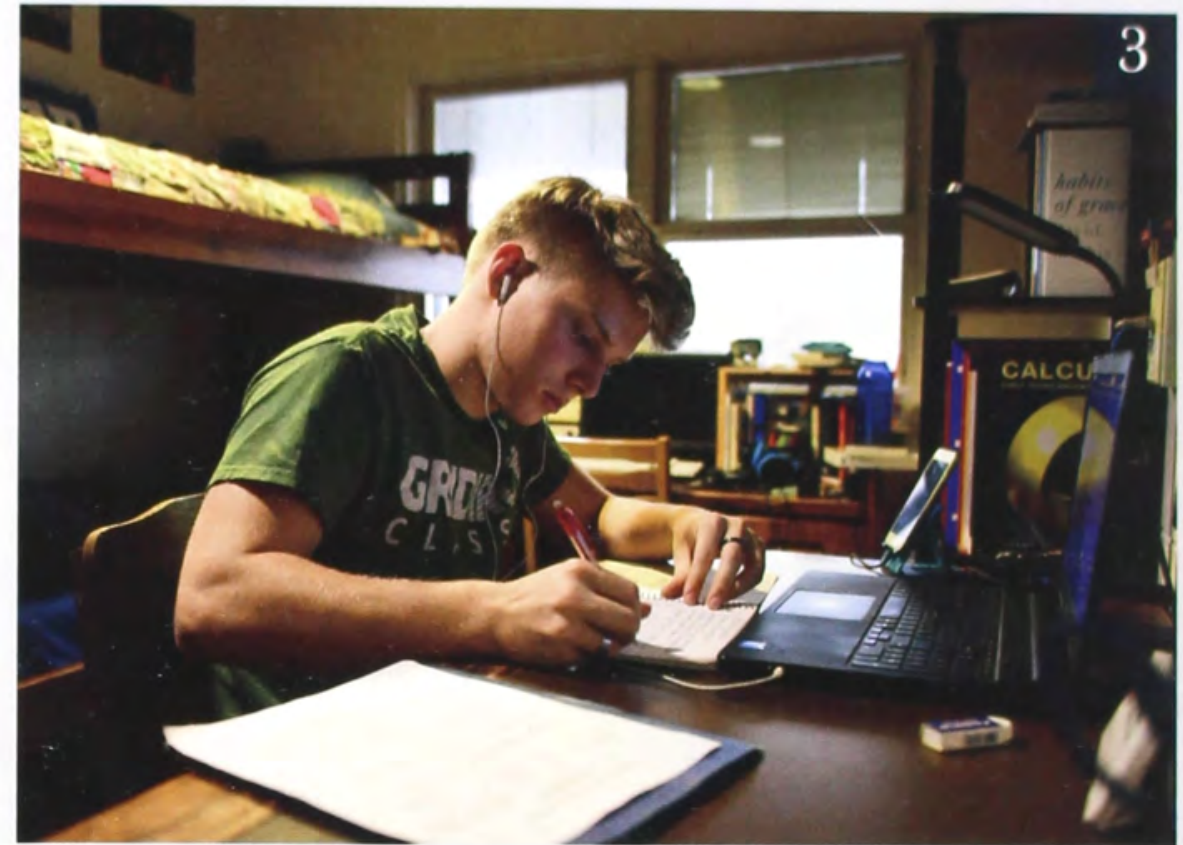

1. Dr. Grigorenko teaches her class over Zoom.

2. Dr. DeWitt teaches from his office over Zoom.

3. Noah Harvey works on his homework in Lawlor. Some students were allowed to stay in the dorms under special circumstances.

4. Dr. Lee teaches his class virtually from the lobby of the BTS.

5. Professor Porter, the chair of the Music department, teaches her class remotely.

\section{A music student plays his guitar for his assignment remotely over Zoom with Professor Porter.}

7. A class meets together over Zoom. 


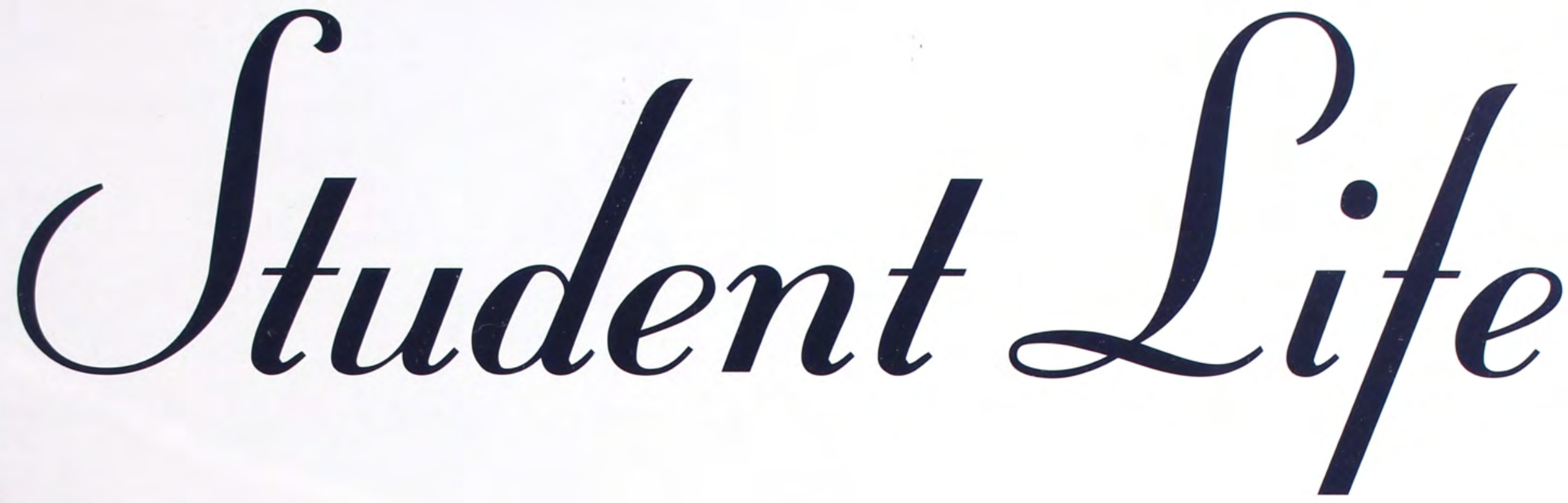

Community at Cedarville was supported by many factors: active dorm life, daily chapel, campus-wide events, and passionate faculty (just to name a few), but there was also a vital component that tied it all together: the students. This year, we joined together as dorms, orgs, and friend groups to have fun, make friends, and ultimately fight for each other's joy in Christ. We left as best friends with people we hadn't even met a few months before, and because of our community, we emerged smarter, stronger, and more mature in our faith.

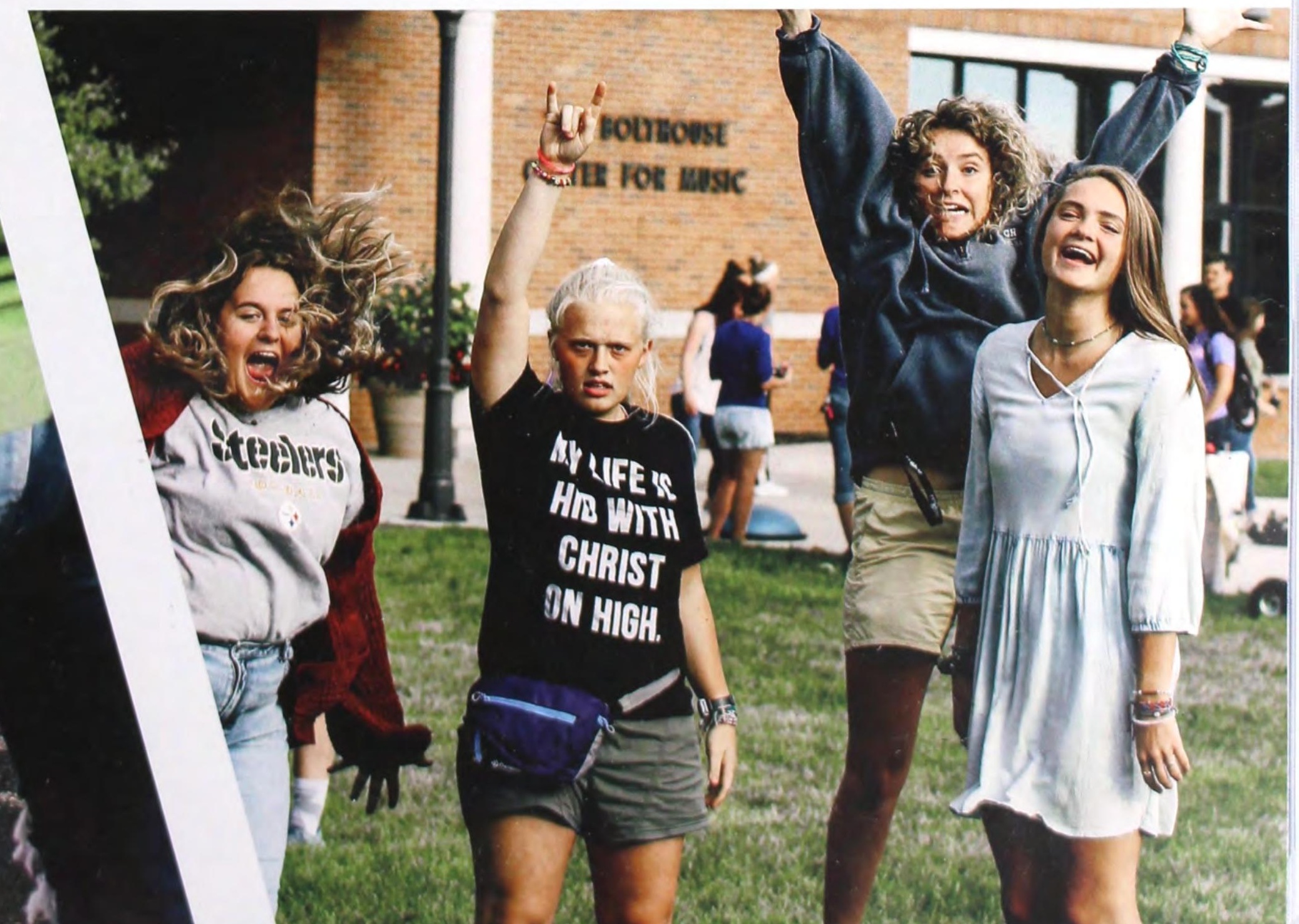


Every dorm offers an opportunity to get involved

in events. Julianna Mitten has had the opportunity

to serve as an RA for McKinney Hall for the past

two years. "My favorite all-dorm event this year

was the McKinney/Johnson Galentines Party held

in the BTS youth rooms in February," Mitten said.

"We had waffles and fondue, along with crafts and

table games." The environment of life in the dorms

at Cedarville is something that is difficult to obtain

after graduation. "I think I will miss just the simple

day-to-day aspects of dorm life more than I will miss

the specific events, but I think the events I will miss

the most will be the Saturday brunches and the

fellowship created among the RA team as we plan

and host dorm events for others," Mitten said. She

has enjoyed her time in the dorms and hopes the

experience will help her in the future. "I pray that

the lessons I learned about life-on-life discipleship

and memory-making will continue to shape the way

I participate in church ministries and neighborhood

community post-graduation,” Mitten said.
1. St. Clair Upper Front poses with Dr. White after chapel. This hall decided to make Ab Night shirts after doing nightly workouts together every night.

2. Dane Secor, Connor Dupee, Gabe Boggs, and Connor Vocac celebrate after their Gridiron Classic game. This game happens yearly between Lawlor and The Hill.

3. Lawlor Printy Bro/Sis units celebrate the new year. They enjoyed a New Year's party in the BTS Youth Room.

4. Printy Res Life walks during the homecoming parade. This parade gave the residents the opportunity to show

their Printy House pride during the event.

5. The Light Blue team poses for a picture before the

Gauntlet. Their team won third place.

6. Units 26, 28, 30, and 32 participate in Printy Wars. Their theme was the Lion King.

7. Teams representing Lawlor and the Hill play flag football. Lawlor won the event this year.
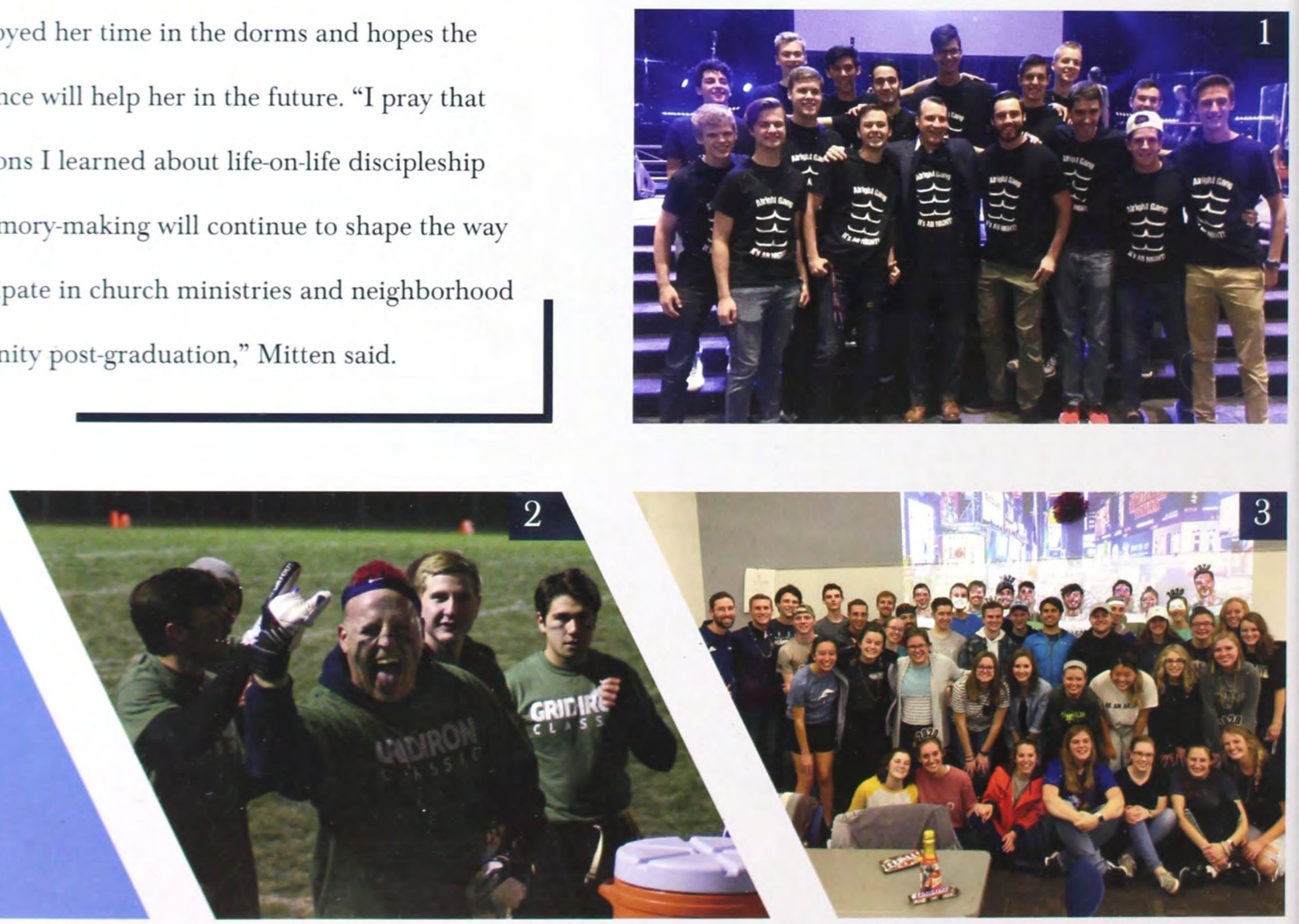

ind

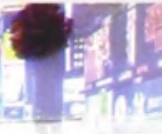

3
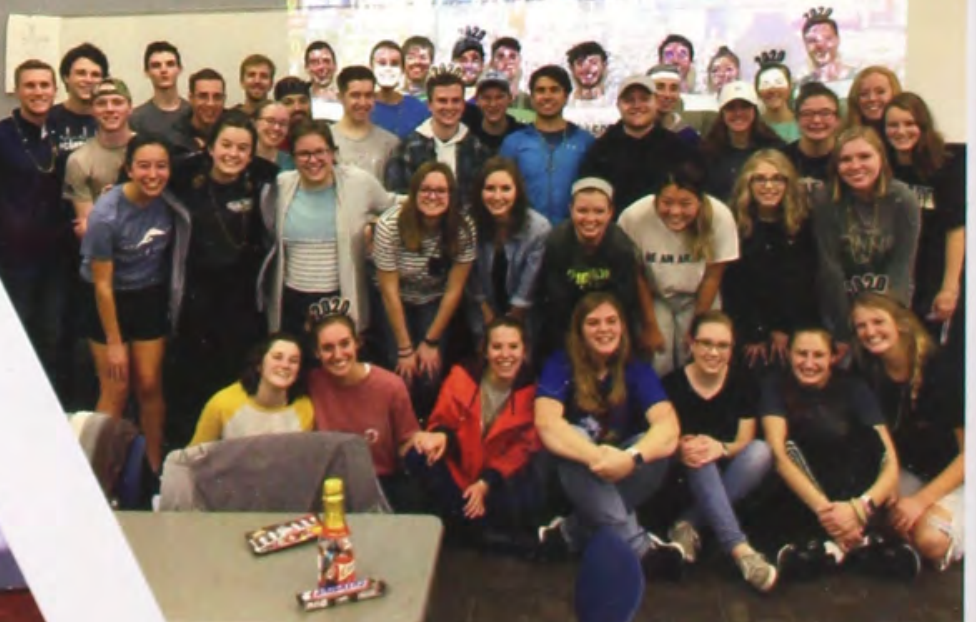

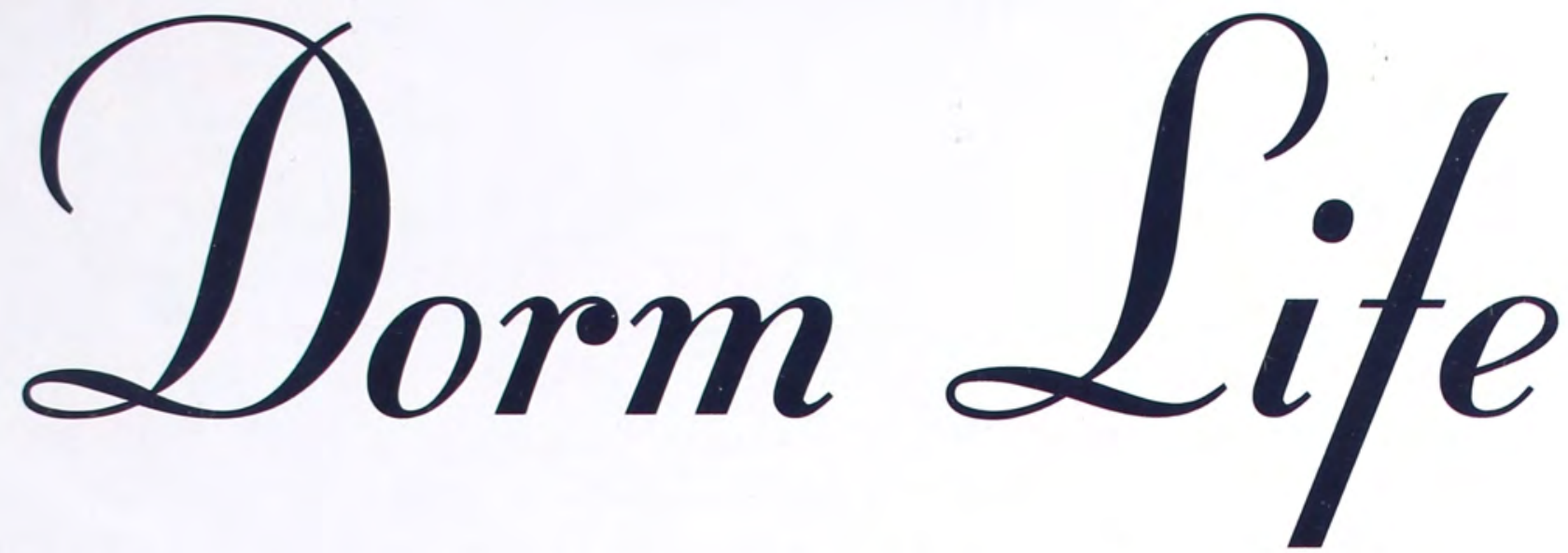

Events like Ab Night, Gridiron, New Year's parties, and the Gauntlet brought together students from each dorm and helped them forge lifelong, meaningful relationships.
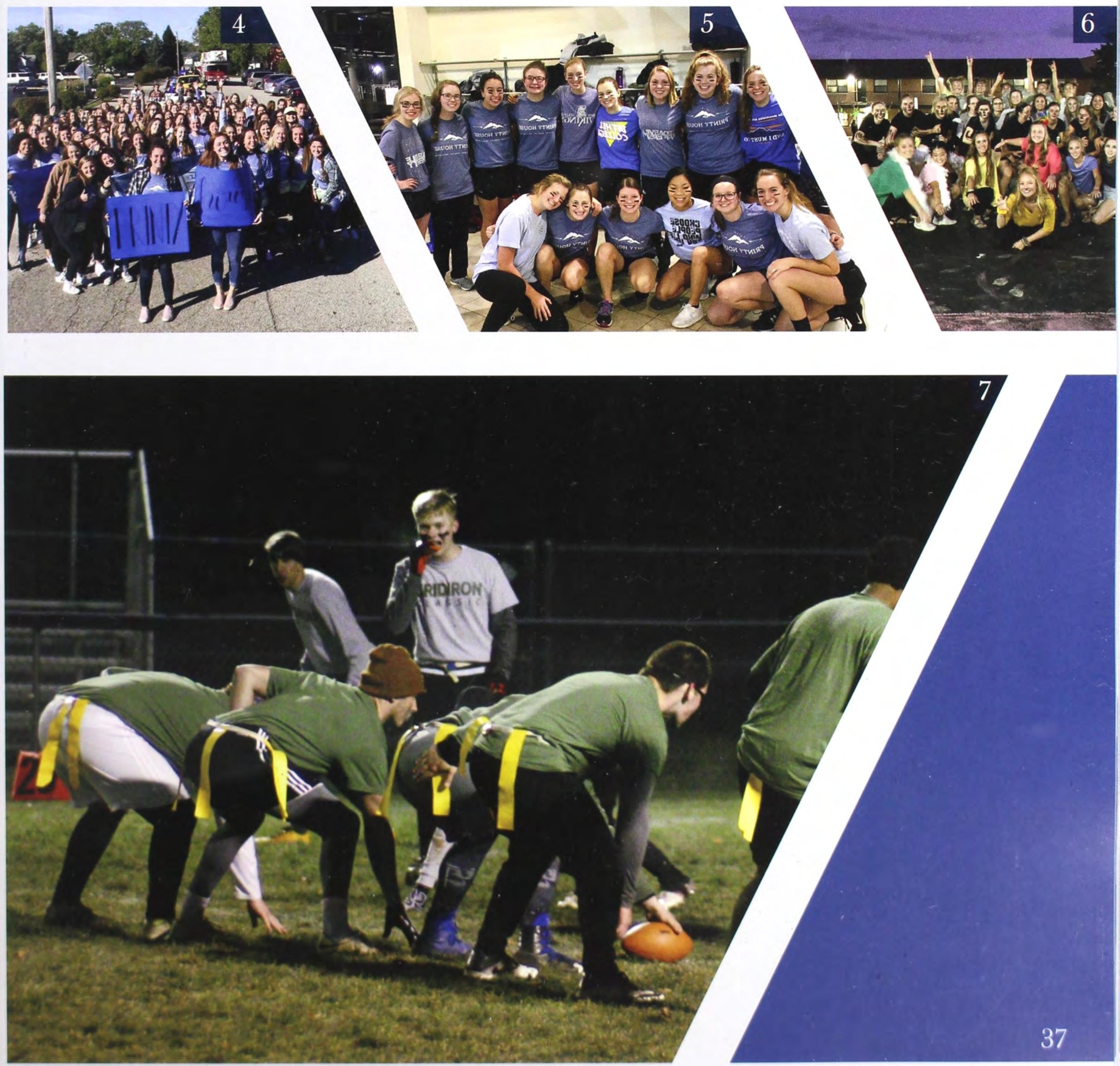


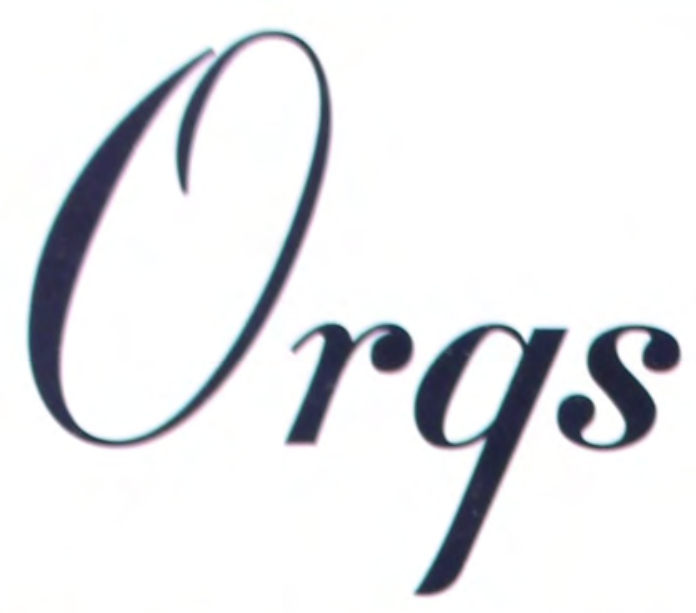

Students pursued their passions in extracurricular student organizations that allowed them to grow their understanding of the world, build relationships with other students, and take a break from homework.
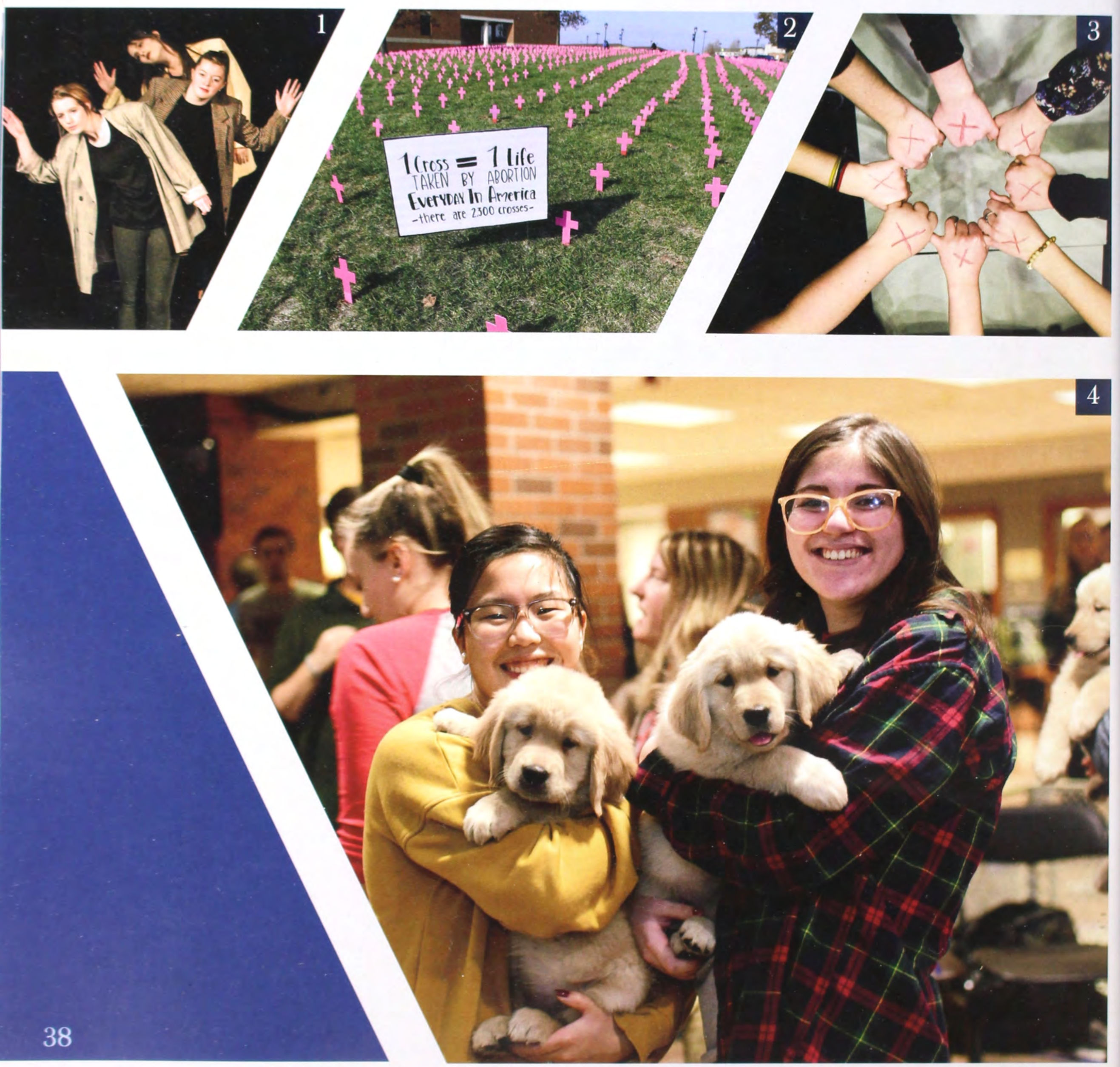
1. Hannah Nichols leans left during her tap dance number. Hannah said this dance was empowering as it included dramatic movements and loud shoes. Out of all the dances she has performed, Hannah said this one was her favorite.

2. Hundreds of crosses line the grass next to the student center. These crosses, set up by Students for Life, represent one life taken away by abortion. The crosses were up for about a week, and many students talked about how moving the display was for them.

3. A group of students holds out their hands to show their red $\mathrm{X}$ drawn on their fists. Drawing a red X showed support for people in slavery around the world. The movement behind this action was called the End It Movement.

4. Anna Webner and Kaziah Speed, members of K9's at the Ville, hold up puppies for the Pause for Paws event. This event was held by K9's at the Ville during finals week with the goal of lifting some stress off students.

5. Gabriella Stewart, Anna King, Abbigayle Snyder, and Andrea Soriano sell sweatshirts for the Neos Company, part of the School of Business Administration, on the BTS patio. The sweatshirts said, "God is faithful," a segmented version of Dr. White's often repeated, "God is faithful. You can trust him."
The dozens of orgs on campus helped build intentional

community and knowledge of new skills among students.

Ayo dance company is one example of an org that

embodies these qualities. They put on two showcases

each year, each with a different theme. This spring

semester's theme was Future Memories. This year's

secretary, Amy Wikrent, shared about AYO canceling

their showcase due to COVID-19. "It has definitely been

hard navigating how to best approach taking the next

steps for seniors who were looking forward to performing

their last dances," Wikrent said. "We know how

important this is for our seniors who have given so much

of themselves to Ayo." The org officers for Ayo decided

to carry over the theme for the spring semester showcase

into this coming fall semester. They also are allowing this

year's seniors to come back for the fall semester showcase

and perform a "senior feature." "The theme of Future

Memories will be perfect for this, since it's about looking

back at the memories we've made and realizing that the

present moment is going to be a memory in the future, so

we have to make our time right now count," said Wikrent.

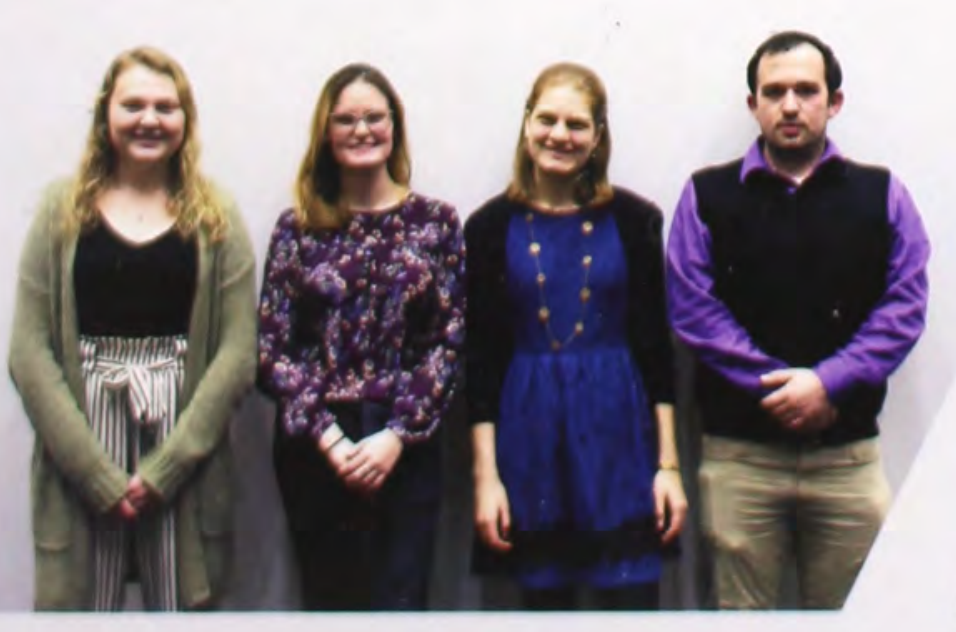

Accounting Society

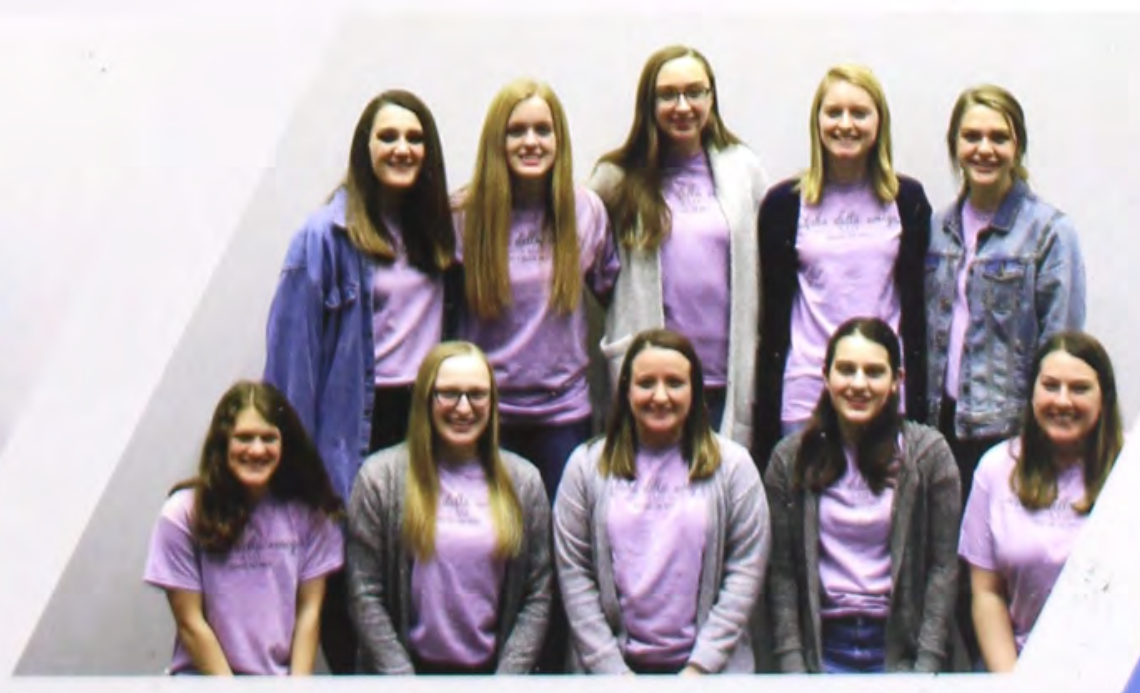

ADO 


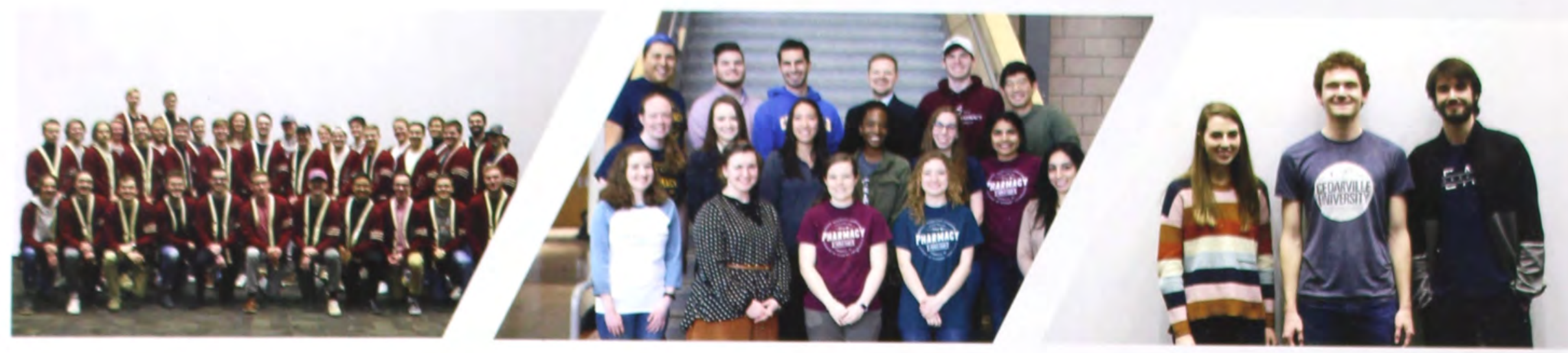

Alpha Chi

American Pharmacists Association

Academy of Student Pharmacists

Association of Information Systems

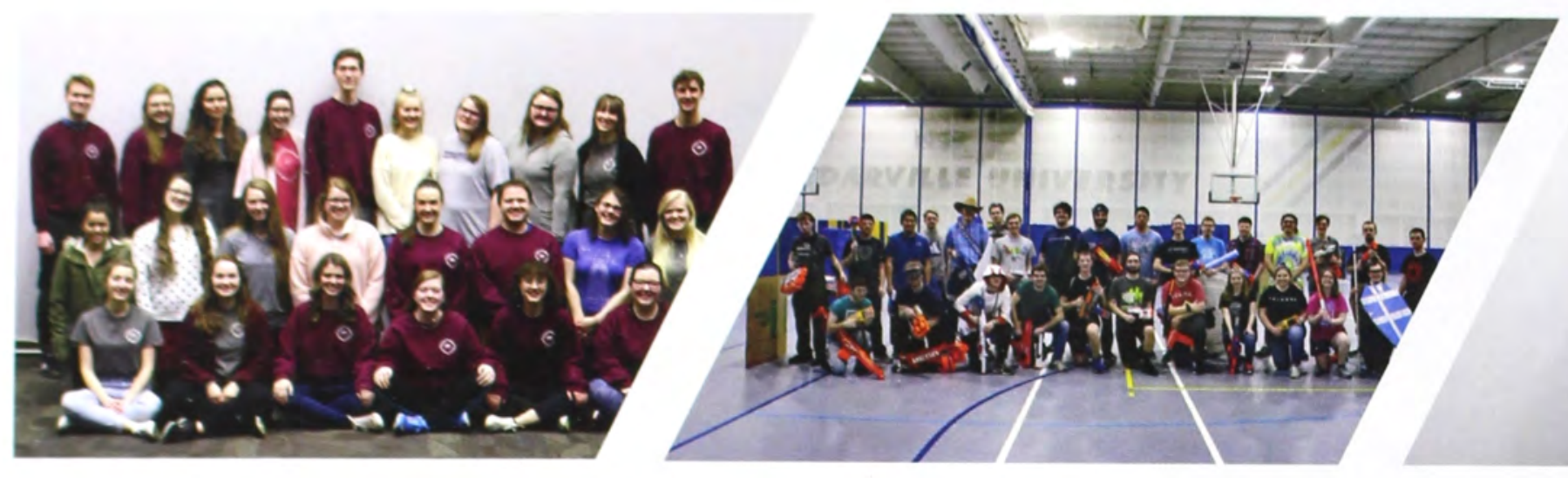

Ayo
Close Quarters Tactical

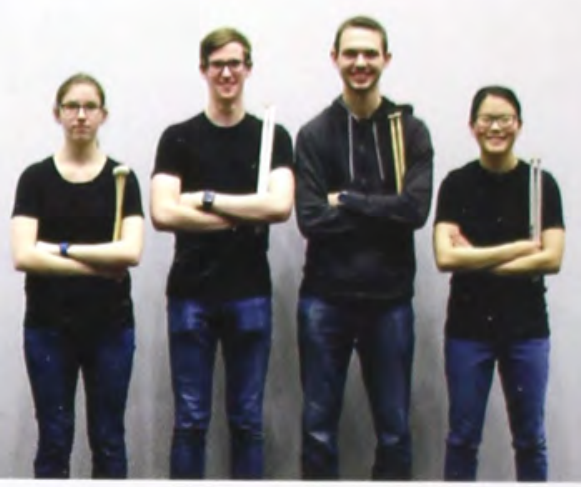

CU Drumline

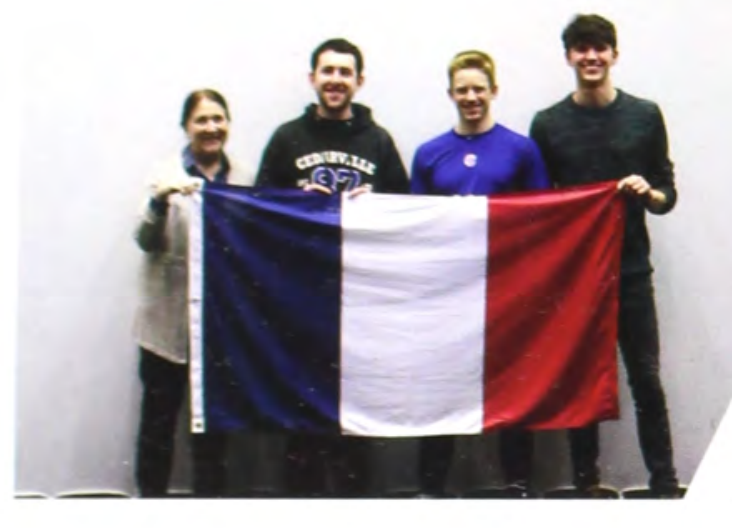

French Club

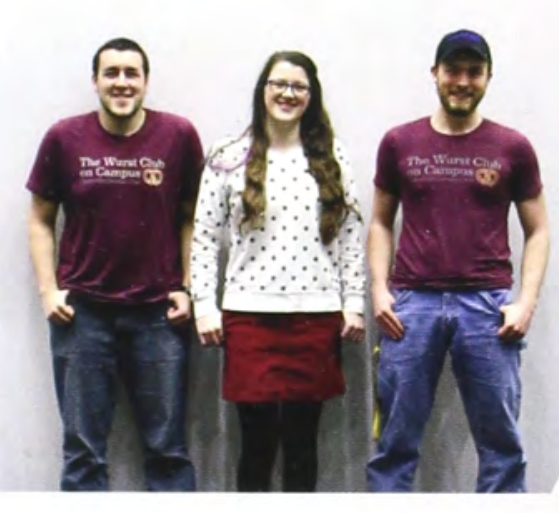

German Club

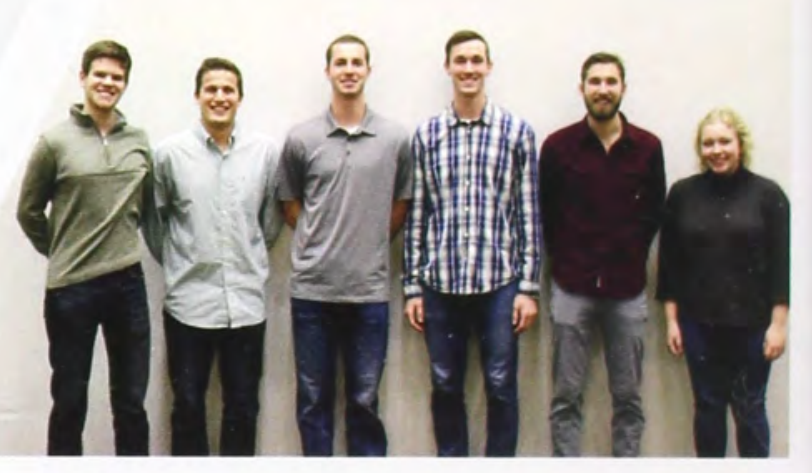

"Hearts for the Homeless

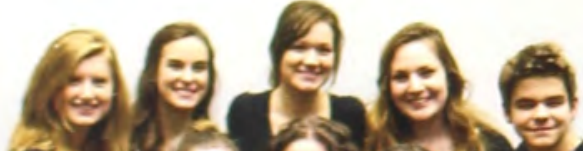

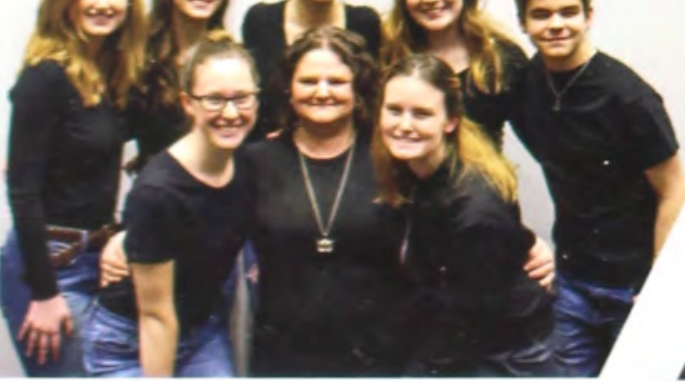

Inernational Justice Mission

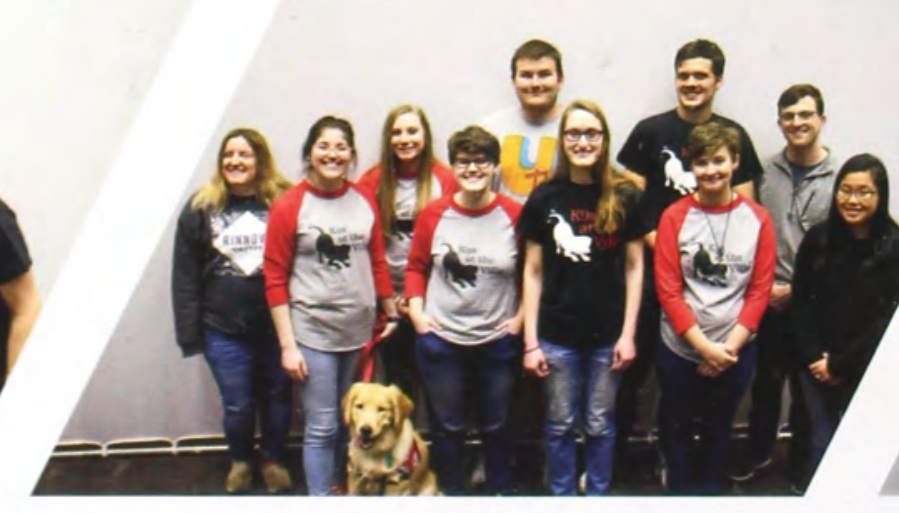

K9s at the Ville

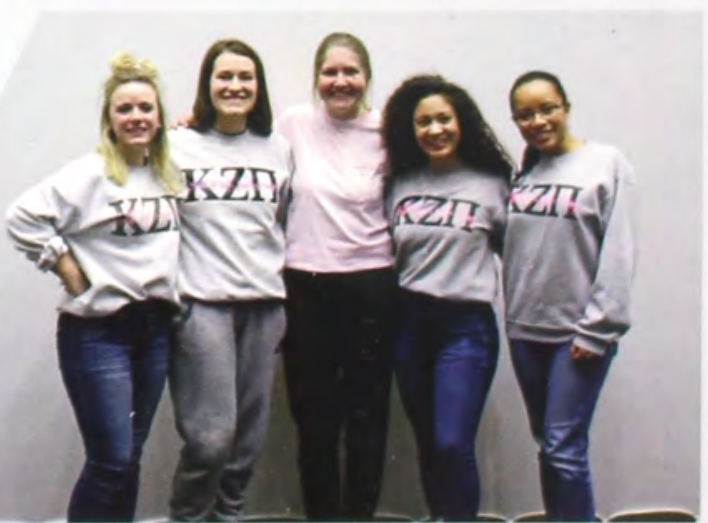

Kappa Zeta Pi 

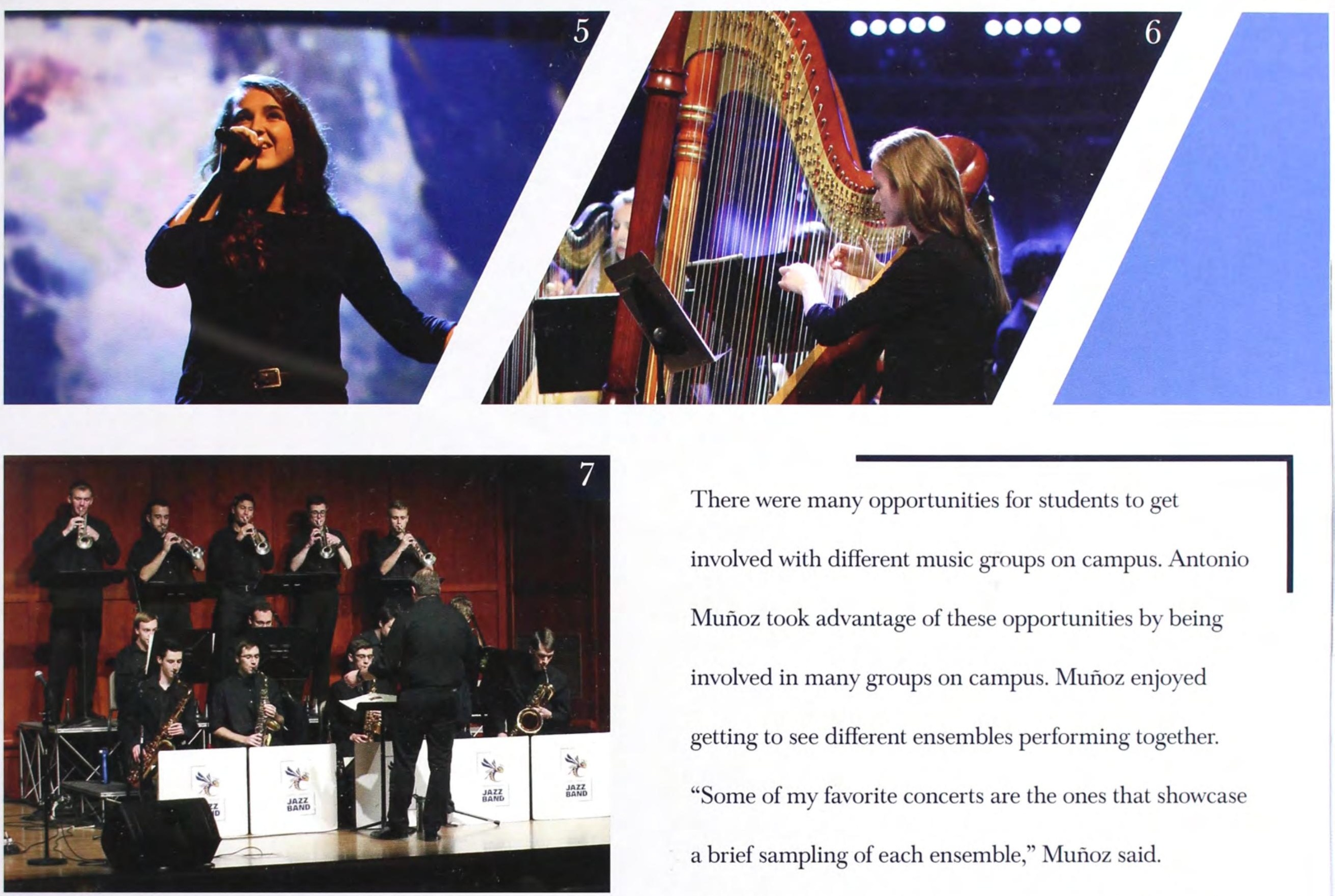

There were many opportunities for students to get

involved with different music groups on campus. Antonio

Muñoz took advantage of these opportunities by being

involved in many groups on campus. Muñoz enjoyed

getting to see different ensembles performing together.

"Some of my favorite concerts are the ones that showcase

a brief sampling of each ensemble," Muñoz said.

"The Community Christmas Concert and the Music

Showcase Concert are two such concerts that occur in

the fall and spring semesters respectively. It is just so

1. The Jazz Band plays some spirited Christmas music in the Recital Hall during their Christmas concert.

2. The Men's Glee Club sings during a concert. In addition to concerts here on campus, the Men's Glee Club also performed for schools, churches, and civic organizations.

3. Jubilate sings on the Chapel stage. Made up of about sixty members, Jubilate pulled together a variety of musical styles selected from various evangelical traditions.

4. The Women's Choir sings together during their concert in the Recital Hall. To be a part of the choir, women had to audition and commit to practicing three hours a week in addition to their academic work.

5. Emma Hill leads Heartsong in worship during their performance.

6. Jacy Stahlut from the Harp Ensemble performs in the chapel.

7. The Jazz Band, directed by Chet Jenkins, performs in the Recital Hall. The Jazz Band started in 1989 and although small, remains one of the most popular ensembles on campus.

cool to see all the musicians on campus involved in our orchestra, wind symphony, jazz band, and choirs all in one place supporting each other." Muñoz was involved in Concert Chorale and Jubilate. While these groups provided an opportunity to make lasting friendships,

Muñoz enjoyed the ministry aspect that was involved as well. "My favorite experience with Jubilate has been the opportunities we get to go out and do ministry in a church," Muñoz said. "We'll come and provide the music for their worship service that day. We have also had the chance to sing at the Creation Museum, sing with Keith and Kristyn Getty, and Travis Cottrell this year." 
The SGA team methodically planned out Campus

Christmas for weeks beforehand. This event took

students' minds off of finals week and helped them

embrace the holiday spirit. The team planned

cookie decorating, mini golf, train rides, and music

performances. Before Campus Christmas began,

the SGA team stayed up all night decorating the

student center, and then went out to breakfast

at Cracker Barrel after the celebration. It was a

tradition that naturally bonded the team and taught

them teamwork and good work ethic. Mitch Carr,

a sophomore on $\mathrm{CAB}$, loved working with the

volunteers and celebrating afterwards. "Campus

Christmas helps us see this is about being servant

hearted and about giving back to the University,"

Carr said. "The volunteers grow through the

same goal, and we get closer through that." Carr

mentioned how he would not have made some of the

friends he did outside of working together all night,

and that is what makes SGA and CAB so special.

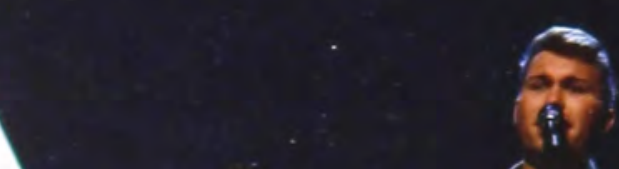

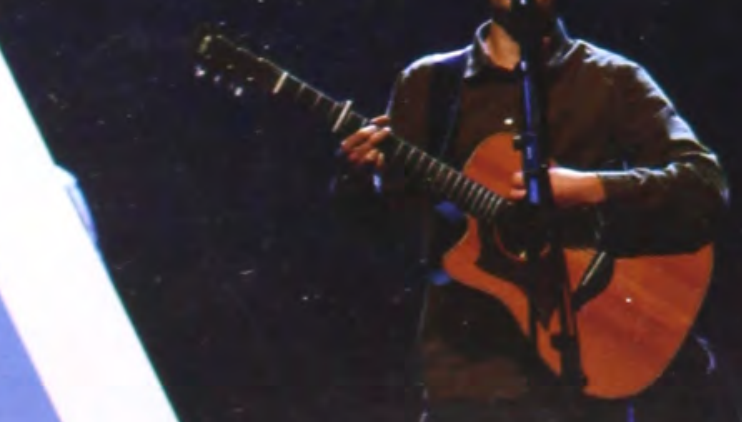

1. Emily Pitts, Erica Zichi, Zach Rubosky, Sarah Shaw Ojeda, and Gwendolyn Peterson pose in front of the fireplace after helping plan Campus Christmas activities. The group was enjoying the Christmas festivities around campus.

2. SGA band leader Ben Knudson leads worship during an SGA chapel.

3. SGA President Sarah Shaw Ojeda and Vice President Zach Rubosky give the Cedarville body announcements on upcoming events and activities to get involved around campus.

\section{Megan Davis sings praises with the SGA band.}

5. Sarah Stricker and Anna Beach pose for a photo while working at Rinnova. The two served as student managers.

6. Stinger raises his hands to hype the student body. This was during an SGA chapel to get students excited for upcoming events being held on campus.

7. Stinger, Zach Rubosky, and Sarah Shaw Ojeda give announcements before worship. They expressed excitement over the events coming to campus.
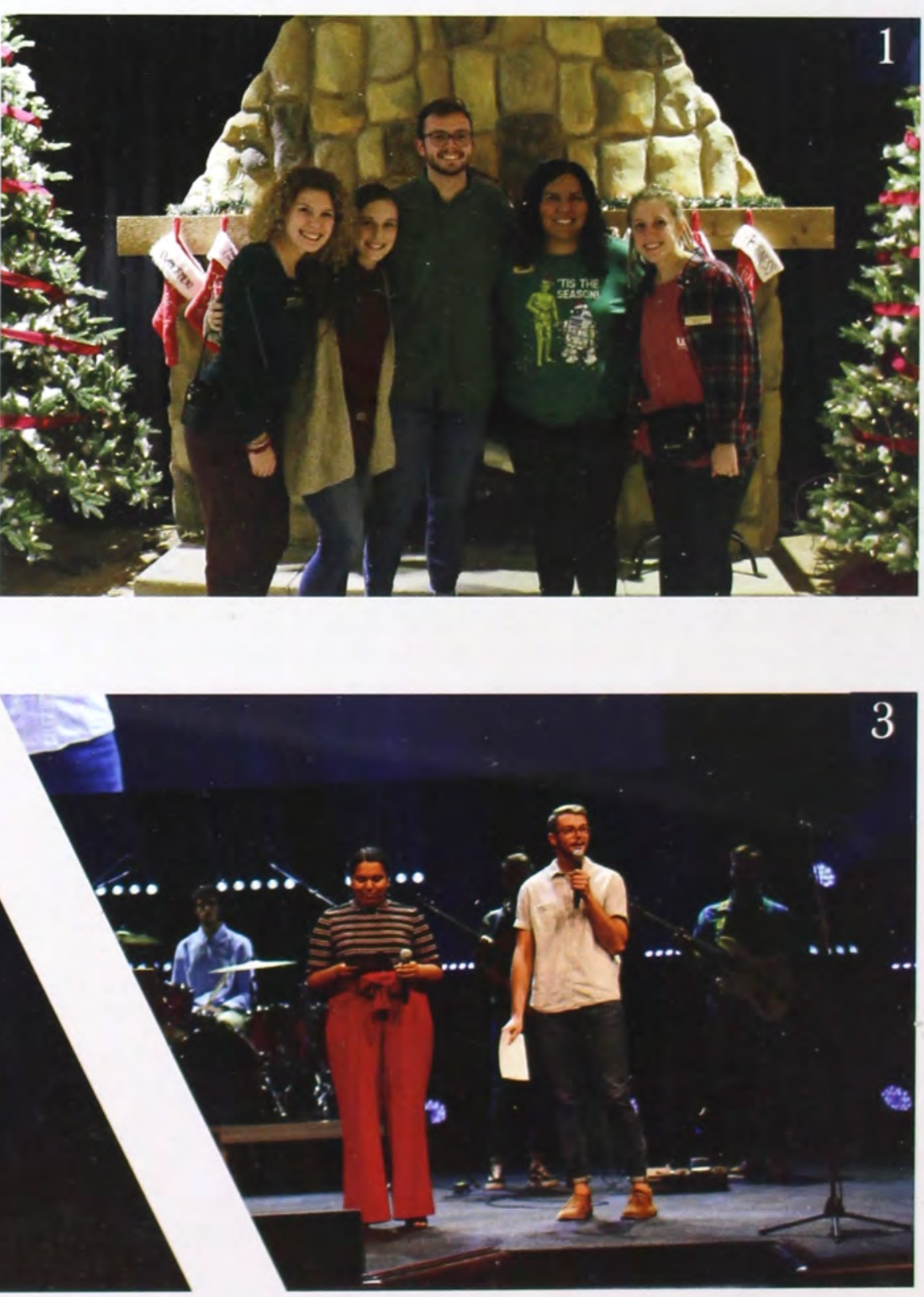

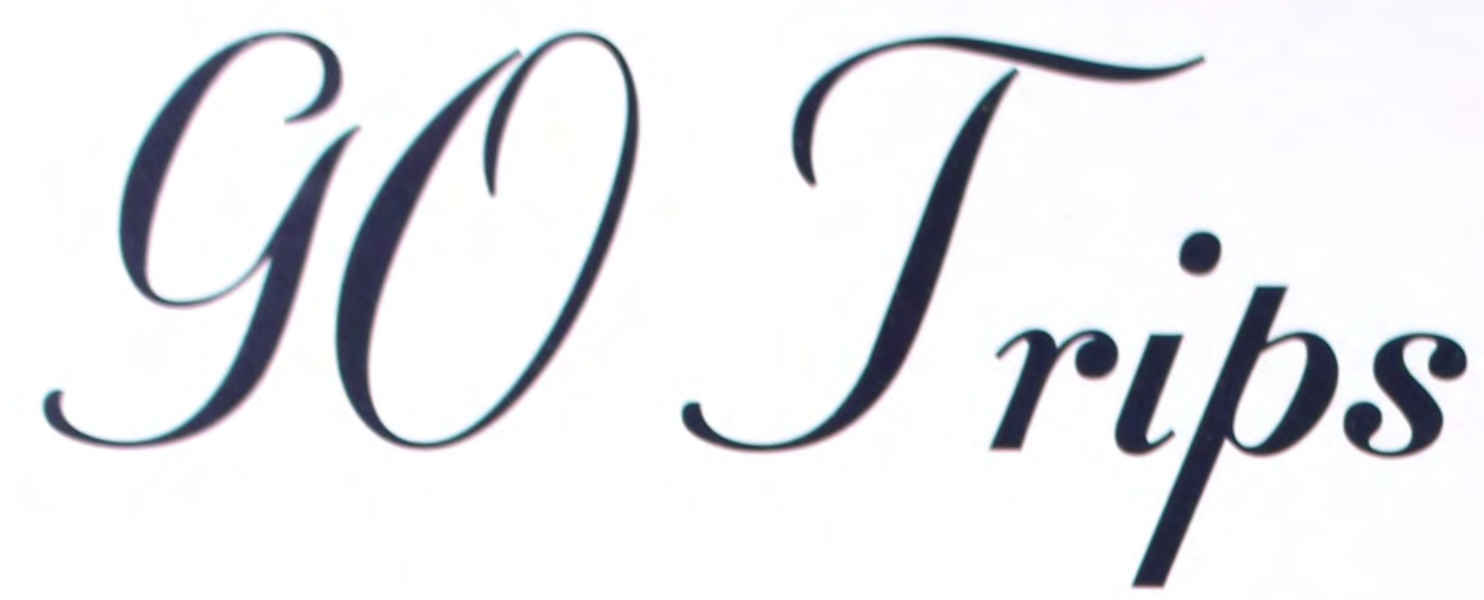

Students went all over the world in different Global Outreach teams to share the gospel with others while helping them with physical needs. All students are encouraged to go on at least one trip before they graduate.
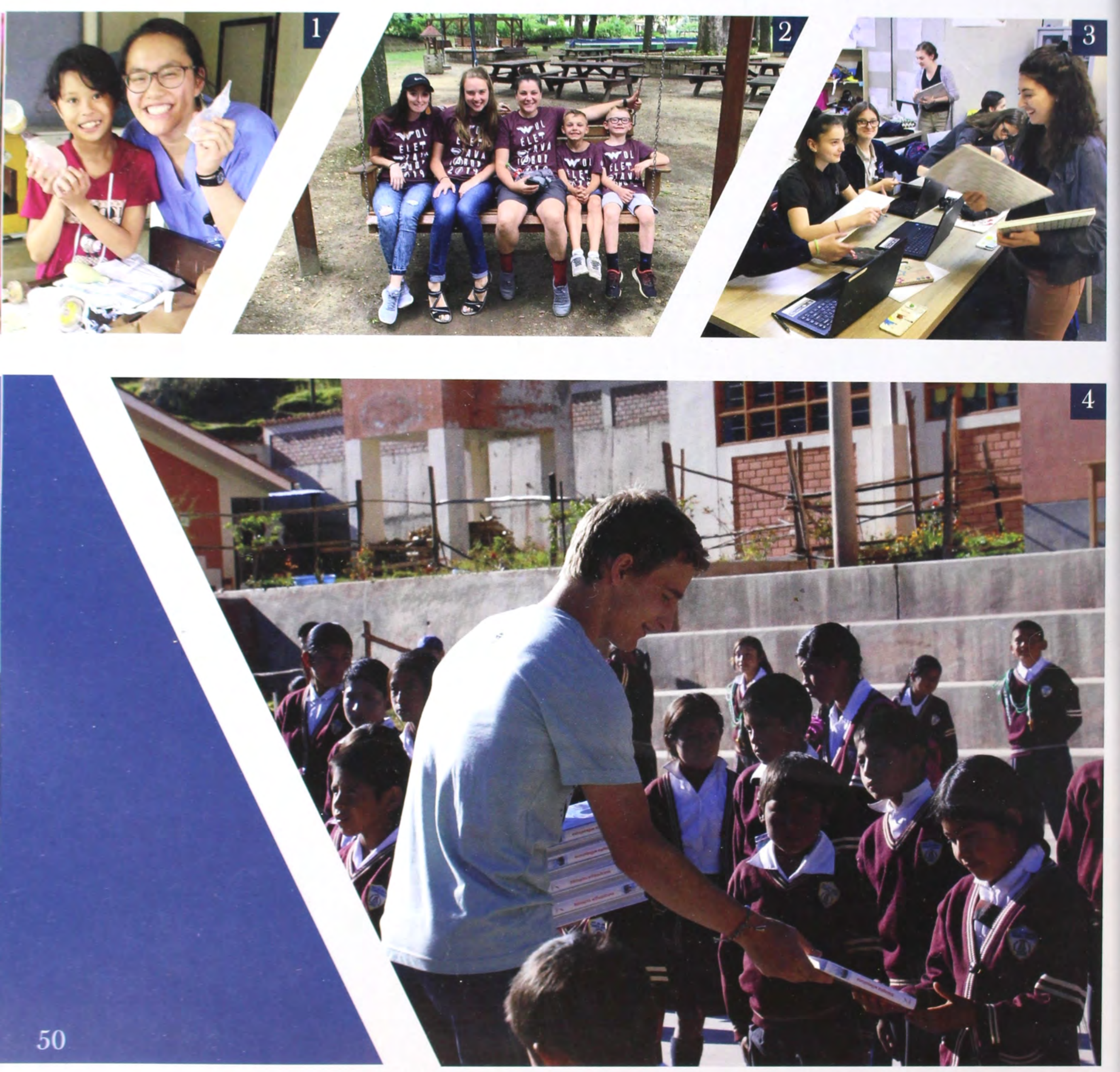


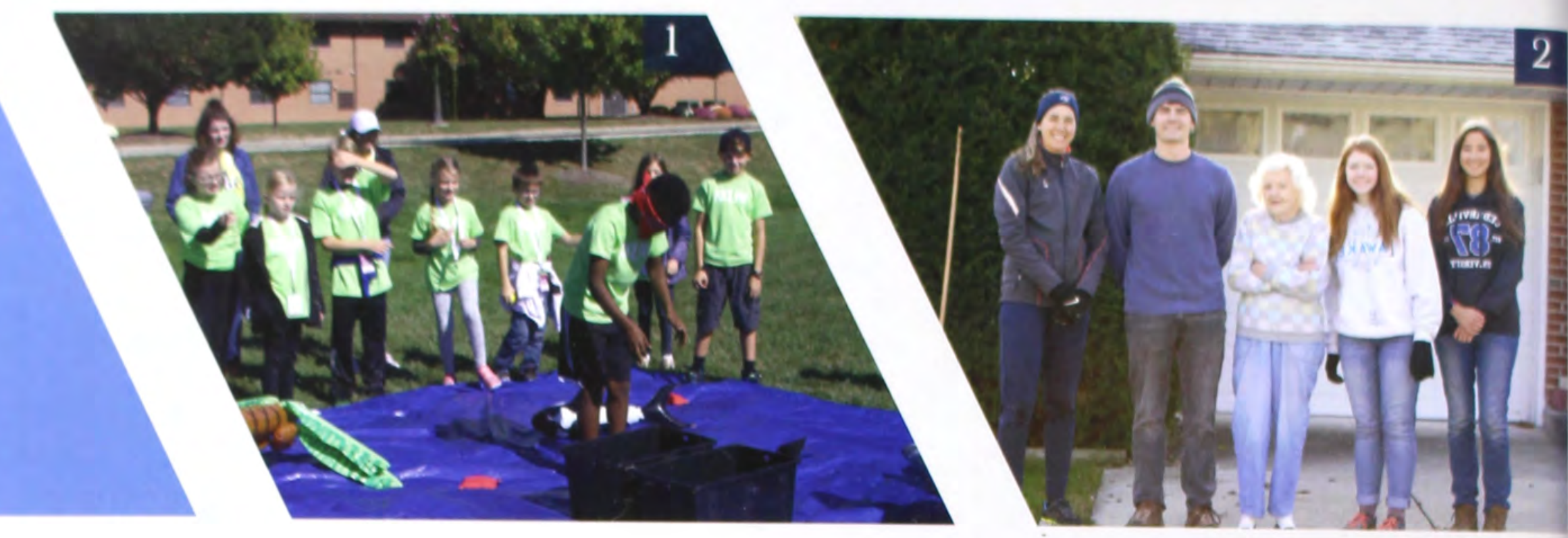

Cedarville provided the opportunity for students to

share the gospel with the surrounding community.

Senior David Daugherty had been involved in CU

Outreach since his freshman year. "CU Outreach is a

collection of teams that each spend one night a week

starting intentional conversations and sharing the

gospel with nearby university students," Daugherty

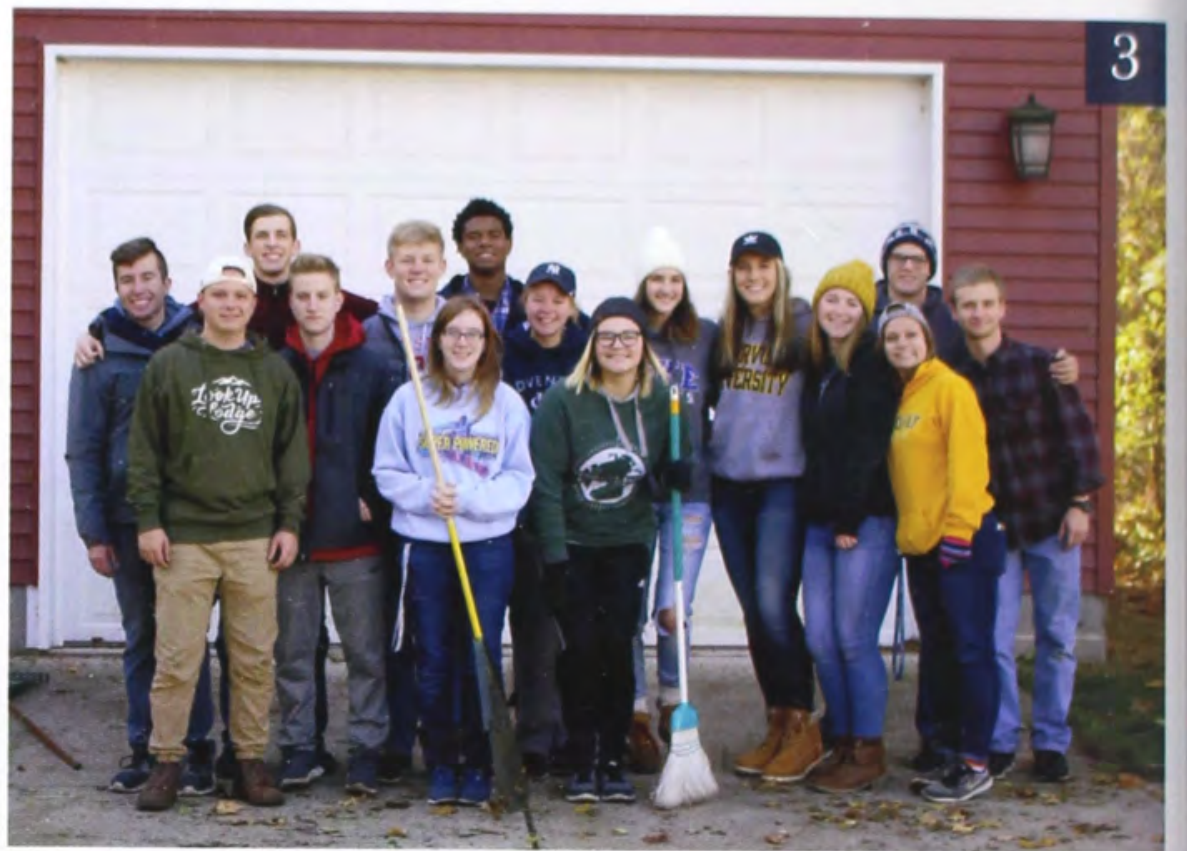

said. This experience was not only influential to the

students he was getting to know, but it also influenced

his own spiritual life. "In all of my Cedarville experience,

nothing has had as profound an effect on my faith as $\mathrm{CU}$

Outreach," Daugherty said. "Having had more mentally

and emotionally stretching conversations through this

ministry than I could ever count, I feel stronger and

more steadfast in my faith than I ever thought possible.”

Because of this experience, he encouraged others to get

involved in this ministry opportunity as well. "It can be

very challenging - terrifying at times. But I have never

once regretted the decision to step out against the fear of

man and start that conversation," he said.

1. Maddie Boccacci and Haile O'Neal lead a group of elementary school students during Junior Jam. The theme this year was "Powerful Persuasion" and was focused on Romans 8:38-39.

2. Skyler Farrand, Colson Cissel, Lauren Penner, and Allison Wise help a local woman with yard work. Each fall, students are invited to attend $\mathrm{CU}$ in the community to help maintain their homes.

3. A Bro-Sis group from Lawlor and Printy participate in $\mathrm{CU}$ in the community. They did yard work and cleaned up houses in Cedarville.

4. Abby Jenks builds gingerbread houses with an elementary student attending the God's Girls Christmas party. During this event, Jenks and the other volunteers were able to host a Christmas dinner, give gifts, and share about Jesus.

5. Abby Shaffer, Allex Teters, and Victoriahna Vander Does rake leaves at $\mathrm{CU}$ in the Community.

6. Jake Allinson waves at students during Junior Jam.

7. Halee McPherson packs boxes for the Operation Christmas Child event. Cedarville students packed 1000 boxes during this event. 


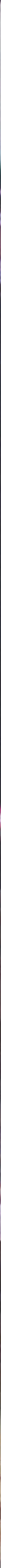




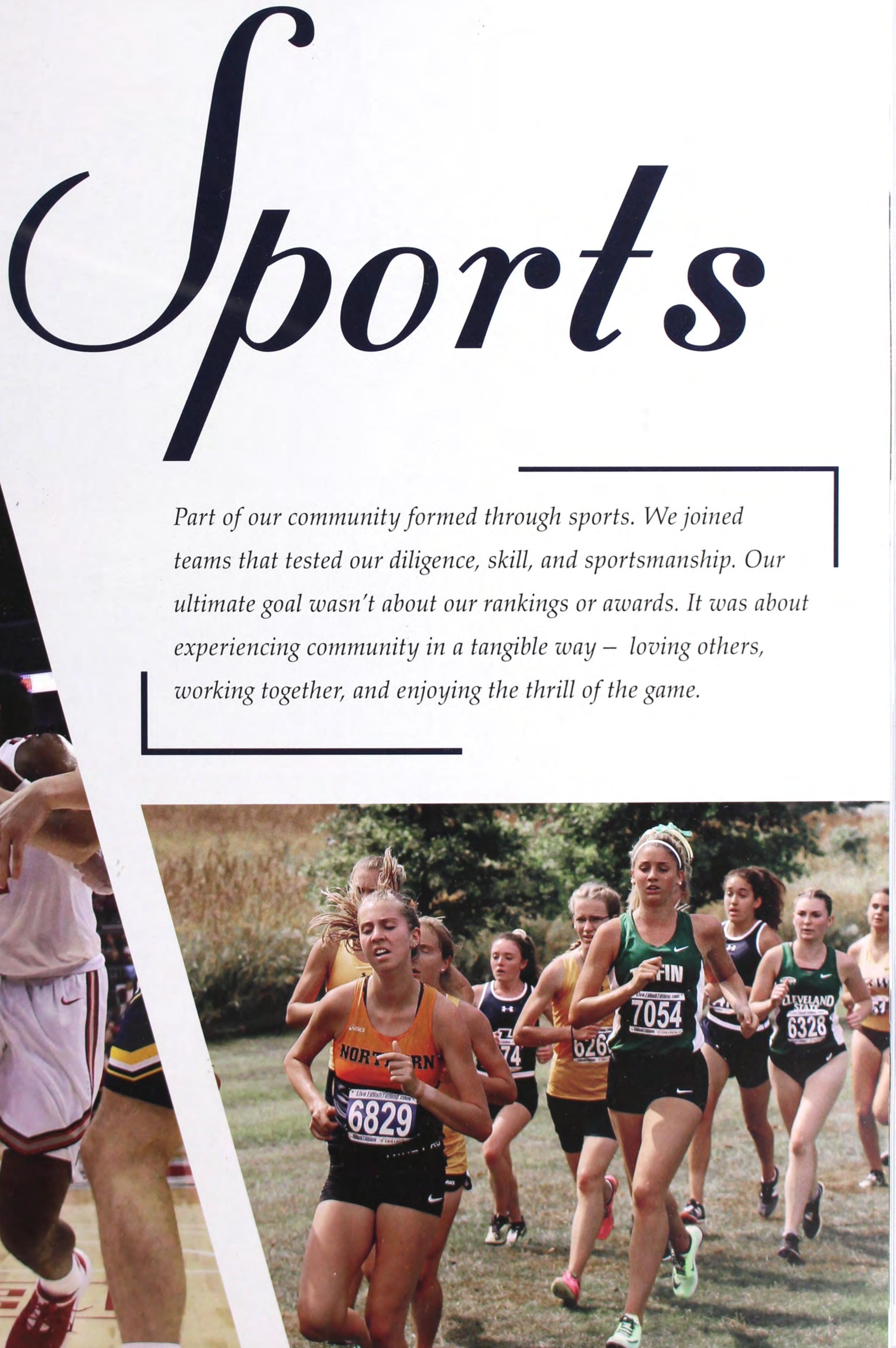



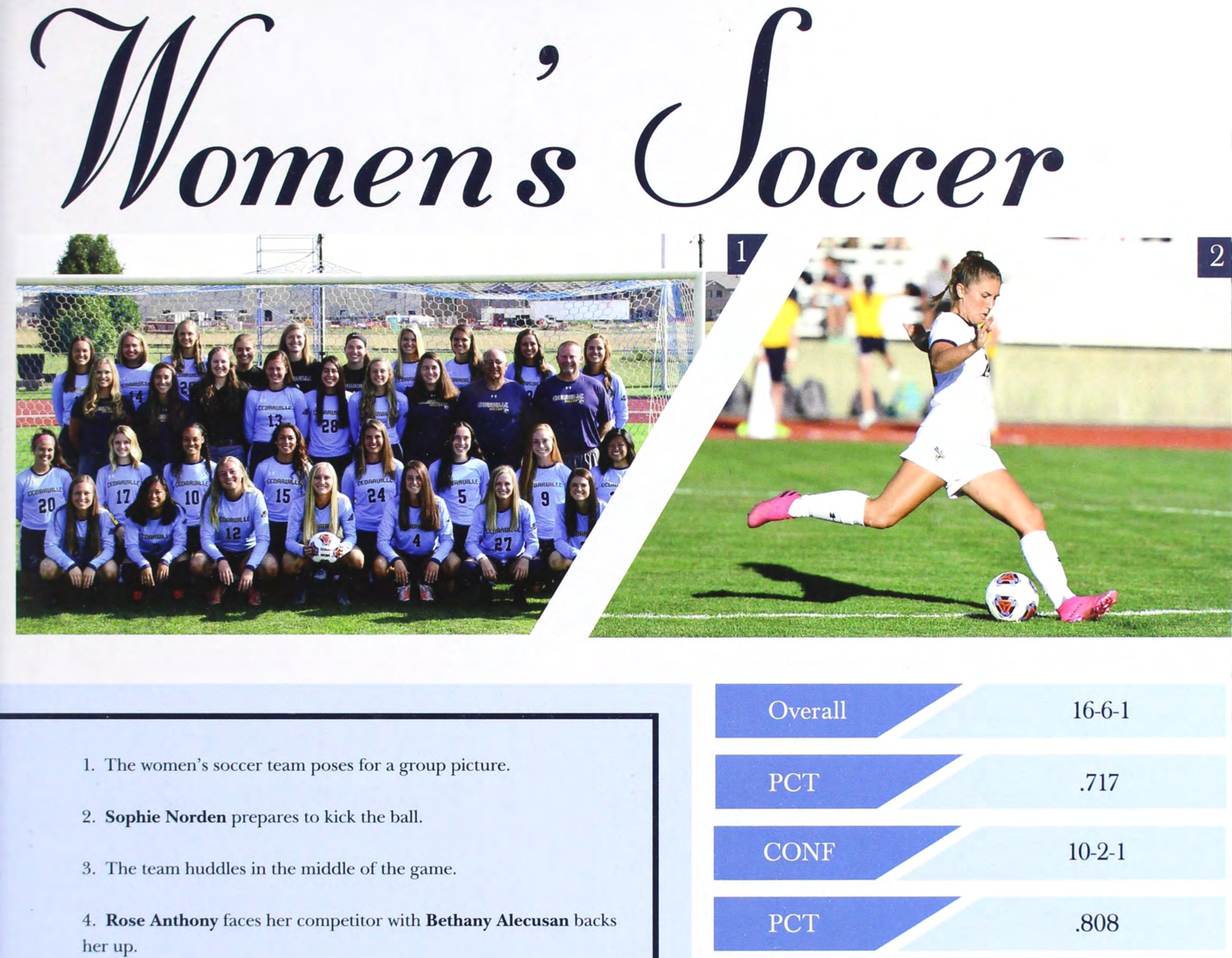

$16-6-1$

1. The women's soccer team poses for a group picture.

2. Sophie Norden prepares to kick the ball.

3. The team huddles in the middle of the game.

4. Rose Anthony faces her competitor with Bethany Alecusan backs her up.

5. Taylor Noll prepares to shoot the ball.

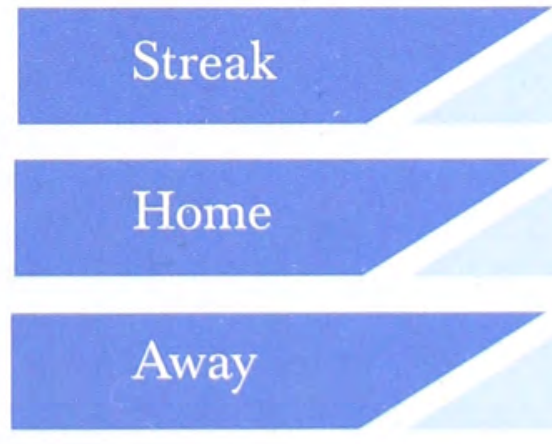

Neutral

.717

10-2-1

.808

W4

8-1-0

4-2-1

$1-3-0$

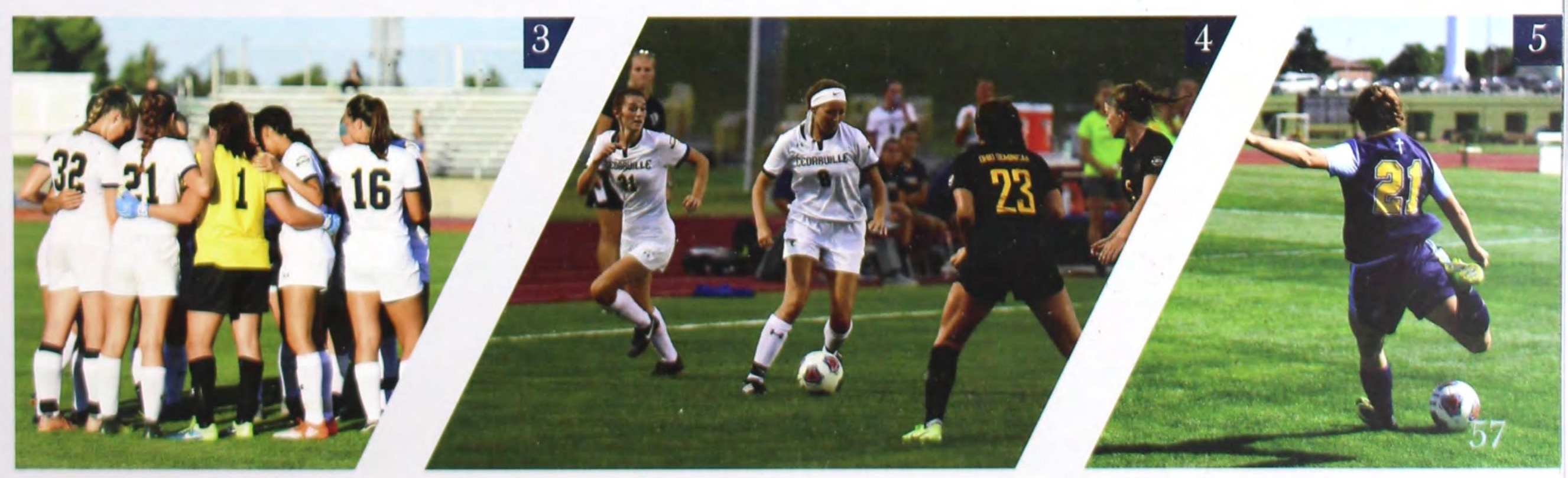



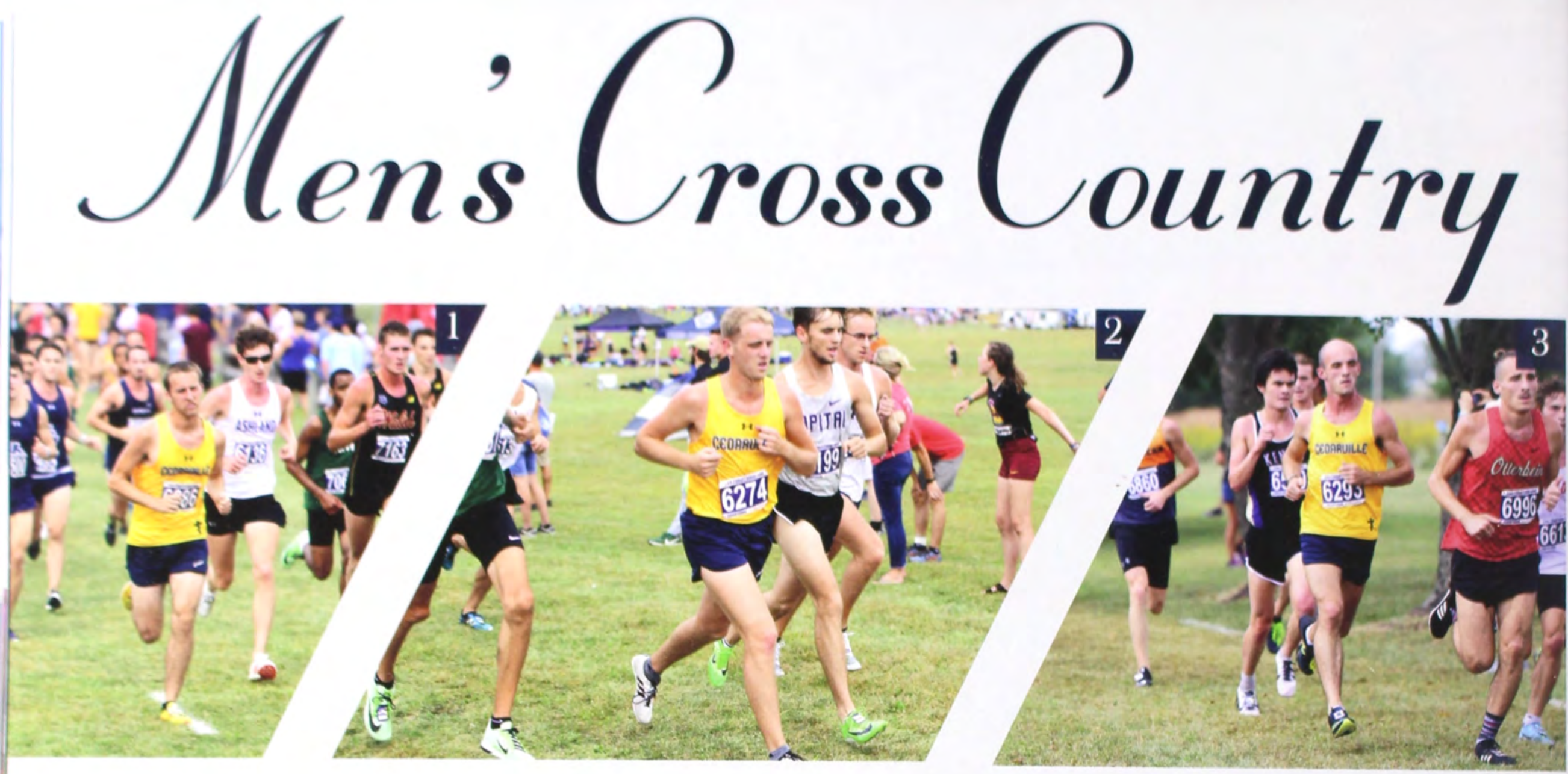

I 9 -

1

$-1$

$-5$

,

(r.

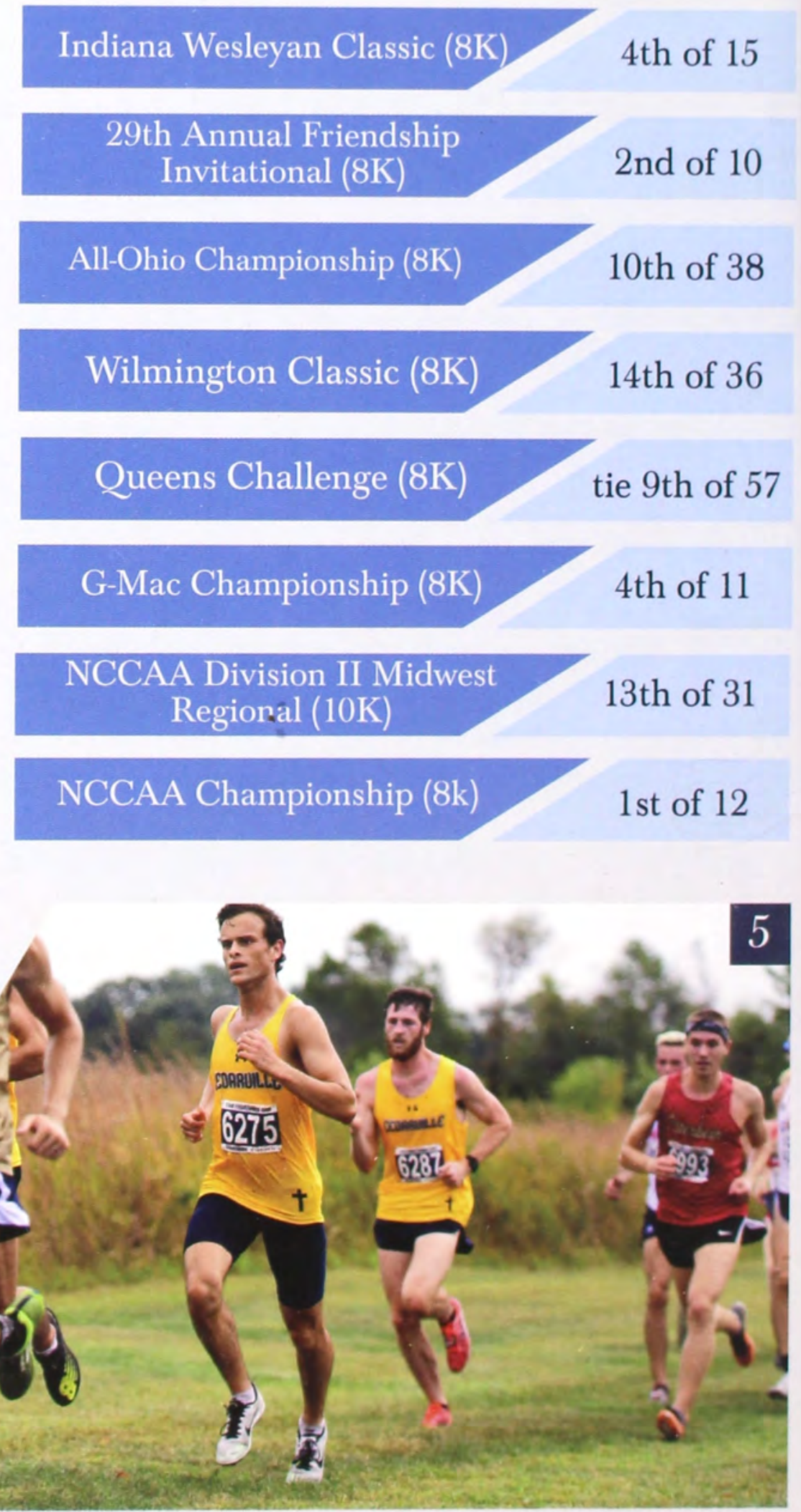

1. Russel Schultz paces next to competitors.

2. Trent Classen takes the lead over a fellow competitor.

3. Alex Weber quickens his pace as he eyes the trail in front of him.

4. Caleb Pendleton speeds ahead as spectators watch.

5. Trevor Cross keeps up with competitors.

Indiana Wesleyan Classic (8K) $\quad 4$ th of 15

All-Ohio Championship (8K) $\quad 10$ th of 38

Wilmington Classic (8K) 14 th of 36

Queens Challenge (8K) tie 9th of 57

G-Mac Championship (8K) $\quad$ th of 11

AA Division II Midwest 

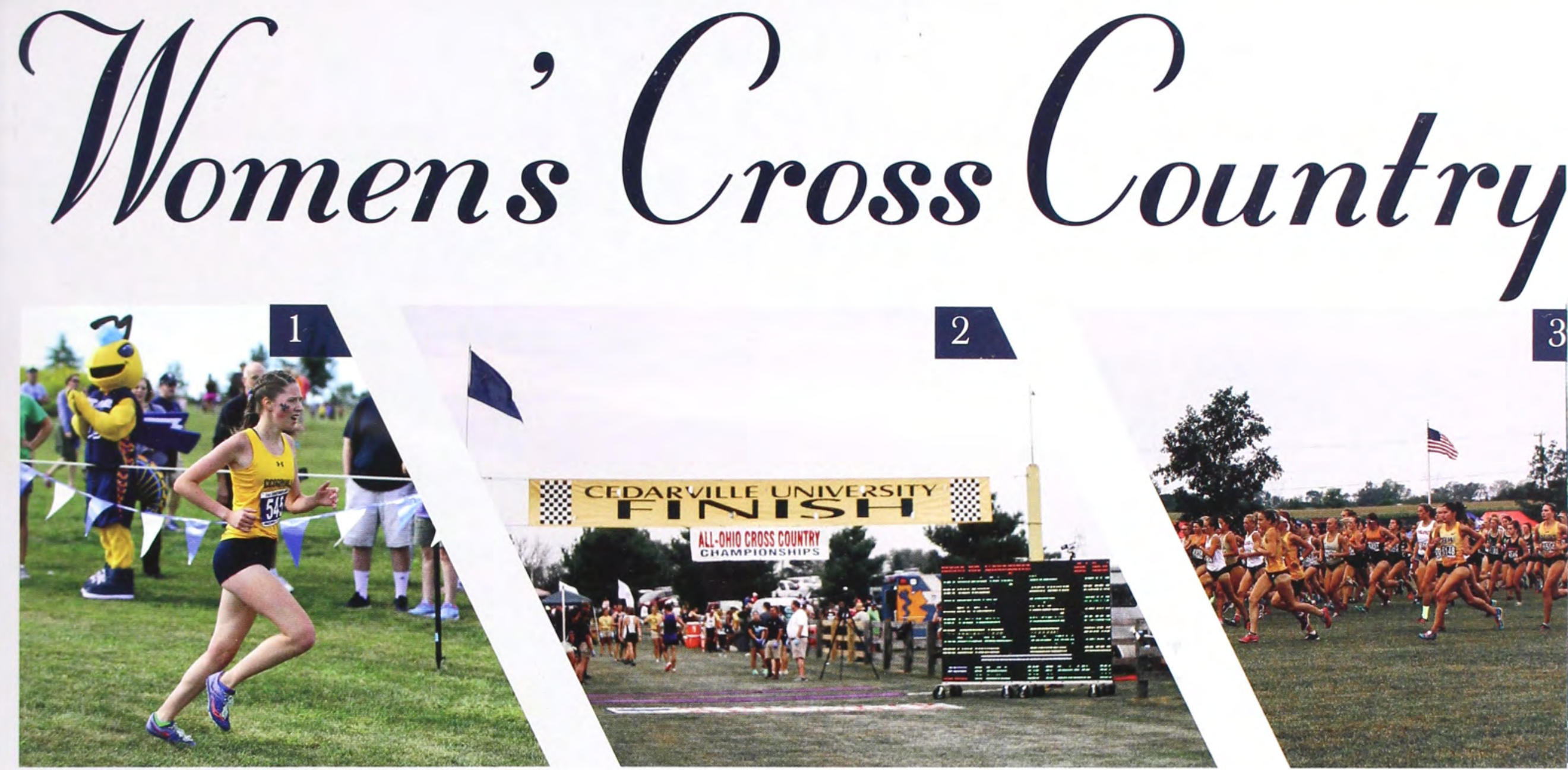

3

Indiana Wesleyan Classic (8K) $\quad 1$ st of 16

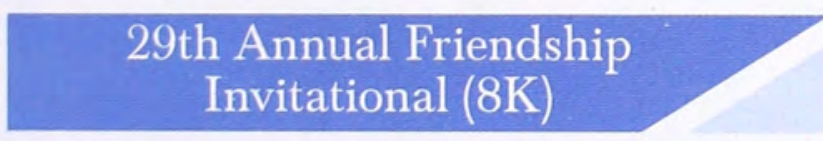

2nd of 11

All-Ohio Championship (8K)

5 th of 35

Wilmington Classic (8K) $\quad 7$ th of 33

Queens Challenge (8K) $\quad 5$ th of 63

G-Mac Championship (8K) $\quad$ 3rd of 12

NCCAA Division II Midwest Regional (10K)

10 th of 32

NCCAA Championship (8k) $\quad 1$ st of 11
1. Cecily Holliday runs ahead of fellow runners. Stinger cheers on the team from the sidelines.

2. The crowd watches runners cross the finish line in anticipation.

3. Runners begin their race in a frenzy. They try to break away from the pack in order to get ahead.

4. Two Cedarville runners pace themselves to keep up with a fellow opponent on a straightaway.

5. Amy Plank keeps up with the pace of opponents around her as they run around a curve in the track.

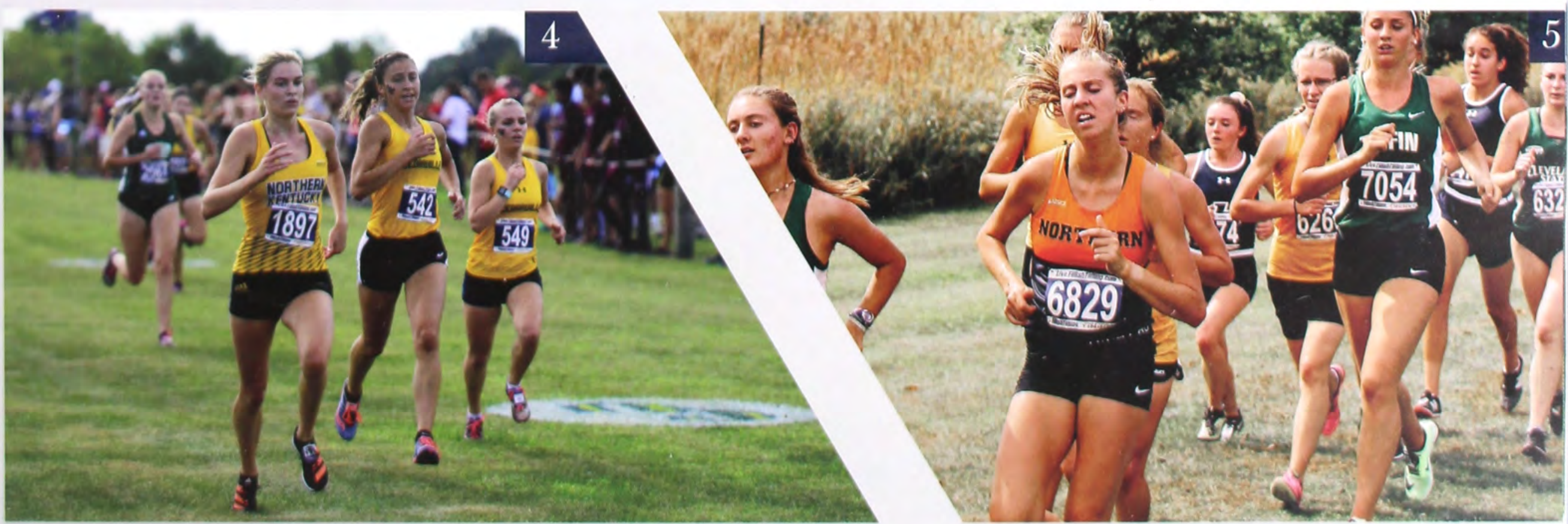



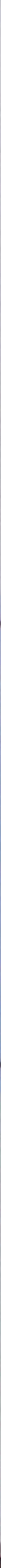

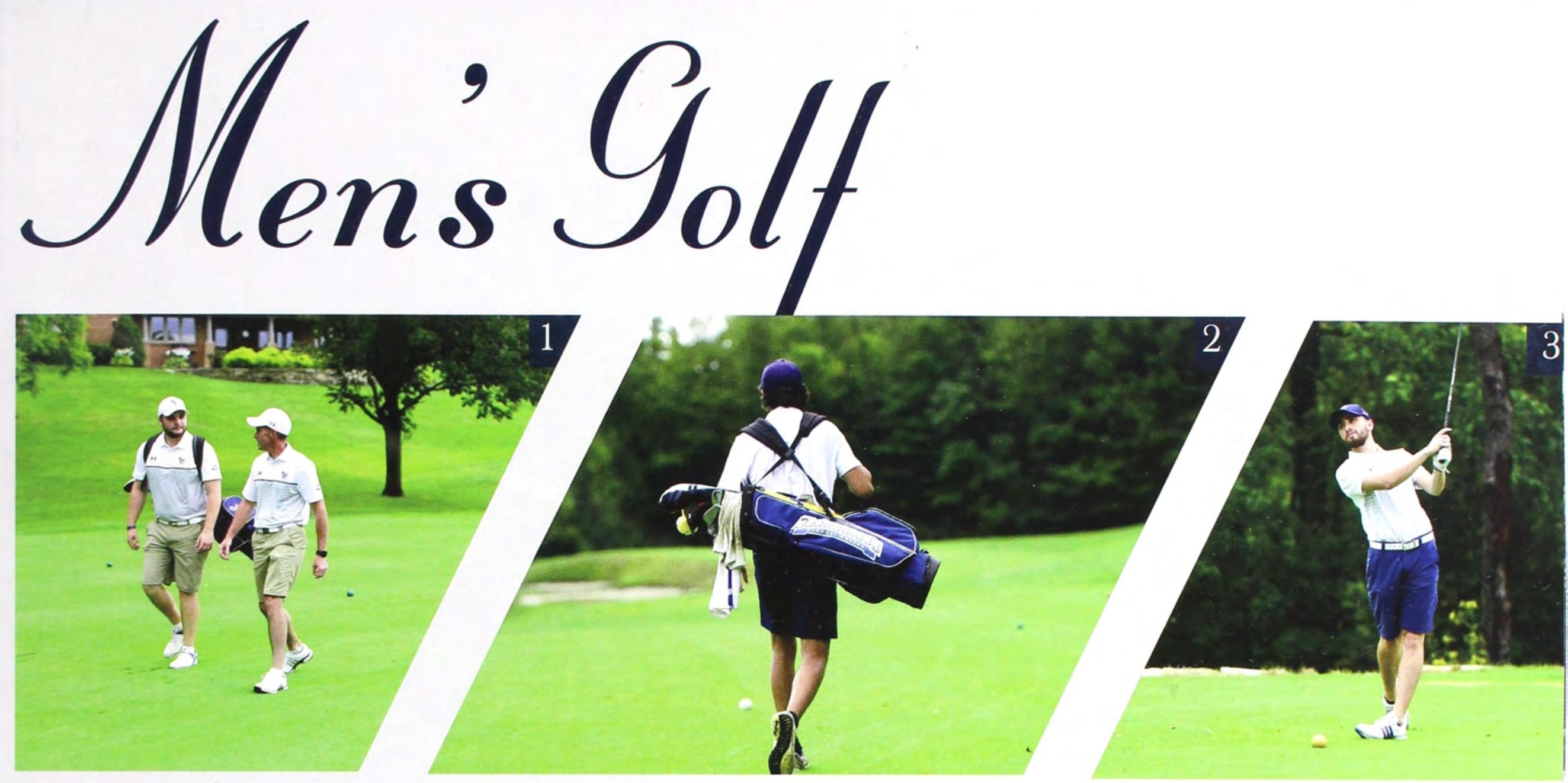

1. Rob Harris talks with his coach while walking down the fairway.

2. Ben Sheard walks down the fairway.

3. Isaac Wood watches his tee shot while taking a swing at the ball.

4. Ben Sheard lines up his putt before taking his shot.

5. Squaring his shoulders, Mitch Jeffe lines up his approach shot.

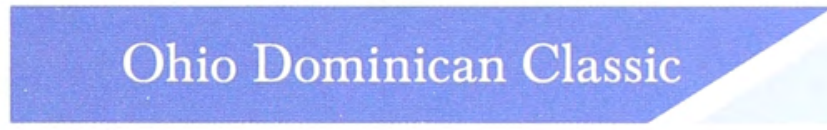

3rd of 6

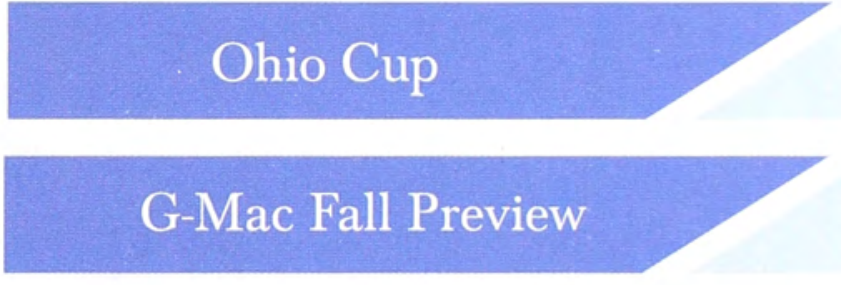

3rd of 12

10 th of 10

Tiffin Memorial

5 th of 9

Cedarville Invitational

1st of 3 rd

NCAA Campionship

5 th of 9

Barton Intercollegiate 3rd of 6
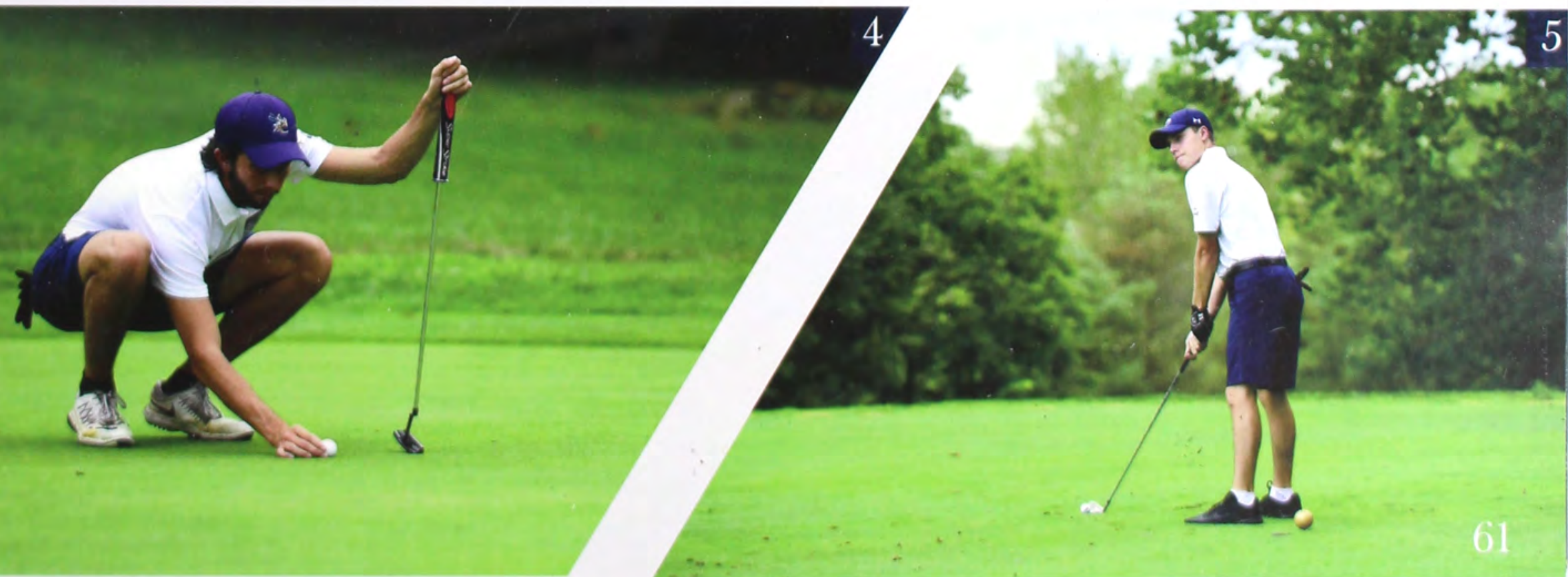

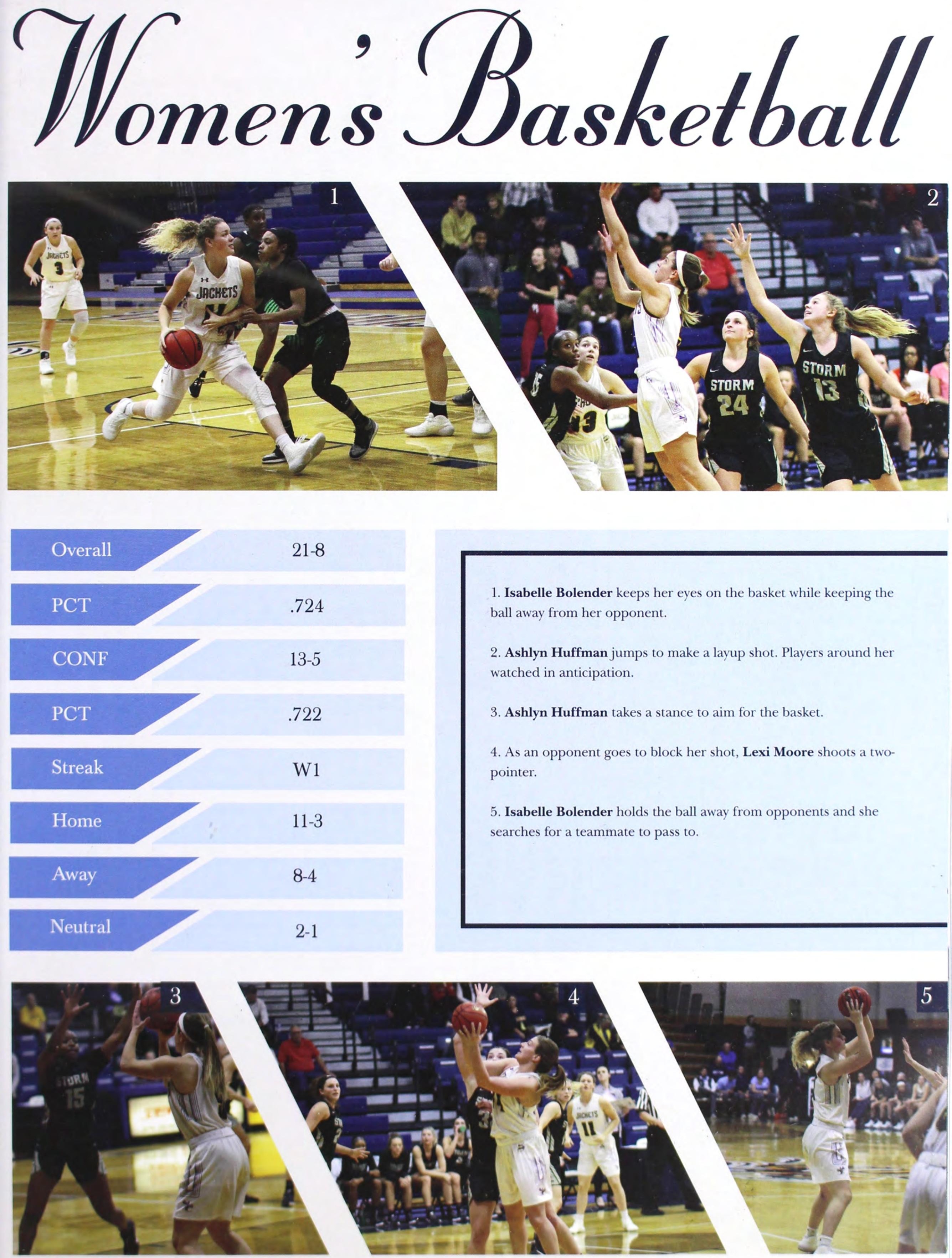

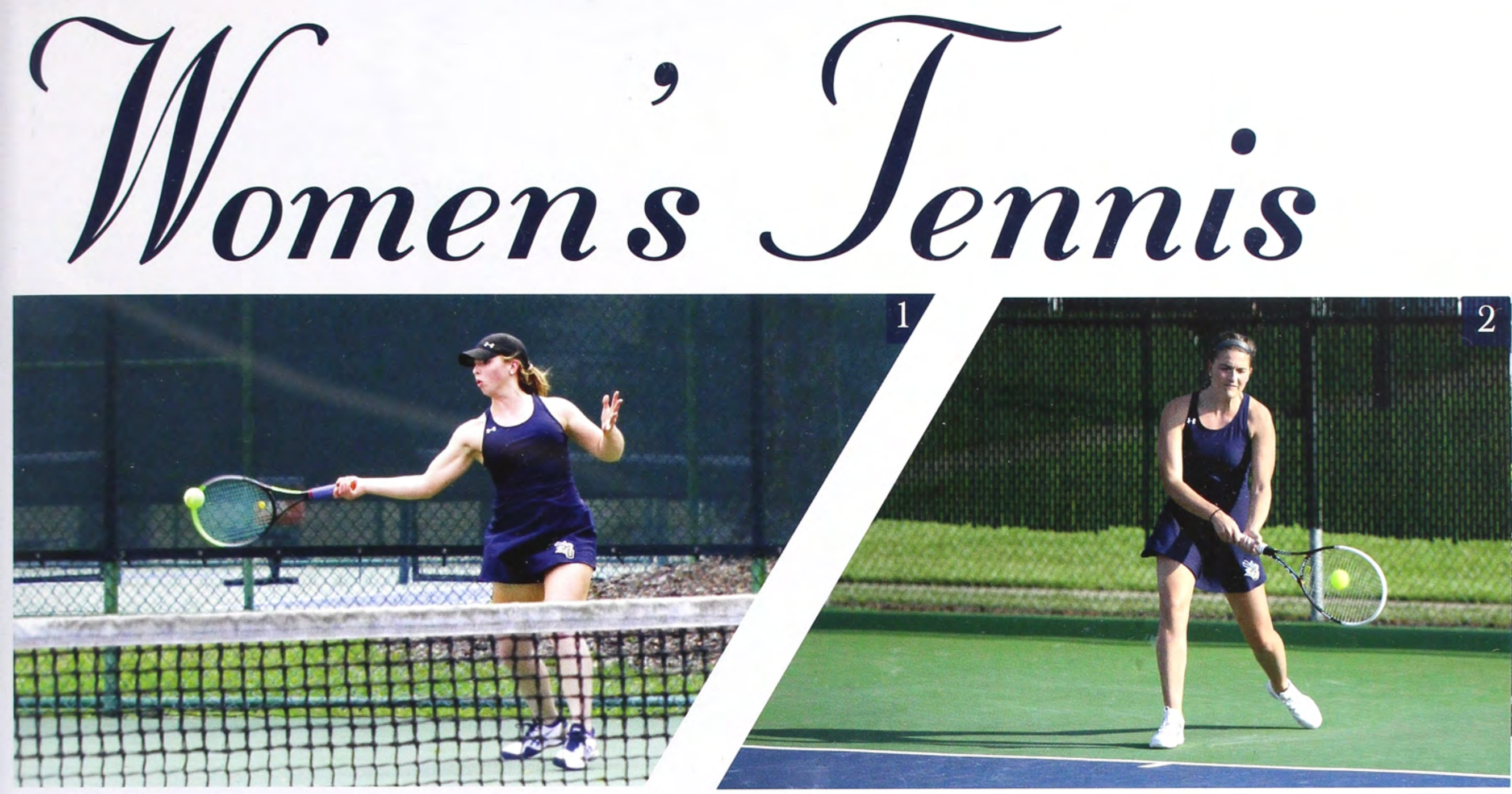

2. Halie Hardwick returns a backhand stroke to her opponent.

3. Abbie Evans outstretches her hand in an attempt to hit a forehand.

4. Lauren Hollis runs up to the ball to complete a forehand.

5. Megan Vandyke powers through her stroke to win the next point.
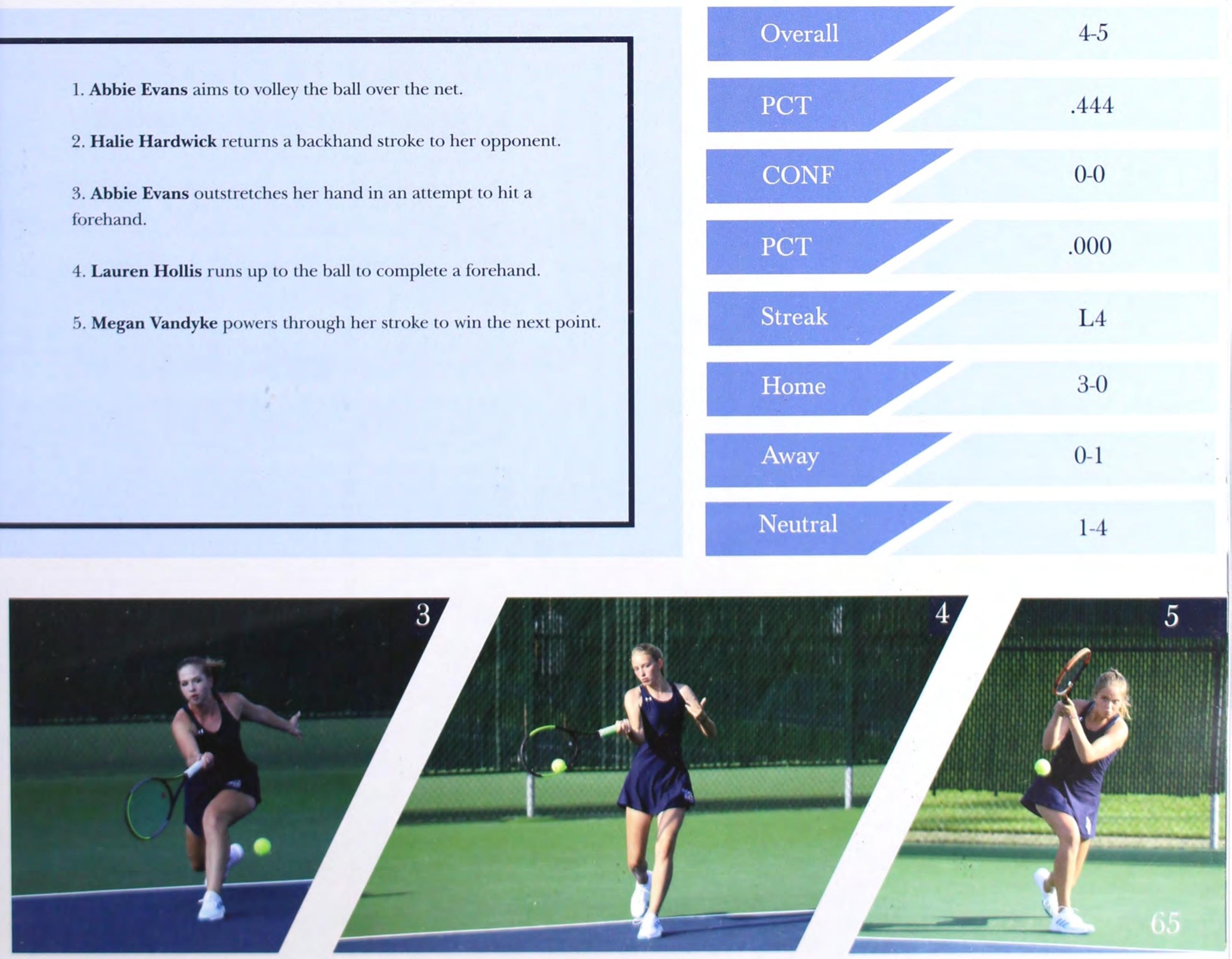


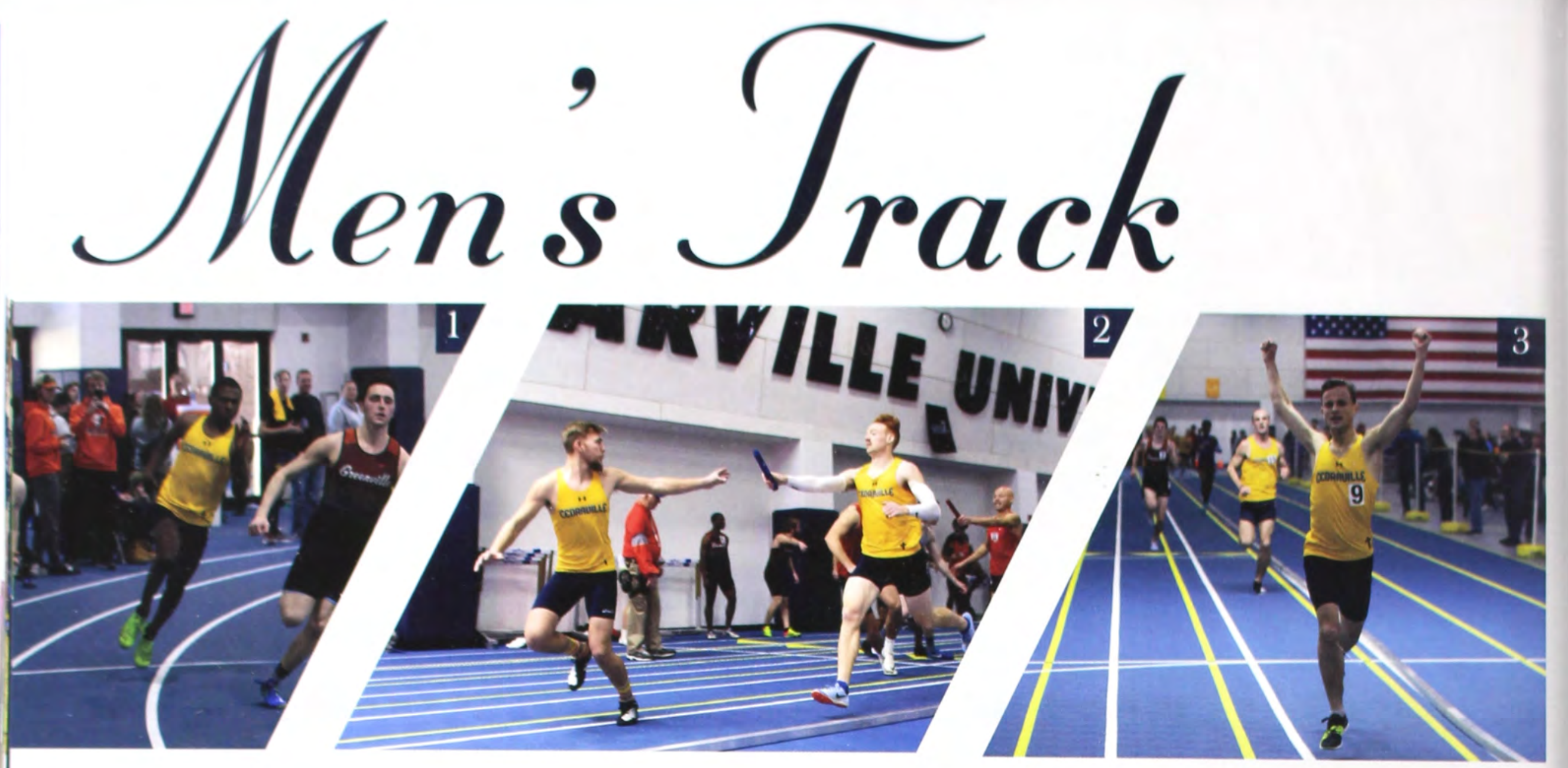

1. Joshua Brown runs the 200-meter race.

2. Joel Gatchell and Ryan Rager exchange the baton during their relay race.

3. Trevor Cross celebrates as he crosses the finish line of his race.

4. Ryan Rager, Joel Gatchell, Caleb Carrico, and Ben Hulbert pose for a picture with their baton.

5. Josh Adkins clears the bar in the pole vault.

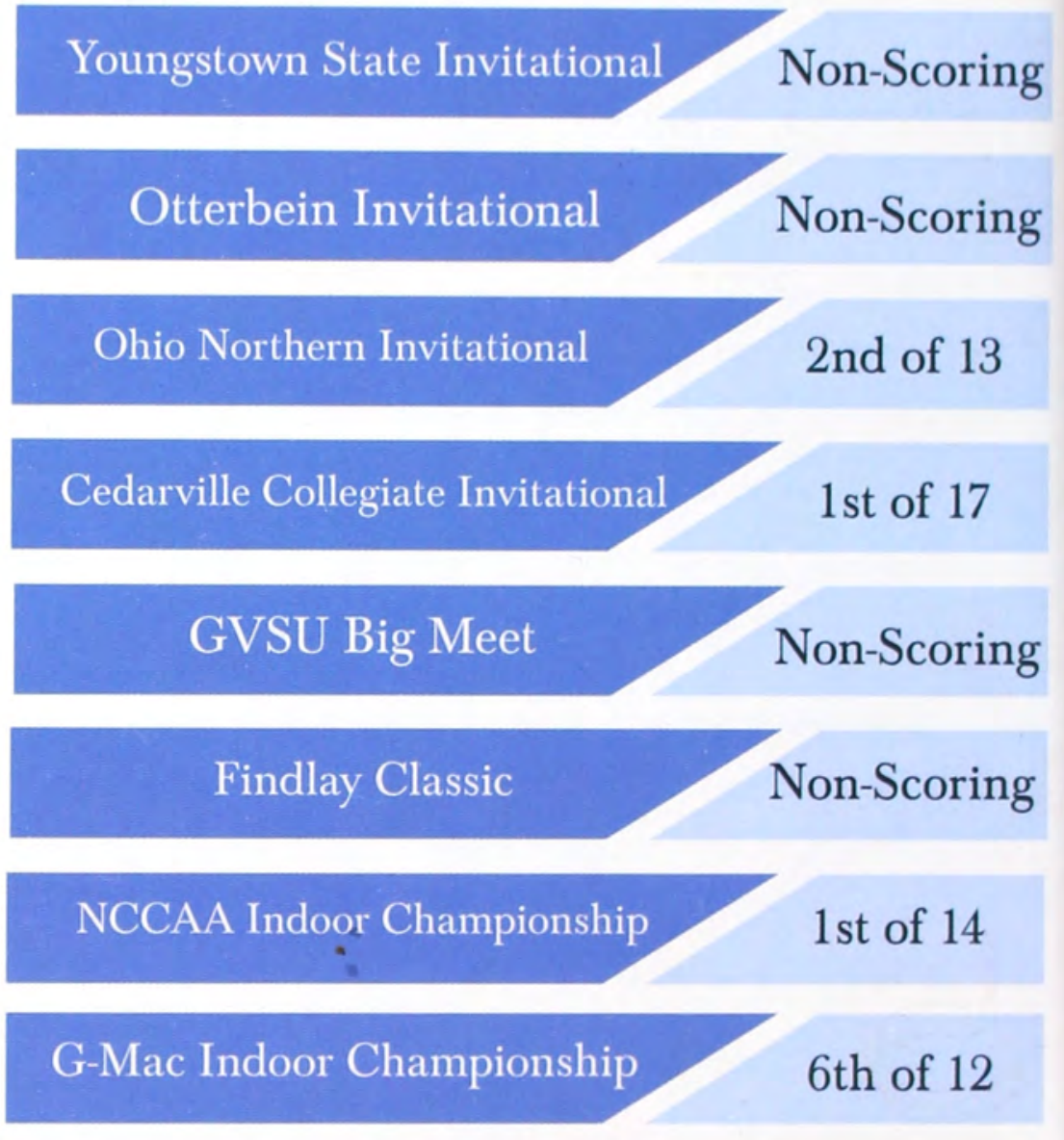

G-Mac Indoor Championship $\quad 6$ th of 12

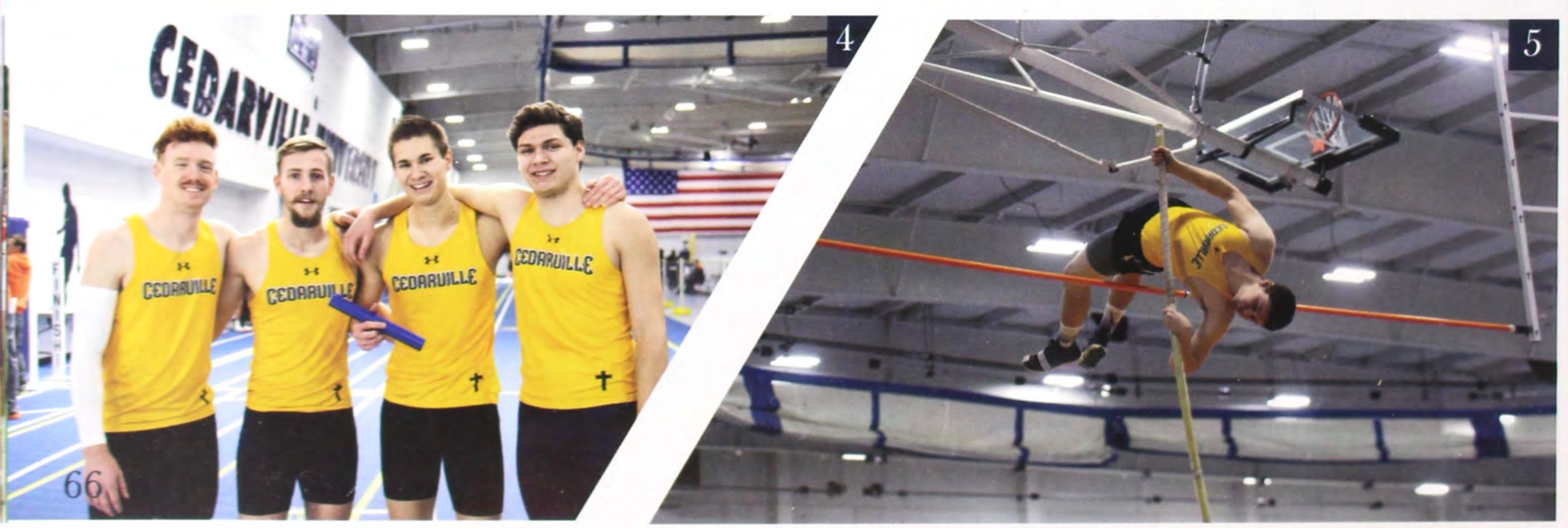




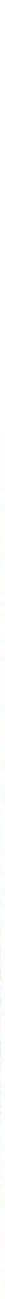

Youngstown State Invitational Non-Scoring

Otterbein Invitational Non-Scoring

Ohio Northern Invitational $\quad$ 2nd of 14

Cedarville Collegiate Invitational 1st of 17

GVSU Big Meet Non-Scoring

Findlay Classic Non-Scoring

NCCAA Indoor Championship $\quad 1$ st of 14

G-Mac Indoor Championship $\quad 5$ th of 13
1. Hannah Johnson runs the 200 -meter race.

2. Hannah Willow does the long jump.

3. Grace Norman runs the mile.

4. Hannah Johnson runs a sprint at the NCCAA Championships.

5. Rachel Sweeney and Lyndsey Bishop run a relay at the NCCAA

Championships.

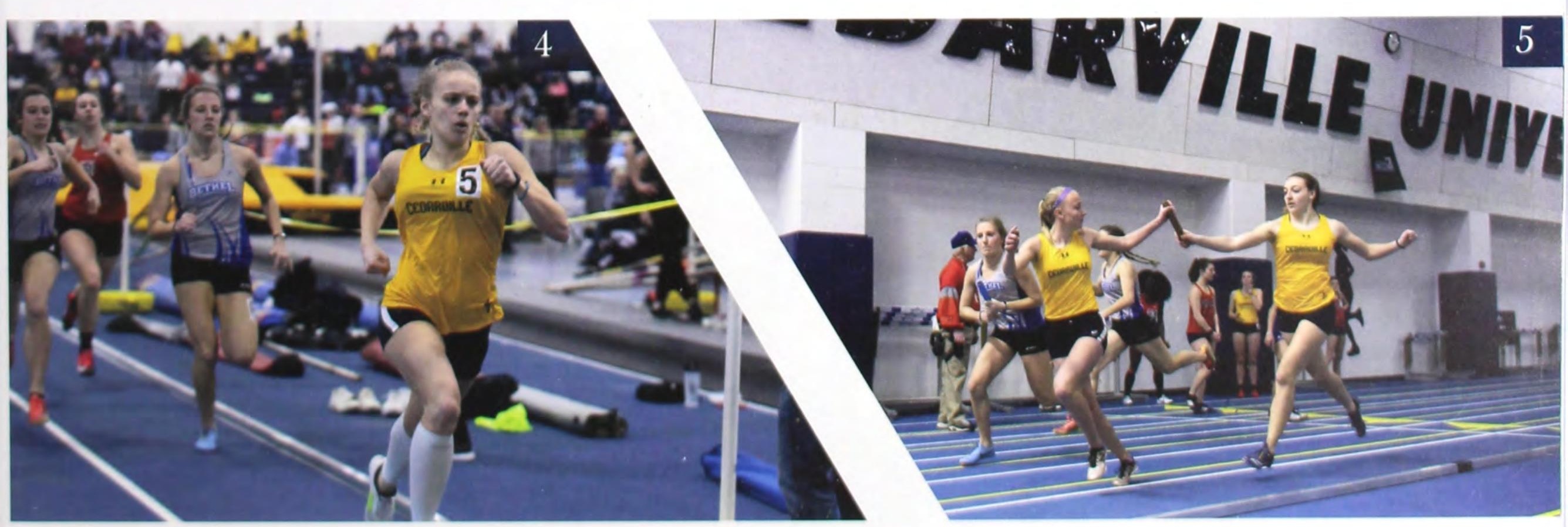




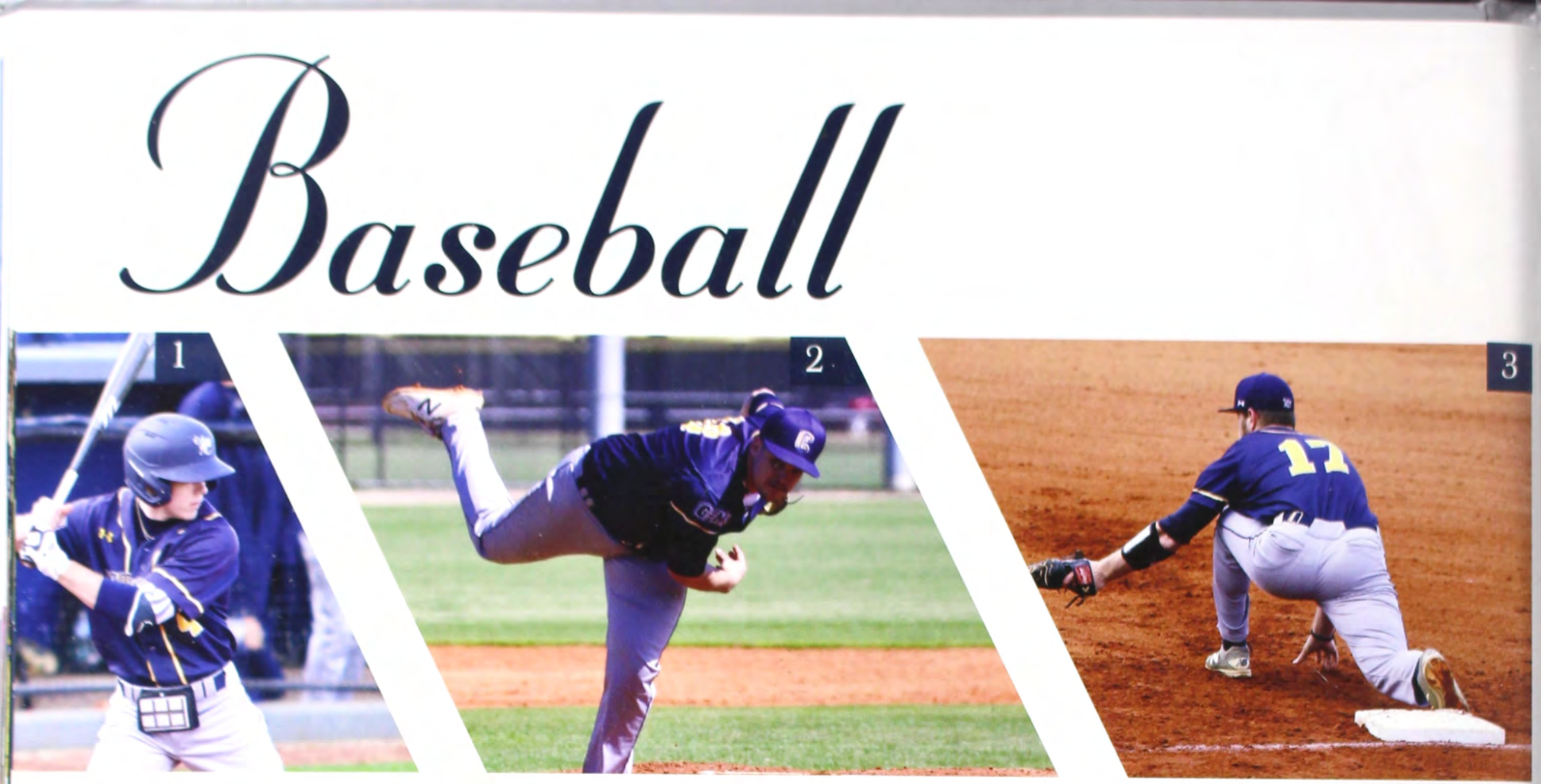

\begin{tabular}{|c|c|c|}
\hline Overall & $7-5$ & \\
\hline PCT & .583 & 1. Austin Brown prepares to swing as he waits at bat. \\
\hline CONF & $0-0$ & 3. Logan Eby prepares to catch the ball as he covers the base. \\
\hline PCT & .000 & 4. Bryce Hughes takes a swing for a hit. \\
\hline Streak & L1 & 5.Payton Eeles and Austin Brown tap their helmets together. \\
\hline Home & $0-0$ & \\
\hline Away & $2-2$ & \\
\hline Neutral & $5-3$ & \\
\hline
\end{tabular}

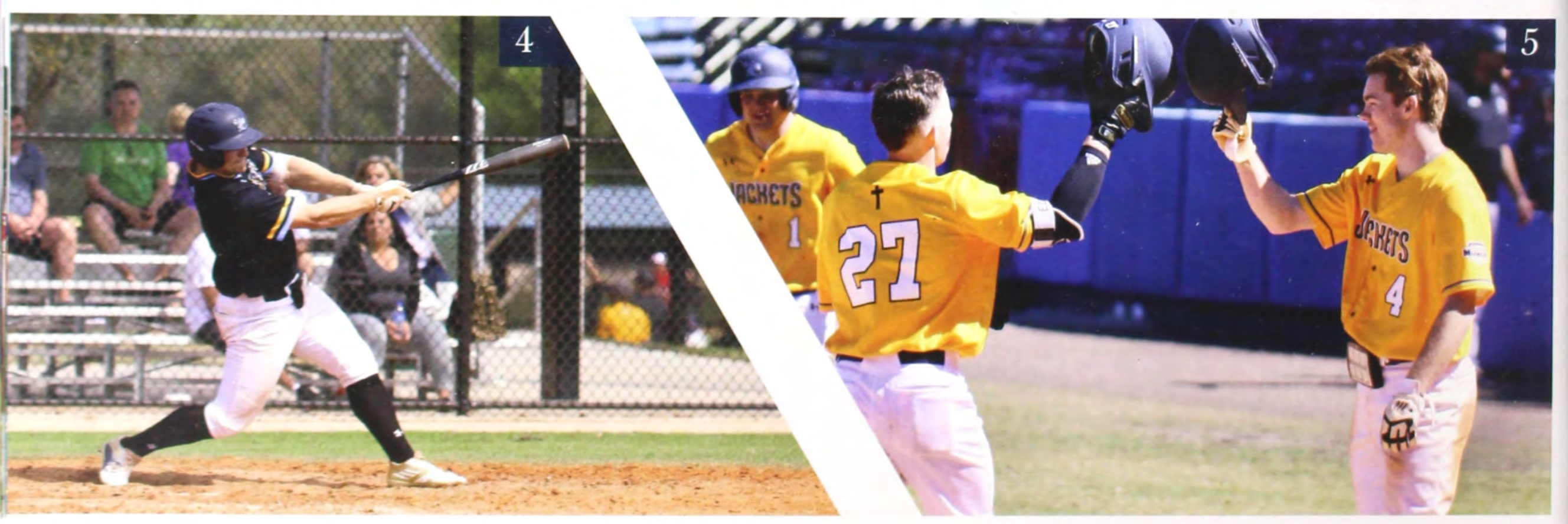



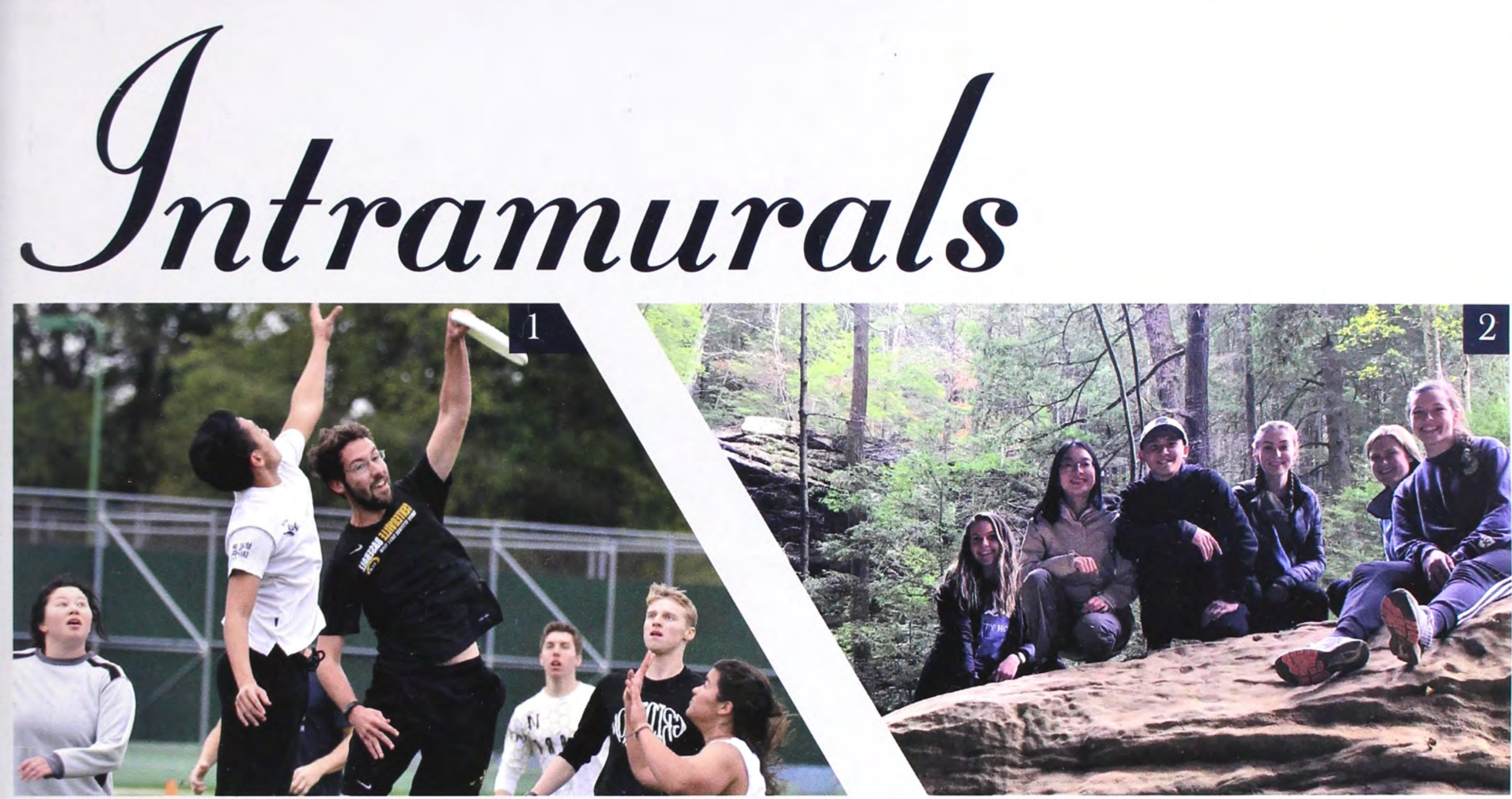

Jake Kenniv had the opportunity to join the intramural frisbee team during his time at

Cedarville University. "As captain of the club frisbee team, personally my favorite part about intramural frisbee is that it's laid back and no pressure," Kenniv said. "It's great to step out on the field knowing that you're going to have a good time and that the outcome doesn't really matter."
1. Matt Robinson leaps to make a catch in an ultimate frisbee competition

2. Eden Liang and fellow outdoors org members take a break from their hike. They spent the day at Hocking Hill State Park led by Professor Matthews.

3. A student sprints across the field as he goes to make a touchdown.

4. Kristin Hannay and friends lean in to smile for a photo after their intramural volleyball championship game.

5. Stuart White throws a disc into the goal to score points for his team.

\section{t}

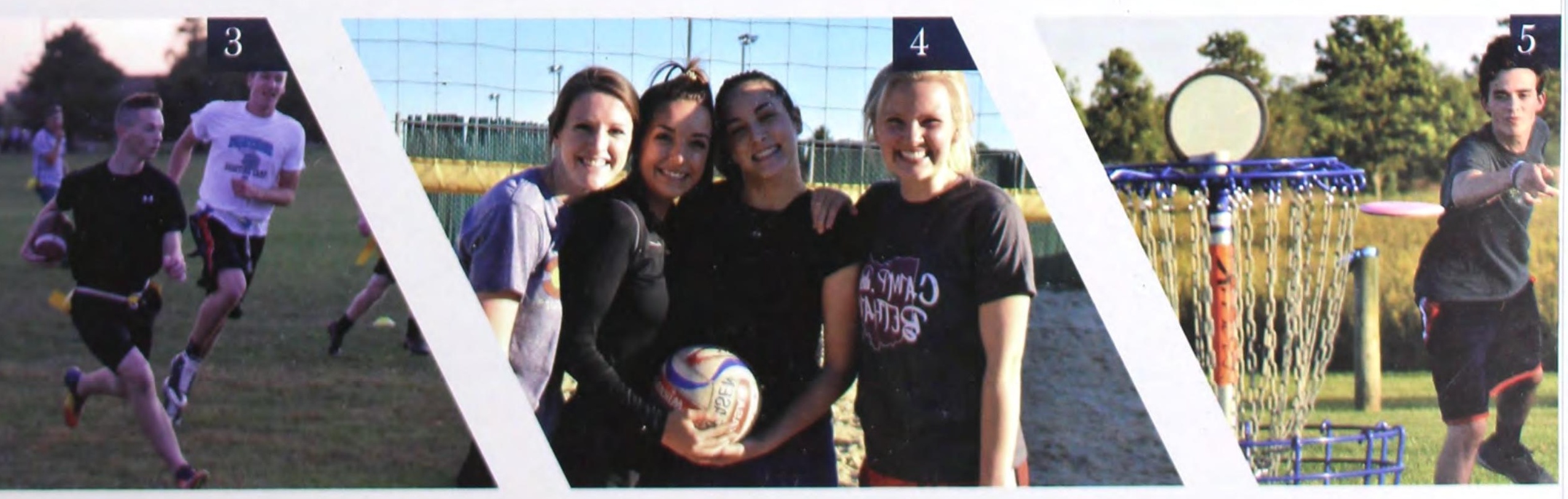



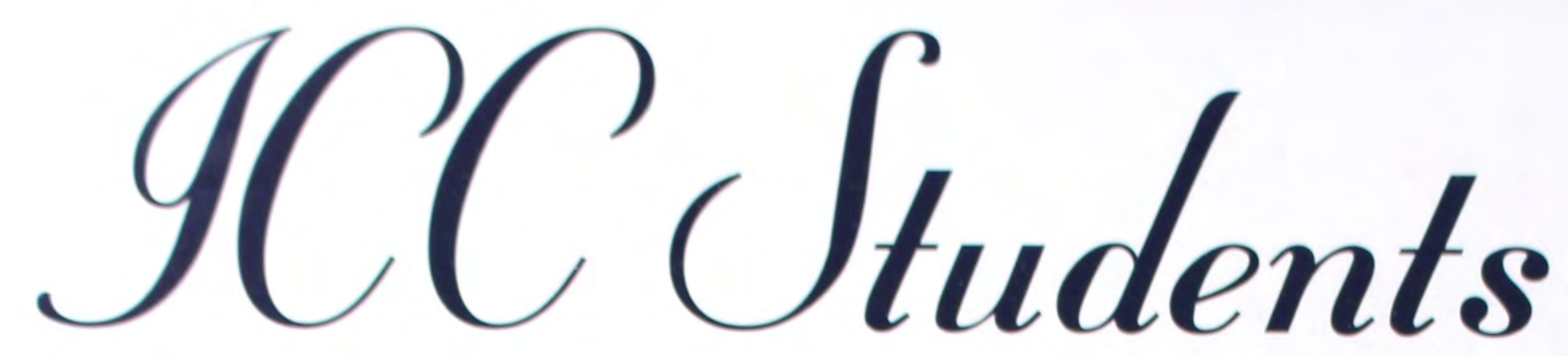

Class of $2020 \mathcal{E} 2021$

Industrial Design majors at Cedarville partner with an

organization called the International Center for Creativity (ICC).

This gives them the opportunity to gain hands-on experience in

studios to prepare for their careers. They get to choose between

computer product design, transportation design, interior space design, and architectural and exterior space design.

Isaac Avala

Emily Bader

Chad Benjamin

Timothy Brewster

Meghan Burns

Luke Custer

Brooks Dibble

Brianna Driver

Joelle Gallardo

Samantha Gibbs

Marcus Gowin

Avery Graham

Jonathon Grunenwald

Jonah Hamby

Will Haskins
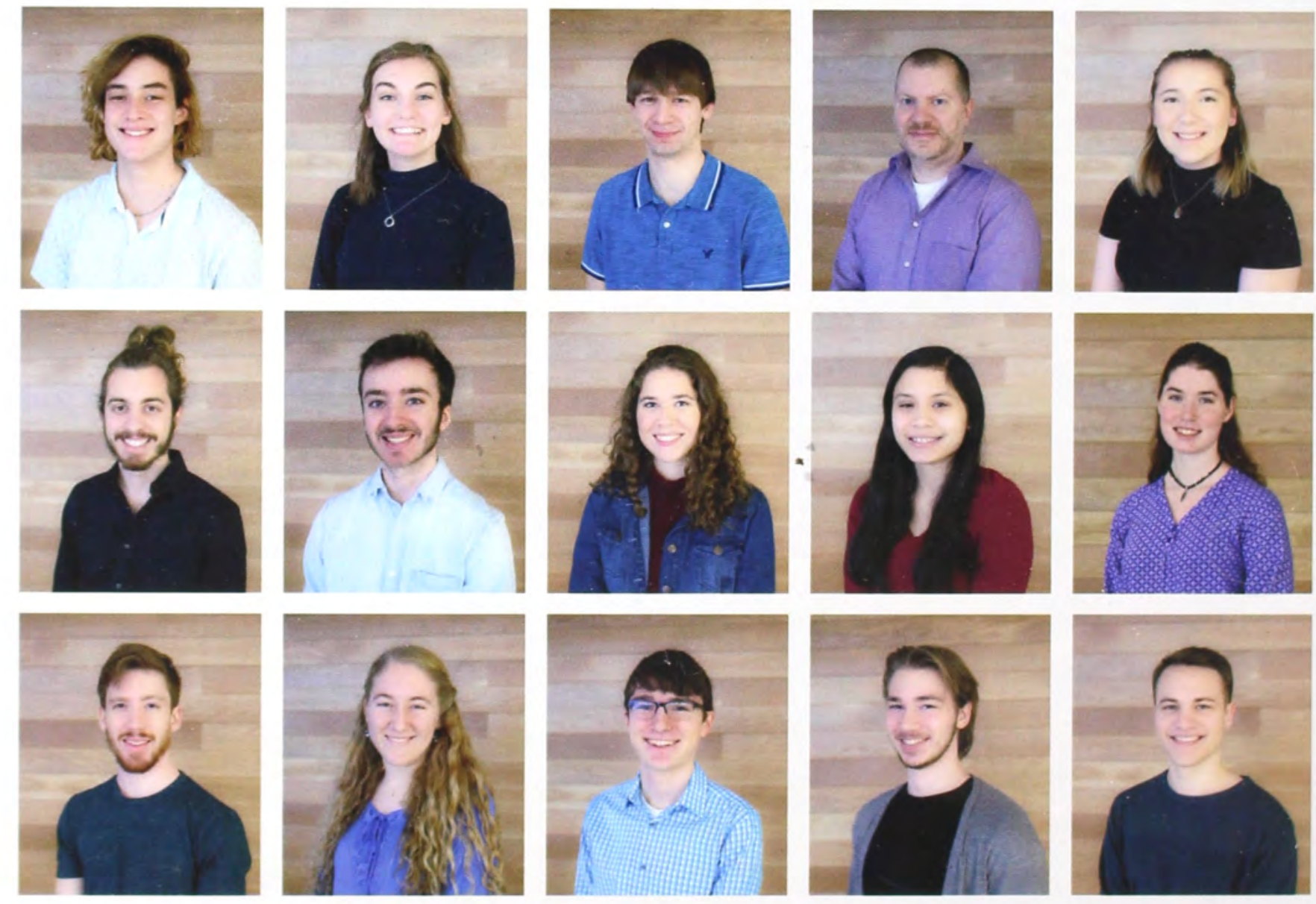

Anita Hayden

Courtland Hendershot

Luke Henig

Jackson Hoshiko

Vorrapon Jirakasemnukul
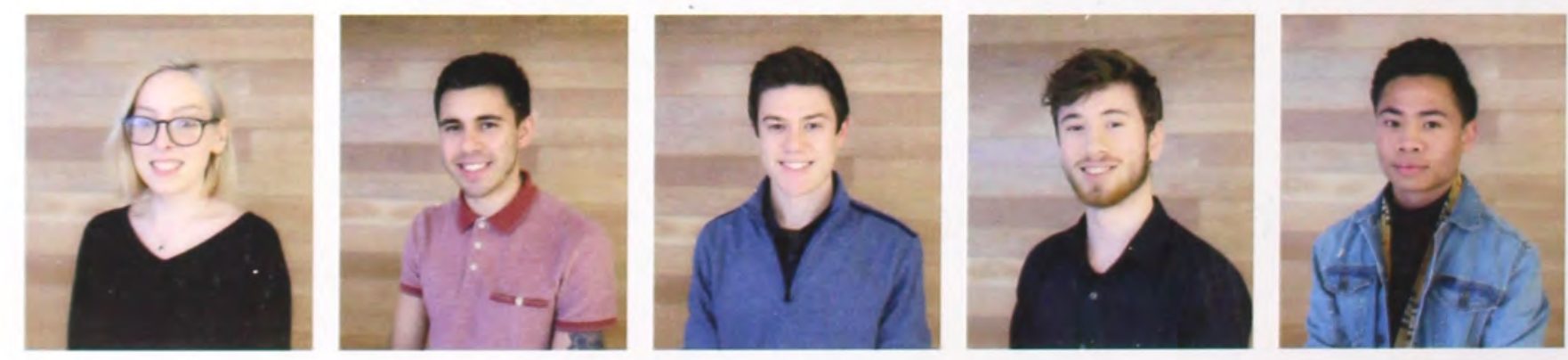
Claire Kaiser

Nathanael Knowlton

Nathan Lloyd

Rae Lynch

Nicholas Mahek

Tamara Marques

Ben Martin

John Mathews

Isaiah May

John Minier

Rebecca Murch

Nathan Osborne

Mitchell Petroff

Anna Pizarro

Nathan Pomles

Saskia Praamsma

Allison Ramsey

Cunyun Rao

Andrew Renner

Robert Saieg

Isiah Shannon

Caleb Stover

LeahAnn Swinford

Olivia Taylor

Isaac Thomas
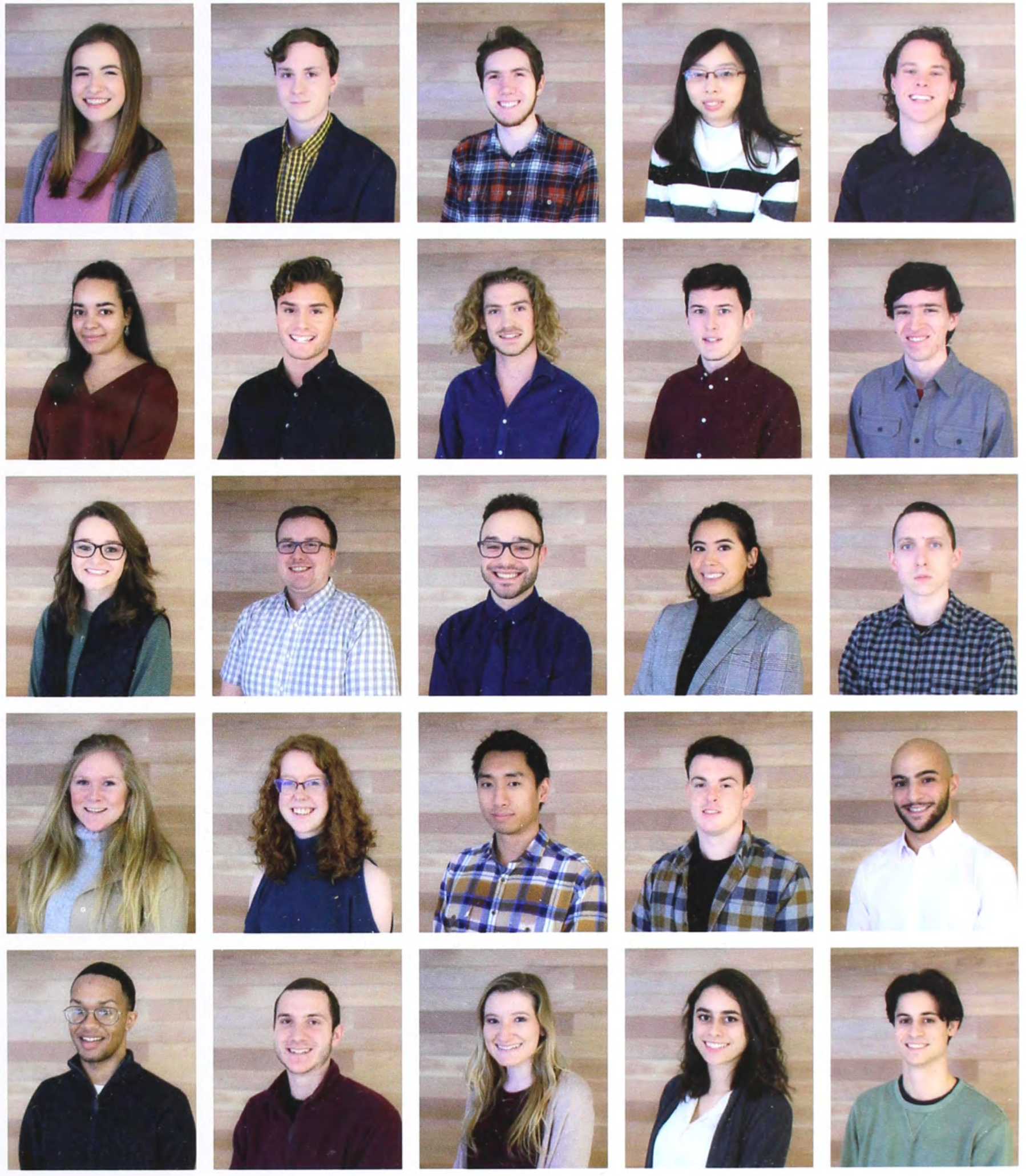

David Watson
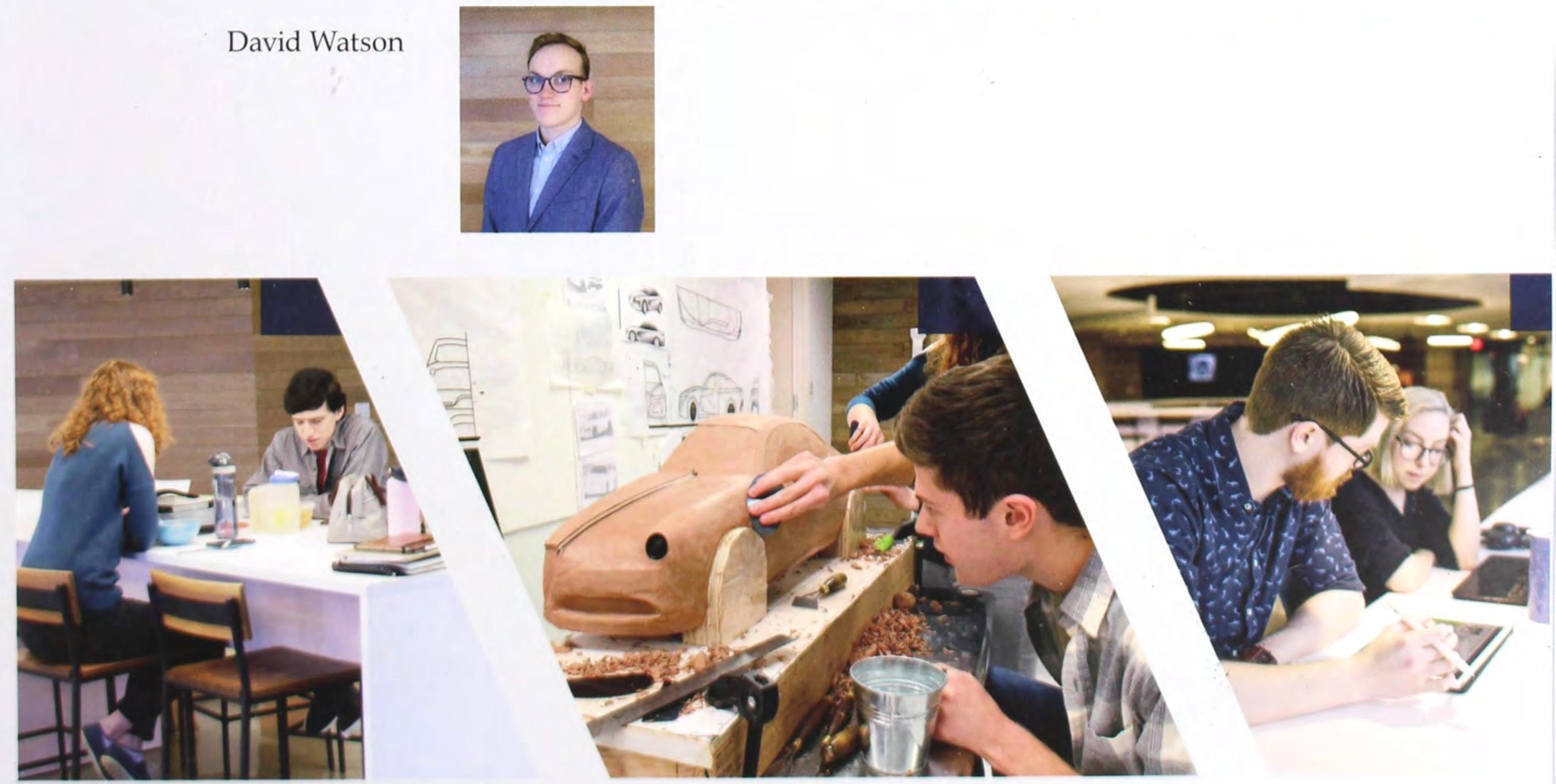


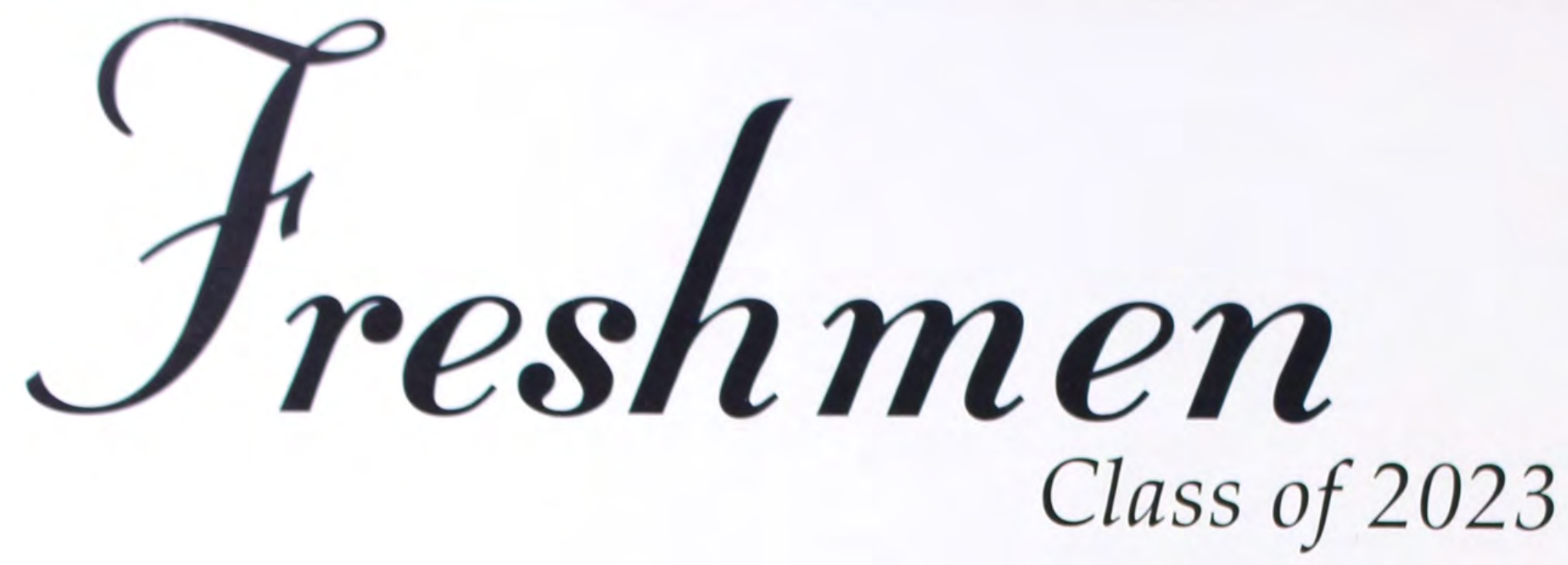

The Freshman Class identity is signified by the word

"Commissioned." This term is drawn from the Great

Commission in Matthew 28:18-20. The purpose of this class

identity is to remind the class of 2023 that they have been called by Christ to take part in disciple making and sharing the Gospel. In doing so, they actively join God's mission for all of mankind.

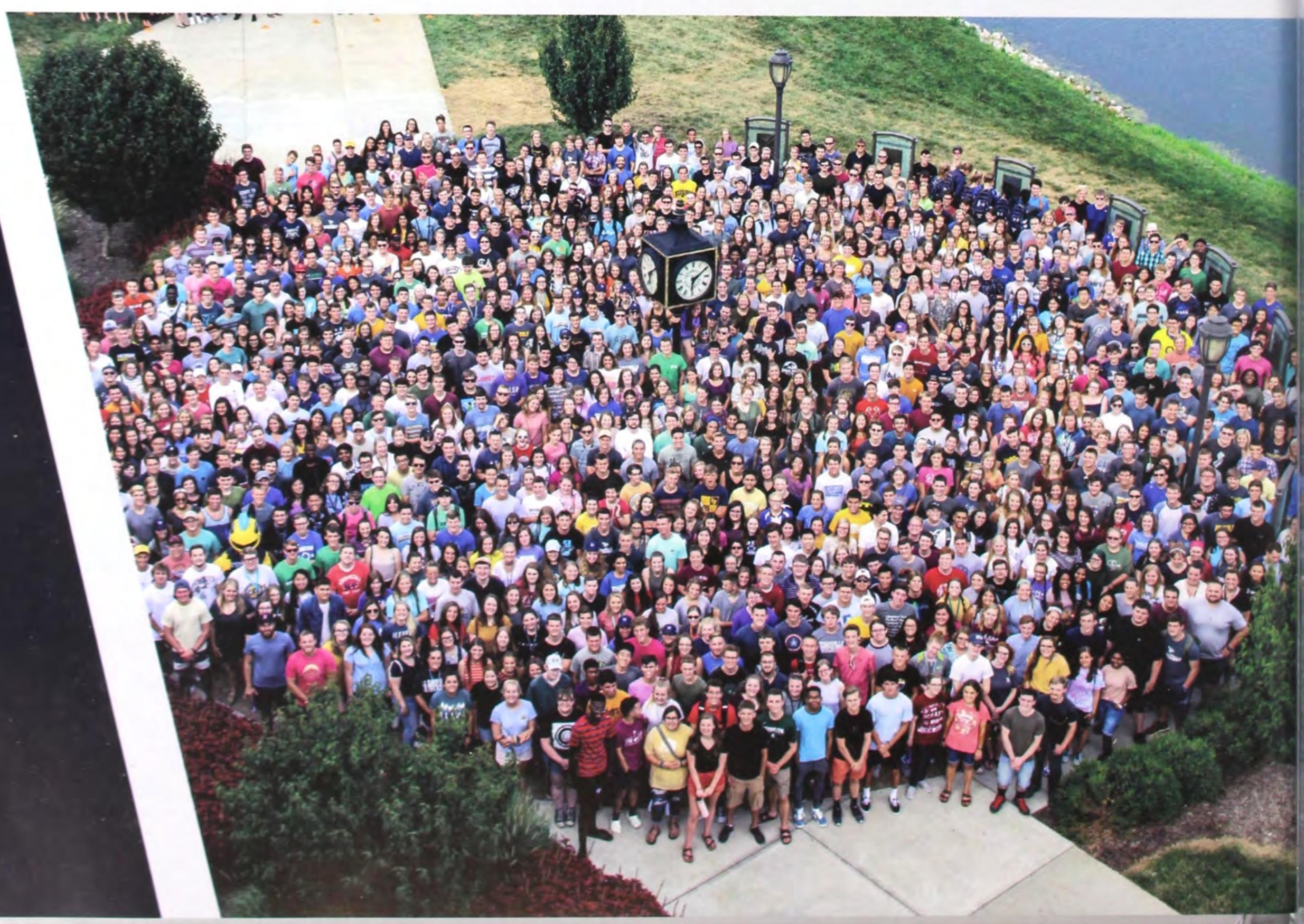


Anthony Alexander

Heidi Anderson

Isabel Anglin

Madeline Ardrey Joanna Atkins

Kezia Augustine

Kaley Aurand

Sarah Baab

Nathan Bailey

Matthew Bandy

Kaitlyn Barnes

Curtis Bartley

Paige Beal

Julia Beauchemin

Allison Belmont

Brandon Black

Danielle Blenis

Alexander Boesch

Keith Bonenberger

Cora Bradley
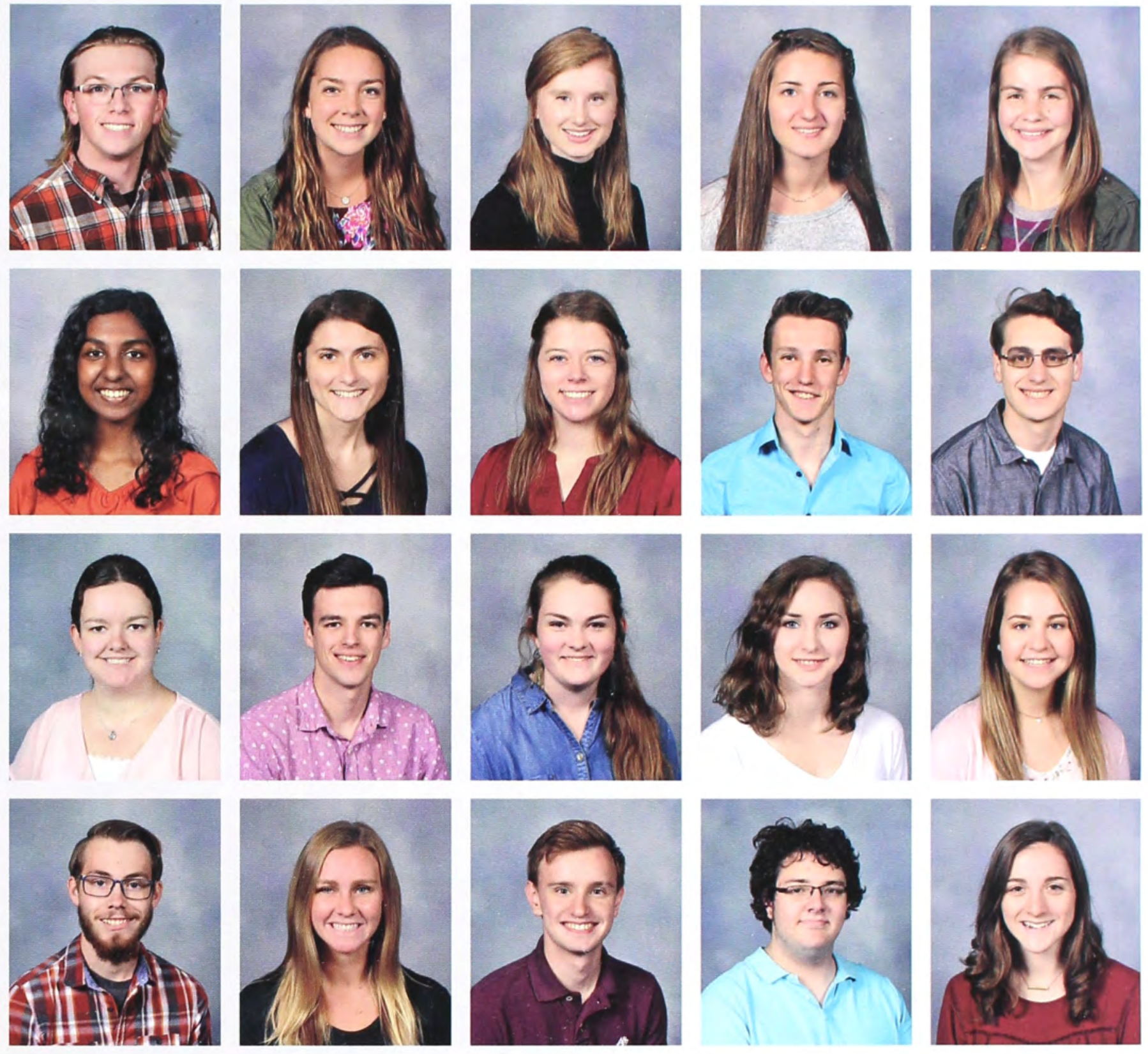

Clinton Brads

Gabrielle Bragg

Cassidy Brammer

Claire Brandes

Nathanael Brown
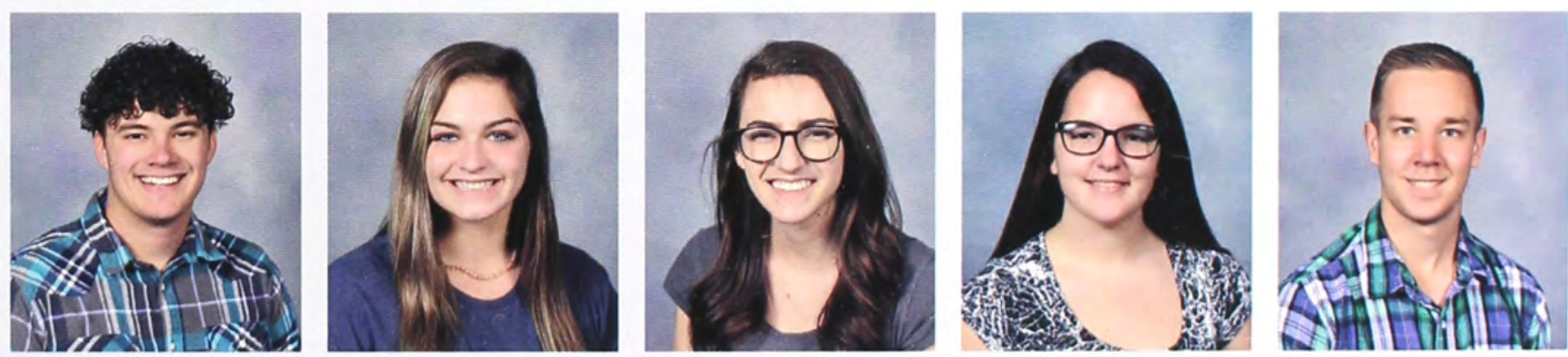

Sarah Brubaker

Zachary Brubaker

Morgan Bruggeman

Gabriel Byrd

Joshua Castle
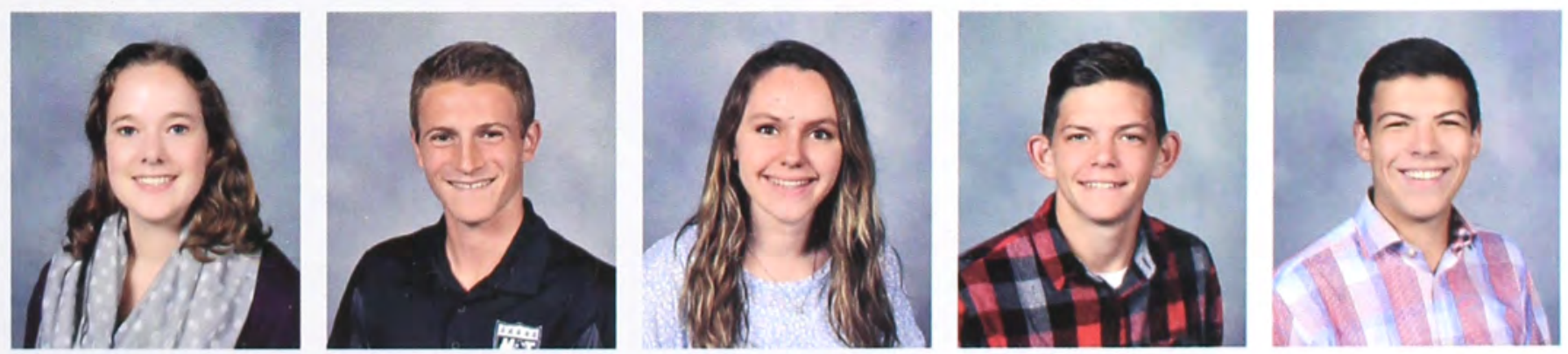

Stephen Chow

Michael Cleverley

Jason Clingenpeel

Garrett Cohea

Janessa Colburn

Emilie Colvin

Kayleigh Conaway

Miriam Cook

Theodore Cook

Austin Cope
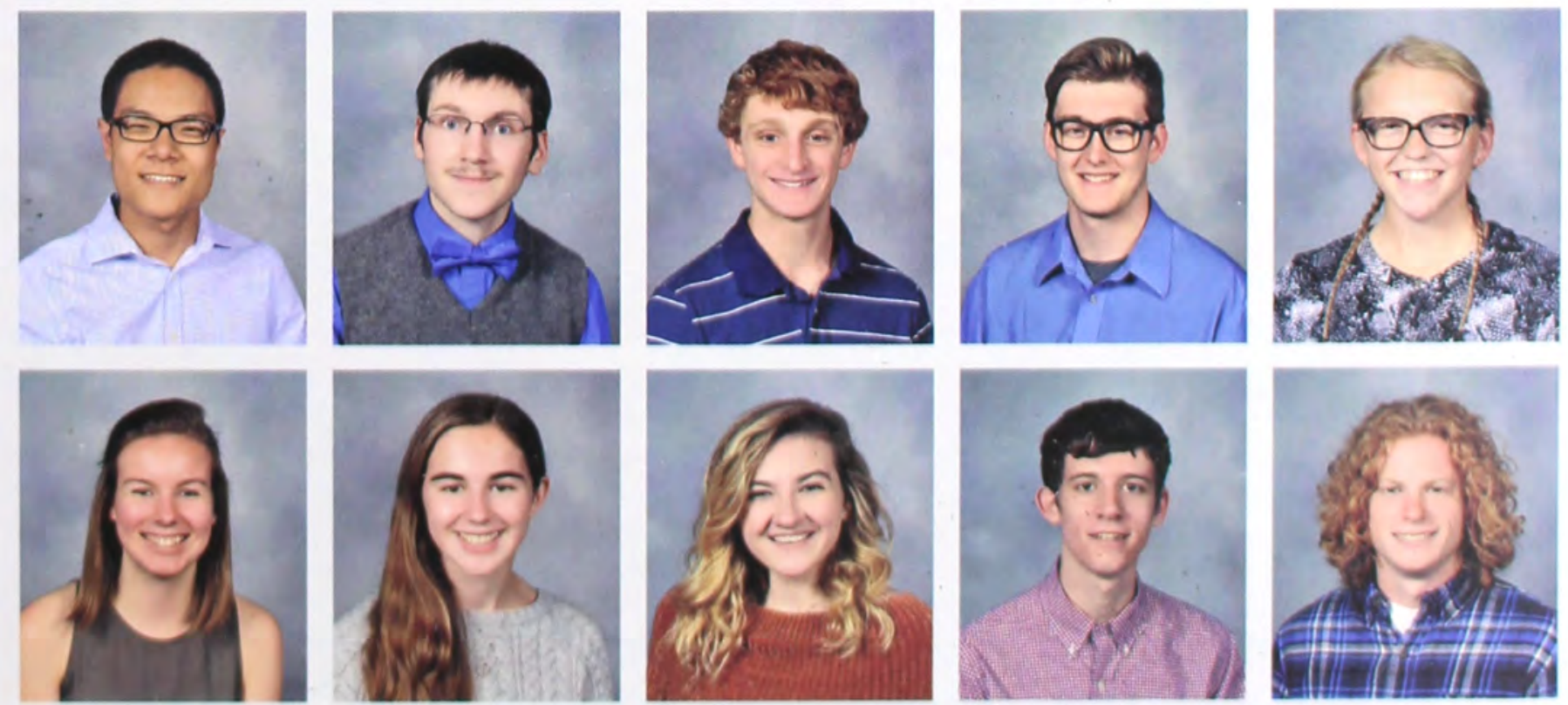
Rachel Cox

James Cunningham

Lauren Cunningham

Hannah Cayla Dakanay

Ellen Davis

Luke Deberny

Kenneth Degarmo

Mallory Delamarter

Noah Derochie Justice Deveney

Michael Devore

Annalyse Dissinger

Ethan Doerstling

Maryssa Duncan

Hannah Dunham

Abigail Dunning

Nathan Dyer

Jordan Edwards

Susan Elder

Laurin Ellis

Victor Ellis

Josiah English

Lindsey Fark

Colin Farris

Micah Fisk

Marissa Folkert

Serena Ford

Alizabeth Foster

Rhyan Fought Kelly Fourman

Preston Fox

Bethlehem Fraser

Olivia Frazier

Lauren Gabor Christianna Galkin

Katelynn Garber

Maria Garcia Lambis Jonathan Gartner
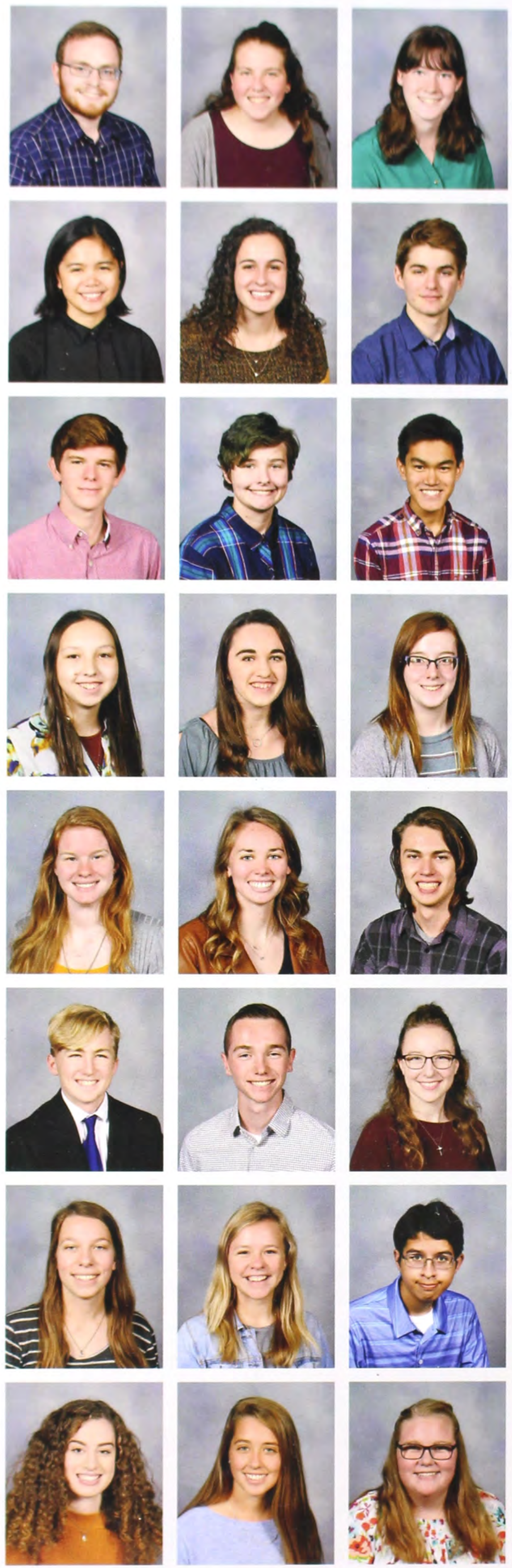
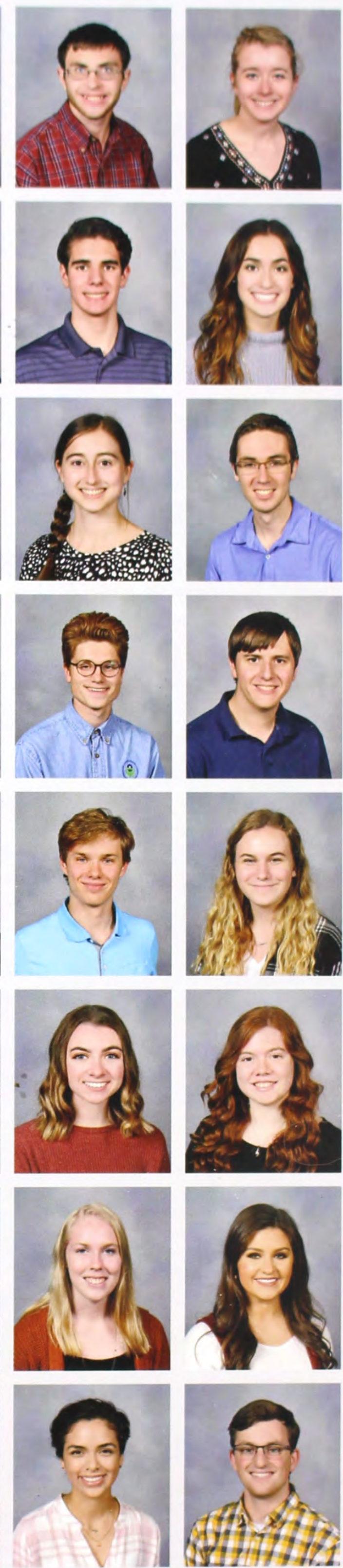
Andrew Gates

William Geist

Joshua Gillum

Trevor Glaum

Dorothy Golden

Amanda Golding

Nicole Gordon

Meagan Gosman

Samantha Grady

Wesley Gray

Grace Gregory

Elizabeth Grunenwald

Elizabeth Gupta

Luke Gustafson

Hannah Hahnenstein

Katherine Hall

Kailee Harris

Noah Harvey

Holly Hasty

Joshua Heagle

Nicole Heath

William Hess

Gabriel Hingst

Rachel Hingst

Mark Hogsed

Mykaela Holst Jordan Hopkins

Samuel Howard

Riley Howell

Samuel Hutchison

Ashley Hyslop

Isabel Ingle

David Isenhower

Adora Istrate

Benjamin Johnson

Sarah Jones

Evan Kakuk

Josiah Kareck

Hannah Karg

Rachel Kauffmann
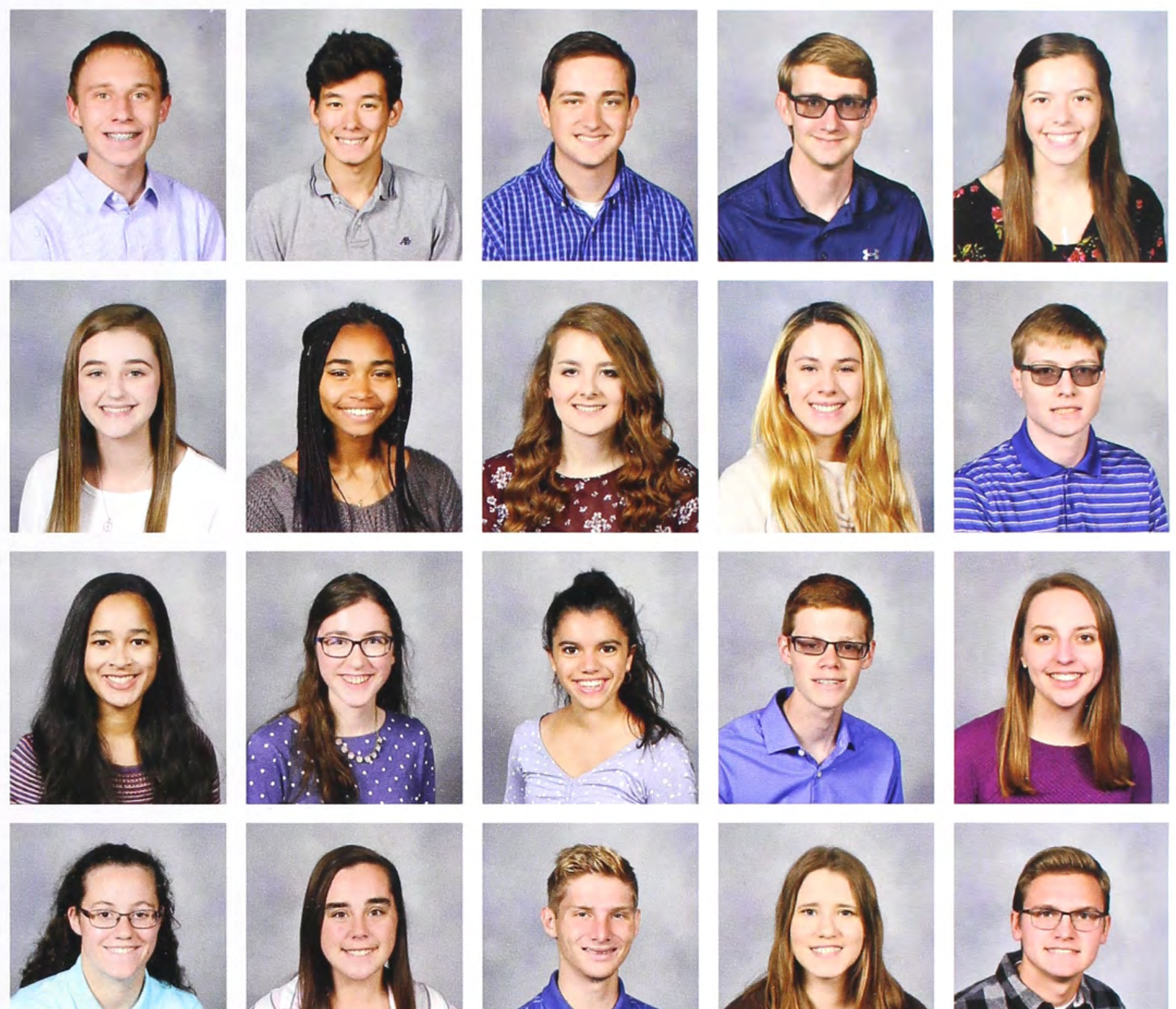

1
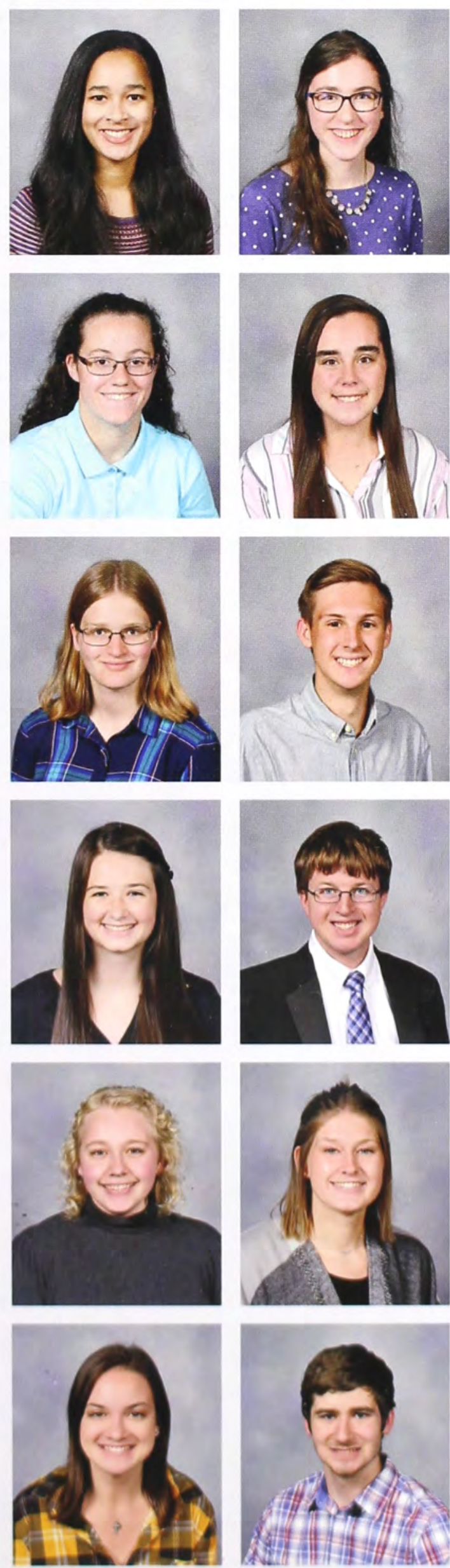
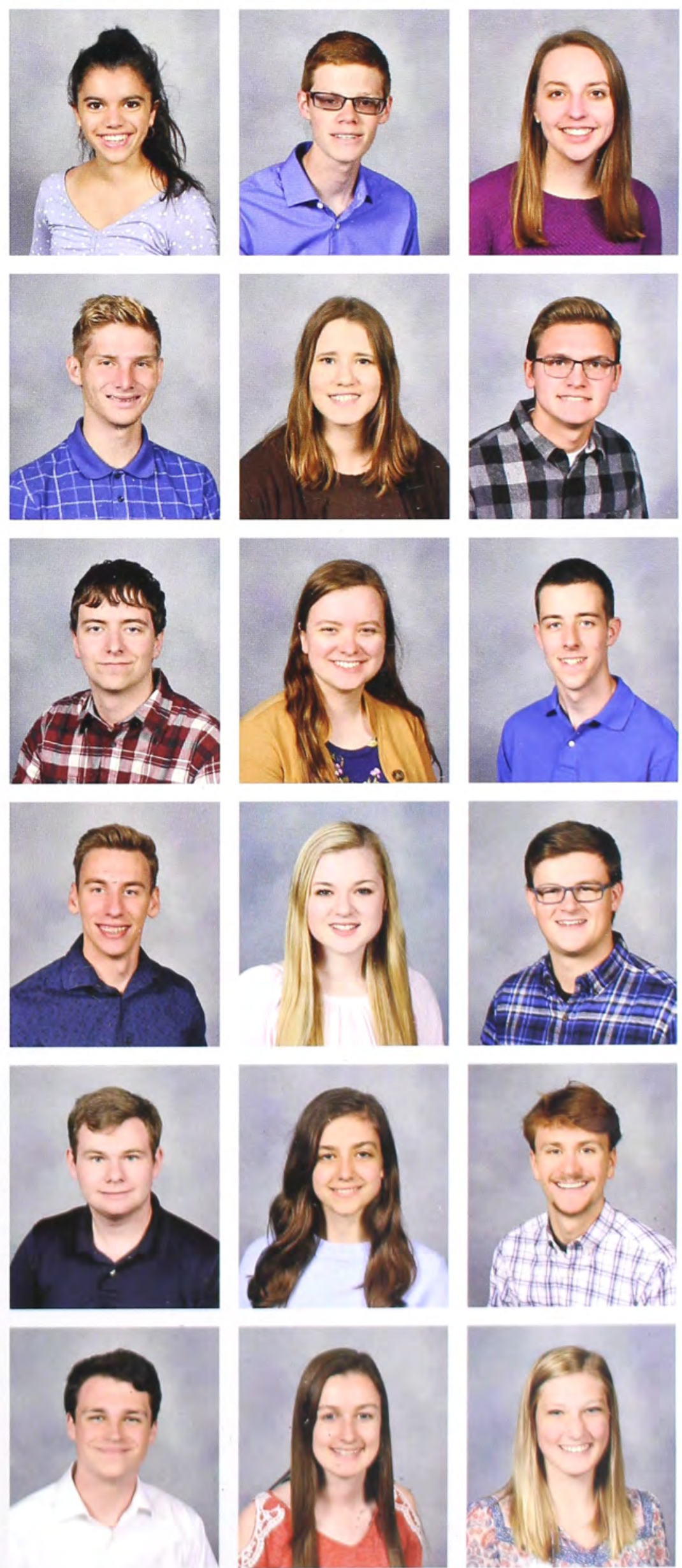

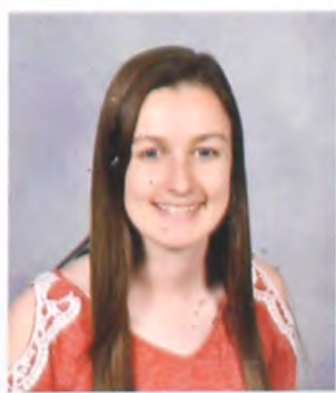

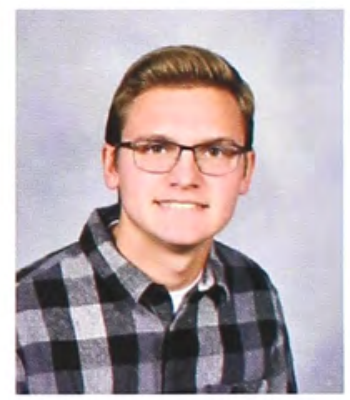
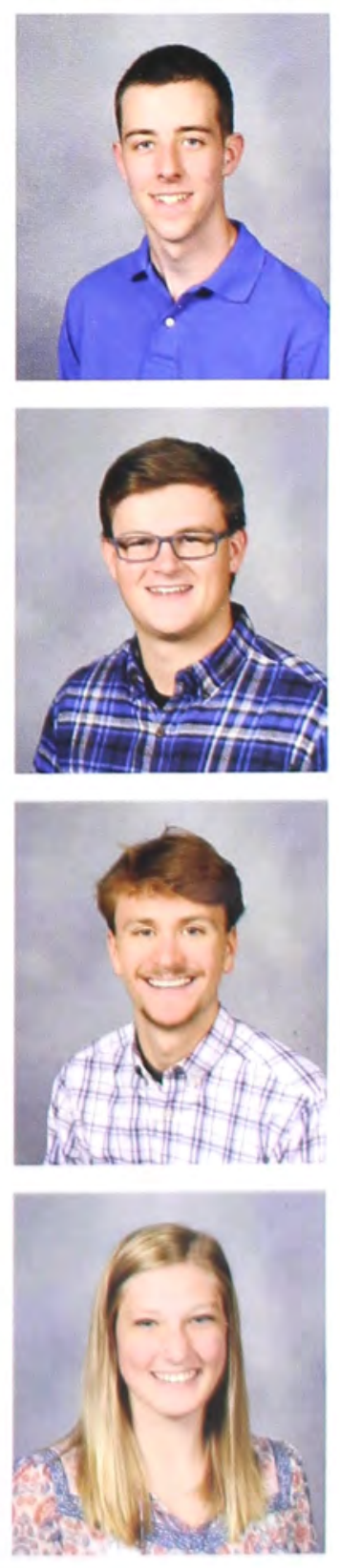
Ienna Kavnor

Allyson Keefer

Isaiah Kelly

Michael Kennedy

Emily Kennell

Sarah Kigar

Abigail King

Emmaline Kinniburgh

David Kollmar

Katie Koteskey

Thaddeus Krueger

Karis Kulp

David Kyler

Marcus Larsen

Brianna Lebs

Noah Lehman Alysia Leightenheimer

Morgan Lemacks

Caleb Lenahan

Elisabeth Lewis

Emily Lewis Kylee Ley

Rachel Lum

Kara Lutz

Lacy Macdonald

Trey McBride

Madison McMillan

Jonah Metcalf

Sharalin Metzger

Andrew Miller

Charis Miller

Emily Miller

Eric Miller

Malachi Morrison

Elise Mourand

Grace Mowery

Ren Murakami

Shallyn Mussinan

Courtney Neer

Rachel Nesmith
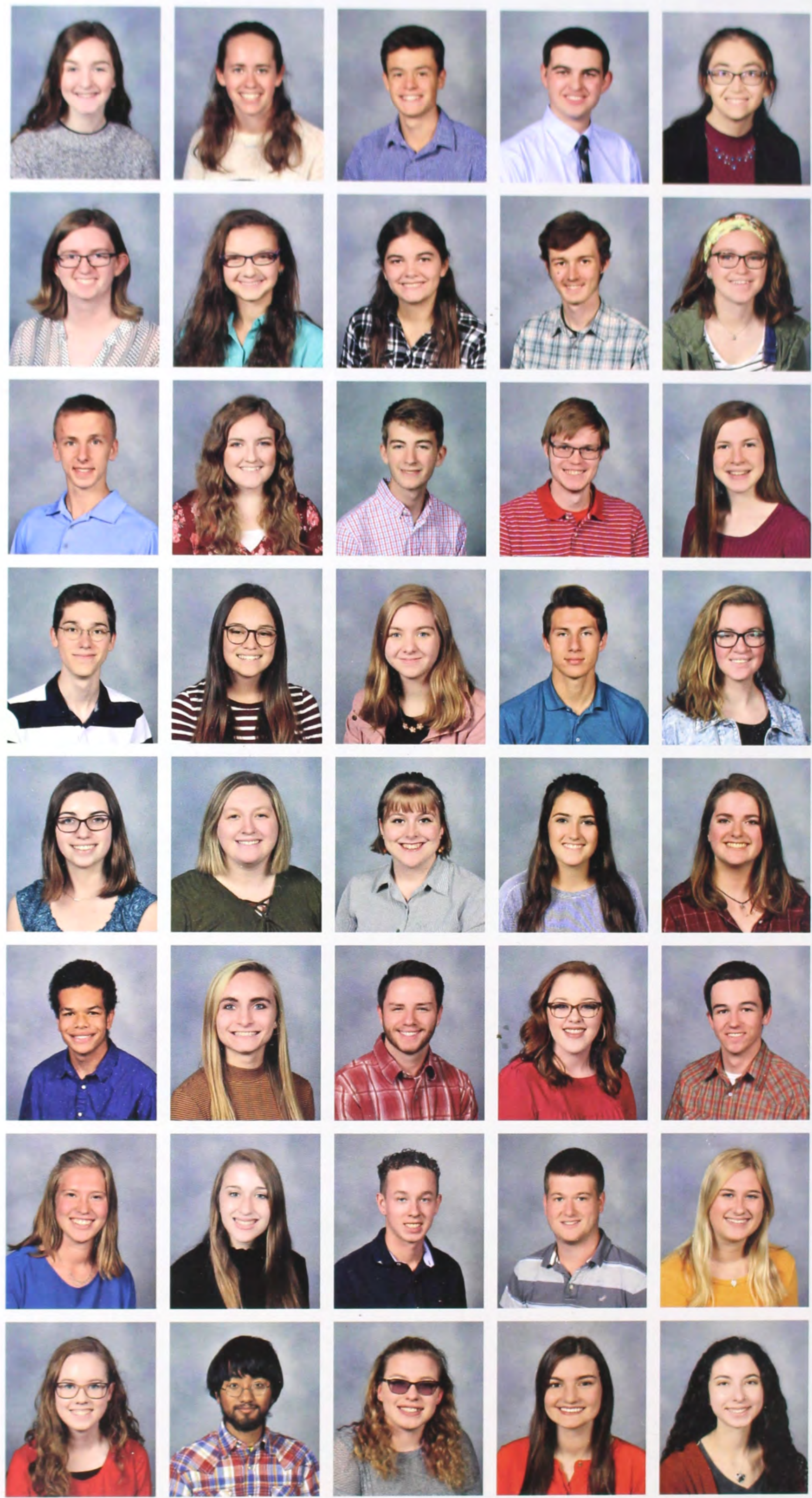
Camden Newell

Kristina Newell

Dillon Nice

Hannah Nicholls

Kaitlyn Nicholls

Gretchen Nichols

Rachel Noe

Sarah Norfleet

Julianna Norris

Elisabeth Novak

Claire Nyberg

Hayden O'Brien

Chukwuebuka Ojukwu

Clayton Ooms Elisa Owens

Jordan Parsons

Triniti Patterson

James Payne

Rachel Pennington

Lael Peterson

Andrew Pierce

Megan Pierce

Tristan Powers

Carmen Priestly

Houston Purcell

Reuben Quade Jaquelin Ramirez Ashley Reynolds

Chase Riebel Justin Robinson

Asher Rohm

Gabriel Roy

Jordyn Rutherford

Jonathan Ryan

Mallory Ryan

Zak Ryan

Keith Dominic Sansalone

Marissa Santi

Erica Saunders

Shawn Scarberry
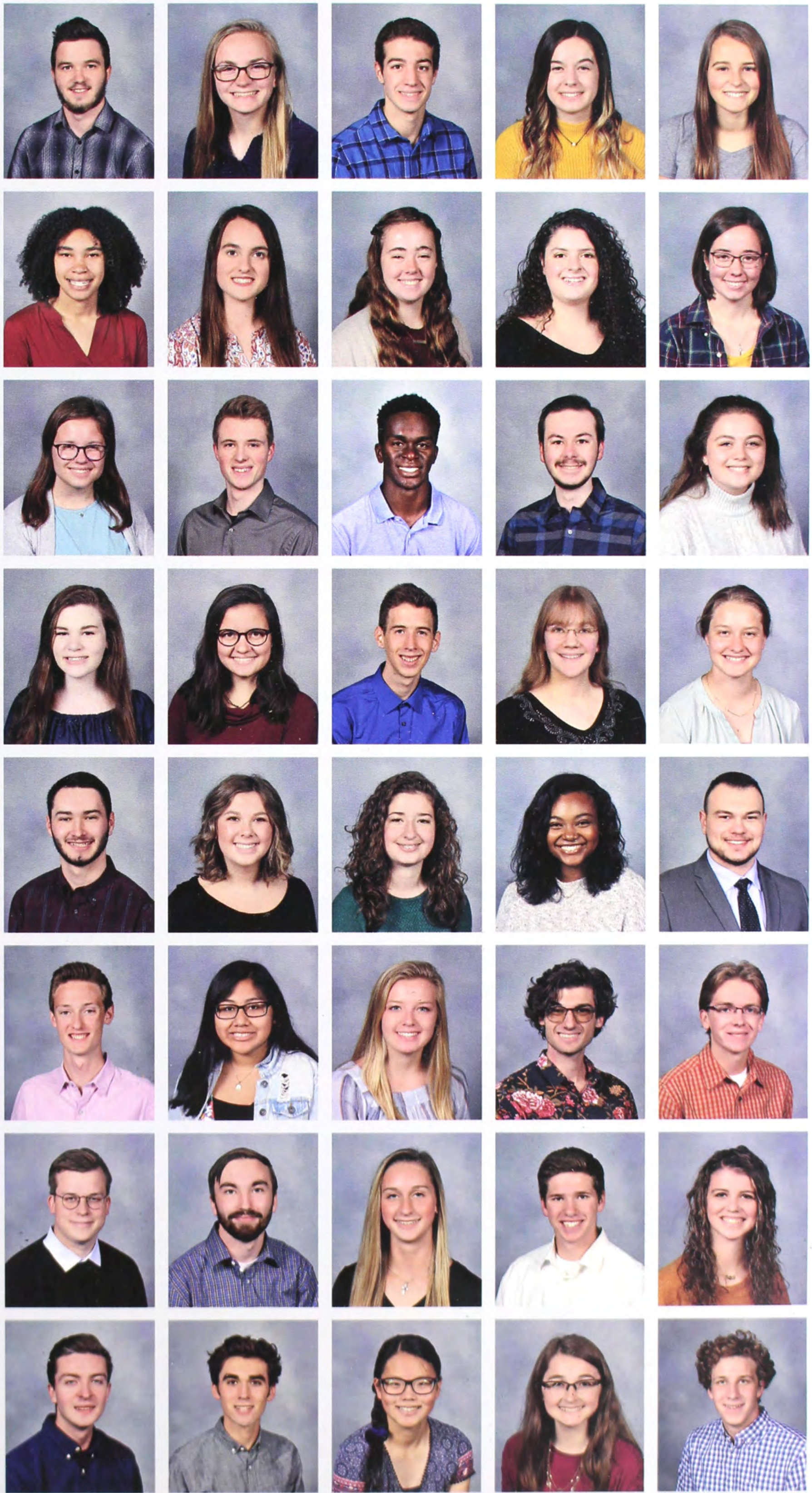
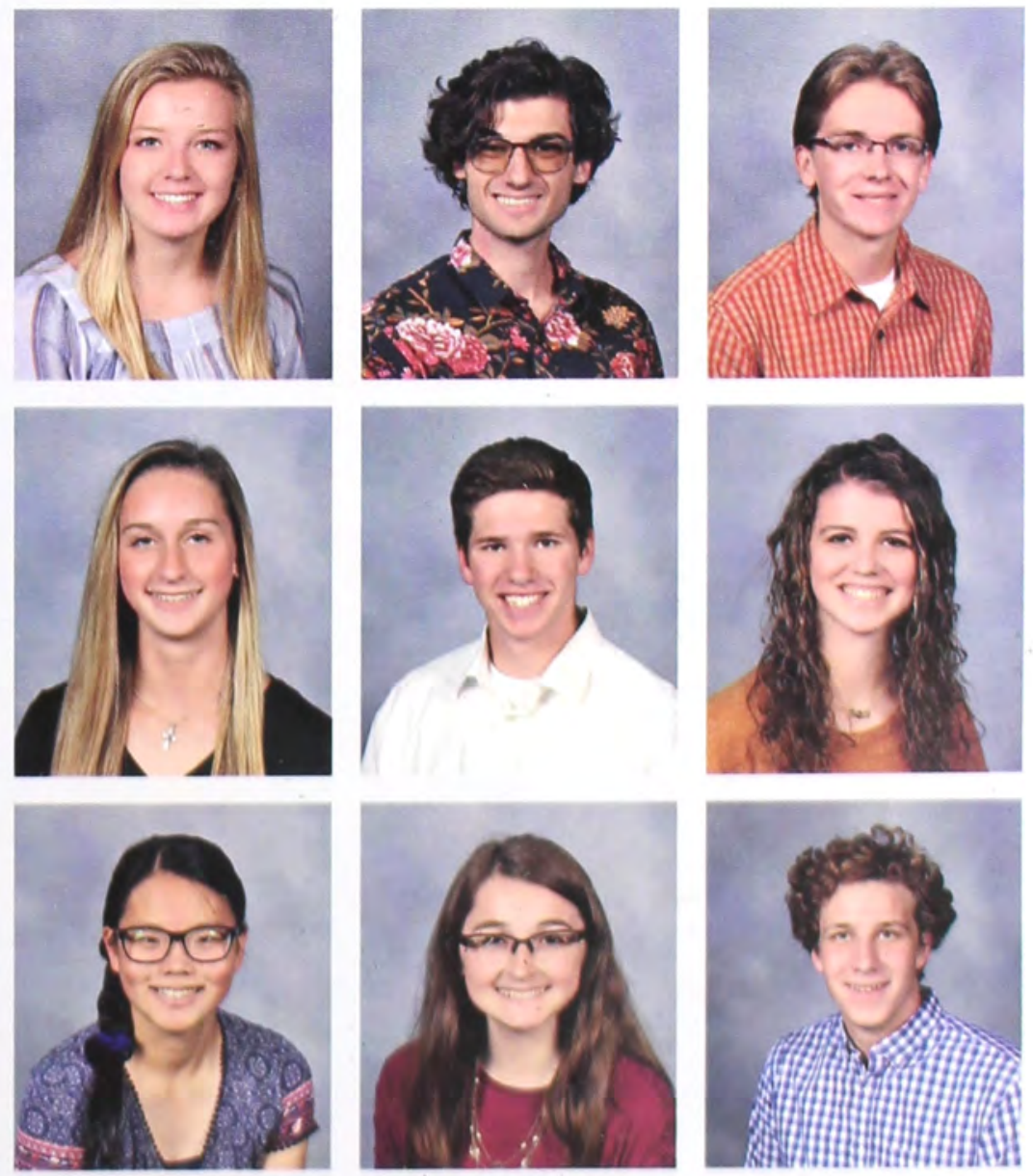
Caroline Schindler

Timothy Schmidt

Lerato Scott

Katelyn Sebring

Ezra Shimabenga

Sage Showers

Corrissa Smith

Karissa Smith

Maria Smith

Isaac Snyder

Alvin Solomon

Micah Spaulding

Josiah St. Clair

Callista Steves

Amelia Stockschlaeder

Andrew Stollings

Aubrey Strong

John Strunk

Kate Suarez

Ethan Swanson

Andrew Swift

Liley Tafelsky

Amy Tate

Brevan Taylor

Daniel Taylor

Allex Teters

Haley Thompson

Caroline Tomlinson

Lily Vanbrocklin

Nathan Vanderwest

Megan Vandyke

Lauren Vanhart

Benjamin Veenstra

Stephen Vinczi

Aubrey Volz

Ryan Wade

Cejay Walker

Maggie Walker

Anna Wallace

Rachel Walquist
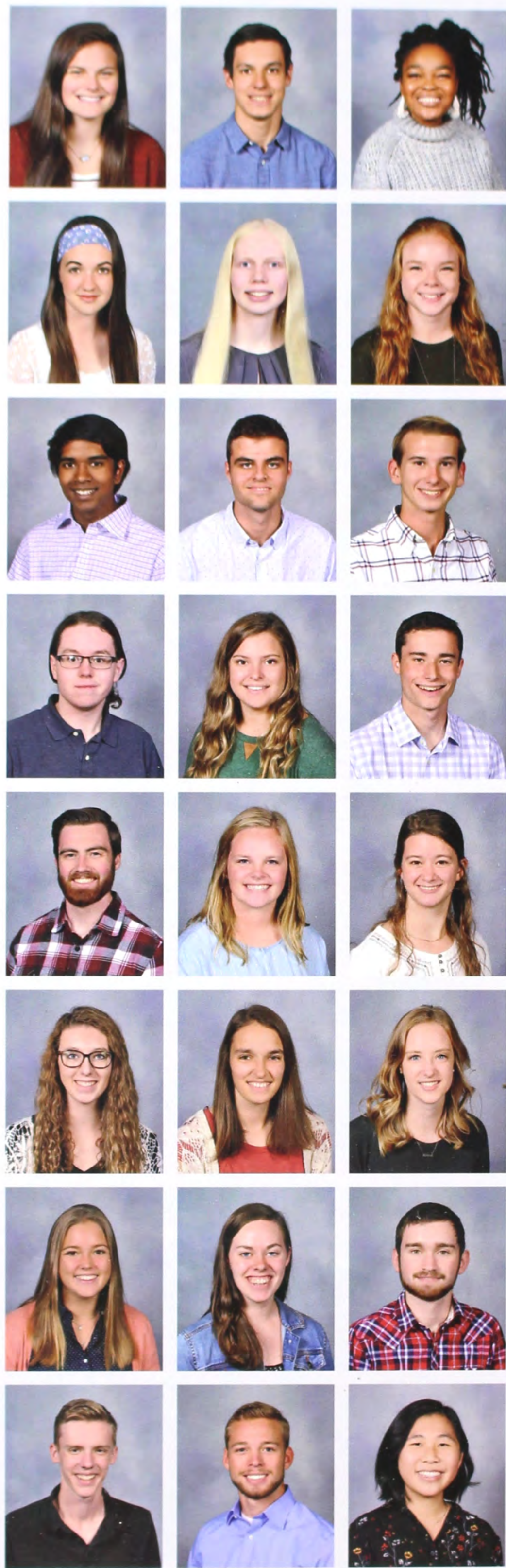
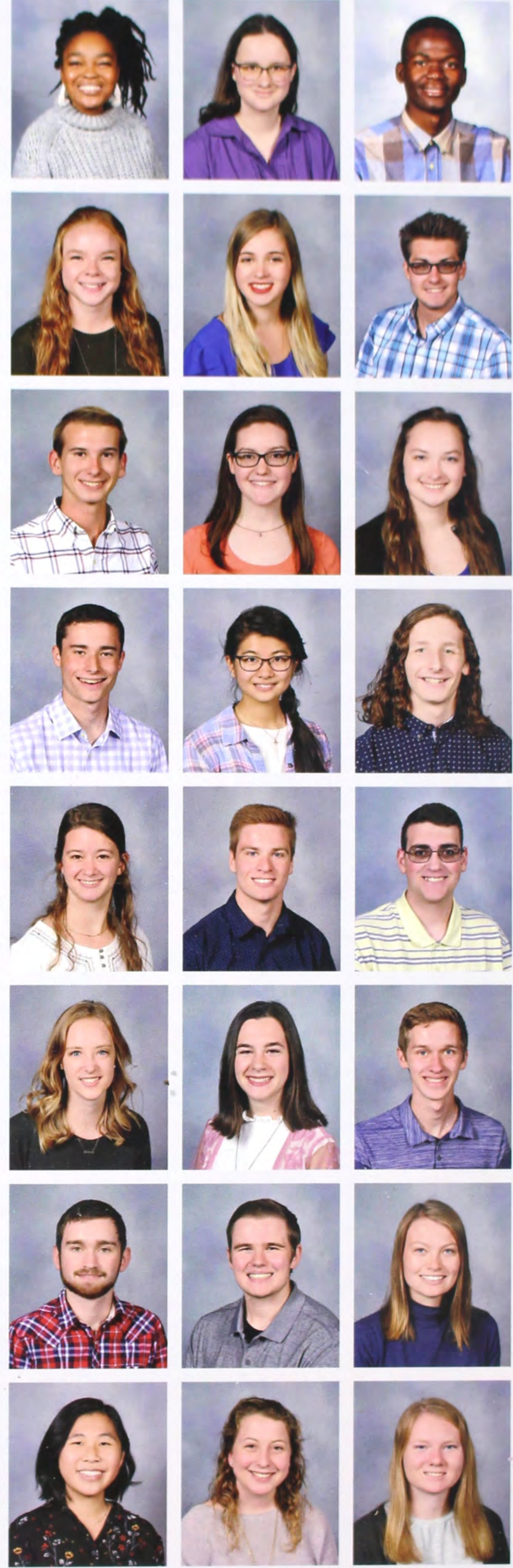
Sarah Whitscell

Maysen Wilson

Everly Wingard Isabel Wolfe

Bethany Wormack

Elizabeth Yearout Abigail Zettlemoyer Betsy Ziegler
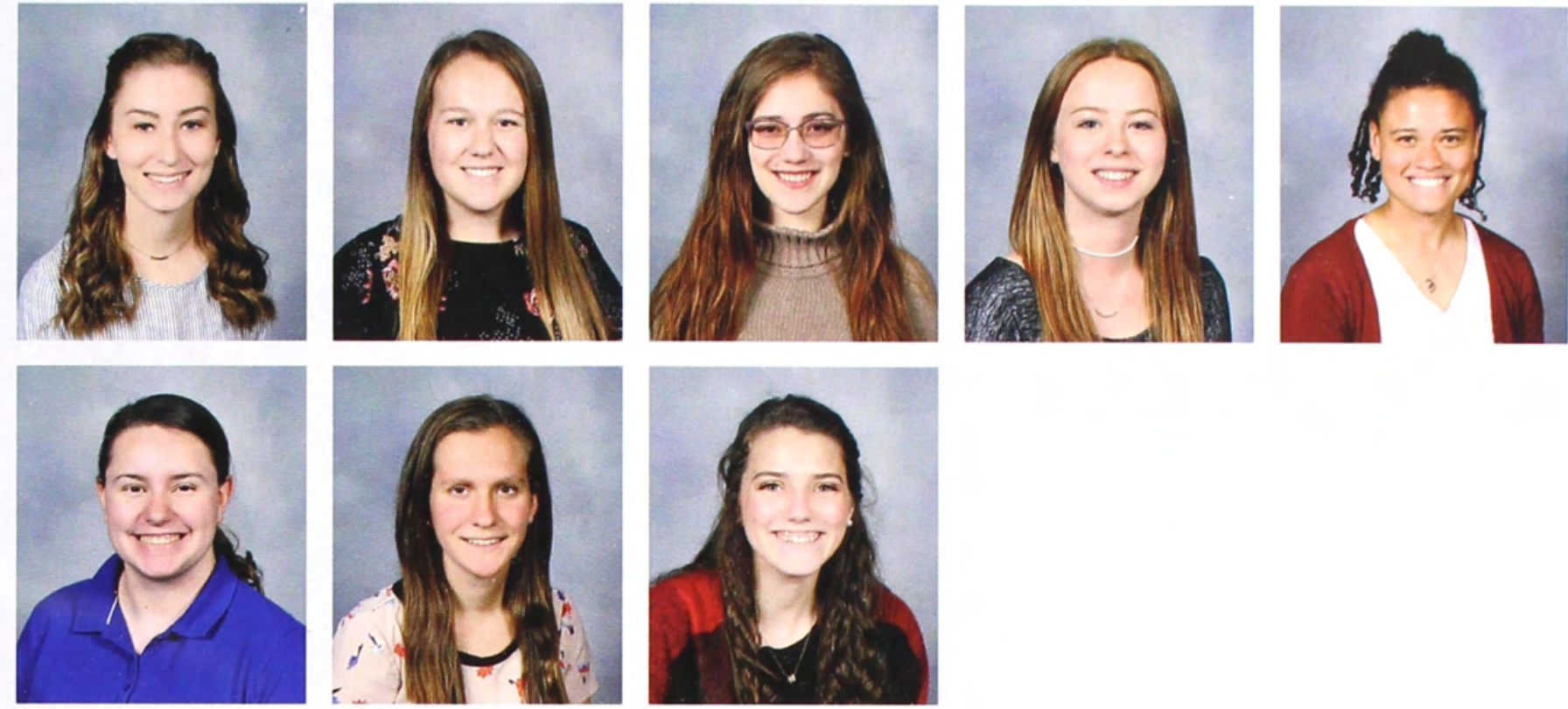


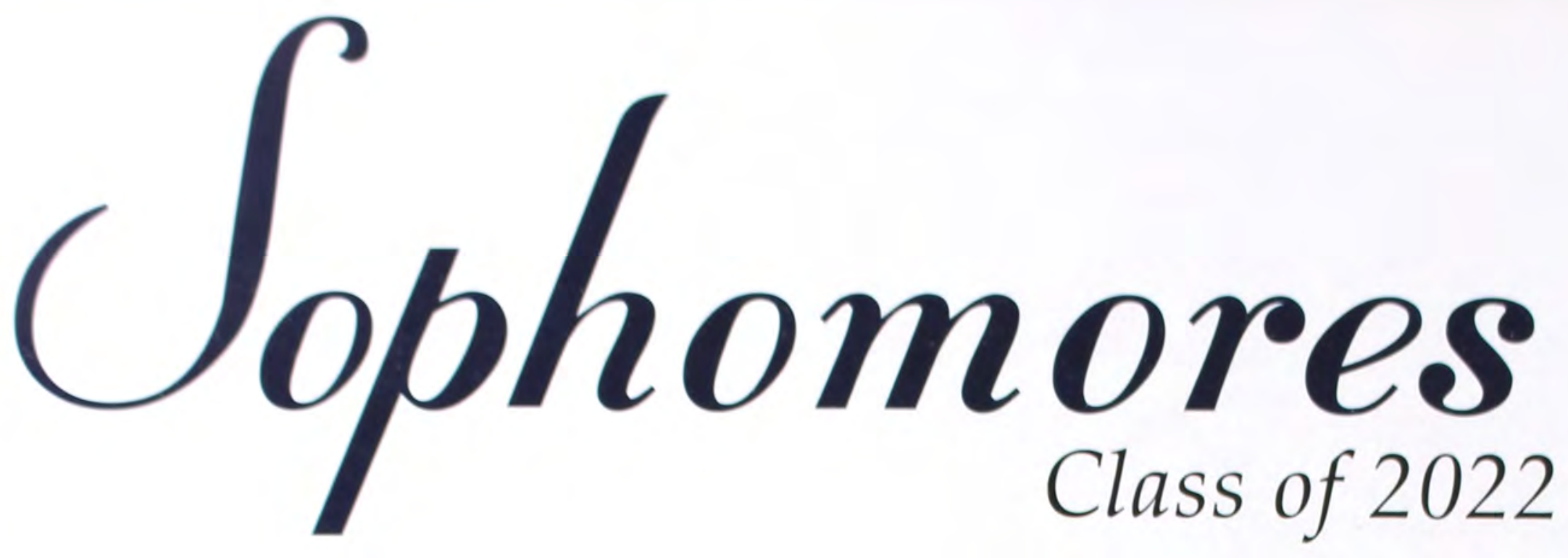

The Sophomore Class identity is marked by the term "Rooted." The concept behind this identity comes from Colossians 2:6-7. It means that the class of 2022 is committed to being rooted in God's Word and established in the faith, and as an outpouring of their relationships with the Lord, they will build intentional, Christlike community that brings glory to God.
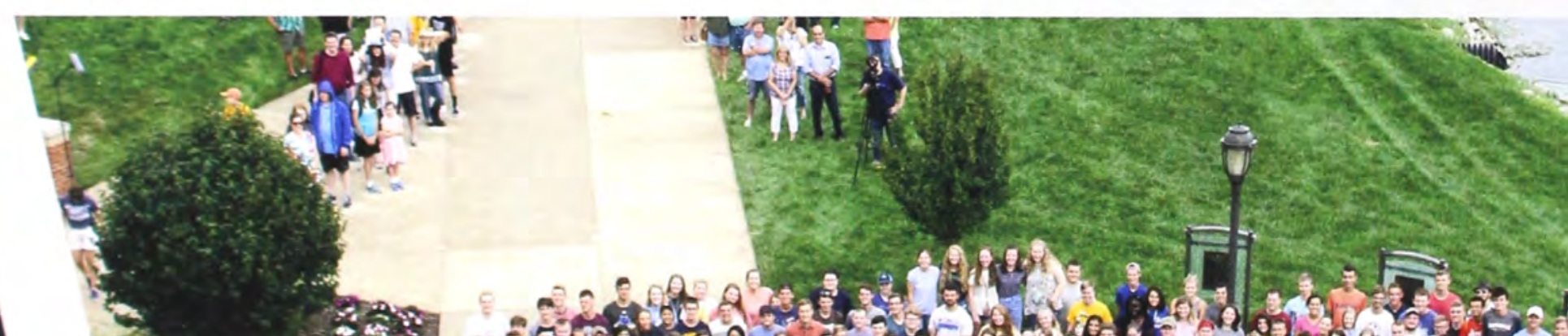

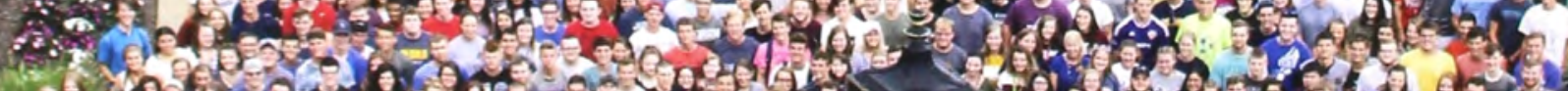

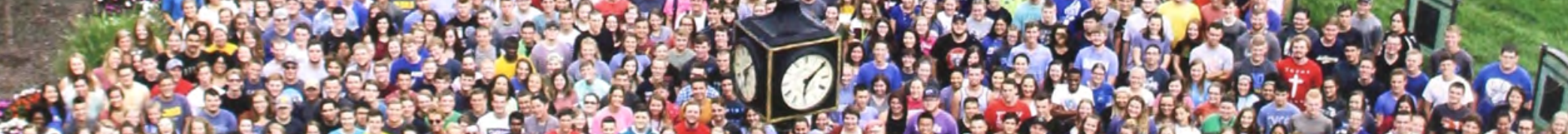

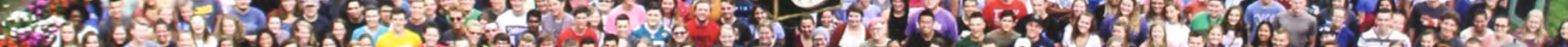

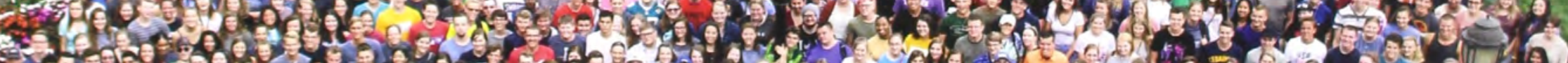

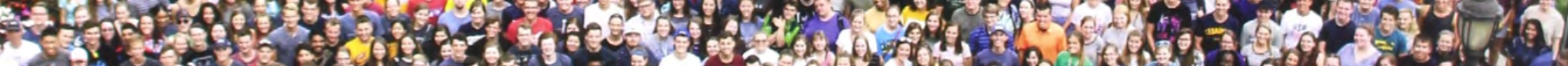

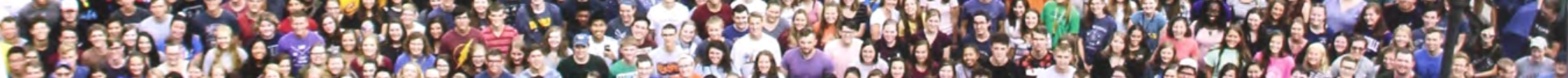
c5. s. 5 -

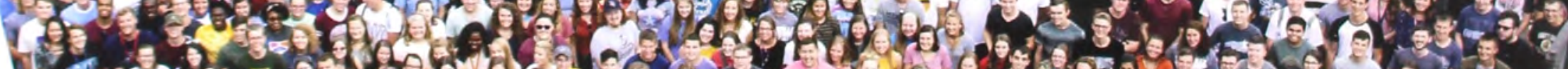

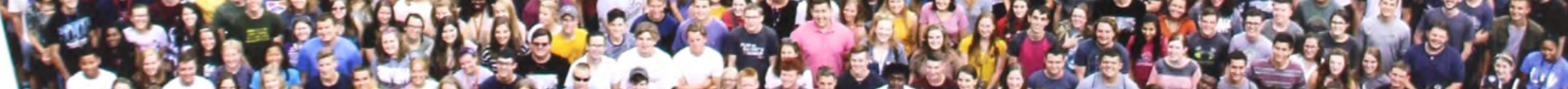

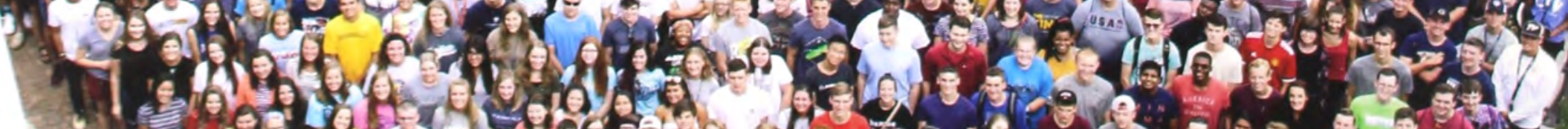

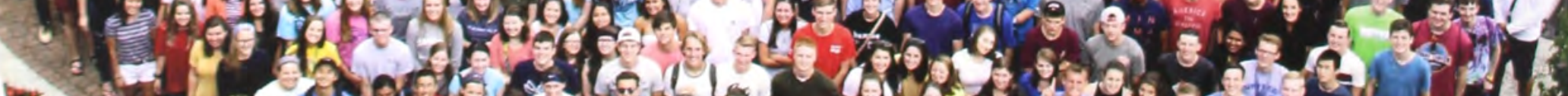

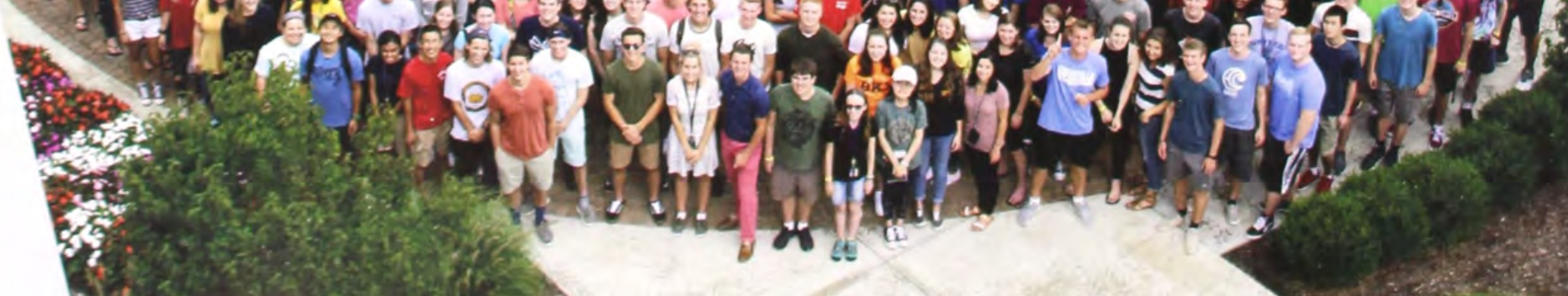


Josiah Balk Justin Ben Jason Blunt Mitchell Bowser William Brethauer

Lincoln Bryant Morgan Bryant Delaney Bynum Mitchell Carr Madeline Chairvolotti

Sierra Chambers Joshua Counts Jackson Crisi Jacob Curran Joshua Curran

Elizabeth Davis Joshua Decker Timothy Dibert Stephanie Dickson Bradley Diller

Natasha Dobson Fiona Downey Bryson Durst Delaney Dykema Micah Eisman

Rita Elgersma Rebekah Ellis Kristen Ensminger Faith Ferguson Cole Fisher

Thomas Folkerts Michaela Gentry Collin Gibson Katie Gosman Sarah Grover

Amber Haney Luke Hannay Hallie Heideman Joseph Heise Josiah Hirschler
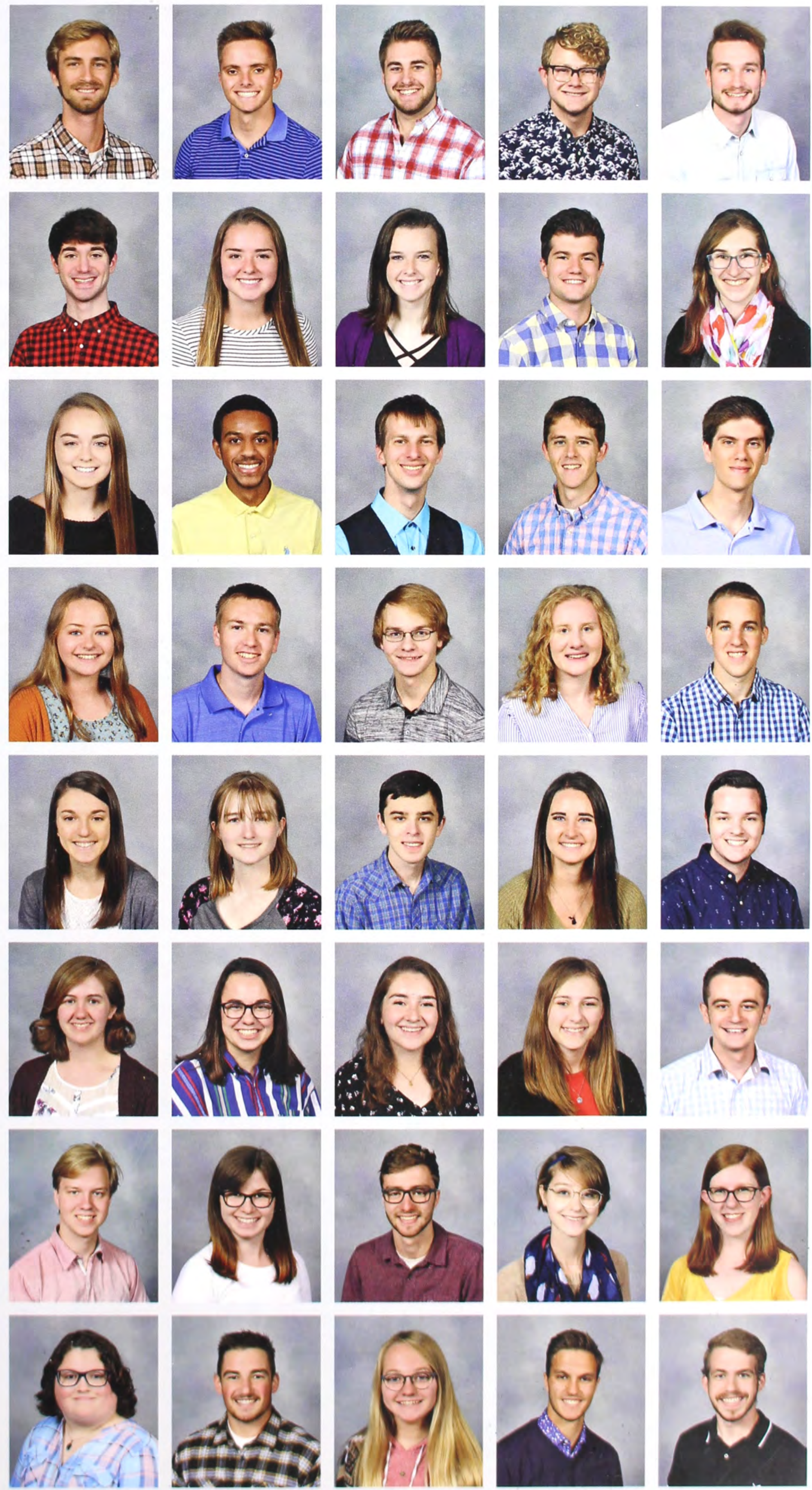
Trent Huelskamp

Malena Jackson

Lydia Jefson

Gloria Jenkins

Abigail Jenks

James Jordan

Elsah Khosrovani

Nicolas Knowlton

Timothy Kohl

Hannah Koogler

Sarah Kroger

Summer Lange

Breanna Lawrence

Nathan Lee

Eden Liang

Benjamin Linville

Bravlen Luke

Timothy Lyall

Jason Magnuson Katherine Marks

Aleah Martone

Adam Marvin

Rufus Mathew

Sarah Maue

Allison May

Madison Maynard

Elizabeth McClain

Paul Miller

Matthew Miskimen

Jana Molinari

Joshua Mundell

Madison Naugle

Khai Nguyen

Hannah Nohrer

Madeline O'Brien

Jillian Ogden Johndavid Parker

Lauren Penner

Jennifer Powell

Deborah Raczykowski
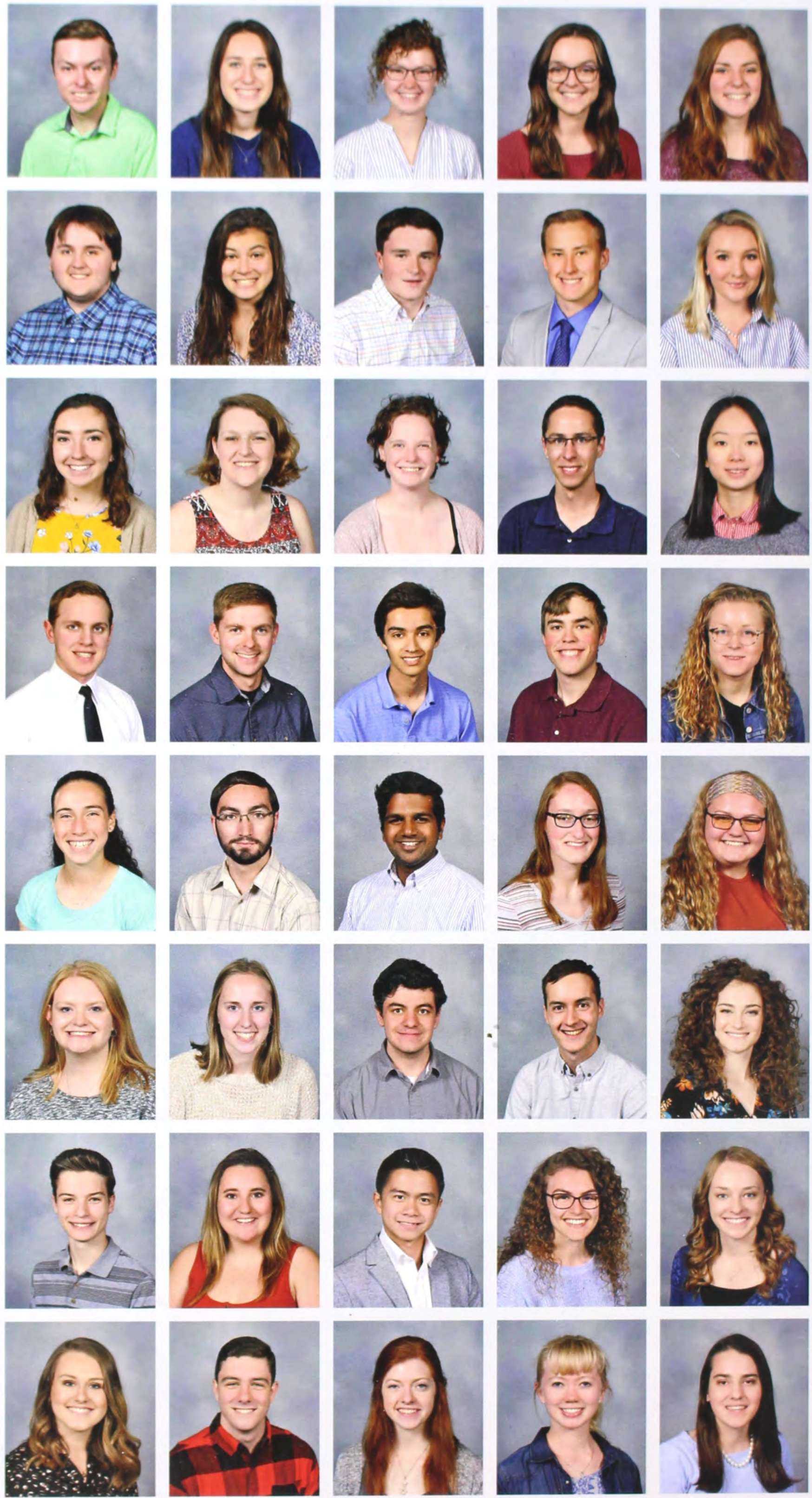
Michelle Schuman Joel Scott Connor Seals Victoria Siefert Nicholas Silveira

Sarah Slater Timothy Spencer Julia Stagg Jonathan Stanhope Caleb Stechschulte

Lydia Switzer Elizabeth Tan Noah Tang Claire Terhaar Abigail Thornton

Victoriahna Vander Does Andrea Vaughn Bethany Wagner Carl Weaver Laura Weaver
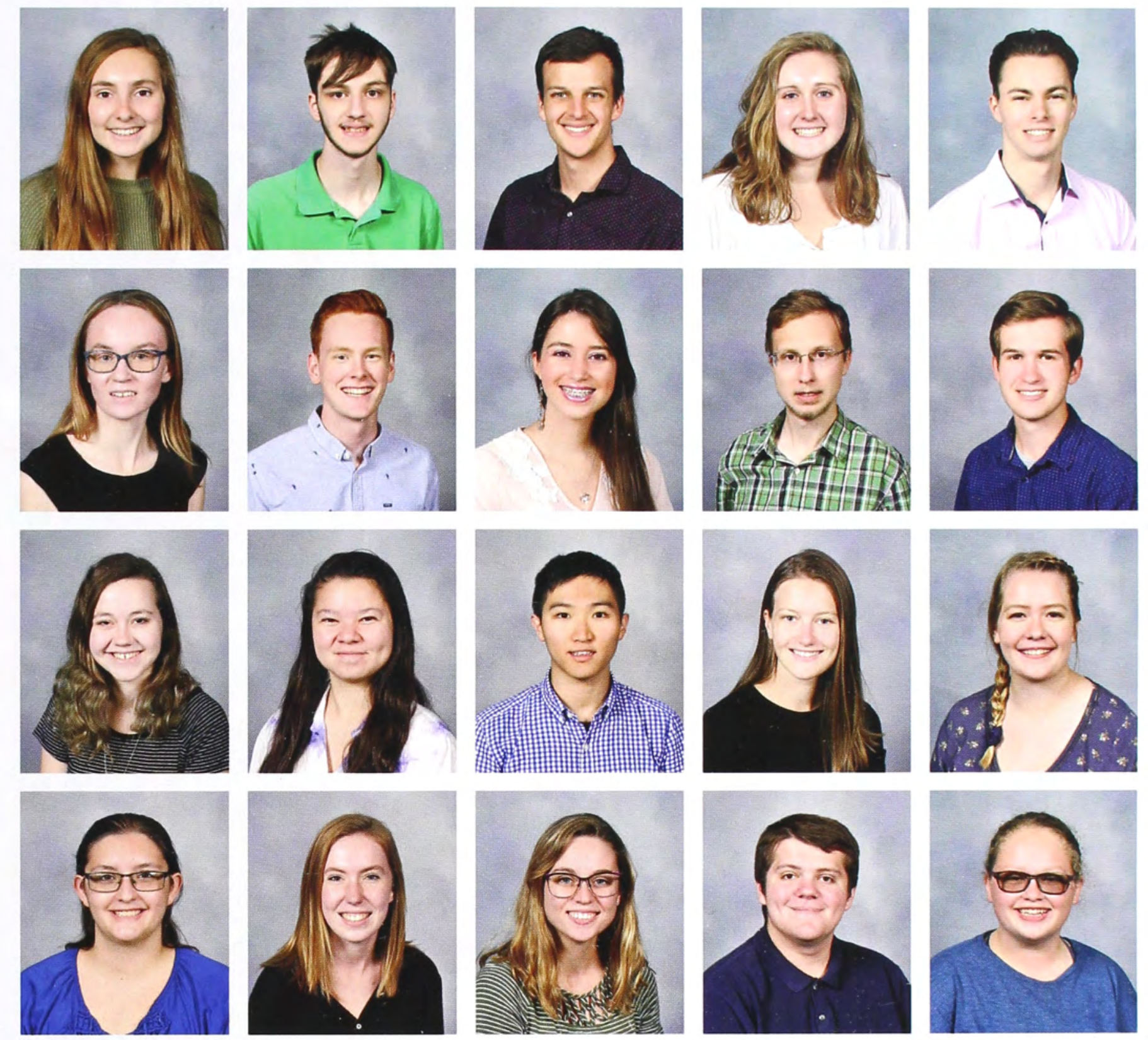


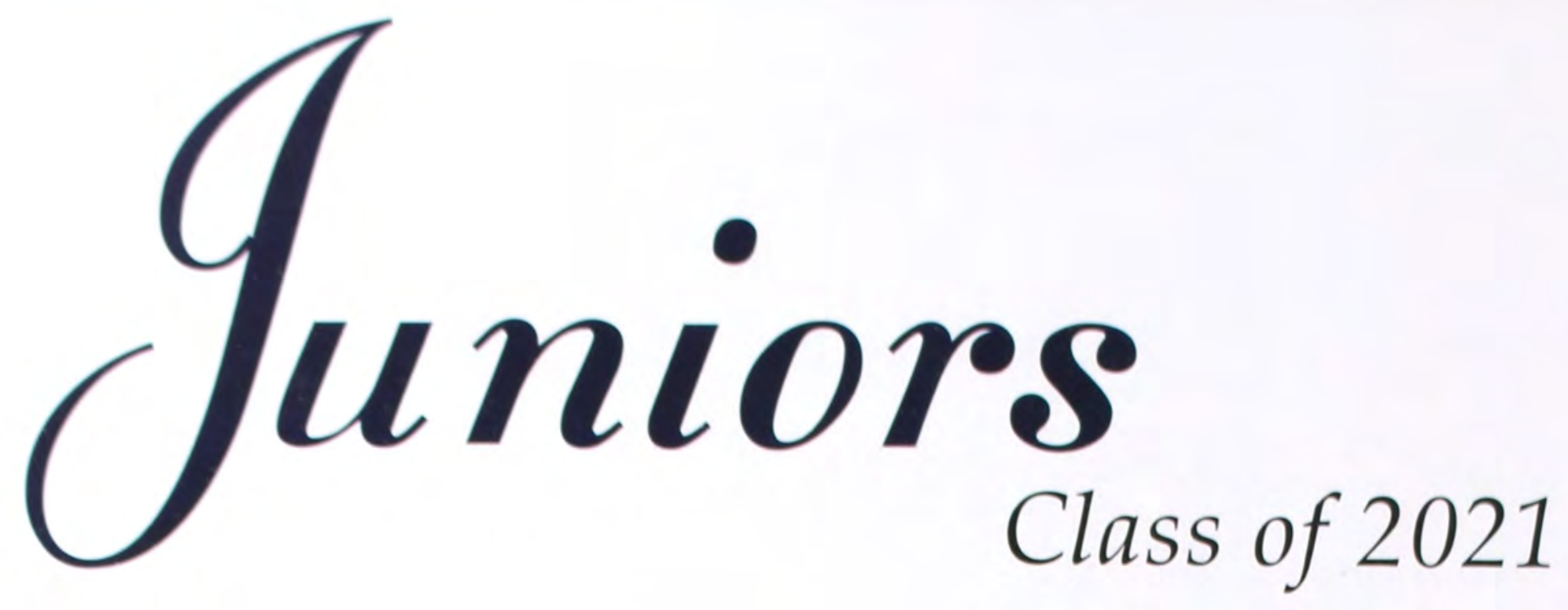

The Junior Class identity is represented by the word "Joyful." It comes from John 15:9-11, and it means that the class of 2021 has joy that doesn't come from their circumstances. Their joy stems from God's love that has been freely given to them. Even though this world constantly changes, God is sovereign and loving, and they can have joy because of Him.

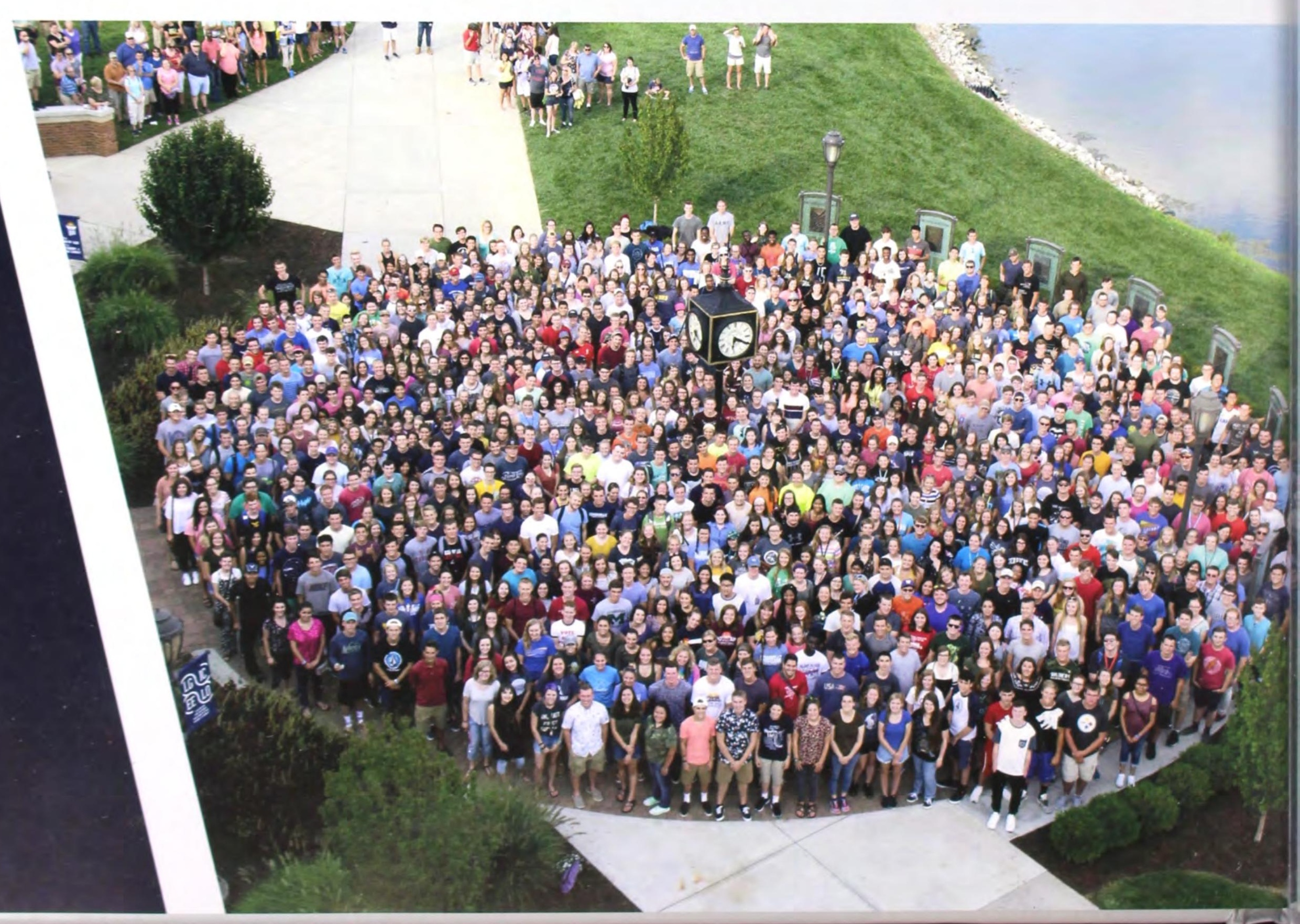


Lorin Barnes

Sarah Bean

Lindsey Bishop

Megan Boyle

Parker Bradley

Joshua Bundy

Zachariah Byrum

Landon Cina

Noah Davis

Luke Denen

Nathaniel Derochie Julia Elmers

Abigail Enloe

Rachelle Everswick

Angela Farlow

Brittany Ferguson

Haley Foster

Alexandra French

Philip Gebauer

Emily Gifford

Ashley Gosman

Mark Handel

Connor Hart

Michael Hiett

Madeline Hurst

Alex Istrate

Kyrie Eleyson Johnston

Adelinne Jones

David Kauffmann

Anna King

Emily Kuhn

Joslyn Laflamme

Kelsey Laing

Noelle Lansford

Laura Lasich

Katie Linville

Daniel Lively

Trevor Loula

Addalyn Love

Carina Luiken
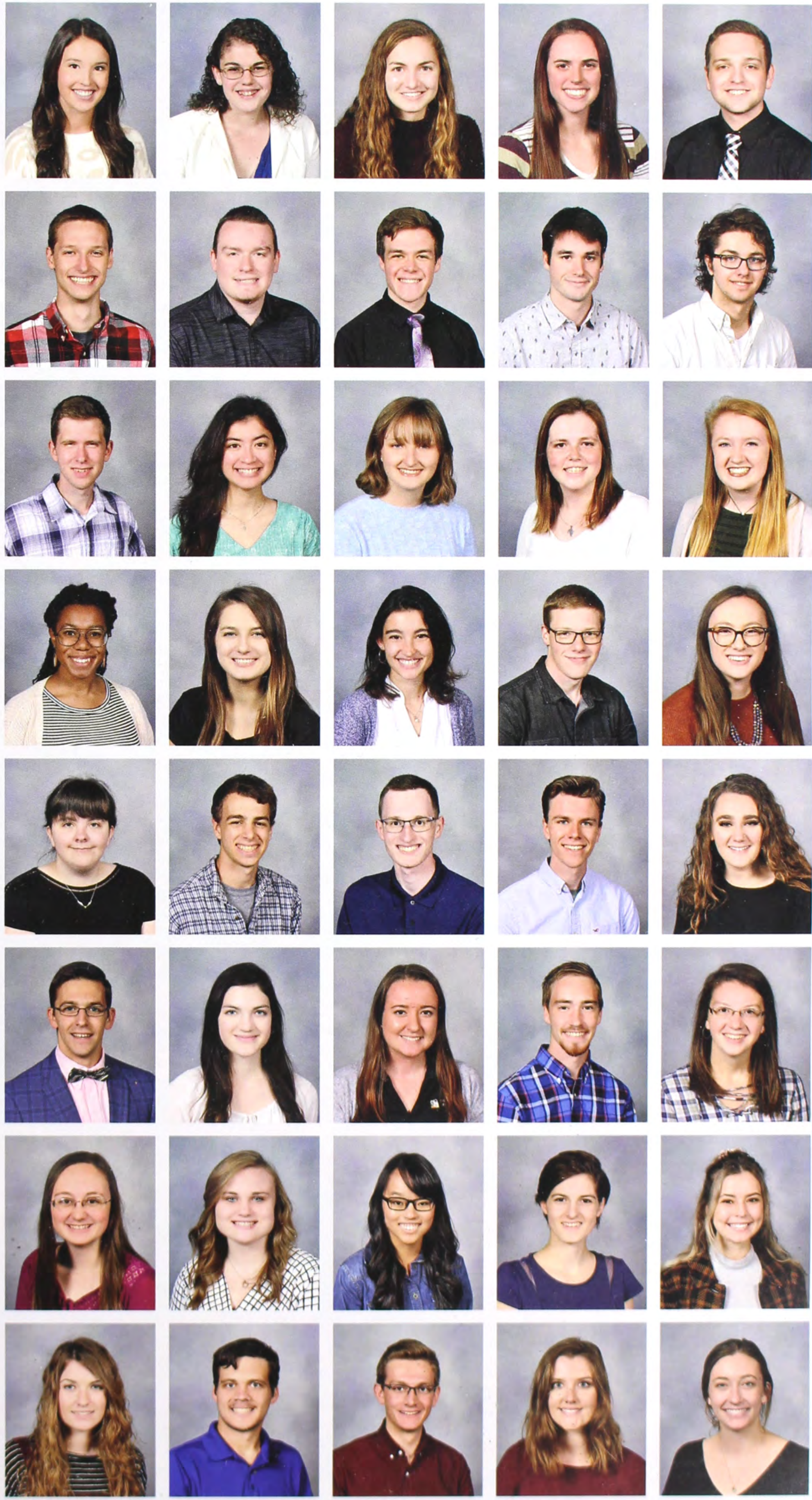
Kiley Mach

Levi Marcum

Laura McKenna

Ahna Mellinger

Stephen Mentzer

Kristina Mills

Molly Moses

Laura Neer

Meredith Nelson

Richard Nyquist

Beth Oldham Jeremy Patricca

Jason Paulus

Olivia Peak

Breanna Potts

Kavla Reilly Benjamin Richmond

Ashley Riddle

Jake Ringstrand Madison Roberts

Claire Salser

Chloe Sodonis

Jacy Stahlhut

Ian Steptoe

Ryan Stikeleather

Daniel Urban Emma Van Veldhuizen Jason Wandling

Lydia Watson Brienna Weigner

Corrin Winsor
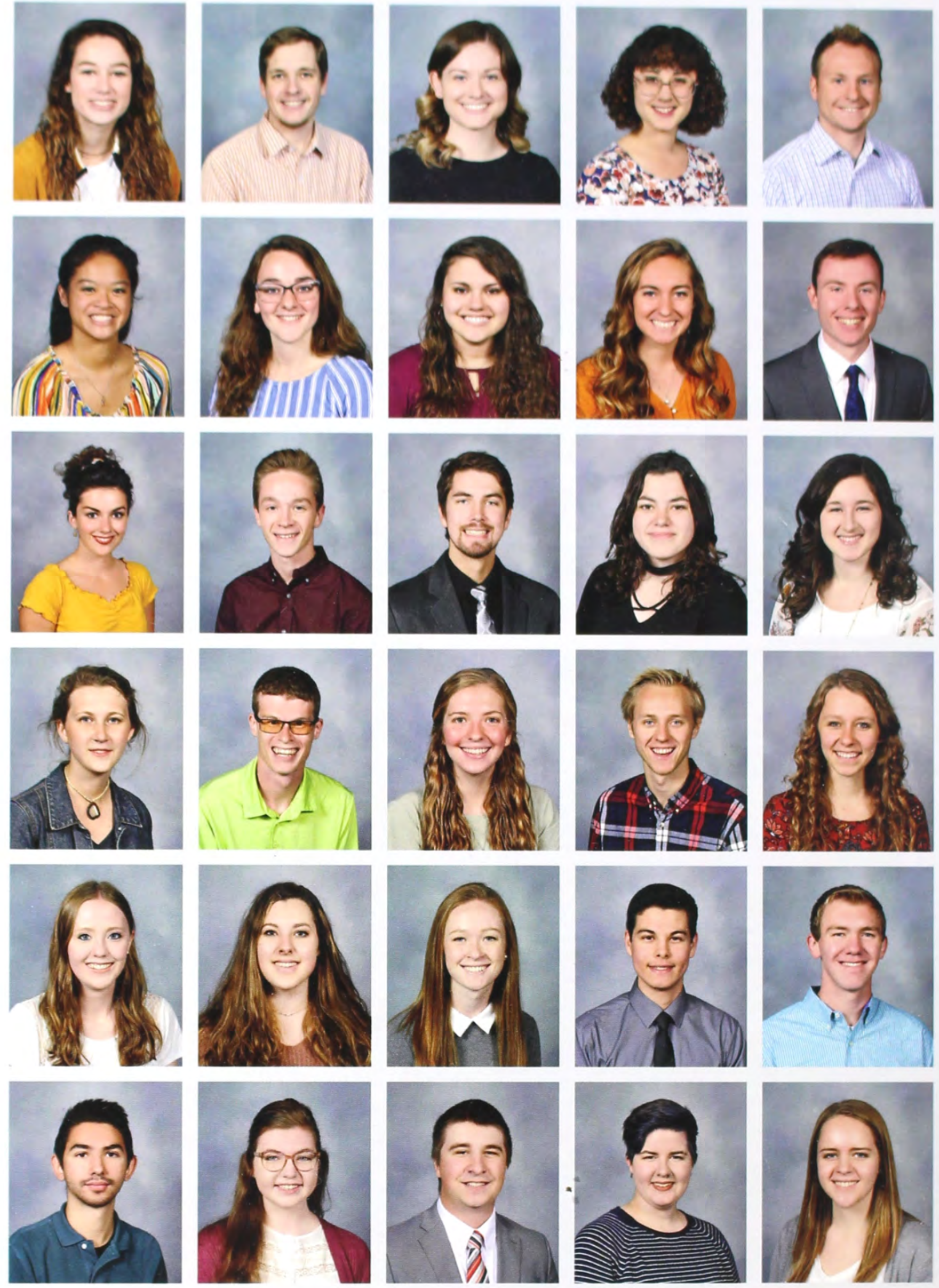

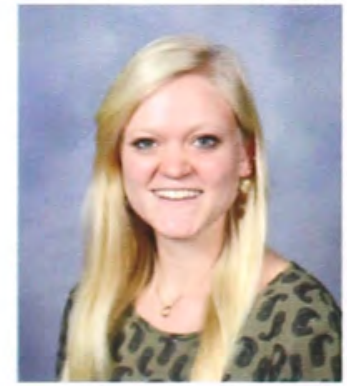




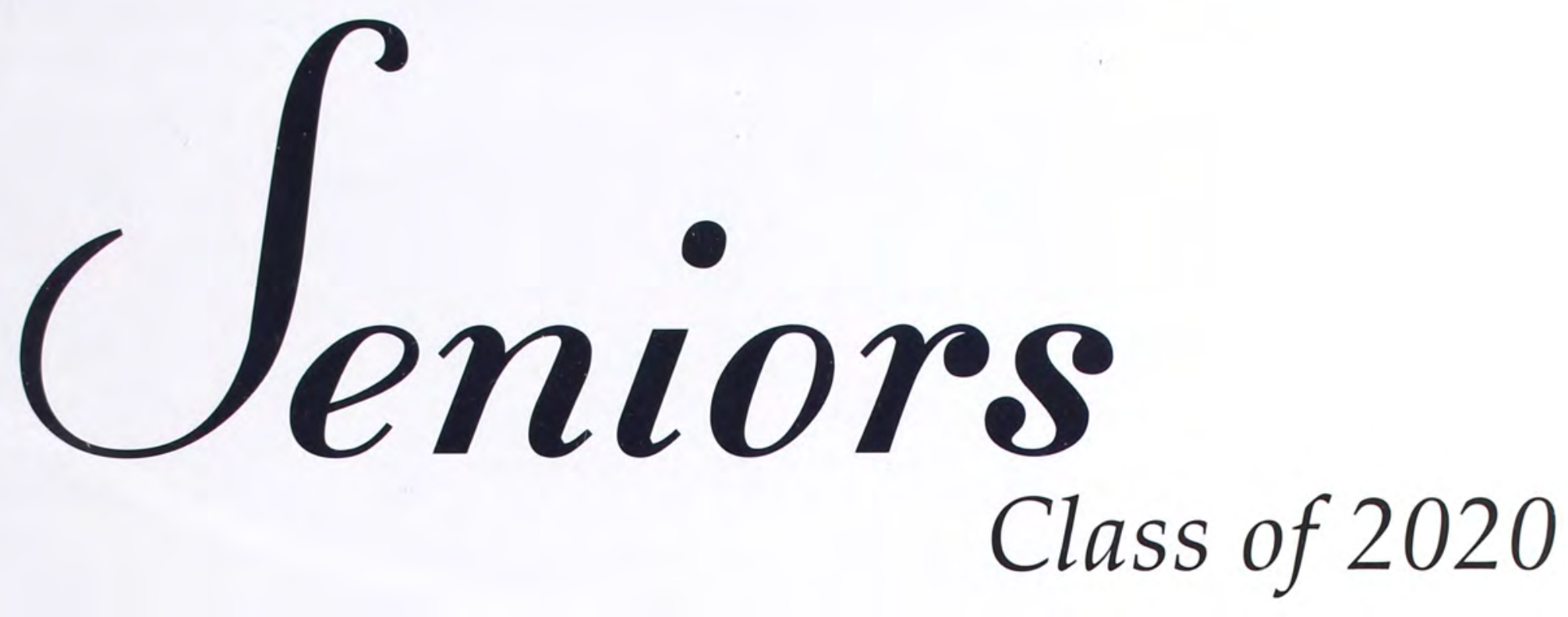

The Senior Class Identity is characterized by the word

"Seekers." The idea is introduced in Psalm 27:4. It means that the class of 2020 is always looking for opportunities to serve God and others. During their time on campus, and in their lives after graduation, their goal is to actively seek out ways to bring glory to God and others and live a life of service in His name.

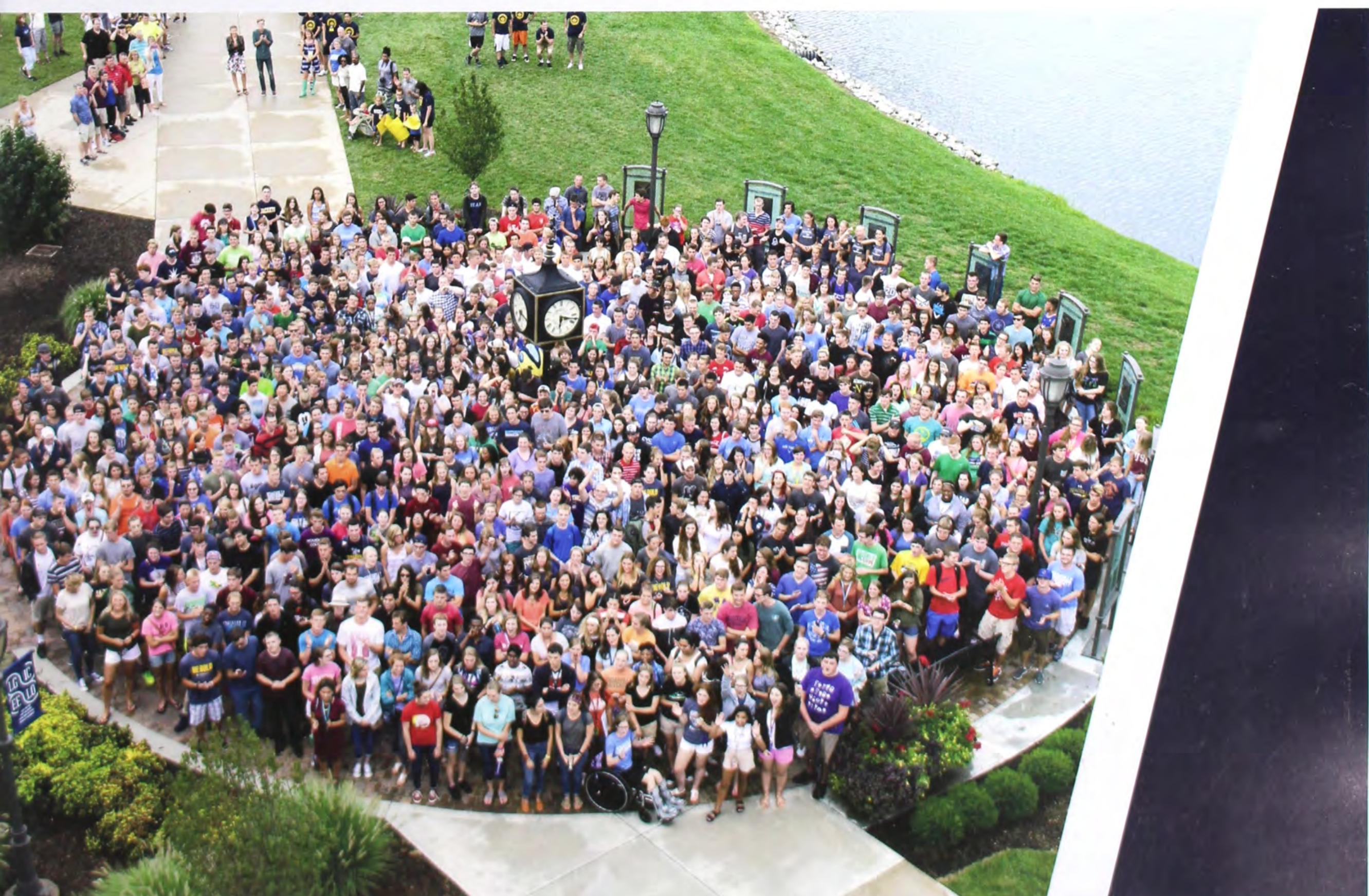


Joseph Adams

Leah Adams

Joshua Adewole

Avonlea Adkins

Garrett Agans

Shelby Ahlborg Isabelle Armstrong McKenna Armstrong

Micah Aviles Alyssa Bach

Victoria Baker Ryan Ball

Laura Bannister Carlos Barahona Maurer

Eric Barnes Rachel Barnette

Leah Bartlam Jordan Beal

Kori Beal

Caroline Beckman

Daniel Beckmann Joel Beckmeyer Chloie Benton

Chloe Bequillard
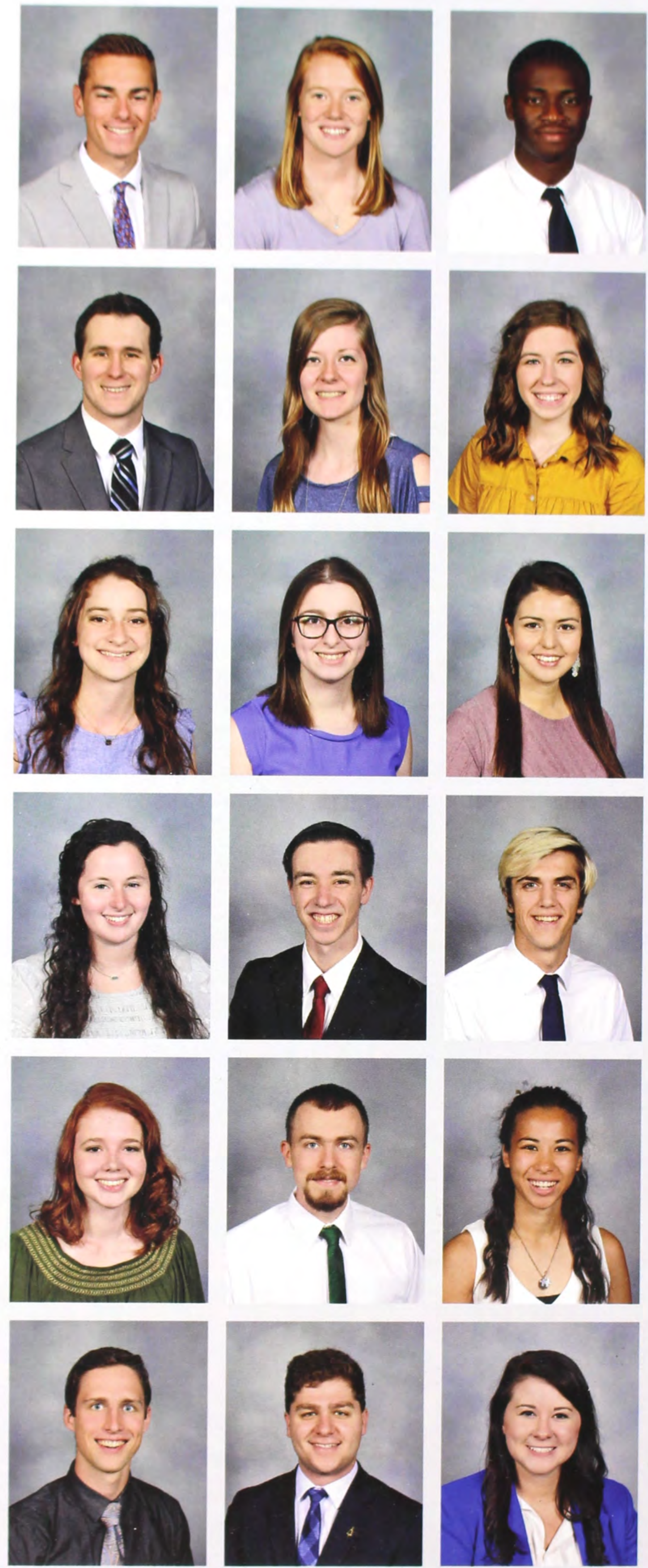
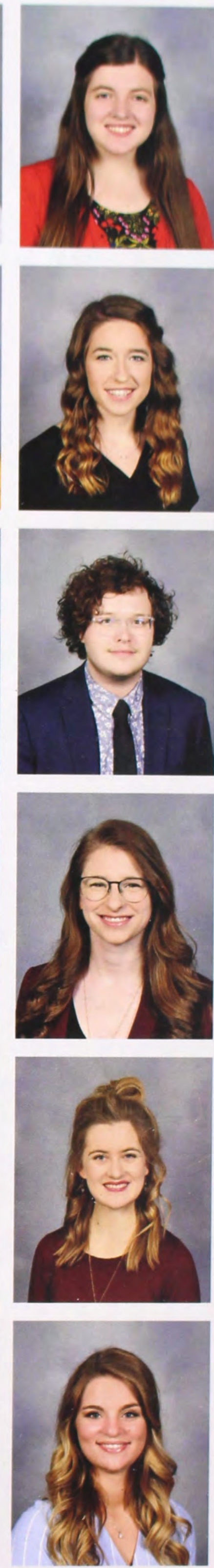
Carrie-Grace Bergan

Kylie Beste Joshua Betcher Andrew Bitner

Elisabeth Blank

Gillian Bolds Cassandra Boyer

Karina Brady

Mimi Brandon

Zachary Bretz Michael Brocker Wesley Brooks

Kelly Brown Jonathan Bryant

Analice Burd Emma Burgess

Grace Burket Kip Burmeister

Claire Burton Marie Butts

Jack Byerley Kearsten Byerley Holly Caldwell Carissa Caples
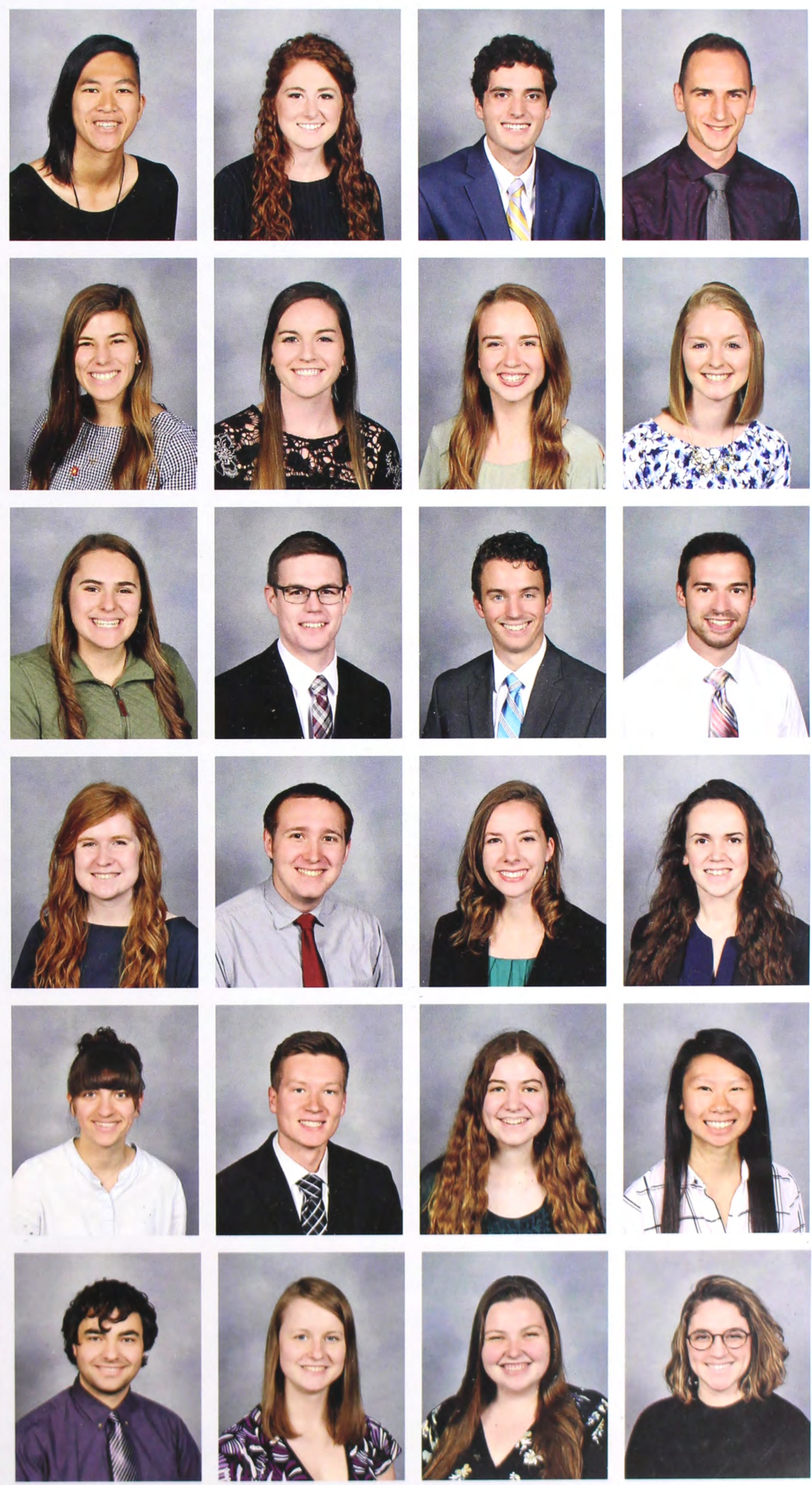
Bethany Carson

Kristina Cater

Benjamin Chapa

Eric Chevrette

Ashley Childers

Brandon Christen

Grace Christiansen

Chad Clark

Kristyn Cline Jordan Clingenpeel Holly Cochenour Olivia Coon

Micayla Cooper Evan Cornwall

Paul Coviello Connor Creekmur

Jessica Czyzewski Joshua D'Anna Jared Dickerson Austin Doub

Danae Dray Isaac Dye

Denise Dykema Abigail Edsell
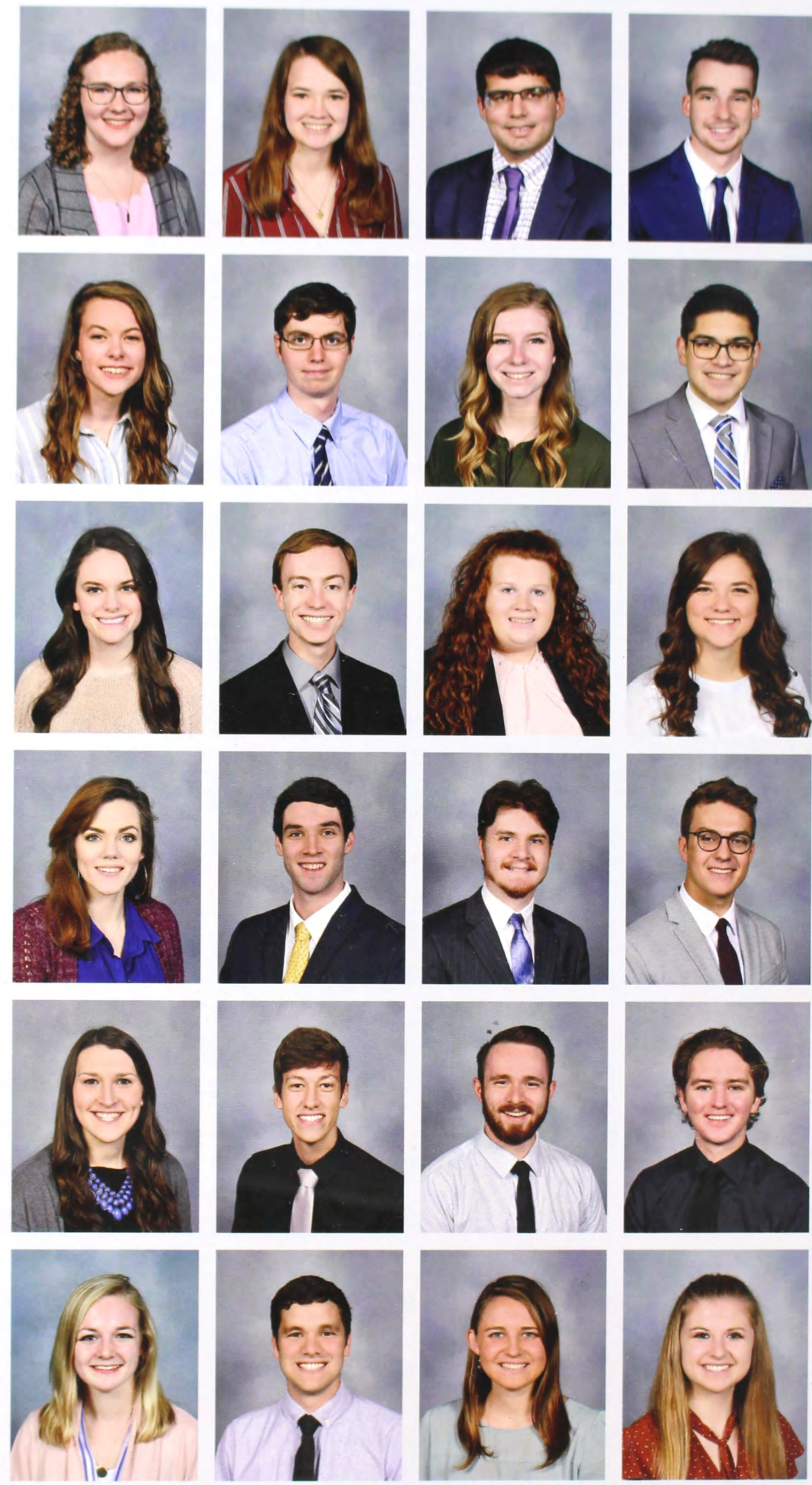
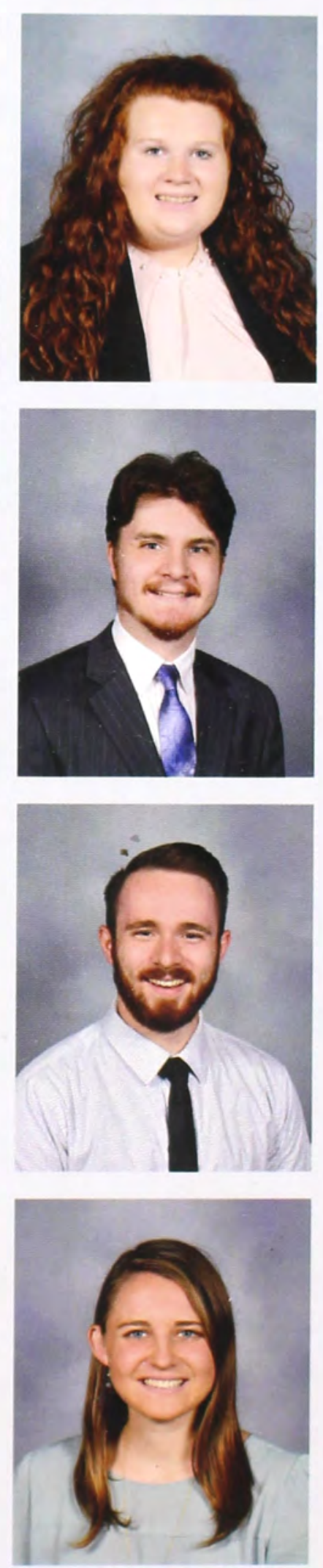
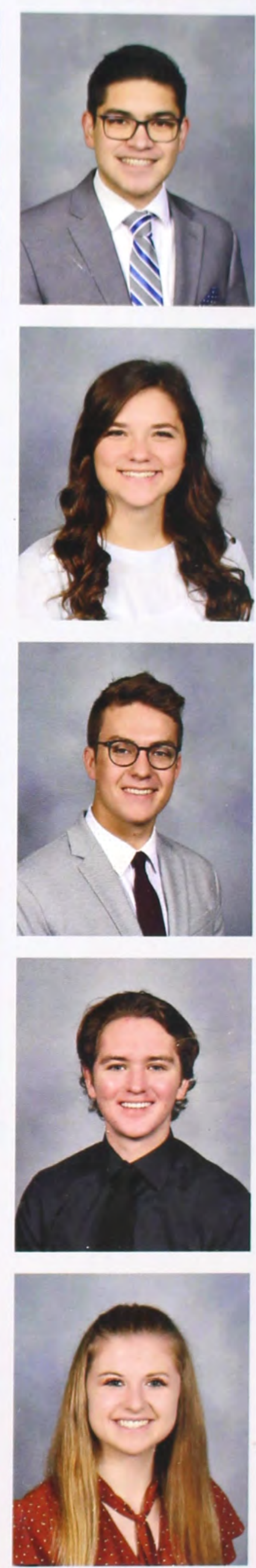
Anna Edwards Amanda Elkin

Kaily Ellis Anna Espling

Kristen Farley Rachel Farynyk Madelyn Fawcett Claire Feathers

Elizabeth Ferris

Hannah First

Hope Fischer Hadley Flener

Kaitlyn Flint Tayana Fowler Andrew Fretwell Rachel Frye

Daniel Garcia Allison Garlock Giselle Gearhart Jacob Gebauer

Melissa Gernert Kristopher Gibboney David Gibbs Priscila Gonzalez Osorio
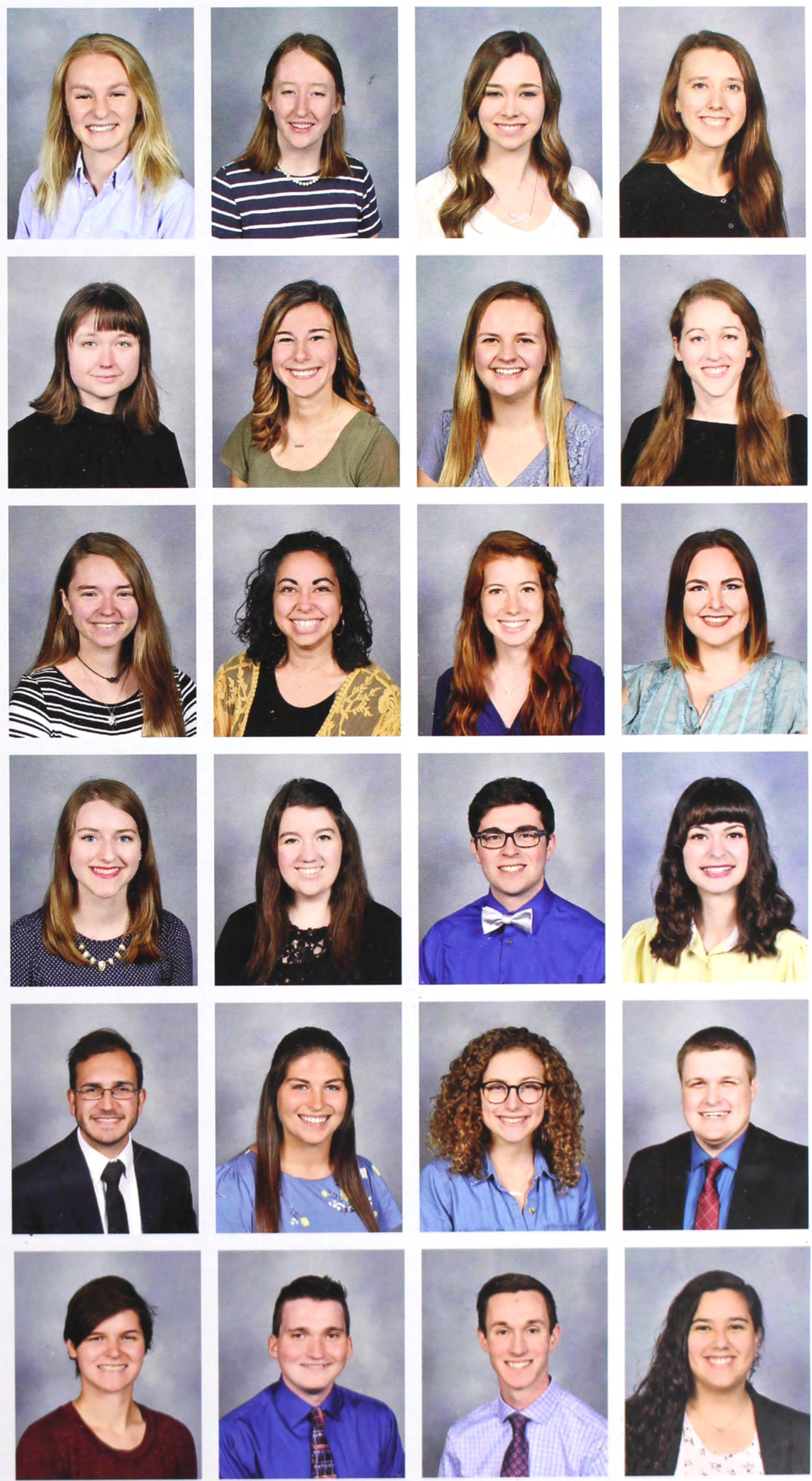
Faith Gorlich

Sara Grether Alexandria Haddix Hannah Hallett

Breanna Hamilton Joy Hanson Kennedy Harless Leah Harper

Sarah Harris Sierra Hartings Joshua Hartt Alexis Heatwole

Hannah Heft Emily Heidenreich Elena Hein Samantha Hershberger
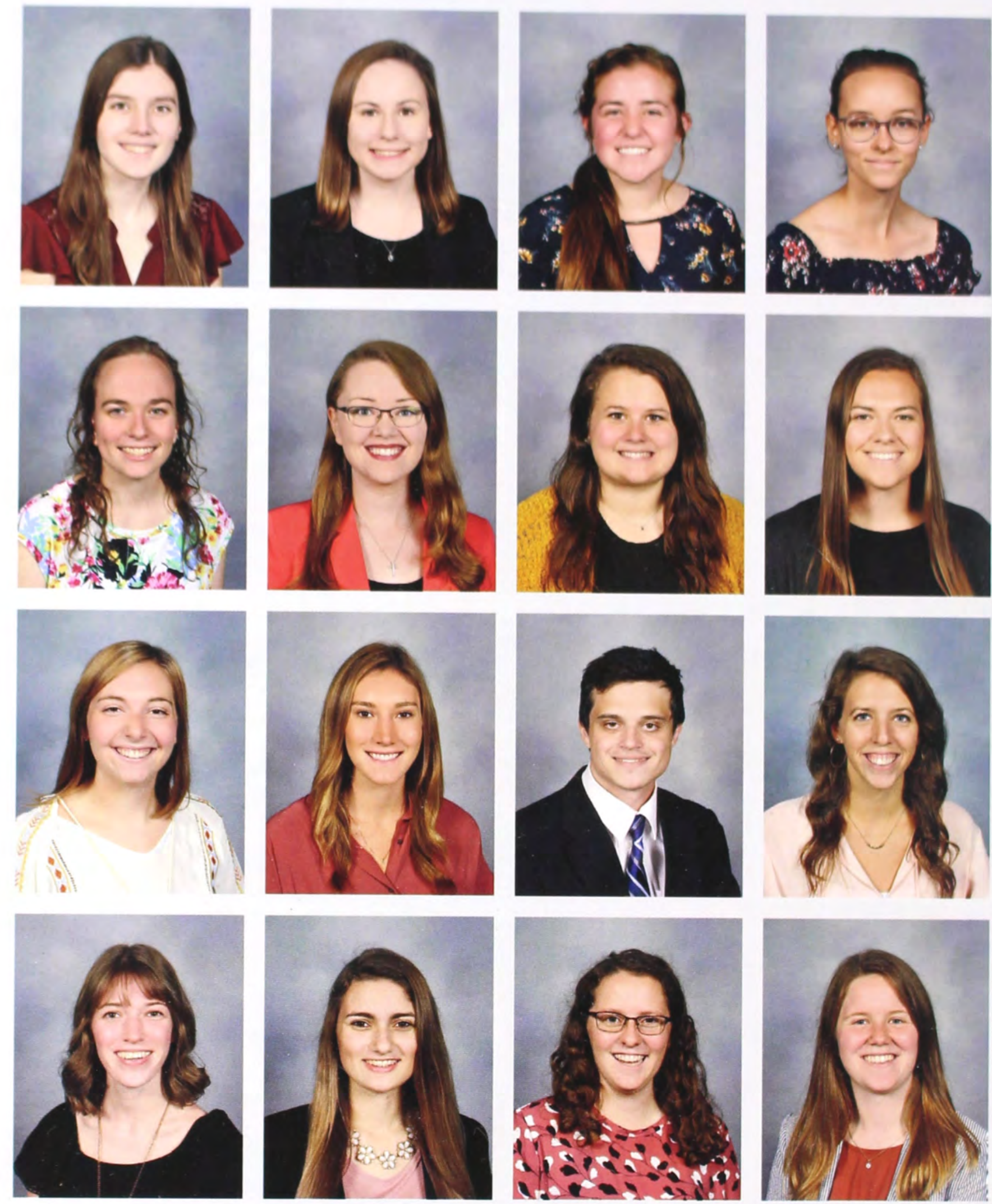

Elisabeth Hess

Megan Hess

Brooke Hieronymus Bonnie Higgins
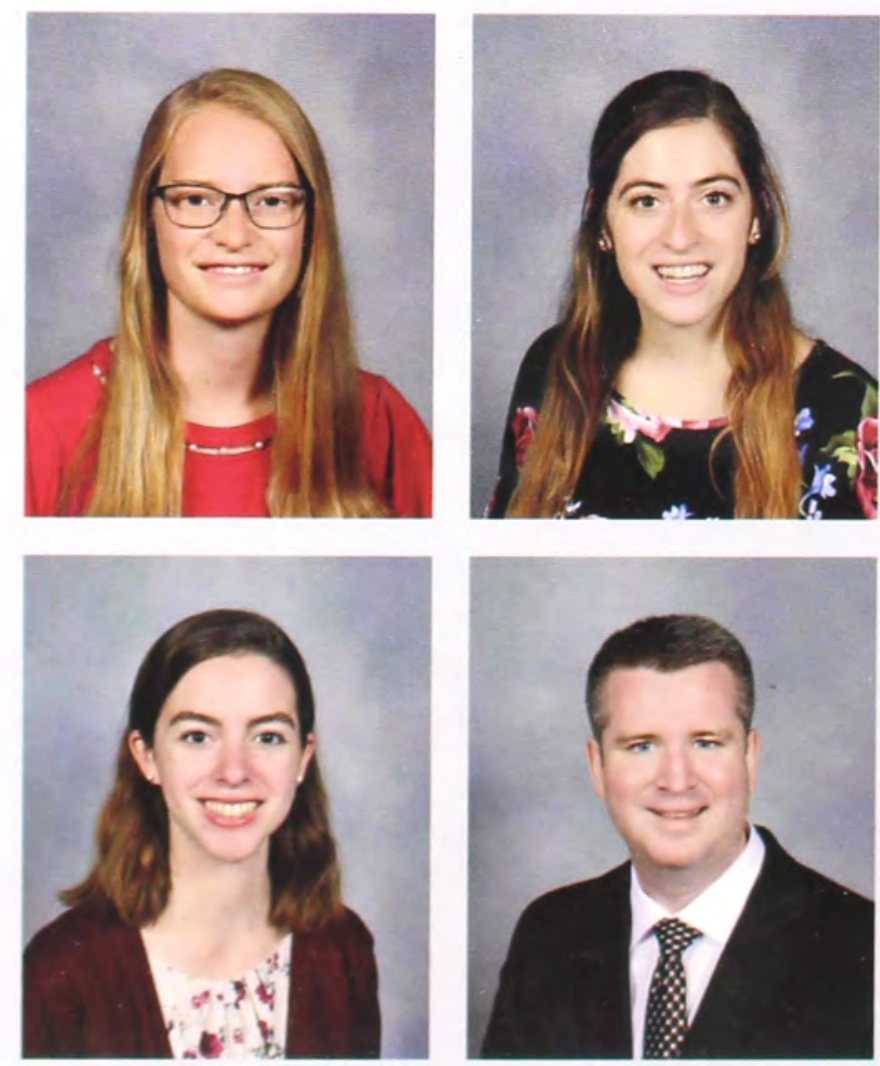
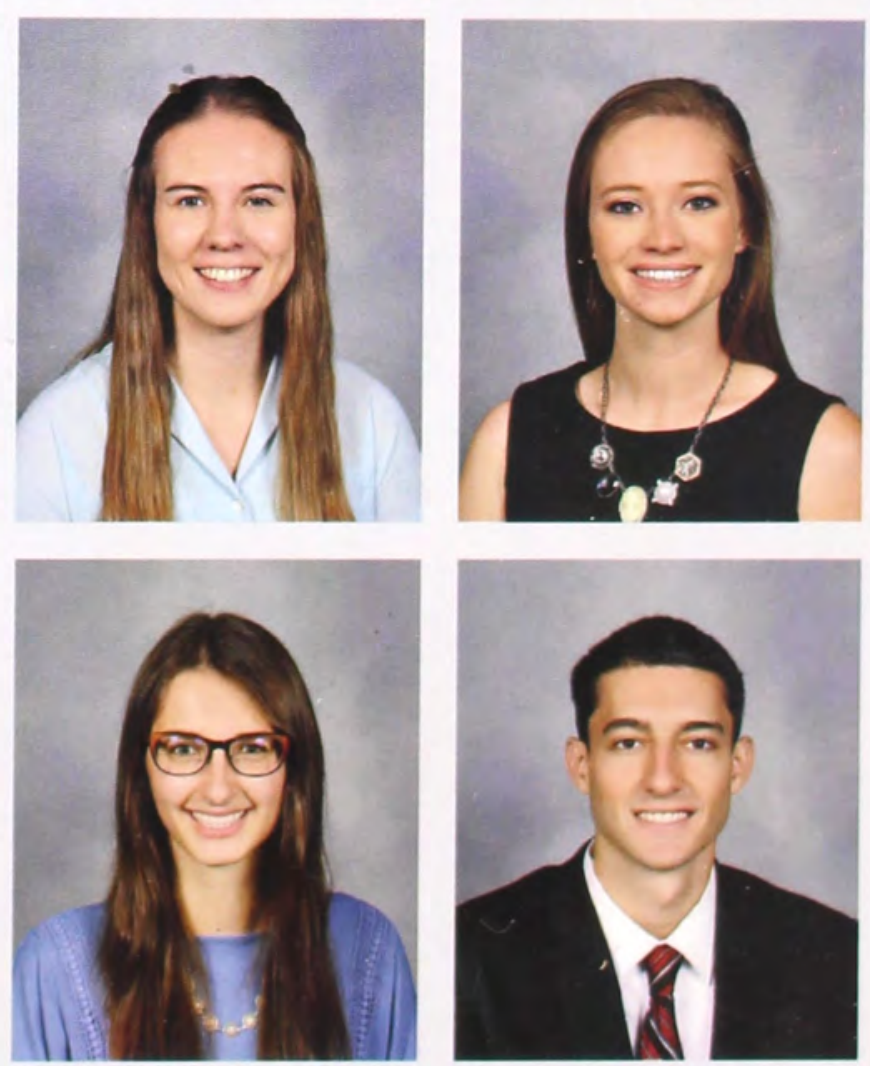
Rachel Hostetler Jonathan Hudson Sara Humphrey Tabitha Huschilt

Katelyn Huyser Gabrielle Imfeld Sarah Imhoff Stephen Ingis

Arianna Jackson

Caleb Jackson Maria Jacob Abbey Jacobs

Lauren Jacobs Meghan Jacobs Lydia Jacobsen Kaitlin Jarboe

Joshua Jenks Sarah Jennings Anna Johnson Erin Johnson

Sarah Johnson Savannah Johnson Hannah Johnston Hannah Joiner
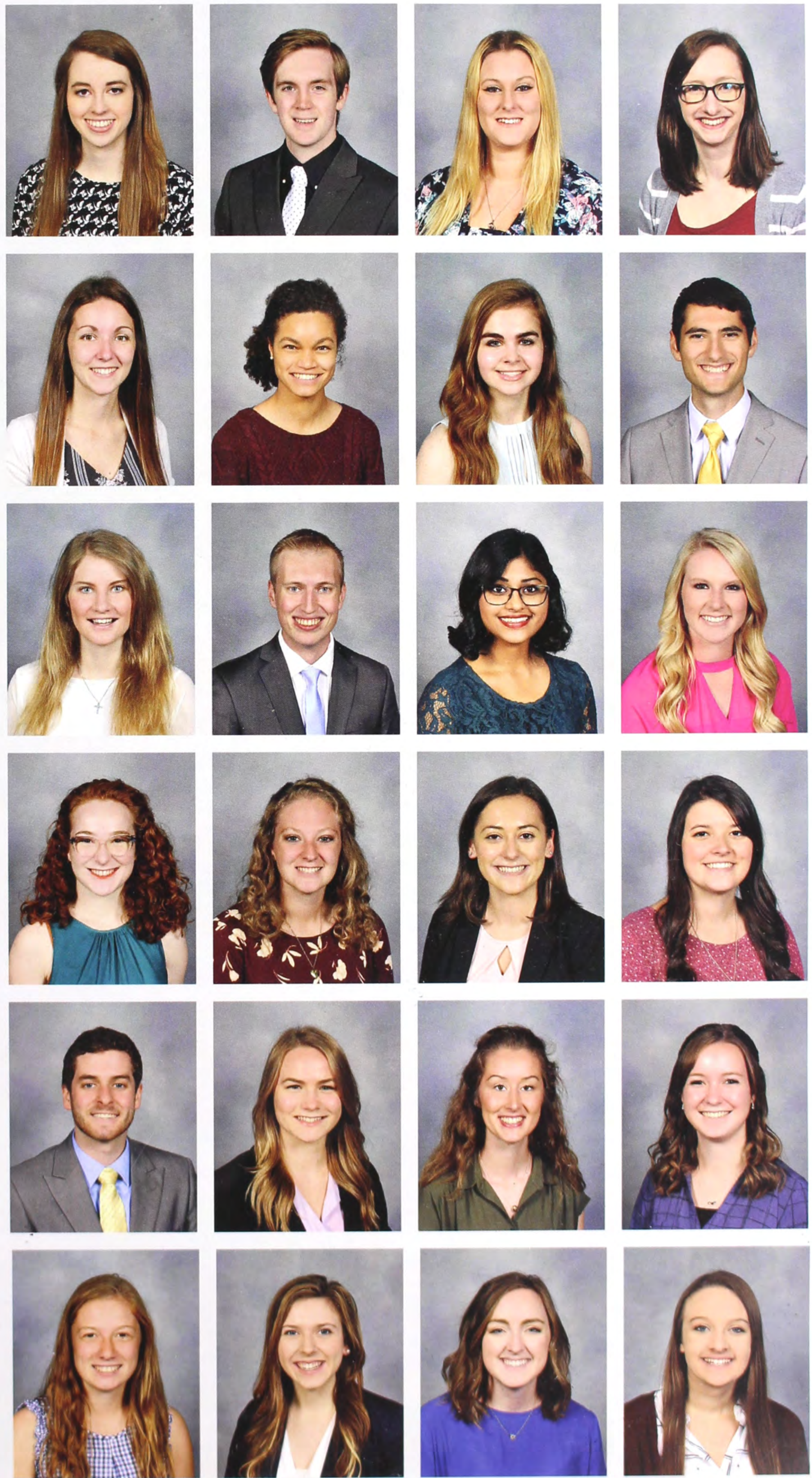
Kendall Jones

Anna Kaster

Anna Keiter

Zachary Kemp

Paul Kempton

Katelyn Kennedy

Julia Kicinski

Hannah Kilgore

Mallory King Andrew Kistler

Naomi Kohler Geoffrey Koteskey

Abigail Krakora Julie Krudop Benjamin Lachance Shannon Lamonte

Chloe Lance Joshua Lankford Josiah Lansford Meghan Largent

Jacob Lashuay

Nia Learned Madeline Lenze Alexis Limbers
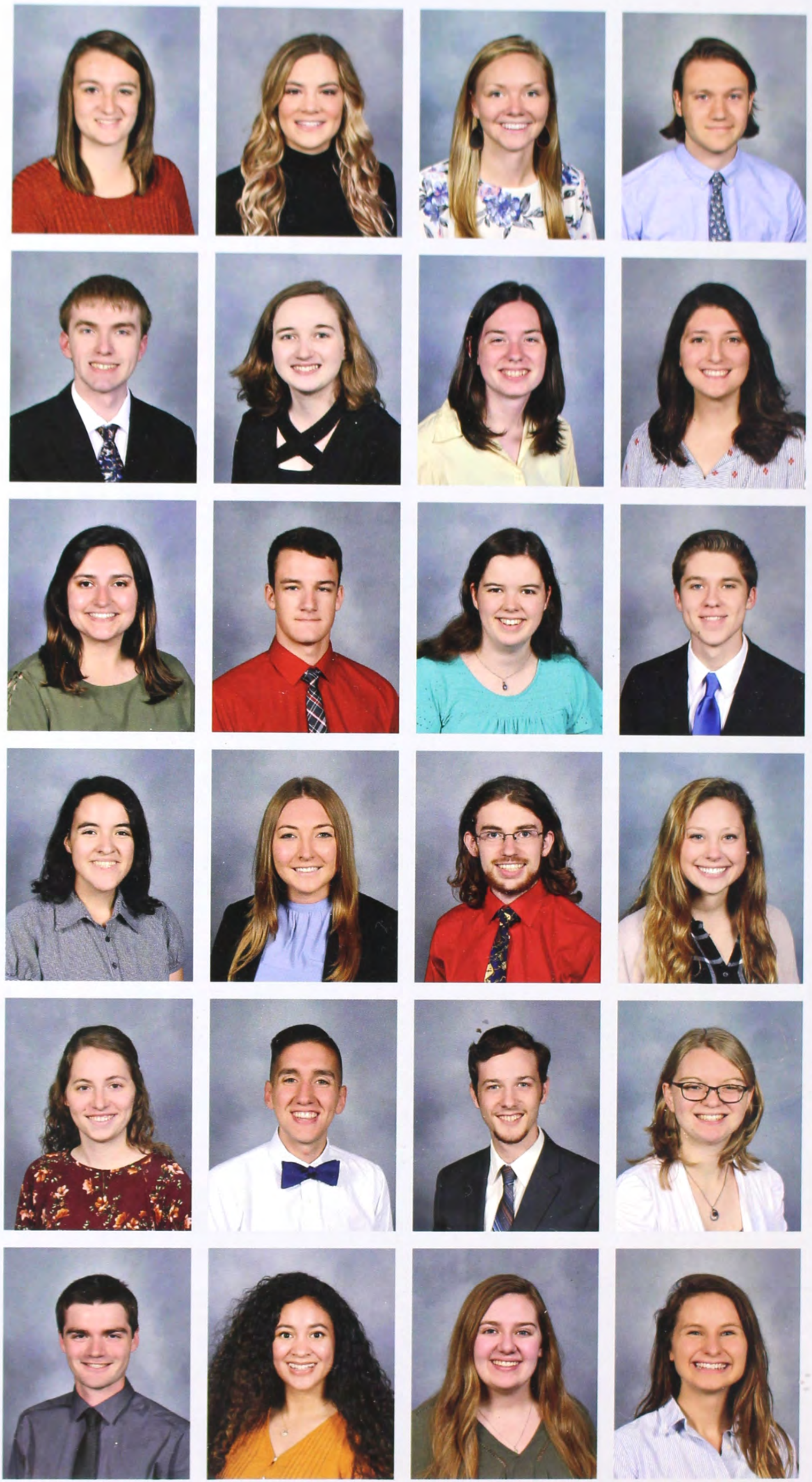
Gabrielle Longe Anna Luttenegger

Rachel Lynch Joseph Marshall

Hallie Martin Paige Martin Lauren Matson David Mattackal

Michael McCain Jonathan McClain Rebekah McClain Abigail McCormick

Erin McCullough David McDonell James McElroy Kelly McFarlane

Andrew McKay Andrew McMillan Alexandra McMurray Halee McPherson

Ryan Merk Carter Miedema Jesse Miller Aricka Mitchell
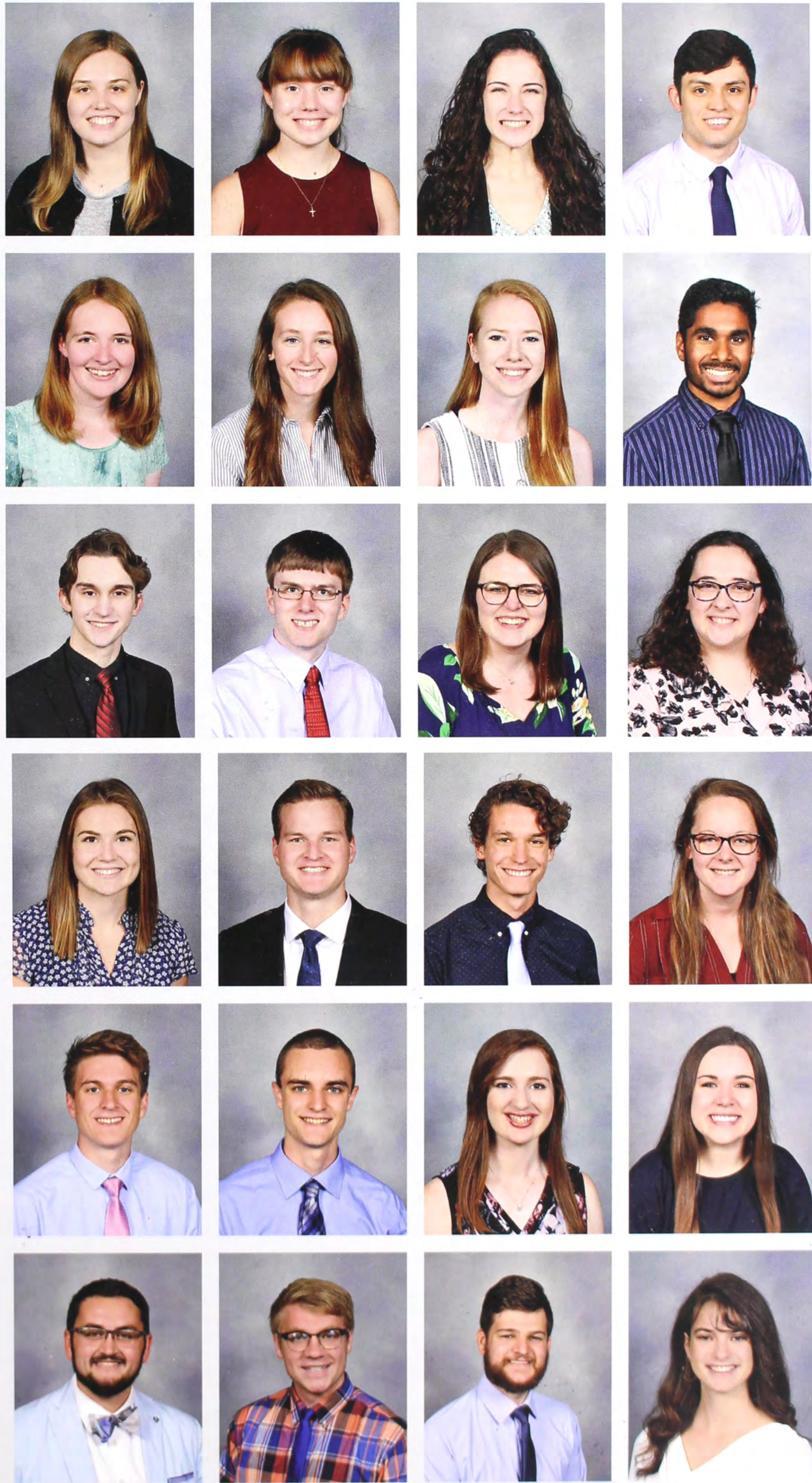
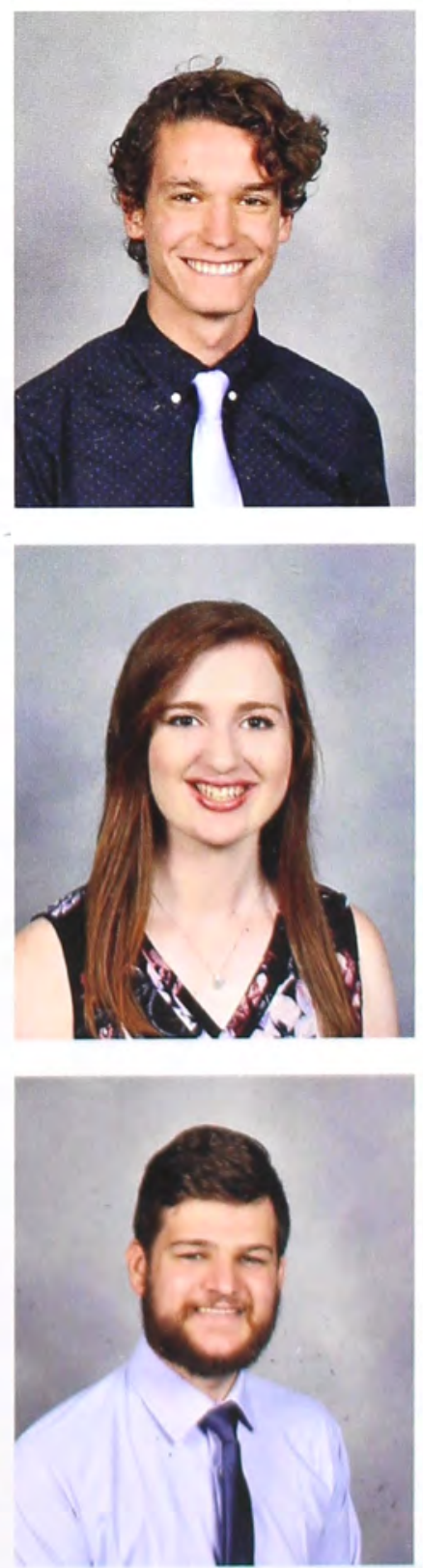
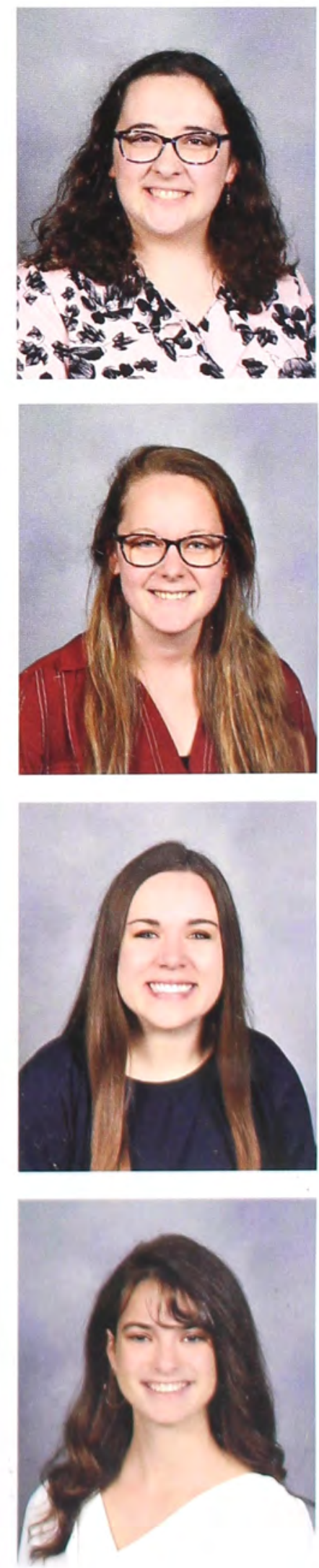
Shaun Mitchell Julianna Mitten

Hope Moore Benjamin Moses

Marylou Mumme Anthony Mummert Emma Mummert Jacob Mundell

Marshall Munsell Abigail Murray Kendall Myers Brianna Noller

Taylor Nunan Ellison Nuse Logan O'Brien Gabriel O’Neal

Michael Oedy Julia Olsen Ethan Ooms Daniel Parker
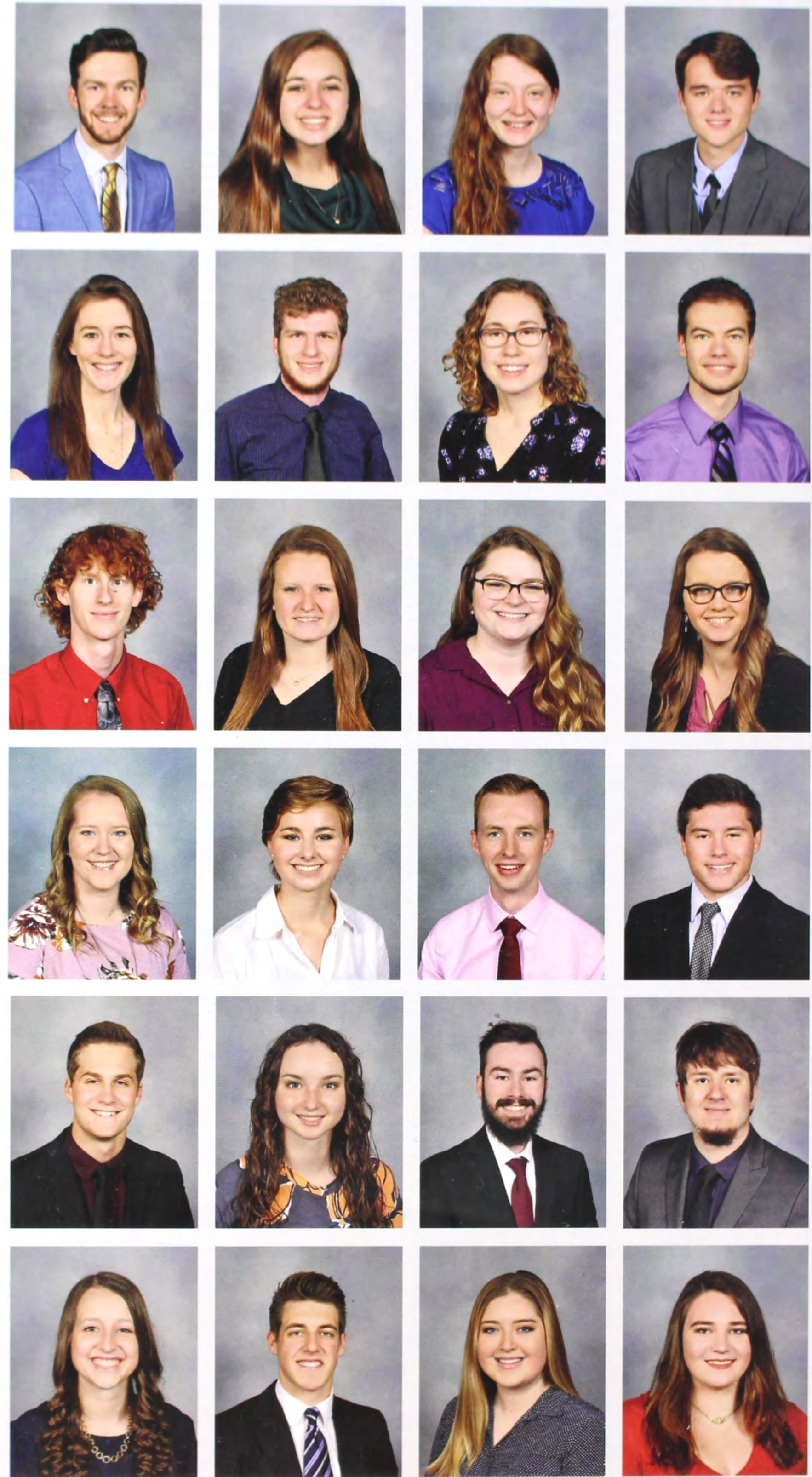

Kristy Parks Jacob Paschall Olivia Patterson Lila Pattison 
Joshua Payne

Shelby Payne

Sarah Pennington

Kelsea Penny

Gwendolyn Peterson

Kurtis Peterson Joseph Petroff Anna Petron
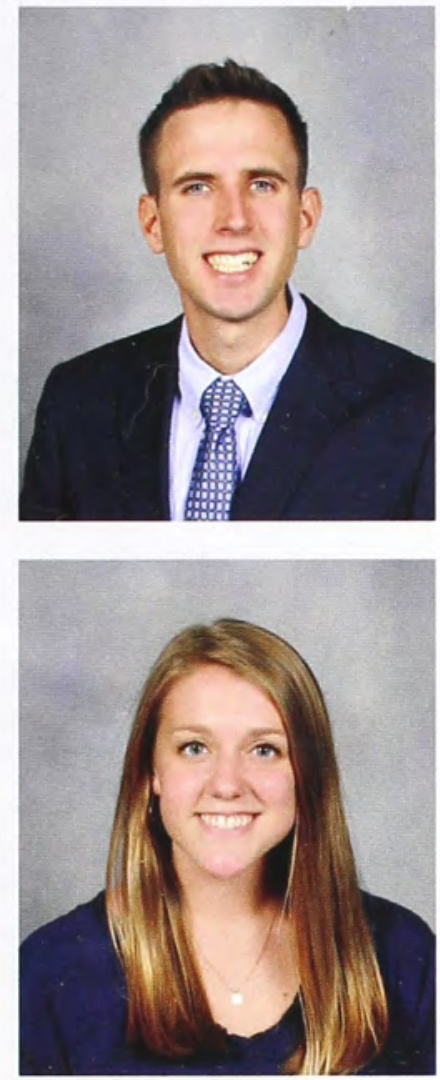

Donald Petron

Natalie Phillips

Emily Pitts

Monica Plank

William Plank

Carlie Poole

Carolyn Pottle Kimberly Powell

Kayla Prater Bethany Priest

Bethany Putnam Cassandra Rakowski

Carolyn Raquet Christiana Rasey Jacob Ratliff Michael Redmond
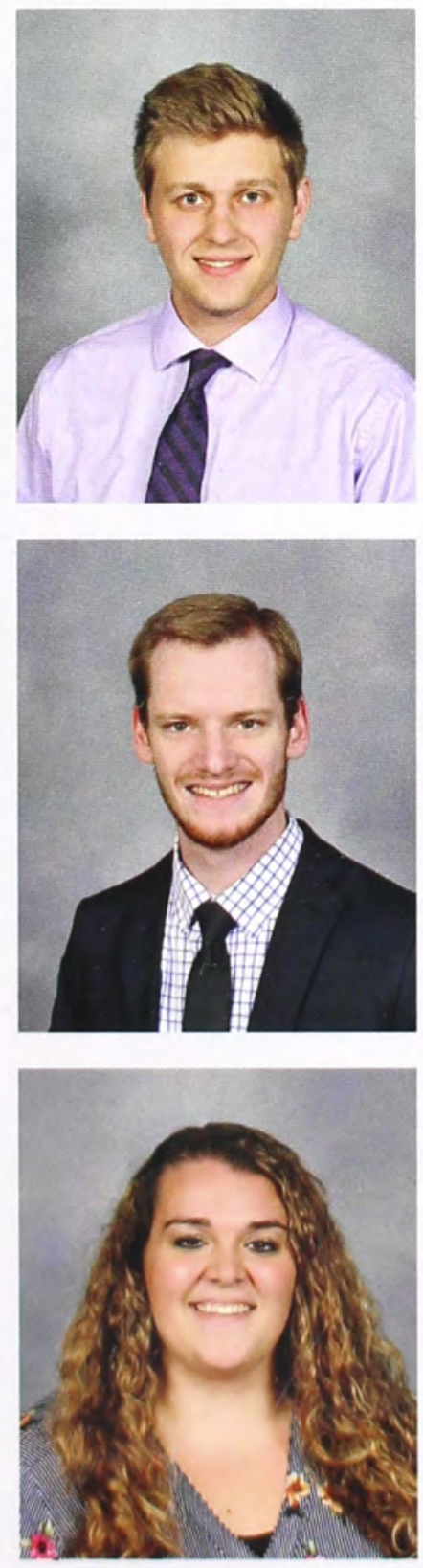
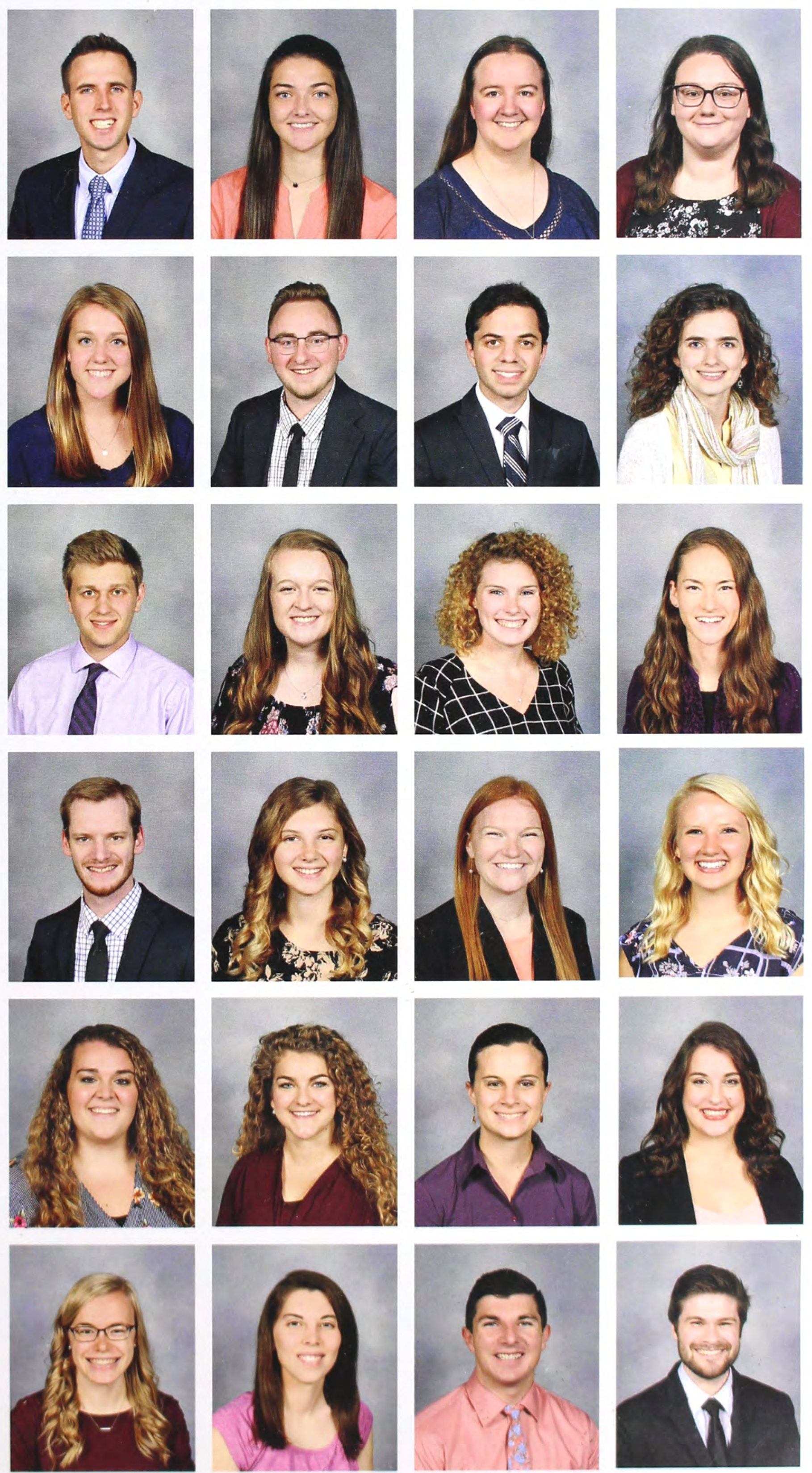
Kevla Redondo

Nicole Reese

James Rice

Paige Riebel

Lauren Ries

Abigail Rivas

Alyssa Roberts

Riley Roberts

Ayja Robinson

Matthew Robinson Christopher Rossiter

Zachary Rubosky

Abigail Russell Miranda Sams Sarah Sanders Lydia Sarver

Emily Savard Samantha Scanlan Ariel Schantz Chad Schmidt

Stephen Schoenwald Andrew Schroer Jeremy Schultz Sadie Searcy
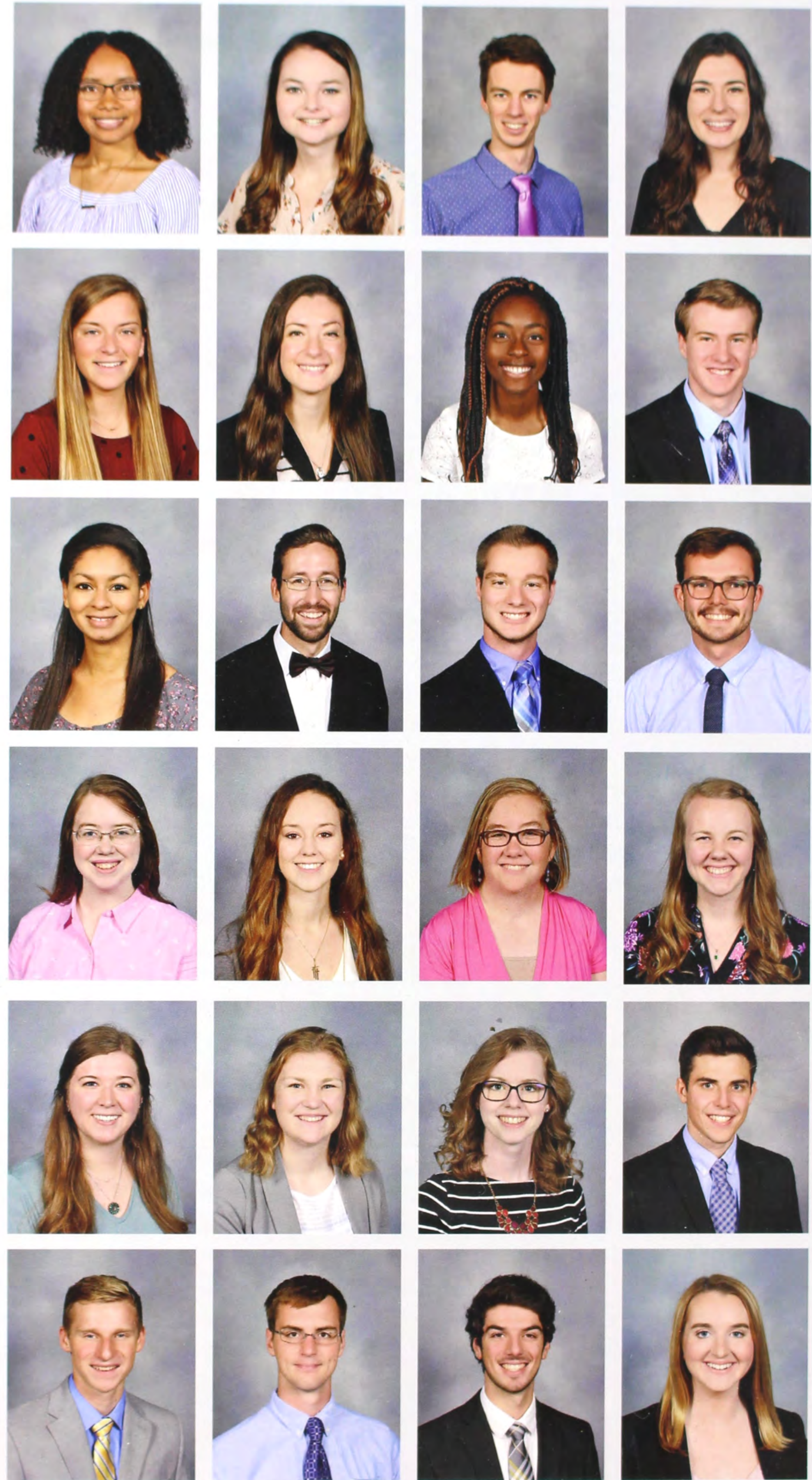
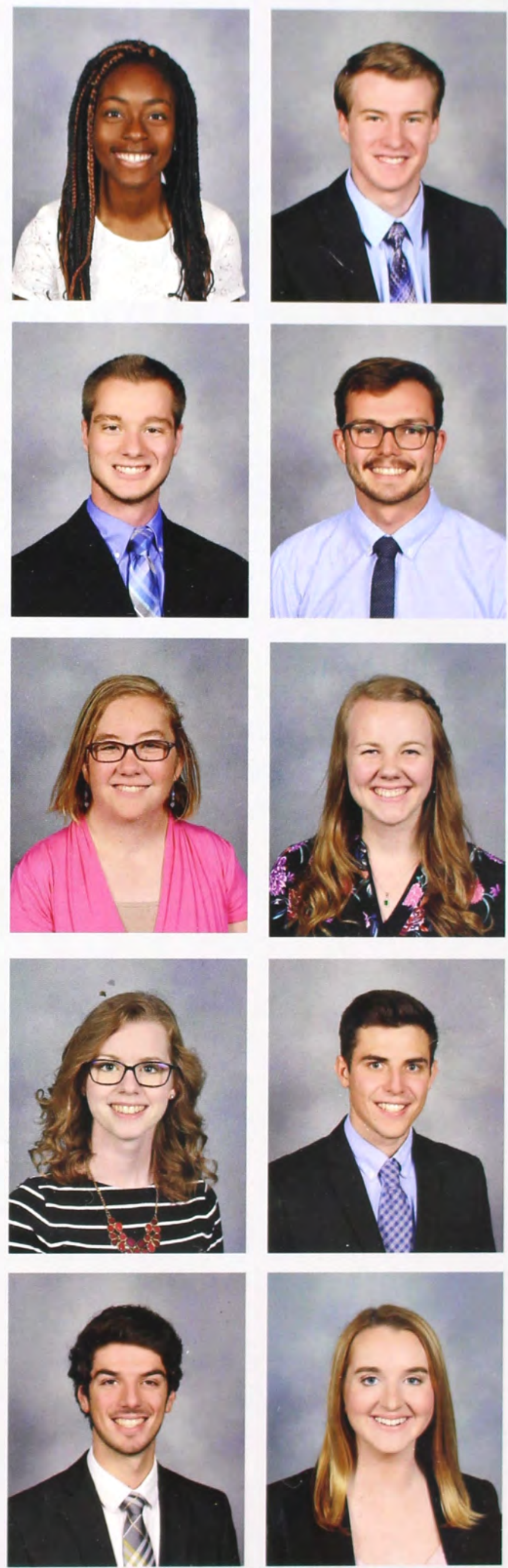
Donald Shade Sarah Shaw Ojeda Wesley Shawver Amiel Shearer

Brooke Shedden Presley-Peyton Shemelia Robert Shoultz Kelsey Shrum

David Sinkonis Brandon Slifer Jacob Snellenberger Eric Souder

Nicole Spencer Haley Spurgeon Jennifer Stafford Christiana Stearns

Natalie Steenwyk Nathaniel Steiner Joshua Stephen Megan Stevens

Lauren Stieferman Abigail Stratman Katie Struble Megan Stuart
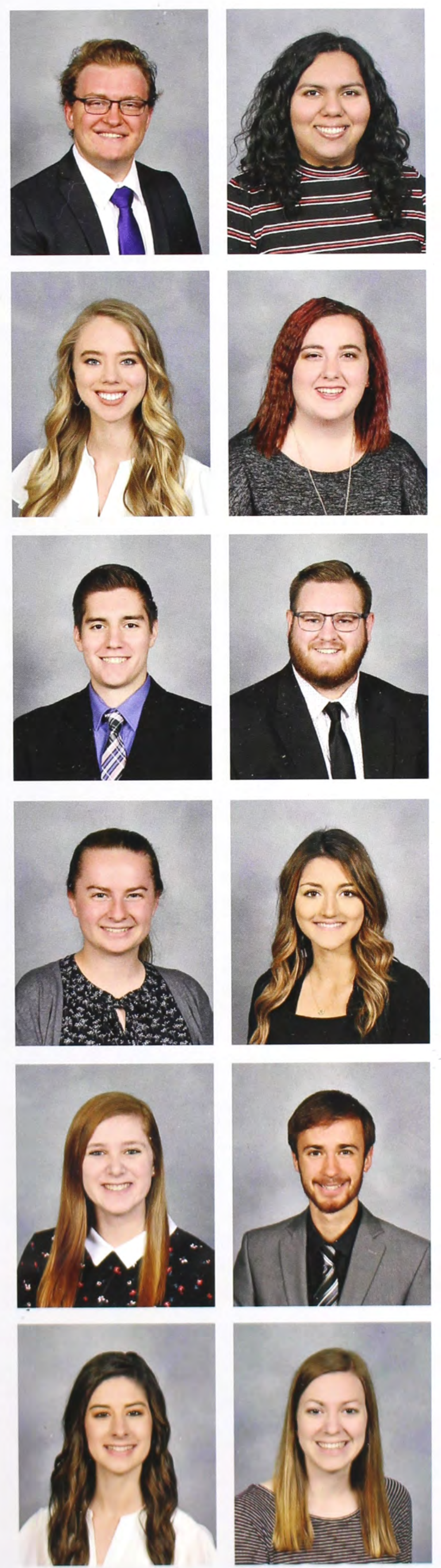
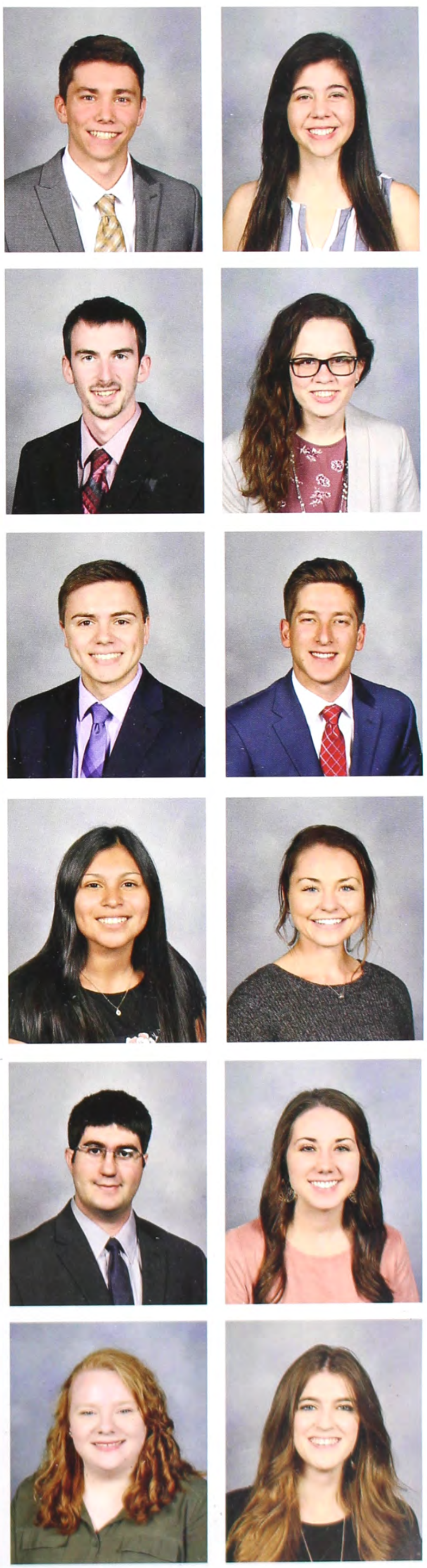
Joann Su

Alethea Surland

Daniel Swank

Micah Switzer

Clay Symington

Milo Tanner

Anna Thayer

Marissa Thompson

Logan Tolsma

Noah Townsend

Karley Trow

Olivia Troyer

Hayley Ttrout

Shannon Tyms

Jessica Ulloa

Timothy Vander Have

Johannes Vandermeij

Aaron Vangeest

Chloe Vann

Nolan Vondracek

Mallory Waayenberg Rebekah Wallace Julia Wallenbeck
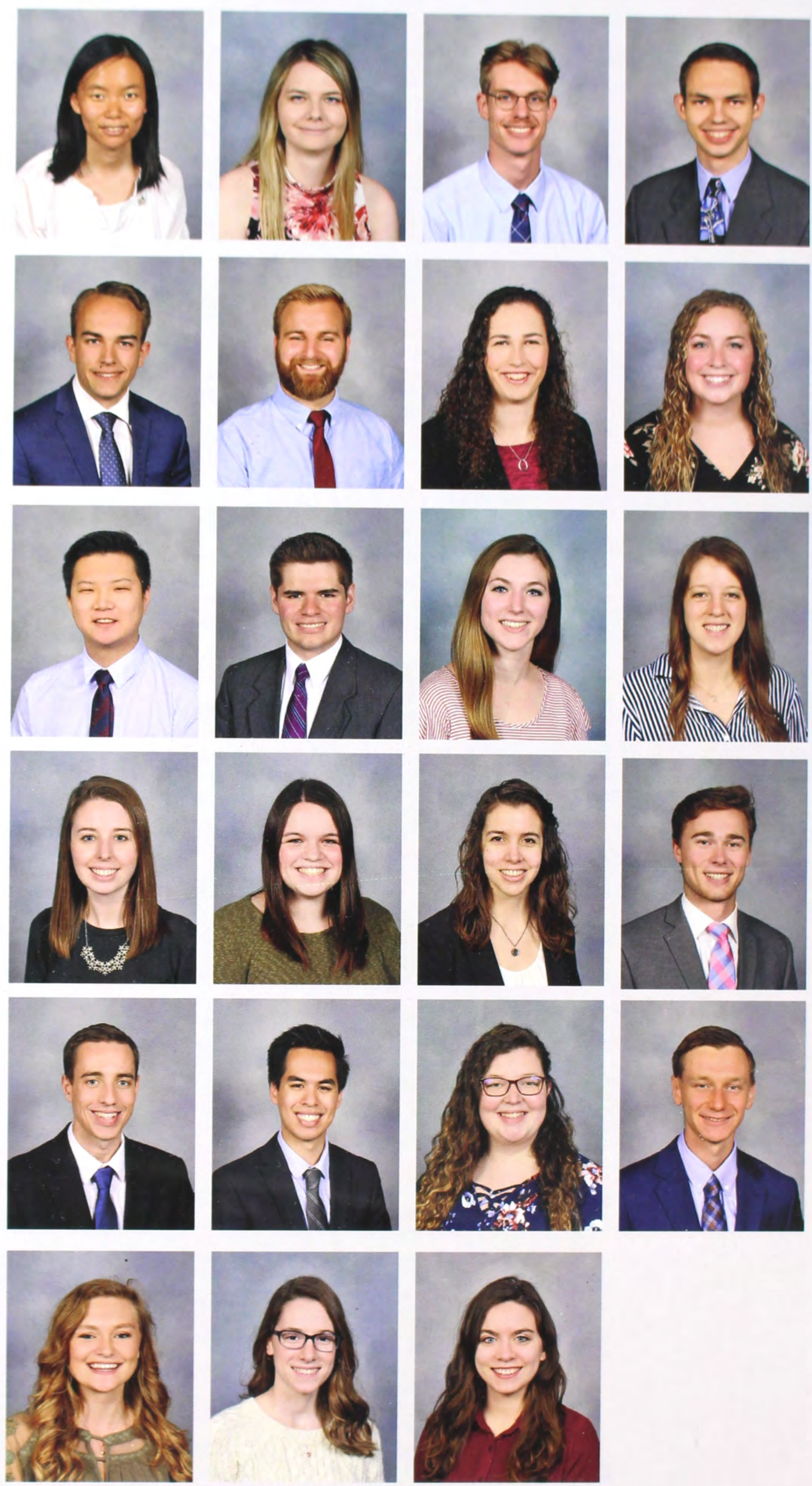
Daniel Waters Reese Watkins

Kayla Welch Jessica Westenberg

Embrissa Wingard Katie Wingert Rachel Wolthoff Ian Woodall
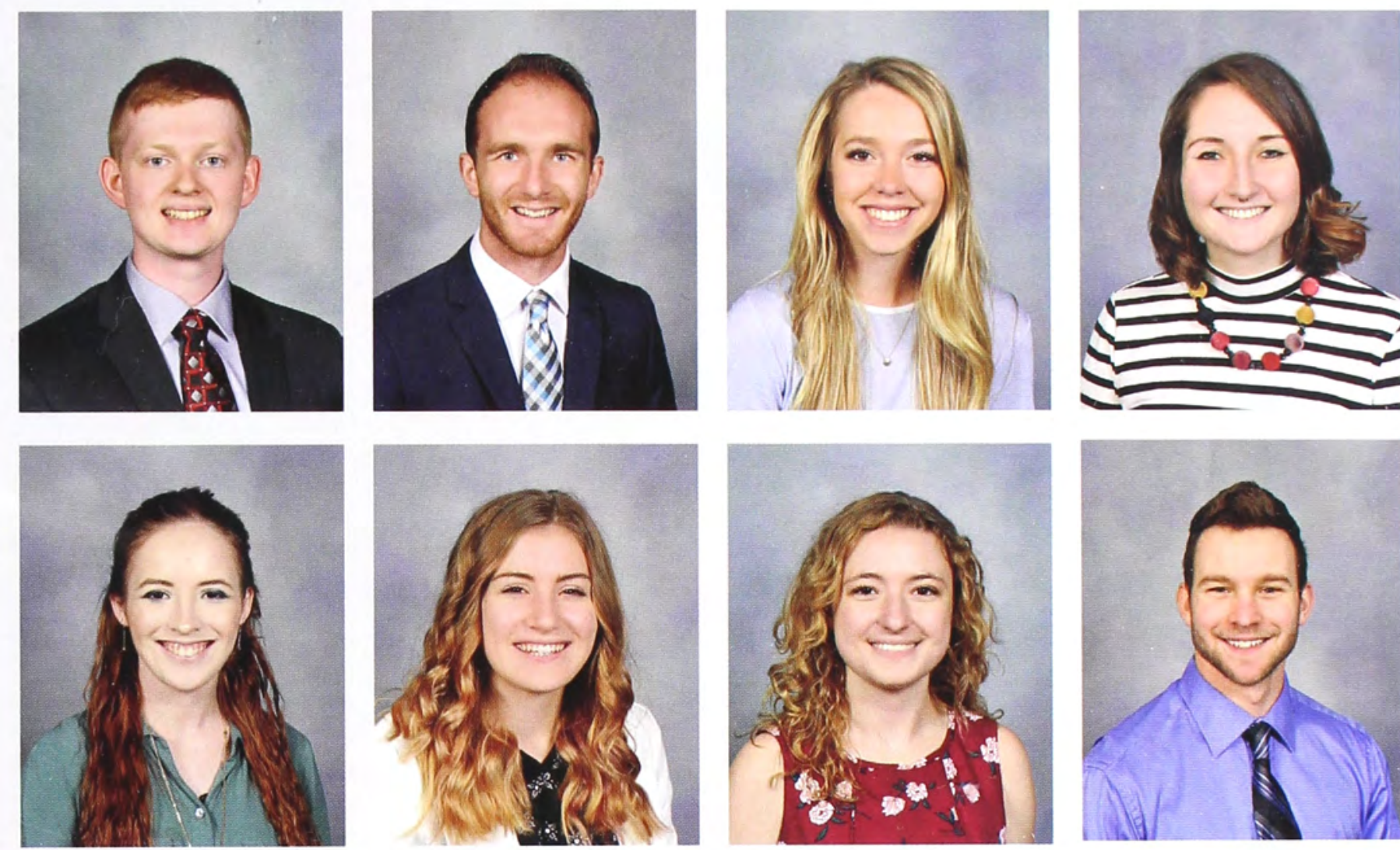

Rebeka Woodall Laura Woodman Alexa Wright Laura Wright
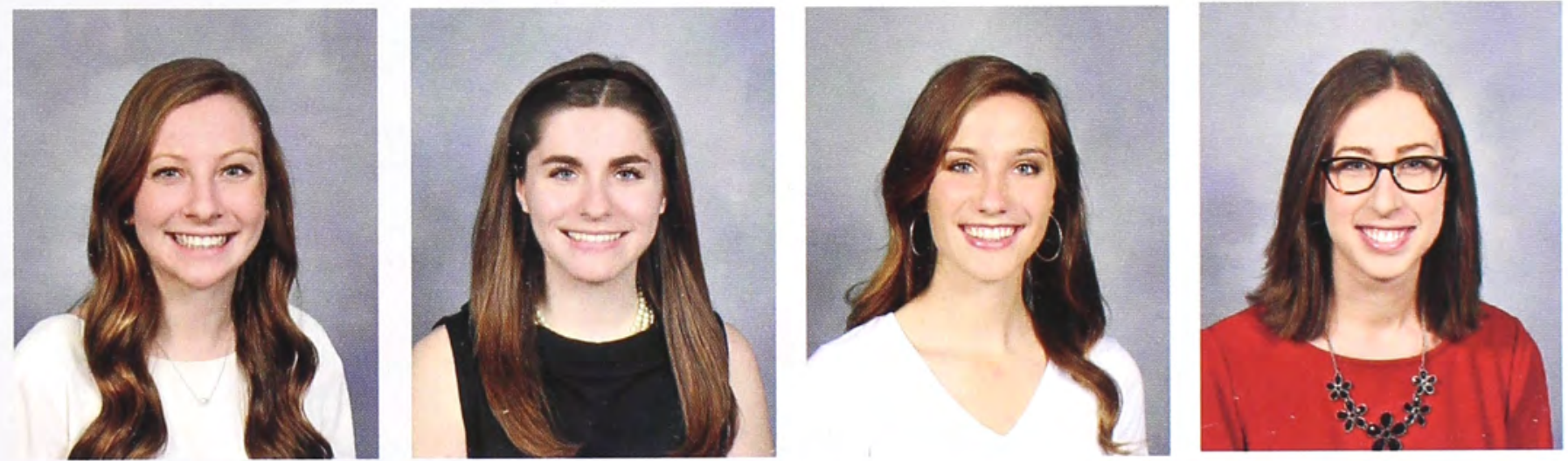

Ella Young John Young

Delaney Yutzy Hannah Zettlemoyer
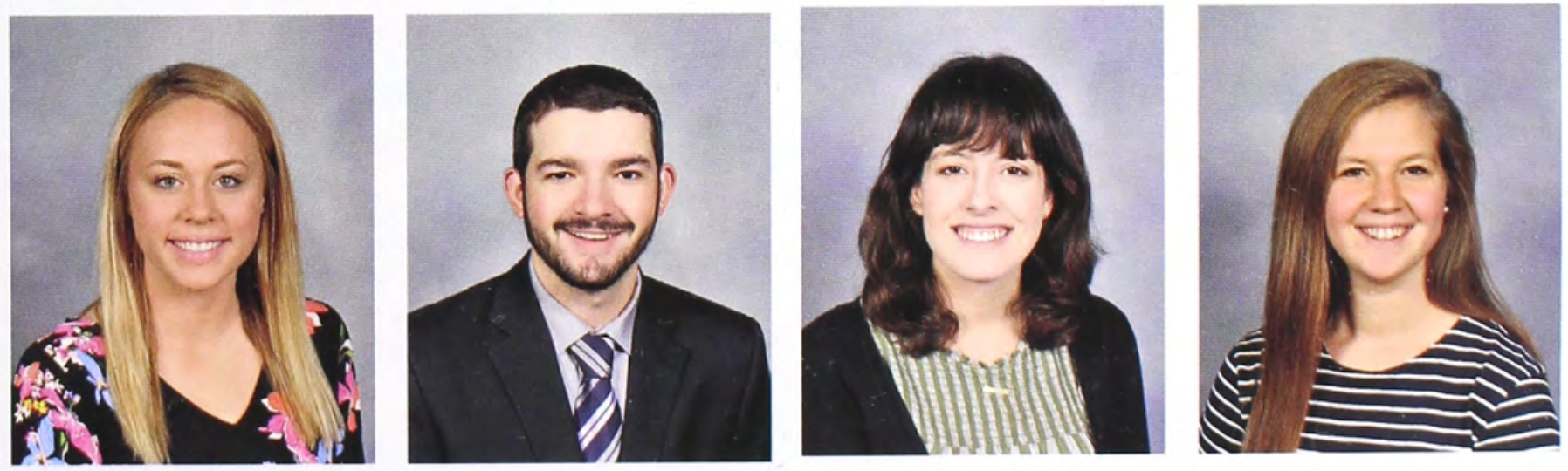

Lisa Zimmermann

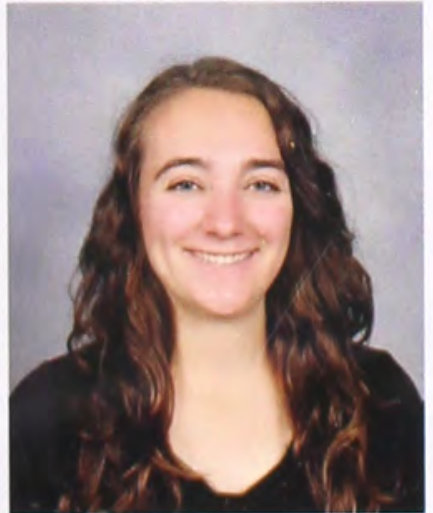




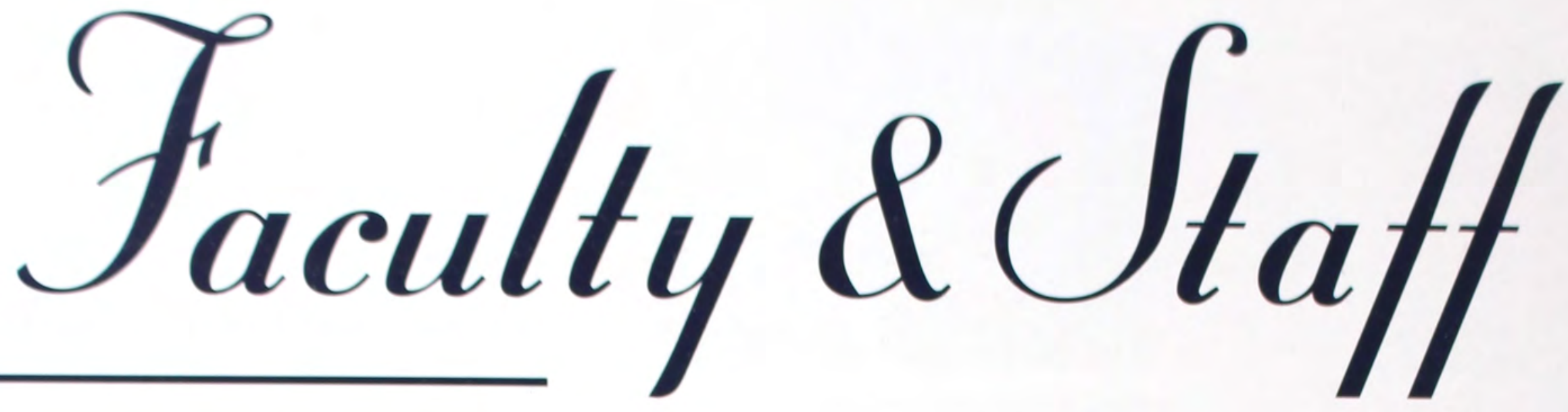

The faculty and staff are a vital piece of what sets Cedarville

apart from other universities. Faculty members taught their

students from a Christian worldview, preparing them to be

successful in their faith and their careers. Staff members ensured

that everything went smoothly on campus and assured that

students would have a positive experience throughout the year.

This year in particular, faculty and staff exhibited flexibility

in response to COVID-19 by learning to serve Cedarville at a

distance. They restructured their work so it could be completed

remotely, ensuring a smooth end to the spring semester.

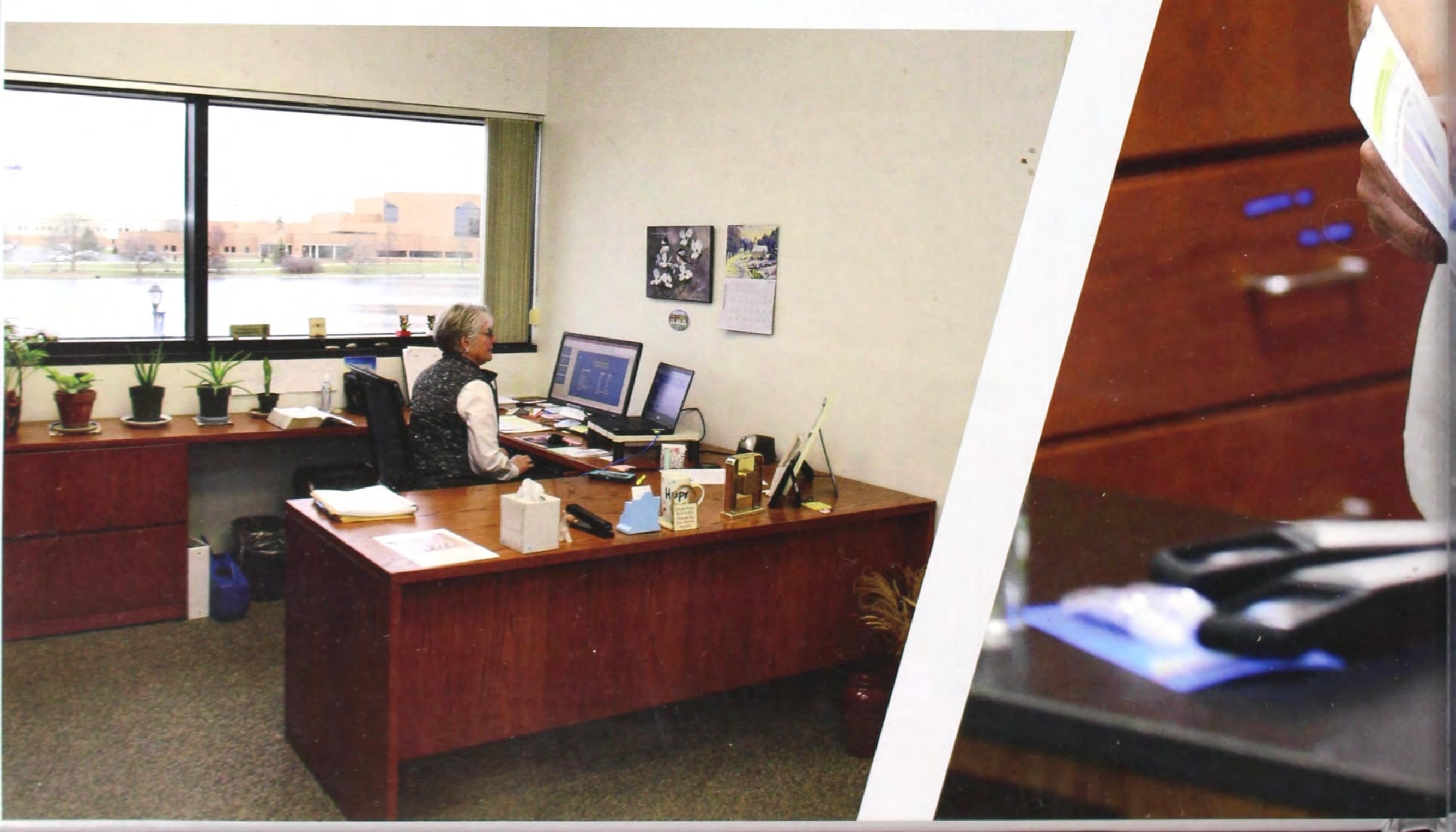




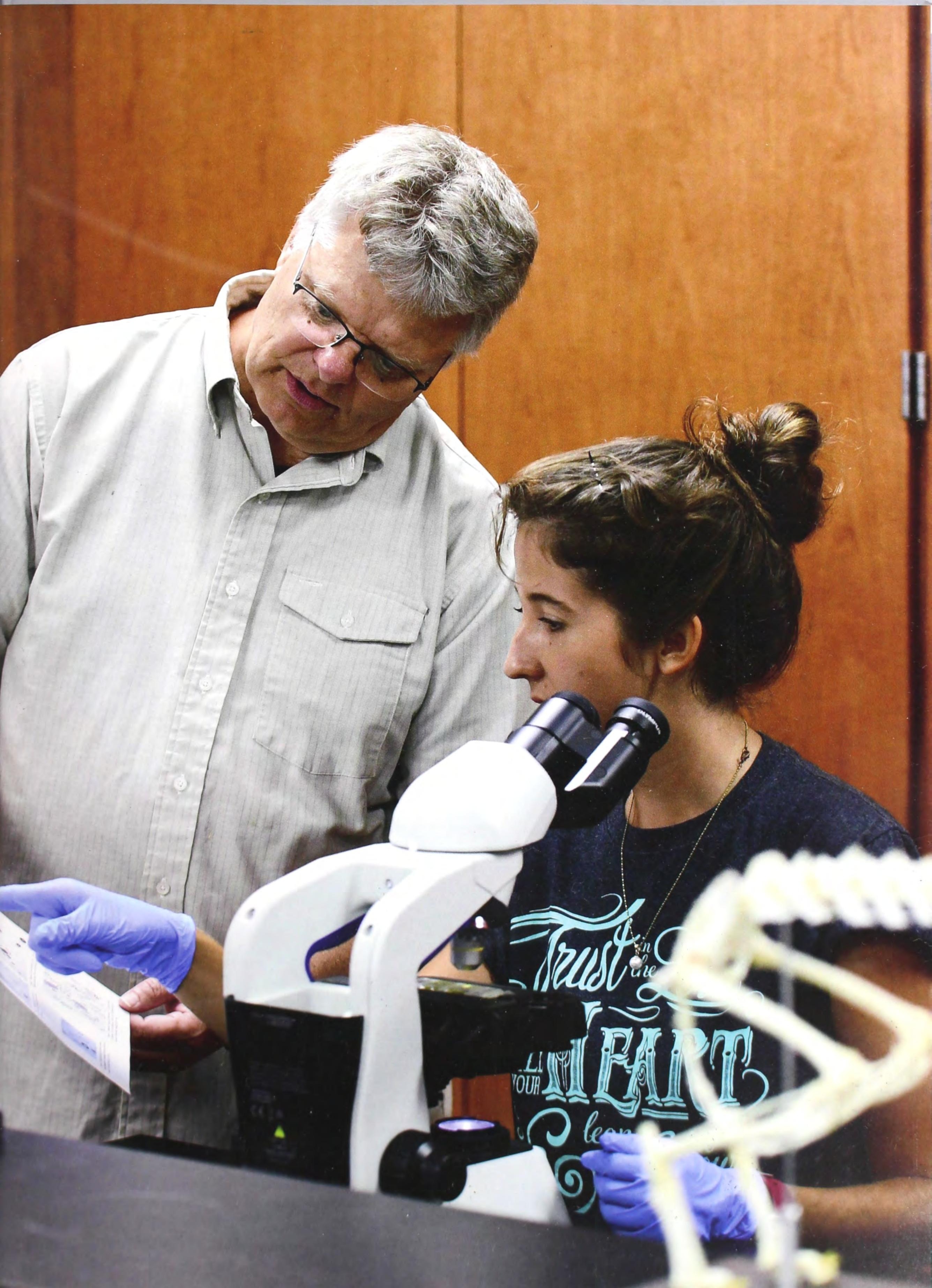




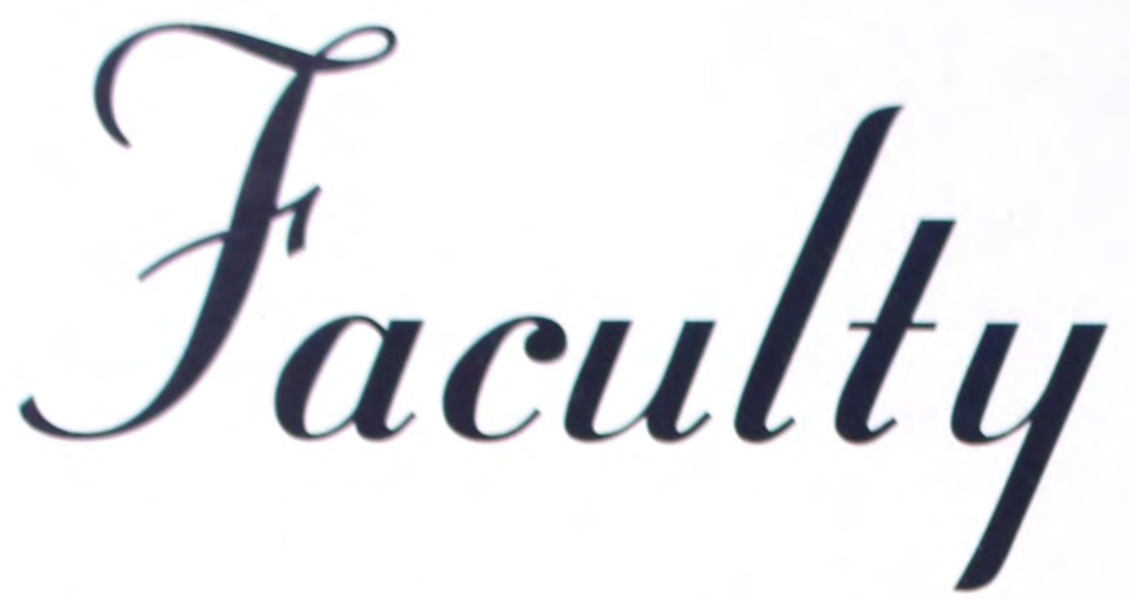

Faculty members spent their year pouring into students, preparing them for their careers. They even invited students to their homes and prayed for them, setting an example of community.
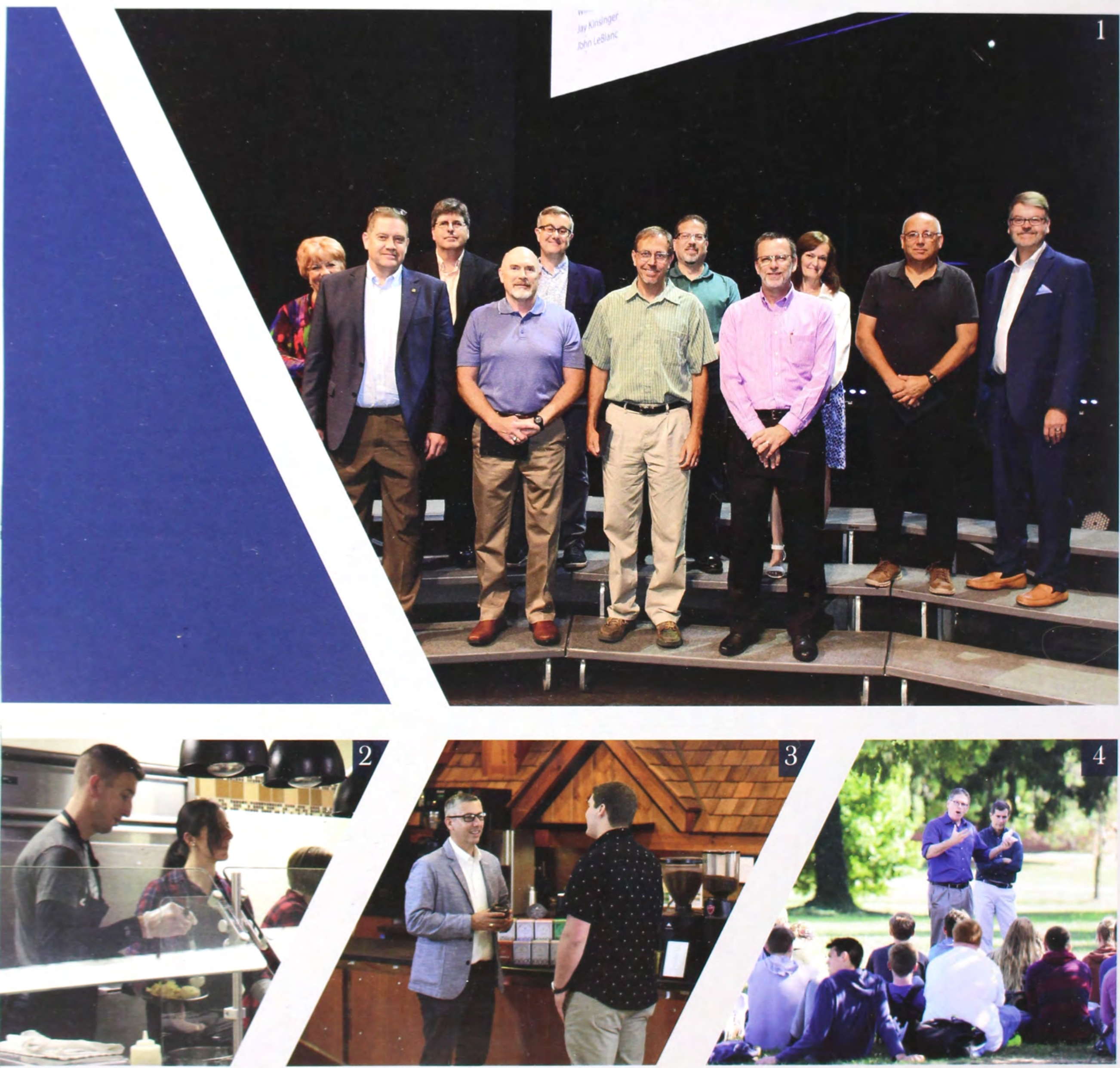


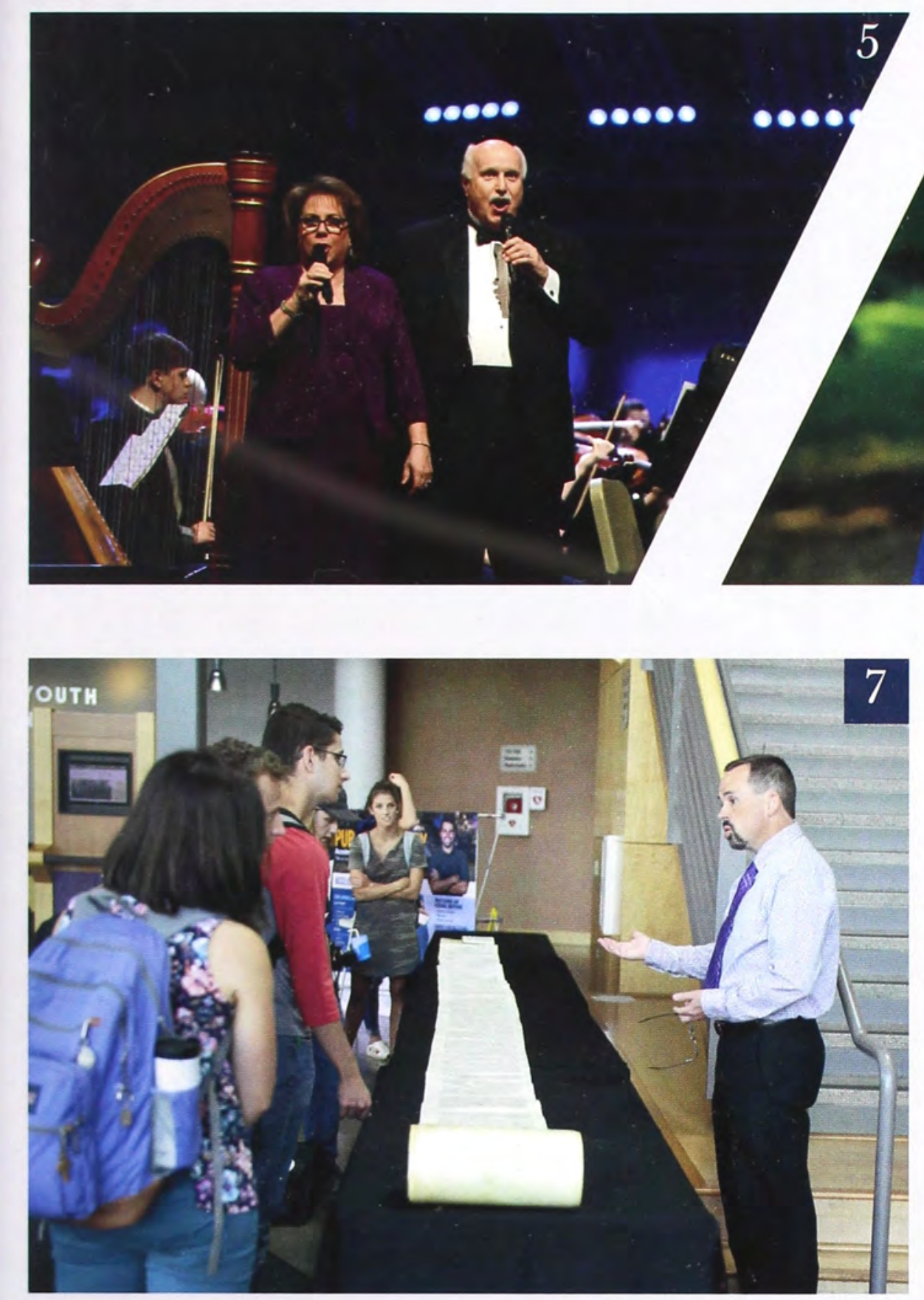

1. Faculty and staff stand together as they are honored for serving Cedarville for over two decades.

2. Dr. Jeremy Kimble and his wife serve students in the line at Chucks. This was during the midnight breakfast during Campus Christmas.

3. Dr. Dan Dewitt and Nathan Mumme talk outside of Rinnova.

4. Dr. Haymond and Dr. Austin teach outdoors about how creativity should be applied in business.

5. Dr. Beth Porter and Dr. Mark Spencer sing " 10,000 Blessings" at the Christmas Concert. This celebration has been a favorite for many years.

6. Dr. Sims and Dr. Rich make goofy faces at the camera during their department photo shoot.

7. Dr. Jason Lee explains the content of the Torah scroll to students. This scroll was given to the university last year.

Spring semester was interesting for faculty due to the coronavirus. Dr. Dan DeWitt experienced unexpected difficulties during this semester. "This year has been different in terms of teaching in that I've never taught an online course," DeWitt said. "Trying to find creative ways to connect with a class, once everyone was sent home from the pandemic, was difficult. I can't imagine what it was like for students." Even though there have been difficulties this semester, there have also been blessings. "My favorite memory this semester was the apologetics seminar that I did with Dr. Billy Marsh on the topic of Tolkien and Lewis' friendship,” DeWitt said.

"We had a great student show out and a wonderful conversation." During the end of the semester,

DeWitt learned about the importance of good leadership. "I would just say that it is a blessing to live in the same town as our Governor Mike DeWine," DeWitt said. "He makes decisions for our entire state, but he takes full ownership of his decisions and models leadership." 
There are many different positions on campus that

help the university run efficiently and effectively.

For example, the Admissions office gave prospective

students the opportunity not only to learn more

about the university, but also to see if it is the right

place for them. Alyson Punzi, a 2019 Cedarville

graduate, spent this school year working as the

Guest Coordinator at the Admissions office. "I

started my full time job at Cedarville the Monday

after graduation," Punzi said. "Despite the turnover

being fast, the transition from student to staff

was pretty easy. Eating lunch with friends who

were faculty or staff was an incredible source of

encouragement." Punzi also found inspiration from

the students she worked with. "My favorite part of

being on staff at Cedarville is by far getting to work

with students," Punzi said. "I get to see God at work

in their lives and be a part of regular discipleship

while I go about my job.”
1. The residence life team gathers outside to pose for a photo by the lake.

2. Dr. White awards all members of faculty and staff who have served for 5 years at Cedarville.

3. Career services staff smiles for a picture - as the head of career services, Jeffrey Reep puts it, "the BEST staff on campus!"

4. Kathy Miller talks with a student about the Cove and its services. The Cove is a great resource for academic needs and assistance.

5. Nat Biggs tells cybersecurity students about the computer equipment they have. The cybersecurity program was more recently added to the majors at Cedarville.

6. Kelly Hellwig sits down with a student in the Bible department. Kelly serves as an administrative assistant as well as an informant on graduate programs.

7. Aaron Cook leads a Bible study with the Discipleship Council members at his house. The $13 \mathrm{DC}$ members met weekly to then lead the 120 Discipleship Group leaders.
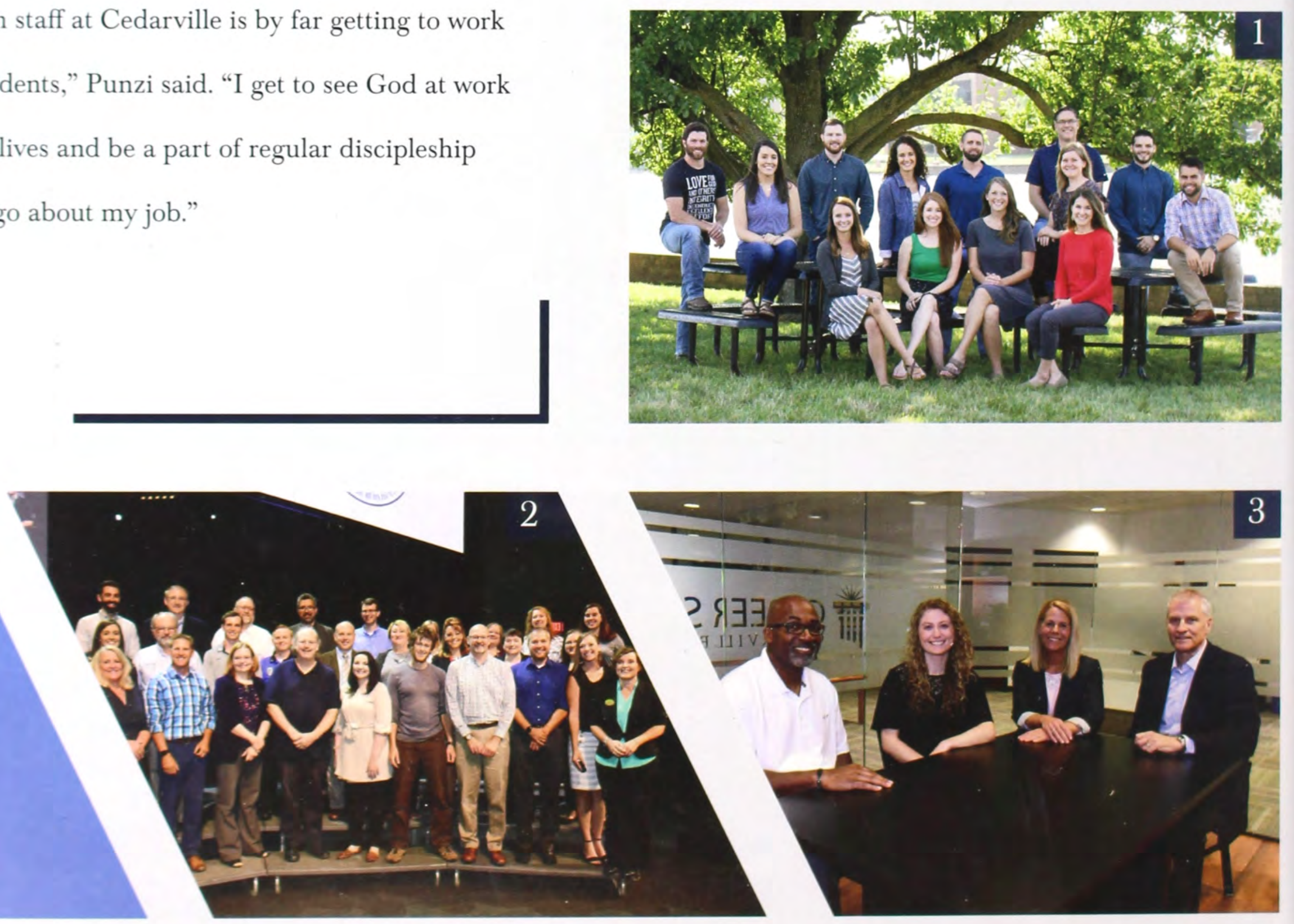


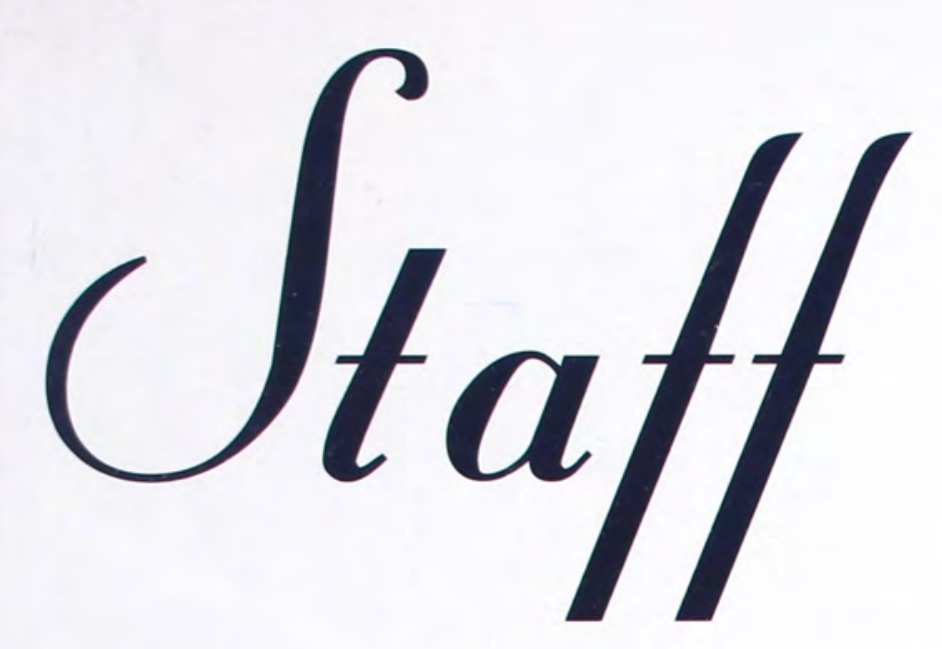

Between administration, residence life, athletics, advancement, business, marketing and communications, enrollment management, student life, and Christian ministries, staff members were the ones who made Cedarville run smoothly.
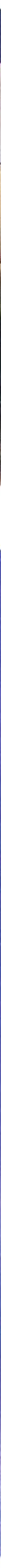

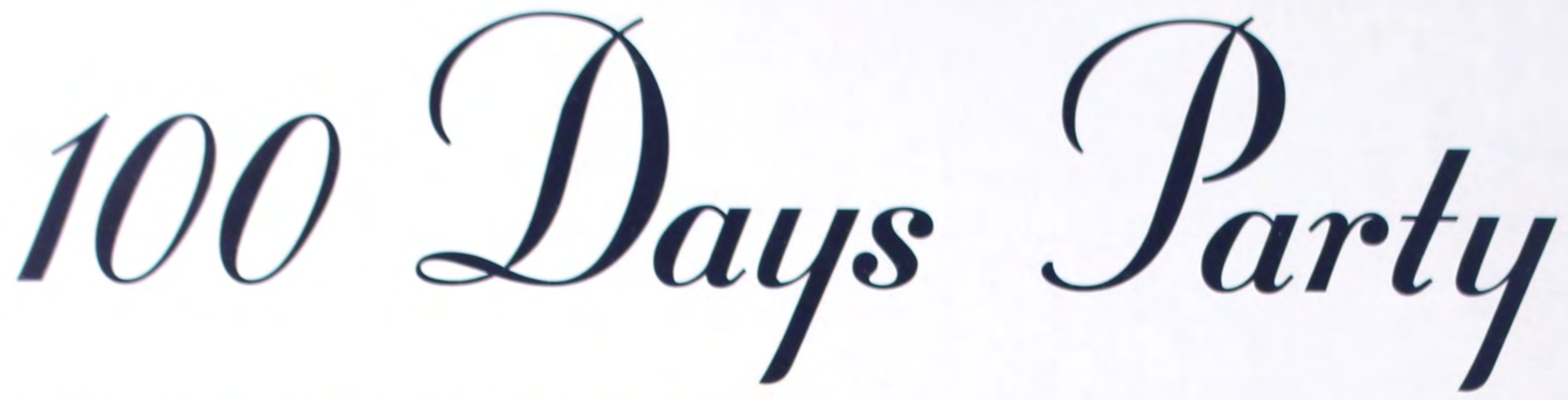

The 100 Days Party was held as a final farewell and night of nostalgia for the senior graduating class. From reconnecting with old friends to reminiscing about the infamous moments unique to the class of 2020, Seniors were able to enjoy an evening together again while the countdown begins to the end of their 1,000 days.
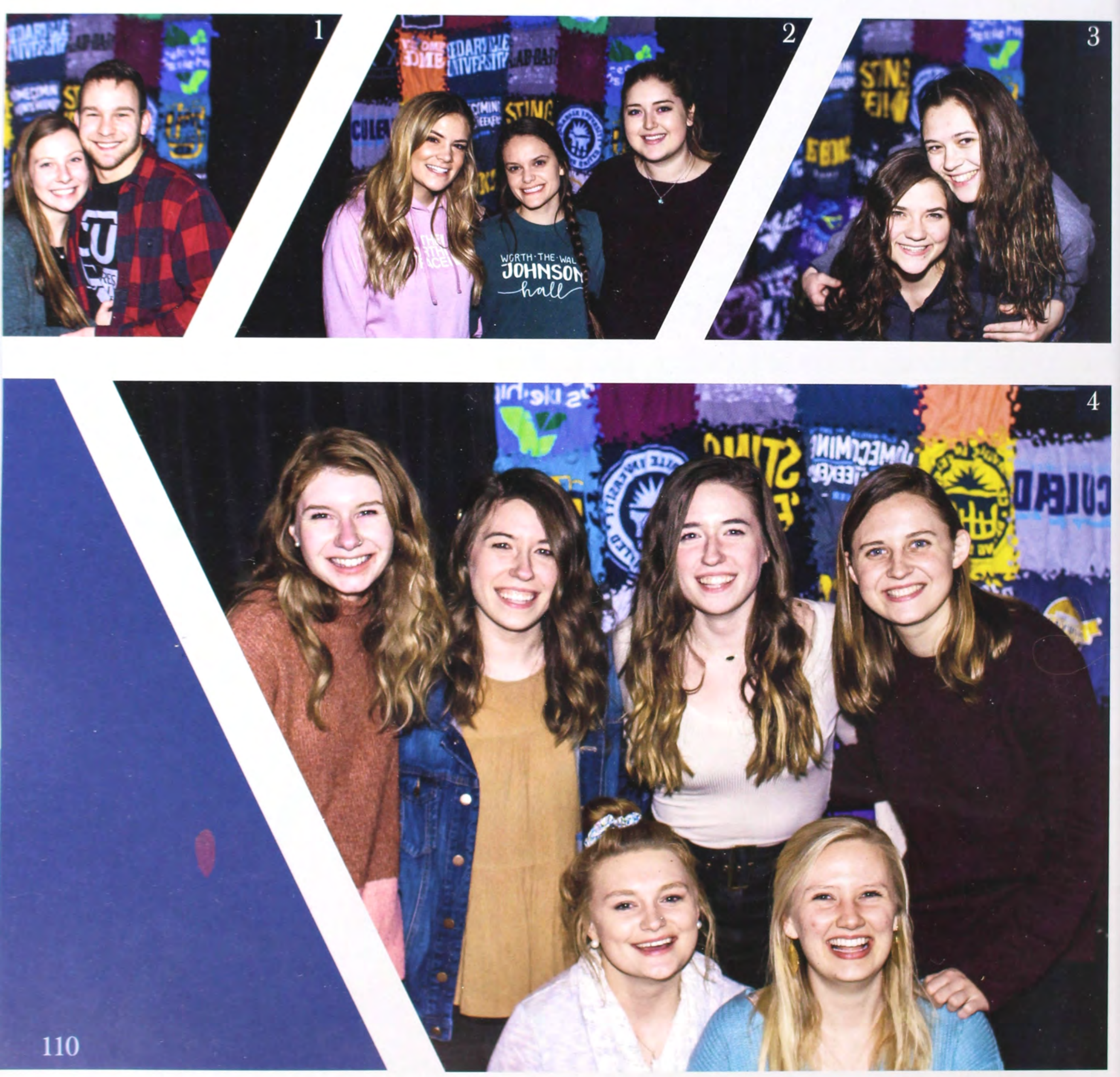

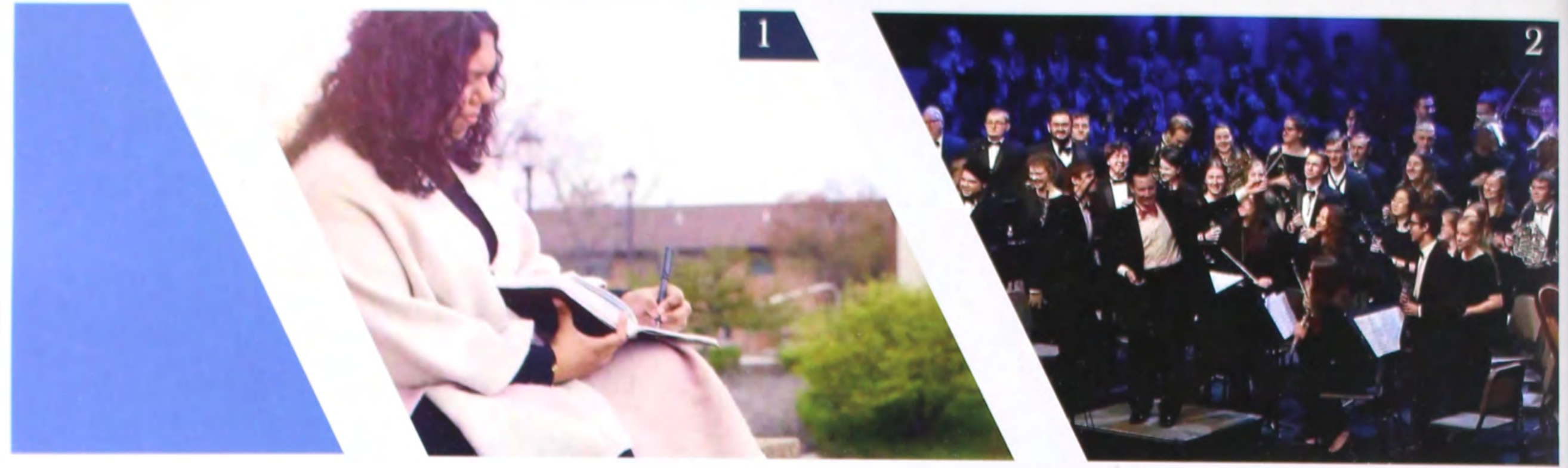

The beginning of 2020 was met with a variety of

hopeful expectations about what was to come. Yet

within months, everything changed due to the

COVID-19 pandemic. It was with a heavy heart

and many tears that Dr. White announced the rest

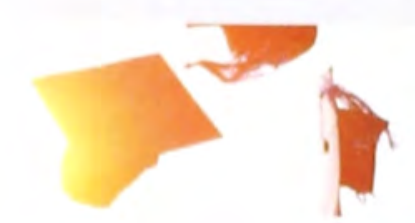

$\nabla$

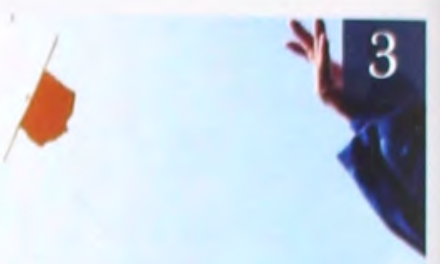

, [CLASS OF 2020]"

of the semester to be online through zoom. For the

graduating class of 2020, this announcement was

less than ideal. After four long years, a lot of money,

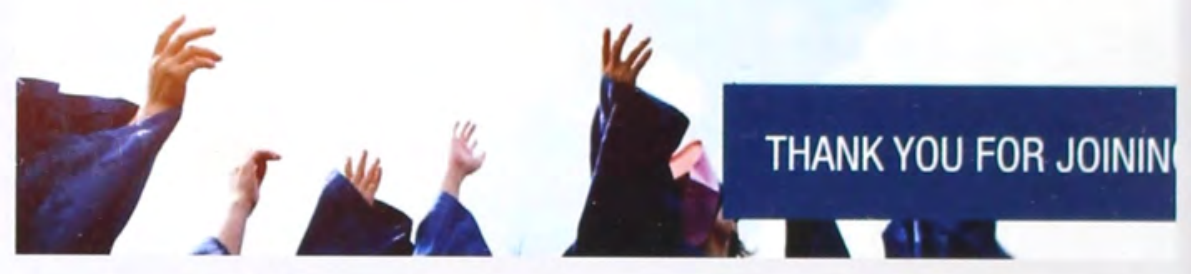

and anticipation for celebrating their degrees, this

seemed like an anticlimactic close. Many seniors

took to social media to express their feelings

regarding the turn of events. Some people focused

on what they were thankful for, even amongst the

trial. Others chose to caption pictures with Bible

verses and worship poems. Though everyone was

simultaneously dealing with the same uncertainty,

Cedarville still chose to honor and show love to their

seniors. A video was put together by faculty and

staff in replacement of the graduation ceremony.

Cedarville's beloved community grew closer

together as they surrounded the seniors, displaying

true intentionality in Christ-like love.

1. SGA President Sarah Shaw reflects on God's

steadfastness and the need to remain thankful in the midst

of life's uncertainty.

2. Dr. White joins the orchestra as 'guest conductor'

during the 20th anniversary of the Community Christmas

Celebration. :

3. The class of 2020 tunes into a pre-recorded video

for graduation. The video honored the senior class and

encouraged them in their endeavors.

4. The Cedar rock is painted for seniors, even after the students went back home.

5. Students worship virtually as a way to give thanks to God even in uncertain times.

6. Dr. White proudly announces the senior class of 2020 as official graduates.

7. Faculty and staff take intentional time to color posters and pose with their families, wishing graduates the best in their future endeavors. 


\section{Senior

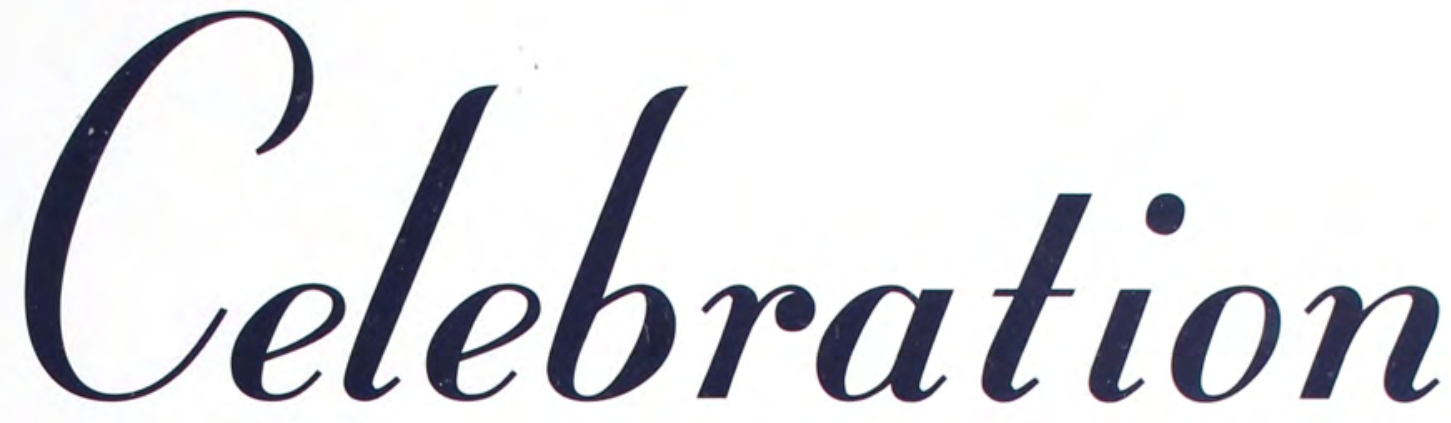

Though graduation did not go as planned, Cedarville found ways to make the milestone memorable for the class of 2020 .
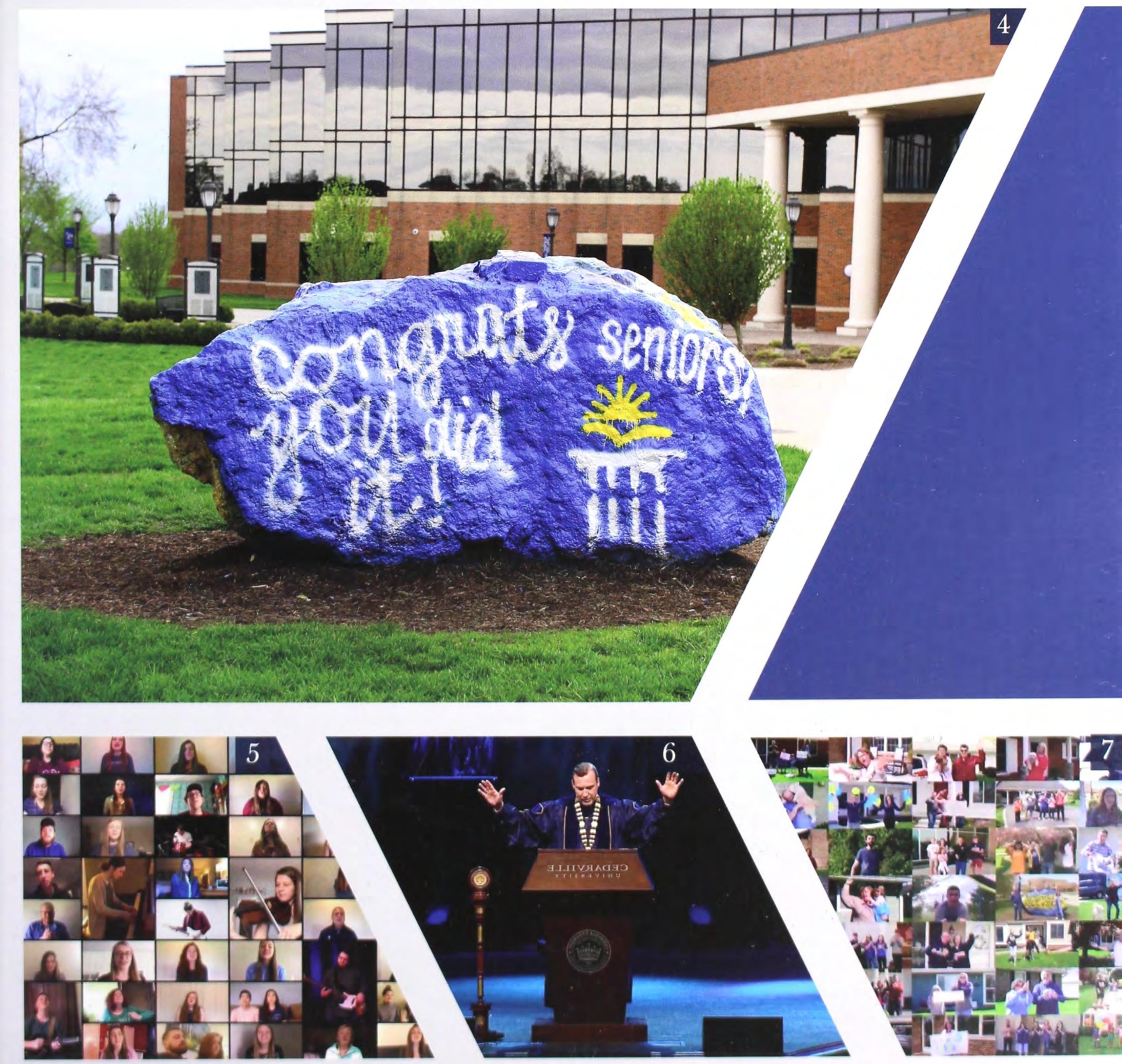


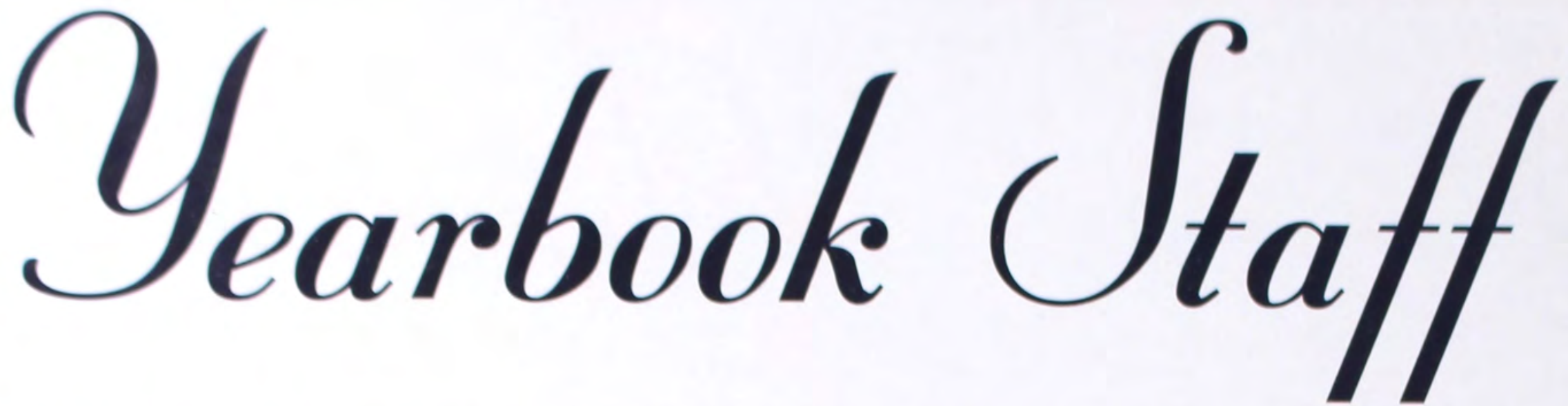

The Miracle Yearbook staff worked to capture memories throughout the year.

The team was comprised of photography, layout, copy, and editorial staff.

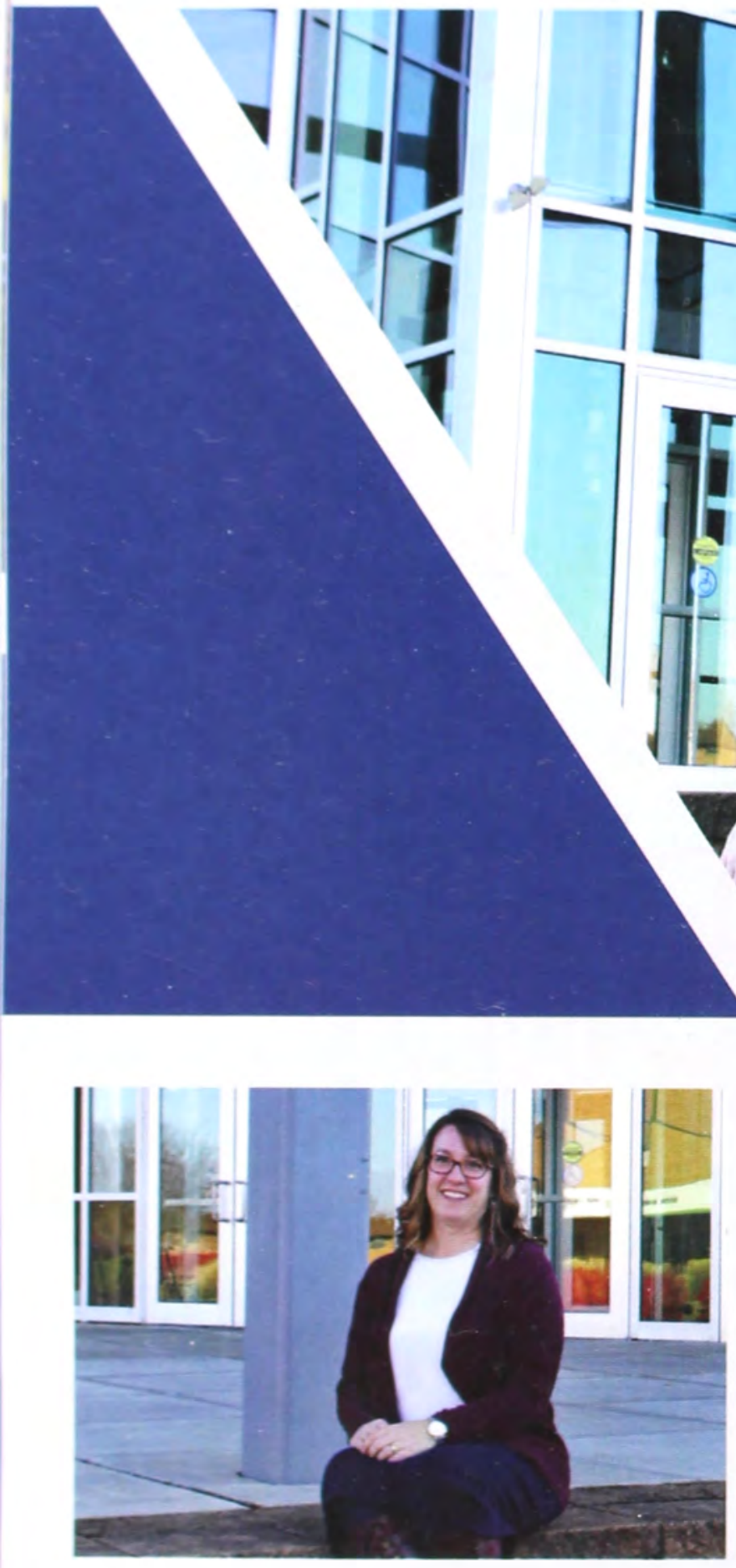

Cyndi Nlesser

Cynthia Messer, an Associate Professor of English, is the Yearbook Faculty Advisor. She provides the yearbook staff with support throughout the year.

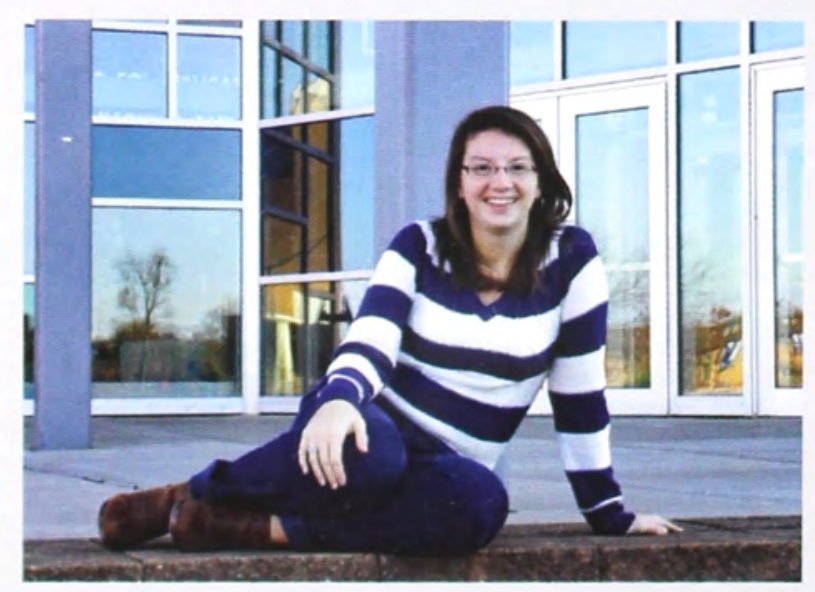

\section{Anna Kinq}

Anna King is a junior Management Major from St Augustine, FL. She acts as the Editor in Chief of the Miracle this year. She creates deadlines, proofs the yearbook, and oversees its production.

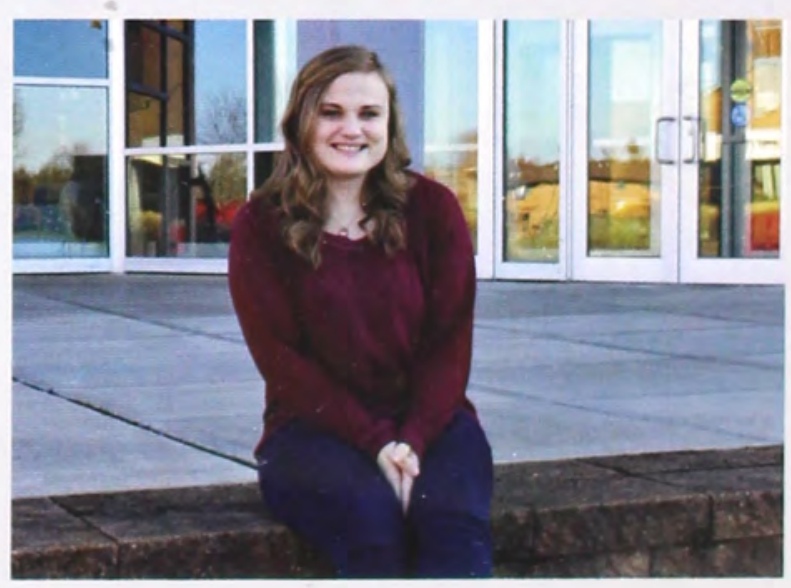

Goslyn Miller

Joslyn Miller is a Junior English Education Major from Wetmore, MI. She is the Administrative Assistant this year. Miller oversees the communications between the yearbook and departments on campus. 


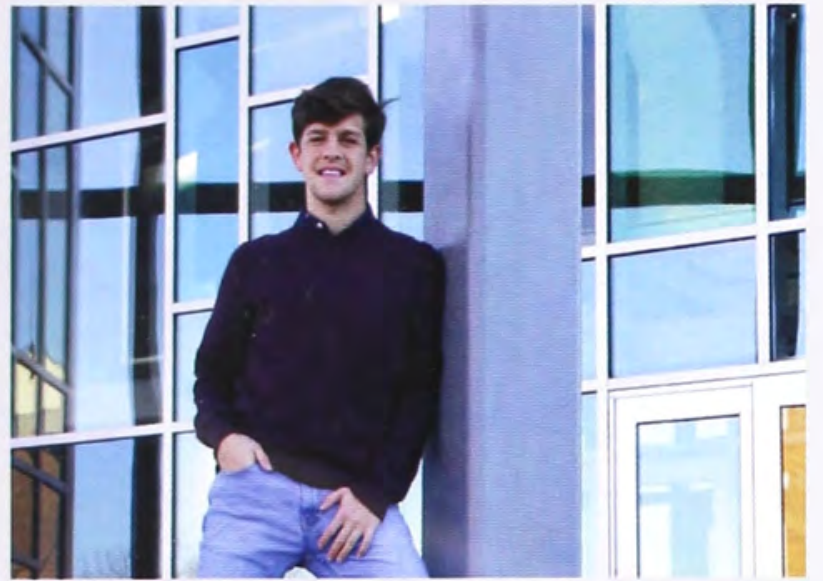

\section{$\mathscr{B}_{\text {en }} \mathscr{D}_{\text {eeter }}$}

Benjamin Deeter is a Junior Political

Science Major from Rimersburg, PA. He is a photographer this year and benefits the staff by taking pictures of on-campus events.

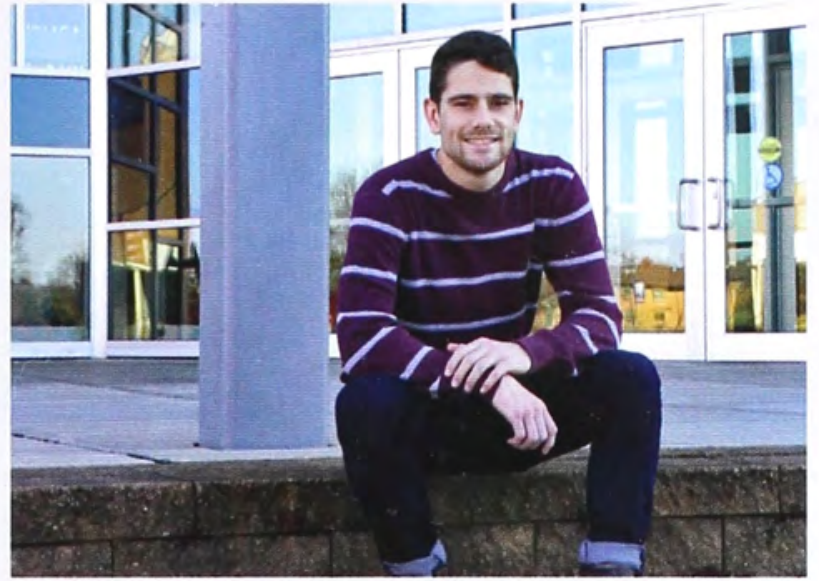

\section{Brady Esper}

Brady Esper is a Senior Youth Ministry and Christian Education Major from Newark, DE. He is a photographer on staff and takes pictures of many events throughout the year.

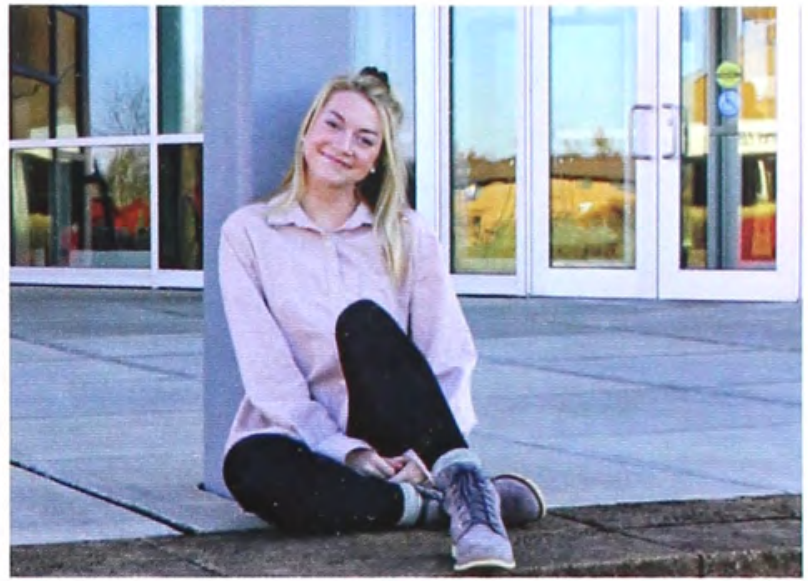

\section{Maddie Batka}

Madelyn Batka is a Junior Psychology Major from Glenview, IL. She is a photographer this year and takes pictures showcasing life on campus

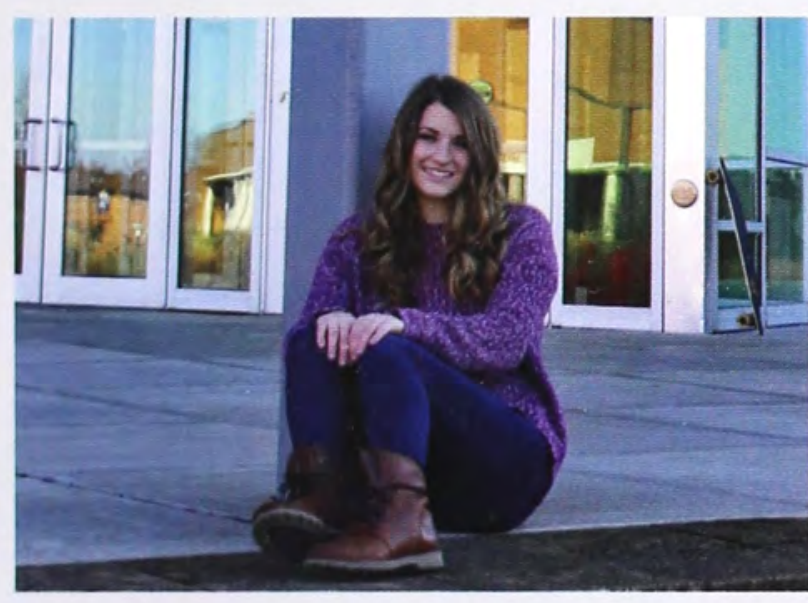

\section{Katie Linville}

Katie Linville is a Junior Electrical Engineering Major with a Minor in Biomedical Engineering from Cincinnati, $\mathrm{OH}$. She is the Photography Editor and leads the photographers on staff by delegating events and editing pictures for the layout team.

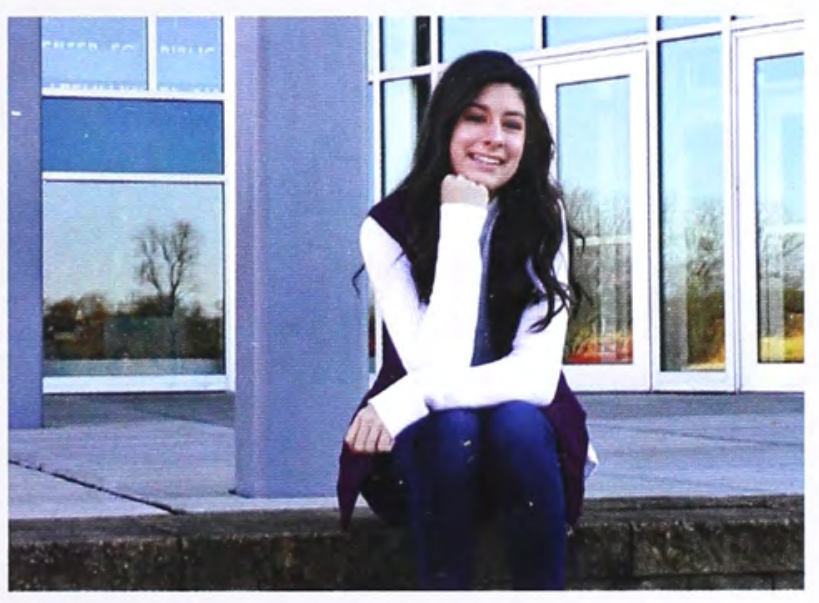

\section{Lauren Stieferman}

Lauren Stieferman is a Senior Visual Communications Design Major with a concentration in Graphic Design and a minor in Studio Art from St. Lewis, MO. She is a Co-Layout Editor who works with Ethan to design the pages and select pictures for the yearbook.

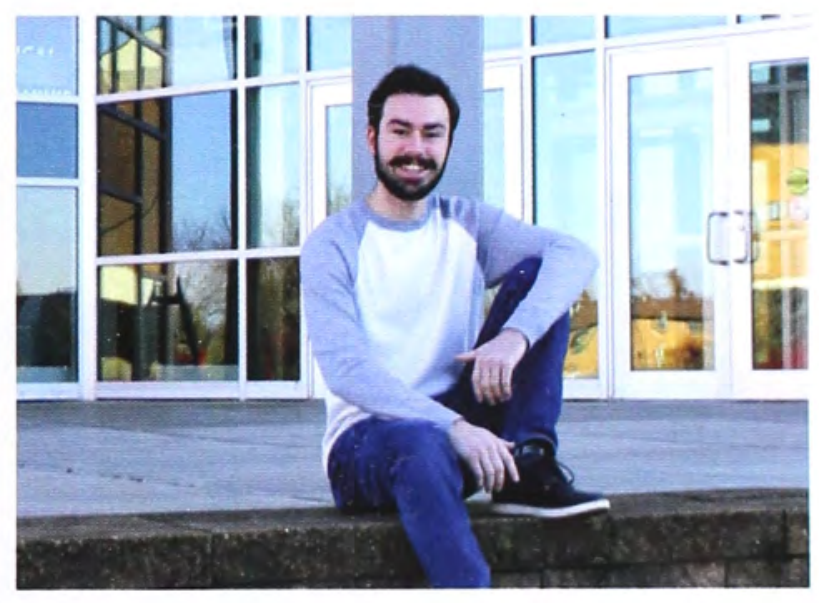

\section{Ethan Ooms}

Ethan Ooms is a Senior Communications major with a minor in Graphic Design from Wentzville, MO. He is a Co-Layout Editor and works with Lauren to select photos and design pages for the yearbook.

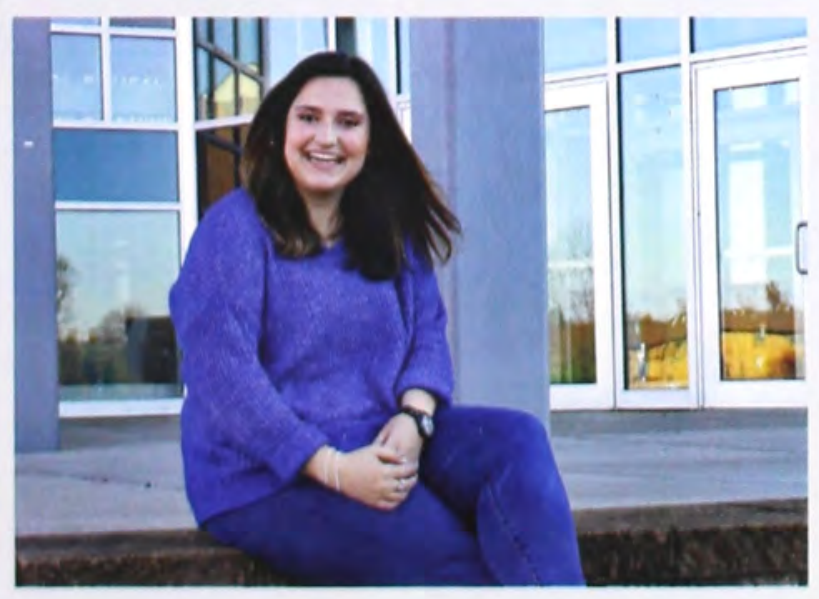

\section{Mallory King}

Mallory King is a Senior Marketing Major with a minor in Psychology from Powell, $\mathrm{OH}$. She is the Copy Assistant this year, which means she writes captions and stories throughout the book.

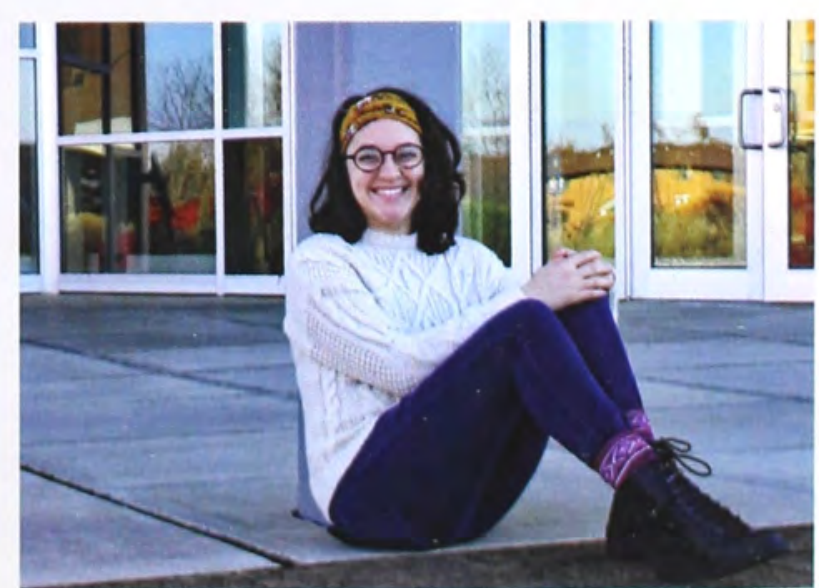

\section{Carissa Caples}

Carissa Caples is a Senior Professional Writing Major with minors in Honors and Women's Ministry from Des Moines, IA. She is the Copy Editor and helps write and edit content for the yearbook. 


\section{Letter from the Editor}

Dear Cedarville,

Wow what a year this has been! Ups and downs with some twists that no one could have ever expected. Before I say anything else, though, I want to take a minute to thank the team that has worked so hard to give you this book. Joslyn, our administrative assistant, thanks for doing all the things from emailing payroll to answering some odd emails...raiding the rice krispie treat box together every week was great. Lauren and Ethan, you are creative layout geniuses and I'm so glad you know what you were doing with InDesign...I loved getting to know you through team-building activities and, wow, does this book look good! Carissa, Mallory, and Maddie, the race to figure out who is in all the pictures never stops...haha. Thanks for all the hard work you did and all the hilarious stories you told in the office. Katie, our wonderful photography editor, somehow you fit us in amongst the hardest year in engineering. I'm glad you were on the staff, or we never would have seen each other even though we lived across the hall all year. Ben and Brady, I didn't get to see much of you, but you worked hard and gave us some great shots for the book...don't forget our office is your office anytime too! I hope each and every one of you has enjoyed being part of the yearbook staff this year. Cyndi, thank you for all you did as an advisor. You have always been available for the staff and have grown me and held me accountable this year. In some ways, I feel like I have a mom who is looking out for me on campus (in all the good ways!!), and for that I am truly grateful.

Our theme for this book was community, and this year our Cedarville community has been put to the test. We have felt community in a lot of great ways, like through prayer sessions and chapel and D-groups. But we felt like we lost it all in the coronavirus announcement. This community is special, and many of us won't ever get to come back as we graduate and move on to the real world. So, amidst all of the emotions, I ask that you look back and reflect over the past years you have been at Cedarville. Thank the Lord for the wonderful time you have had with the Cedarville family. Be glad for all the great things He has done while you were at Cedarville and for all the things He will continue to do in your life. No matter whether you are a freshman or senior, I encourage you to press on in your life, looking for opportunities to influence and build communities that look like Cedarville. Commit yourself to helping others realize the joy that we have when we live our lives amongst other believers that stand strong in Christ. Cedarville is a great place to learn, but there are people all across the world who need you to help experience the same Christian fellowship that we get the blessing of every day.

With love,

Anna, Editor in Chief

The LORD has done great things for us, and we are filled with joy.

Psalm 126:3

And let us consider how we may spur one another on toward love and good deeds...

Hebrews 10:24 


\section{Colophon}

\section{Publisher}

The 2020 Miracle Yearbook was published by Jostens, Inc. It was printed at their plant located in State College, PA. The Jostens representative was Donald Boyd, and the plant coordinator was Crystal Gault.

\section{Cover}

The cover is custom screen and is custome art designed by Ethan Ooms and Lauren Stieferman.

Photos by Scott Huck, Katie Linville, Maddie Batka, Ben Deeter, and Brady Esper.

\section{Cover}

The 2020 Miracle was printed with four color process ink.

\section{Design}

The 2020 Miracle was designed by Ethan Ooms and Lauren Stieferman.

\section{Theme}

The 2020 Miracle theme was a combined brainstorm of the editorial staff.

\section{Production}

The 2020 Miracle was produced on both HP and Apple Computers. Layouts were created using Monarch by Jostens. Programs inside Monarch include Adobe Indesign, Adobe Photoshop, and Adobe Bridge.

\section{Typography}

The heading font style used in this book is AYT Luke size 140 in regular style. The subheading font is AYT Baskerville at 13 pt size in regular style. The main body text font used is also AYT Baskerville at $11.5 \mathrm{pt}$ size in regular style

\section{Photography}

Photos were primarily taken by Katie Linville along with her photography assistants Maddie Batka, Ben Deeter, and Brady Esper. Benjamin Lucas provided photos for ICC. Several photos were taken by Cedarville University photographer, Scott Huck. Jim McAdams provided senior and underclass portraits.

\section{Inquiries}

The Miracle Yearbook office may be contacted for additional information about this book's production at:

Miracle, Cedarville University

251 N. Main St.

Cedarville Ohio 45314

(937) 766-4995

miracle@cedarville.edu 


\section{Closing...}

Ask pretty much anyone at Cedarville what their favorite thing is about living here, and they'll give the same answer: "It's the community." During our time as students, we started to repeat the same response. How could it be anything else? Cedarville distinctly differs from other universities in its community feel.

Over the course of this school year, we learned about what it means to live in community with one another. We lived, ate, praised Jesus, and worked with others from the same student body. We discovered what it was like to have professors and bosses that pray for us, believe in us, and want to make an impact in our lives. We created trendy charcuterie boards for birthday parties in our dorms' study lounges.

We went on short-term mission trips all over the world, and participated in long-term local ministry teams and discipleship groups. "Community" went from an empty word to our favorite part of our undergrad experience. We learned the joy of being given a sense of community, and the joy of fostering it wherever we go.

Our goal in creating this book was to show exactly what community means at Cedarville. We wanted to transport everyone back to the time when they were a college student. We know that life will change. We won't remember what it was like to be in college forever. Our goal was to give it a concrete representation we can look back on in 20 years to remember the beginning of our understanding of true, deep Christian community. Our hope is that it has served as a reminder of everything this year was, while also portraying the undercurrent of Christ's love and the fellowship between all believers that comes from being family through Him. 


\section{Index}

Acosta, Samuel

Adams, Joseph $\quad 90$

Adams, Leah $\quad 90$

Adewole, Joshua 90

Adkins, Avonlea 90

Adkins, Joshua 66

Agans, Garrett 90

Ahlborg, Shelby 90

Ahlgrim, Kimberly 17

Alecusan, Bethany 57

Alexander, Anthony 75

Allard, Anson $\quad 11$

Allinson, Jacob $\quad 52$

Anderson, Heidi $\quad 75$

Anglin, Isabel $\quad 75$

Anthony, Rose $\quad 57$

Ardrey, Madeline $\quad 75$

Armstrong, Isabelle 90, 111

Armstrong, McKenna90, 111

Atkins, Joanna $\quad 75$

Augustine, Kezia $\quad 75$

Aurand, Kaley $\quad 75$

Austin, Jon 107

Aviles, Micah 90

Ayala, Isaac 72

Baab, Sarah $\quad 75$

Bach, Alyssa 90

Bader, Emily $\quad 72$

Bailey, Brooke $\quad 7$

Bailey, Nathan $\quad 75$

Baker, Victoria $\quad 90$

Balk, Josiah 83

Ball, Ryan 90

Bandy, Matthew 75

Bannister, Laura 90

Barahona Maurer, Carlos 90

Barnes, Eric

35,90

Barnes, Kaitlyn

75

Barnes, Lorin $\quad 87$

Barnette, Rachel $\quad 90$

Bartlam, Leah $\quad 90$

Bartley, Curtis $\quad 75$

Batka, Madelyn $\quad 115$

Beach, Anna 44

Beal, Jordan 90

Beal, Kori $\quad 70,90$

Beal, Paige $\quad 75$

Bean, Sarah 87

Beauchemin, Julia 75

Beckman, Caroline 90

Beckmann, Daniel 90

Beckmeyer, Joel $\quad 11,90$

Belmont, Allison $\quad 35,75$

Ben, Justin $\begin{array}{ll}\text { Benton, Chloie } & 90 \\ \text { Bequillard, Chloe } & 90\end{array}$

Bergan, Carrie-Grace 91

Bernhardt, Lauren 35

Beste, Kylie 91

Betcher, Joshua 91

Biggs, Nathanael 108

Bishop, Lindsey $\quad 87$

Bitner, Andrew 91

Black, Brandon 11, 75

Blank, Elisabeth $\quad 26,91$

Blenis, Danielle $\quad 75$

Blunt, Jason 83

Boccacci, Madison 52

Boesch, Alexander 75

Boggs, Gabriel 29, 36

Bolds, Gillian 91

Bolender, Isabelle 63

Bonenberger, Keith 75

Bowser, Mitchell 83

Boyer, Cassandra $\quad 51,91$

Boyle, Megan $\quad 87$

Bradley, Cora $\quad 75$

Bradley, Lydia 26

Bradley, Parker $\quad 87$

Brads, Clinton $\quad 75$

Brady, Karina $\quad 91$

Bragg, Gabrielle $\quad 75$

Brammer, Cassidy 75

Brandes, Claire $\quad 75$

Brandon, Mimi 91

Brethauer, William 83

Bretz, Zachary 91

Brewster, Timothy 72

Brocker, Michael 91

Brooks, Wesley 91

Brown, Austin 68

Brown, Joshua $\quad 66$

Brown, Kelly $\quad 16,91$

Brown, Nathanael $\quad 75$

Brown, Veronica 70

Brubaker, Sarah $\quad 75$

Brubaker, Zachary $\quad 75$

Bruggeman, Morgan 75

Bryant, Jonathan 91

Bryant, Lincoln 83

Bryant, Morgan 83

Bundy, Joshua $\quad 87$

Burcham, Charlotte 7

Burd, Analice $\quad 91$

Burgess, Emma 91

Burket, Grace $\quad 91$

Burmeister, Kip 91

Burns, Brian 47

Burns, Meghan 72

Burr, Abigail 7

Burton, Claire
Butts, Marie $\quad 91$

Byerley, Jack 91

Byerley, Kearsten 91

Bynum, Delaney 83

Byrd, Gabriel $\quad 75$

Byrum, Zachariah $\quad 87$

Caldwell, Holly $\quad 91$

Camacho, Natasha 8

Caples, Carissa $\quad 91,115$

Carr, Mitchell 44, 47, 83

Carrico, Caleb 66

Carson, Bethany 92

Castle, Joshua $\quad 75$

Cater, Kristina $\quad 92$

Chairvolotti, Madeline

Chambers, Sierra 83

Chapa, Benjamin 92

Chapman, Kelsey 69

Chevrette, Eric $\quad 92$

Childers, Ashley 92

Chow, Shannon 51

Chow, Stephen $\quad 75$

Christen, Brandon 92

Christiansen, Grace 92, 111

Cina, Landon 87

Cissel, Colson $\quad 52$

Clark, Chad 92

Classen, Trent 58

Cleverley, Michael 75

Cline, Kristyn 92

Cline, Noah $\quad 68$

Clingenpeel, Jason $\quad 75$

Clingenpeel, Jordan 92

Cochenour, Holly 92

Cohea, Garrett $\quad 75$

Colburn, Janessa 75

Cole, Olivia $\quad 50$

Colgan, Sarah 47

Colon, Beka 43

Colvin, Emilie $\quad 75$

Conaway, Kayleigh 75

Cook, Aaron $\quad 108$

Cook, Miriam 75

Cook, Theodore $\quad 75$

Coon, Olivia $\quad 92,111$

Cooper, Micayla 92

Cope, Austin $\quad 75$

Copeland, Samuel 76

Cornwall, Evan 92

Counts, Joshua 83

Coutsouridis, Stephanie

Coviello, Paul 92

Cox, Rachel $\quad 76$

Creekmur, Connor 92

Crisi, Jackson 83

Cross, Trevor 58, 66

Cunningham, James 76 
Cunningham, Lauren 76

Curran, Jacob $\quad 83$

Curran, Joshua $\quad 83$

Custer, Luke $\quad 72$

Cvammen, Rvan 64

Cimbalak, Conlan 8

Czuzewski, Jessica 92

D'Anna, Joshua 92

Dakanay, Hannah Cayla

Dalton, Parker $\quad 47$

Daugherty, David 52

Davis, Bethan 47

Davis, Elizabeth $\quad 83$

Davis, Ellen $\quad 76$

Davis, Megan 44

Davis, Noah 87

Deberny, Luke $\quad 76$

Decker, Joshua 83

Deeter, Benjamin 115

Degarmo, Kenneth 76

Delamarter, Mallory 76

Denen, Luke 87

Derochie, Nathaniel 87

Derochie, Noah $\quad 76$

Deveney, Justice $\quad 76$

Devore, Michael 76

Dewitt, Daniel 30, 107

Dibble, Brooks $\quad 72$

Dibert, Timothy 83

Dickerson, Jared 92

Dickson, Stephanie 20,83

Diller, Bradley 83

Dissinger, Annalyse 76

Dobson, Natasha 83

Doerstling, Ethan $\quad 76$

Doub, Austin 92

Downey, Fiona 83

Dray, Danae $\quad 19,92$

Driver, Brianna 72

Duncan, Maryssa 76

Dunham, Hannah 76

Dunning, Abigail 76

Dupree, Connor 36

Durst, Bryson 83

Dye, Isaac

26, 92

Dyer, Nathan

Dykema, Delaney

Dykema, Denise

Eby, Logan

Edris, Melanie

Edsell, Abigail

Edwards, Anna

Edwards, Jordan

Eiginger, Kara

Eisman, Micah

Elder, Susan

Eles, Payton
Elgersma, Rita

Elkin, Amanda $\quad 93$

Ellis, Kaily $\quad 93$

Ellis, Lauren $\quad 35$

Ellis, Laurin $\quad 76$

Ellis, Rebekah $\quad 83$

Ellis, Victor $\quad 76$

Elmers, Julia $\quad 87$

$76 \quad$ English, Josiah 76

Enloe, Abigail $\quad 87$

Ensminger, Kristen 83

Esper, Brady $\quad 115$

Espling, Anna $\quad 93$

Estepp, Patrick 62

Estes, Kenan $\quad 51$

Evans, Abigail $\quad 65$

Evans, Joseph 12

Everswick, Rachelle 87

Fark, Lindsey $\quad 76$

Farley, Kristen $\quad 93$

Farlow, Angela $\quad 87$

Faro, Brett $\quad 56$

Farrand, Skyler $\quad 52$

Farris, Colin $\quad 76$

Farynyk, Rachel 93

Fawcett, Madelyn 93

Feathers, Claire $\quad 93$

Ferguson, Brittany 87

Ferguson, Faith $\quad 83$

Fernandes, Guilherme

Ferris, Elizabeth $\quad 93$

First, Hannah 93

Fischer, Hope $\quad 93,111$

Fisher, Cole 83

Fisk, Micah $\quad 76$

Flaugher, Arica $\quad 69$

Flener, Hadley 93

Flint, Kaitlyn 93

Folkert, Marissa $\quad 76$

Folkerts, Thomas 83

Ford, Serena $\quad 76$

Foster, Alizabeth $\quad 76$

Foster, Haley $\quad 87$

Fought, Rhyan $\quad 76$

Fourman, Kelly $\quad 76$

Fowler, Tayana 93

Fox, Preston $\quad 76$

Fraser, Bethlehem $\quad 76$

Frazier, Olivia $\quad 76$

French, Alexandra 87

Fretwell, Andrew $\quad 93$

Frye, Rachel 93

Frye, Ryan $\quad 70$

Gabor, Lauren $\quad 76$

Gagarinas, Gabriella 7

Gagarinas, Isaac 19

Galkin, Christianna 76
Gallardo, Joelle $\quad 72$

Gallogly, Meghan 111

Garber, Katelynn $\quad 76$

Garcia Lambis, Maria

Garcia, Daniel 93

Garlock, Allison $\quad 93$

Gartner, Jonathan $\quad 76$

Gatchell, Joel $\quad 66$

Gates, Andrew $\quad 77$

Gearhart, Giselle $\quad 93$

Gebauer, Jacob $\quad 93$

Gebauer, Philip $\quad 87$

Geist, Alissa $\quad 47$

Geist, William $\quad 77$

Gentry, Michaela $\quad 83$

Gernert, Melissa $\quad 93$

Gibboney, Kristopher 93

Gibbs, David 93

Gibbs, Samantha $\quad 72$

Gibson, Collin $\quad 83$

Gifford, Emily $\quad 87$

Gillis, Matthew $\quad 17$

Gillum, Joshua $\quad 77$

Glaum, Trevor $\quad 77$

Golden, Dorothy 77

Golding, Amanda 77

Gonzalez Osorio, Priscila

Gordon, Nicole $\quad 77$

Gorlich, Faith $\quad 94$

Gosman, Ashley 87

Gosman, Katie 83

Gosman, Meagan 77

Gowin, Marcus $\quad 72$

Grady, Samantha 77

Graeff, Ben 26

Graeff, Daniel 26

Graham, Avery $\quad 72$

Gray, Wesley $\quad 77$

Green, Quinton 11,62

Gregory, Grace $\quad 77$

Grether, Sara $\quad 94$

Grigorenko, Margaret30

Griffith, Zach $\quad 35$

Grover, Sarah $\quad 83$

Grunenwald, Elizabeth

Grunenwald, Jonathon

Guaita, Joshua 8

Guckenberger, Joshua 11

Gundolf, Faith $\quad 70$

Gupta, Elizabeth $\quad 77$

Gustafson, Luke $\quad 77$

Haddix, Alexandria 94

Hahnenstein, Hannah

Hall, Katherine $\quad 77$

Hallett, Hannah 94

Hamby, Jonah $\quad 72$

Hamilton, Breanna 94 
fandel, Mark 87

Ianey, Amber $\quad 83$

Iannay, Kristin $\quad 71$

Iannay, Luke 83

Hansher, Blake $\quad 23$

Ianson, Joy 94

Hardwick, Halie $\quad 65,111$

Harless, Kennedy 94, 111

Jarmon, Elizabeth 51

Harper, Leah 94

Harris, Kailee $\quad 77$

Harris, Robert $\quad 61$

Harris, Sarah 94

Hart, Connor $\quad 87$

Hartings, Sierra $\quad 94$

Hartt, Joshua 94

Harvey, Noah $\quad 30,77$

Haskins, William 72

Hasty, Holly $\quad 77$

Hayden, Anita $\quad 72$

Haymond, Jeffrey 107

Heagle, Joshua $\quad 77$

Heath, Nicole $\quad 77$

Heatwole, Alexis $\quad 94$

Hedlund, Jenna 7

Heft, Hannah $\quad 11,94$

Heideman, Hallie 83

Heidenreich, Emily 94

Hein, Elena $\quad 51,94$

Heise, Joseph 83

Hellwig, Kelly 108

Helmers, David 70

Hendershot, Courtland

Henig, Luke $\quad 72$

Henninger, Brevin 70

Hershberger, Samantha

Hertzel, Elizabeth 111

Hess, Elisabeth $\quad 94$

Hess, Megan 94

Hess, William 77

Hieronymus, Brooke 94

Hiett, Michael 87

Higgins, Bonnie 94

Hill, Emma 43

Hingst, Gabriel $\quad 77$

Hingst, Rachel $\quad 77$

Hinks, Meredith 94

Hintz, Abigail 7

Hirschler, Josiah 83

Hitchcock, Michael 94

Hogsed, Mark 77

Holliday, Cecily $\quad 59$

Hollis, Lauren $\quad 65$

Holst, Brianna 94

Holst, Mykaela $\quad 77$

Hood, Marshall $\quad 94$

Hopkins, Jordan 77
Hoshiko, Jackson

Hostetler, Rachel 72

Howard, Samuel $\quad 77$

Howell, Riley $\quad 77$

Hudson, Jonathan 95

Huelskamp, Trent 84

Huffman, Aaron 3

Huffman, Ashlyn 63

Hughes, Bryce $\quad 68$

Hulbert, Benjamin 66

Humphrey, Sara 95

Hurst, Madeline $\quad 87$

Huschilt, Tabitha 95

Hutchison, Samuel 77

Huyser, Katelyn 95

Hyslop, Ashley $\quad 77$

mfeld, Gabrielle 95

Imhoff, Sarah $\quad 95$

Ingis, Stephen 95

Ingle, Isabel 77

Isenhower, David $\quad 77$

Istrate, Adora $\quad 77$

Istrate, Alex $\quad 87$

Ivester, Michele $\quad 35$

Ivester, Taylor $\quad 35$

Jackson, Arianna 95

Jackson, Caleb 95

Jackson, Malena 84

Jacob, Maria 95

Jacobs, Abbey 95

Jacobs, Lauren $\quad 12,95$

Jacobs, Meghan 95

Jacobsen, Lydia $\quad 95$

Jarboe, Kaitlin 95

Jeffe, Mitchell 61

Jefson, Lydia $\quad 84$

Jenkins, Chester $\quad 43$

Jenkins, Gloria $\quad 84$

Jenks, Abigail $\quad 52,84$

Jenks, Joshua 95

Jennings, Sarah 95

Jirakasemnukul, Vorrapon 72

Johnson, Anna 95

Johnson, Benjamin 77

Johnson, Erin $\quad 95$

Johnson, Hanah 67

Johnson, Hunter 12

Johnson, Sarah 95

Johnson, Savannah 95

Johnston, Hannah 95

Johnston, Kyrie Eleyson

Joiner, Hannah 95, 104

Jones, Adelinne 87

Jones, Kendall 96, 104

Jones, Sarah 77

Jordan, James $\quad 84$

Kaiser, Claire
Kakuk, Evan

Kareck, Josiah

77

Karg, Hannah

23, 77

Kaster, Anna

77

Katahara, Bryce

96, 104, 111

Kauffmann, David $\quad$ 20,87

Kauffmann, Rachel 77

Kaynor, Jenna

78

Keefer, Allyson

78

Keiter, Anna

96, 104

Kellerman, Emery

Kelly, Isaiah

70

Kemp, Zachary

78

Kempton, Paul

96, 104

Kempton, Paul

Kennedy, Katelyn

96

104

Kennedy, Michael

96, 104

Kennell, Emily

78

78

Khosrovani, Elsah

Kicinski, Julia

84

Kigar, Sarah

96,104

Kilgore, Hannah

78

Kimble, Jeremy

96,104

107

King, Abigail

78

King, Anna

$39,87,114$

King, Mallory

$96,104,115$

Kinniburgh, Emmaline $\quad 78$

Kistler, Andrew $\quad 96,104$

Klimek, Kristin 12

Kline, Kristen 111

Knowlton, Nathanael 73

Knowlton, Nicolas 84

Knudson, Benjamin 44

Kohl, Timothy 84

Kohler, Naomi 96, 104

Kollmar, David $\quad 78$

Koogler, Hannah 84

Koteskey, Geoffrey 96,104

Koteskey, Katie $\quad 78$

Krakora, Abigail $\quad 96,104$

Kroger, Sarah $\quad 84$

Krudop, Julie $\quad 96,104$

Krueger, Thaddeus 78

Kuhn, Courtnie $\quad 50$

Kuhn, Emily $\quad 87$

Kulp, Karis $\quad 78$

Kyler, David $\quad 78$

Lachance, Benjamin 96, 104

Laflamme, Joslyn $\quad 87,114$

Laing, Kelsey 87

Lambert, Keenen 64

Lamonte, Shannon 96, 104

Lance, Chloe $\quad 96,104$

Landis, Todd $\quad 7$

Lange, Summer $\quad 84$

Lankford, Joshua $\quad 96,104$

Lansford, Josiah $\quad 96,104$ 


\begin{tabular}{|c|c|c|c|c|c|}
\hline Lansford, Noelle & 87 & Mathews, John & 73 & Mourand, Elise & 78 \\
\hline Largent, Meghan & 96,104 & Mathisen, Alec & 7 & Mowery, Grace & 78 \\
\hline Larsen, Marcus & 78 & Matson, Lauren & 97,105 & Mumme, Marylou & 98 \\
\hline Larson, Andrea & 35 & Mattackal, David & 97,105 & Mumme, Nathan & 107 \\
\hline Lashuay, Jacob & 96 & Mattocks, Emily & 26 & Mummert, Anthony & 29,98 \\
\hline Lashuay, Jacob & 104 & Maue, Sarah & 84 & Mummert, Emma & 98 \\
\hline Lasich, Laura & 87 & Maughmer, Branden & 62 & Mundell, Jacob & 98 \\
\hline Lawrence, Breanna & 84 & May, Allison & 84 & Mundell, Joshua & 84 \\
\hline Learned, Nia & 96,104 & Maynard, Madison & 84 & Munoz, Antonio & 43 \\
\hline Lebs, Brianna & 78 & McBride, Trey & 78 & Munsell, Marshall & 98 \\
\hline Lee, Jason & 30,107 & McCain, Michael & 97,105 & Murakami, Ren & 78 \\
\hline Lee, Nathan & 84 & McClain, Elizabeth & 84 & Murch, Rebecca & 73 \\
\hline Lehman, Noah & 78 & McClain, Jonathan & 97,105 & Murray, Abigail & 98 \\
\hline Leightenheimer, Alys & 78 & McClain, Rebekah & 97,105 & Mussinan, Shallyn & 78 \\
\hline Leitch, Zachary & 35 & McClean, Allison & 7 & Myers, Kendall & 98 \\
\hline Lemacks, Morgan & 78 & McCormick, Abigail & 97,105 & Naugle, Madison & 84 \\
\hline Lenahan, Caleb & 78 & McCullough, Erin & 97,105 & Neer, Courtney & 78 \\
\hline Lenze, Madeline & 104 & McDonell, David & 97,105 & Neer, Laura & 88 \\
\hline Lenze, Madeline & 96 & McElroy, James & 97,105 & Nelson, Meredith & 88 \\
\hline Lewis, Elisabeth & 78 & McFarlane, Kelly & 97,105 & Nesmith, Rachel & 78 \\
\hline Lewis, Emily & 78 & McKay, Andrew & 97,105 & Newell, Camden & 79 \\
\hline Ley, Kylee & 78 & McKenna, Laura & 88 & Newell, Kristina & 79 \\
\hline Liang, Eden & 71,84 & McKinion, Randall & 26 & Nguyen, Khai & 84 \\
\hline Limbers, Alexis & $16,96,105$ & McMillan, Andrew & 97,105 & Nice, Dillon & 79 \\
\hline Linville, Benjamin & 84 & McMillan, Madison & 78 & Nicholls, Hannah & 79 \\
\hline Linville, Katie & 87,115 & McMurray, Alexandra & a $\quad 97,105$ & Nicholls, Kaitlyn & 79 \\
\hline Lively, Daniel & 87 & McPherson, Halee & $52,97,105$ & Nichols, Gretchen & 79 \\
\hline Lloyd, Nathan & 73 & Mellinger, Ahna & 88 & Nichols, Hannah & 39 \\
\hline Long, Theresa & 67 & Melson, Richard & 17 & Noe, Rachel & 79 \\
\hline Longe, Gabrielle & 97,105 & Mentzer, Stephen & 88 & Nohrer, Hannah & 84 \\
\hline Lord, Heather & 69 & Merchant, Diane & 13 & Noll, Taylor & 57 \\
\hline Loula, Trevor & 87 & Merk, Ryan & 97,105 & Noller, Brianna & 98,111 \\
\hline Love, Addalyn & 87 & Messer, Cynthia & 114 & Norden, Sophia & 57 \\
\hline Luiken, Carina & 87 & Metcalf, Jonah & 78 & Nordquist, Lydia & 7 \\
\hline Luke, Braylen & 84 & Metzger, Sharalin & 78 & Norfleet, Sarah & 79 \\
\hline Lum, Rachel & 78 & Miedema, Carter & 97,105 & Norman, Grace & 67 \\
\hline Luttenegger, Anna & 97,105 & Miller, Andrew & 78 & Norris, Julianna & 79 \\
\hline Lutz, Kara & 78 & Miller, Brooke & 69 & Novak, Elisabeth & 79 \\
\hline Lyall, Timothy & 84 & Miller, Charis & 78 & Nunan, Taylor & 98 \\
\hline Lynch, Rachel & $73,97,105$ & Miller, Emily & 78 & Nuse, Ellison & 98 \\
\hline Lyons, Jonathan & 17 & Miller, Eric & 78 & Nyberg, Claire & 79 \\
\hline Macdonald, Lacy & 78 & Miller, Jesse & 97 & Nyquist, Richard & 88 \\
\hline Mach, Kiley & 88 & Miller, Kathleen & 108 & O'Brien, Hayden & 79 \\
\hline Machia, KT & 19 & Miller, Macy & 8 & O'Brien, Logan & 98 \\
\hline Magnuson, Jason & 84 & Miller, Paul & 84 & O'Brien, Madeline & 84 \\
\hline Mahek, Nicholas & 73 & Mills, Kristina & 88 & O'Mara, Chris & 17 \\
\hline Mantis, Nicholas & 17 & Minier, John & 73 & O'Neal, Gabriel & 98 \\
\hline Marcum, Levi & 88 & Miskimen, Matthew & 84 & O'Neal, Haile & 52 \\
\hline Marks, Katherine & 84 & Mitchell, Aricka & 97 & Oedy, Michael & 98 \\
\hline Marques, Tamara & 73 & Mitchell, Shaun & 98 & Ogden, Jillian & 84 \\
\hline Marshall, Joseph & 97,105 & Mitten, Julianna & $19,36,98$ & \multicolumn{2}{|c|}{ Ojukwu, Chukwuebuka } \\
\hline Martin, Benjamin & 73 & Molinari, Jana & 84 & Olari, Benjamin & 70 \\
\hline Martin, Hallie & 97,105 & Moore, Hope & 98 & Oldham, Beth & 12,88 \\
\hline Martin, Paige & 97,105 & Morrison, Malachi & 78 & Olsen, Julia & 98 \\
\hline Martone, Aleah & 84 & Moses, Benjamin & 98 & Ooms, Clayton & 79 \\
\hline Marvin, Adam & 84 & Moses, Molly & 88 & Ooms, Ethan & 98,115 \\
\hline Mathew, Rufus & 84 & Moss, Cole & 64 & Osborne, Nathan & 73 \\
\hline
\end{tabular}


Owens, Elisa

?aris, Alexandra 23

?ark, Westin 47

?arker, Daniel 98

?arker, Johndavid 84

?arks, Kristy $\quad 98$

?arsons, Jordan 79

Jaschall, Jacob $\quad 98$

Jatricca, Jeremy $\quad 88$

?atterson, Olivia $\quad 98,111$

?atterson, Triniti 79

Jattison, Lila $\quad 98$

Paulus, Jason $\quad 88$

Jayne, James $\quad 79$

?ayne, Joshua $\quad 99$

Jayne, Shelby $\quad 99$

eak, Olivia 88

'endleton, Caleb 58

Penner, Lauren 20,52,84

Pennington, Rachel 79

'ennington, Sarah 99

’enny, Kelsea ' 99

'eterson, Gwendolyn 44, 99

'eterson, Kurtis $\quad 99$

'eterson, Lael $\quad 79$

'etroff, Joseph 99

'etroff, Mitchell 73

'etron, Anna $\quad 99$

'etron, Donald 99

'ettus, Matthew 8

'hillips, Natalie $\quad 99$

'ierce, Andrew $\quad 79$

'ierce, Megan 79

itts, Emily $\quad 44,99$

'izarro, Anna 73

'lank, Amy $\quad 59$

lank, Monica 99

Jank, William 99

'oling, Dawson 64

oole, Carlie $\quad 99$

'orter, Beth 30, 107

ottle, Carolyn $\quad 99$

otts, Breanna 88

owell, Jennifer $\quad 26,84$

'owell, Kimberly $\quad 99,11$

owers, Tristan 79

raamsma, Saskia 73

rater, Kayla 99

riest, Bethany 99

riestly, Carmen 79

unzi, Alyson $\quad 108$

urcell, Houston 79

utnam, Bethany 99

Zuade, Reuben 8,79

Zuandt, Hannah 26

Raczykowski, Deborah

Rager, Ryan
Rakowski, Cassandra 99

Ramirez, Jaquelin $\quad 79$

Ramsey, Allison $\quad 73$

Rao, Cunyun 73

Raquet, Carolyn $\quad 99$

Rasey, Christiana $\quad 99$

Ratliff, Jacob $\quad 99$

Redmond, Michael 99

Redondo, Keyla $\quad 100$

Reed, Teghan 23

Reep, Jeffrey 108

Reese, Nicole $\quad 100$

Reilly, Kayla $\quad 88$

Renner, Andrew $\quad 73$

Reynolds, Ashley $\quad 79$

Rice, James $\quad 100$

Rich, David $\quad 107$

Richmond, Benjamin 88

Riddle, Ashley $\quad 88$

Riebel, Chase $\quad 79$

Riebel, Paige $\quad 100$

Ries, Lauren $\quad 100$

Riley, Makayla 7

Ringley, Samuel 11

Ringstrand, Jake $\quad 8,88$

Rivas, Abigail $\quad 100$

Roberts, Alyssa $\quad 100$

Roberts, Madison 88

Roberts, Riley $\quad 100$

Robinson, Ayja $\quad 20,100$

Robinson, Justin $\quad 79$

Robinson, Matthew 71, 100

Rohm, Asher $\quad 79$

Rossiter, Christopher 100

Rourke, Anne $\quad 69$

Rowan, Mark 56

Rowe, Wes 69

Roy, Gabriel $\quad 79$

Rubosky, Zachary $\quad 44,100$

Russell, Abigail $\quad 100$

Rutherford, Jordyn 79

Ryan, Jonathan 79

Ryan, Mallory $\quad 79$

Ryan, Zak $\quad 79$

Saieg, Robert $\quad 73$

Salser, Claire $\quad 88$

Salviano, Andre $\quad 56$

Sams, Miranda $\quad 100$

Sanders, Sarah $\quad 100$

Sansalone, Keith Dominic 79

Santi, Marissa $\quad 79$

Sarver, Lydia $\quad 100$

Saunders, Erica $\quad 79$

Savard, Emily $\quad 100$

Scanlan, Samantha 100

Scarberry, Shawn 79

Schaffer, Isabella 7
Schantz, Ariel

100

Schindler, Caroline 80

Schmidt, Chad $\quad 100$

Schmidt, Timothy 80

Schoenwald, Stephen 100

Schroer, Andrew $\quad 100$

Schultz, Jeremy 100

Schultz, Russel $\quad 58$

Schuman, Michelle 85

Scott, Joel 85

Scott, Lerato $\quad 80$

Seabra, Kayla 8

Seals, Connor $\quad 26,85$

Searcy, Sadie $\quad 100$

Sebring, Katelyn $\quad 80$

Secor, Dane 36

Sexton, Grace 8

Shade, Donald 101

Shaffer, Abigail $\quad 12,52$

Shannon, Isiah 73

Shaw Ojeda, Sarah 44, 101, 112

Shawver, Wesley 101

Sheard, Benjamin 61

Shearer, Amiel 101

Shedden, Brooke 101

Shemelia, Presley 19

Shemelia, Presley-Peyton 101

Shimabenga, Ezra 80

Shoultz, Robert 101

Showers, Sage $\quad 80$

Shrum, Kelsey 101

Siefert, Victoria $\quad 85$

Silveira, Nicholas $\quad 85$

Sims, Kevin $\quad 107$

Sinkonis, David 101

Sizer, Sarah $\quad 35$

Slater, Sarah $\quad 85$

Slifer, Brandon $\quad 101$

Smith, Corrissa $\quad 80$

Smith, Emma 7

Smith, Jeffrey 111

Smith, Karissa $\quad 80$

Smith, Maria $\quad 80$

Smith, McKenna 69

Snellenberger, Jacob 101

Snyder, Abbigayle 39

Snyder, Isaac $\quad 80$

Sodonis, Chloe $\quad 88$

Solomon, Alvin $\quad 80$

Soriano, Andrea 39

Souder, Eric $\quad 101$

Spaulding, Micah $\quad 80$

Speed, Kaziah 39

Spencer, Mark : 107

Spencer, Nicole $\quad 101$

Spencer, Timothy 85

Spurgeon, Haley 101 


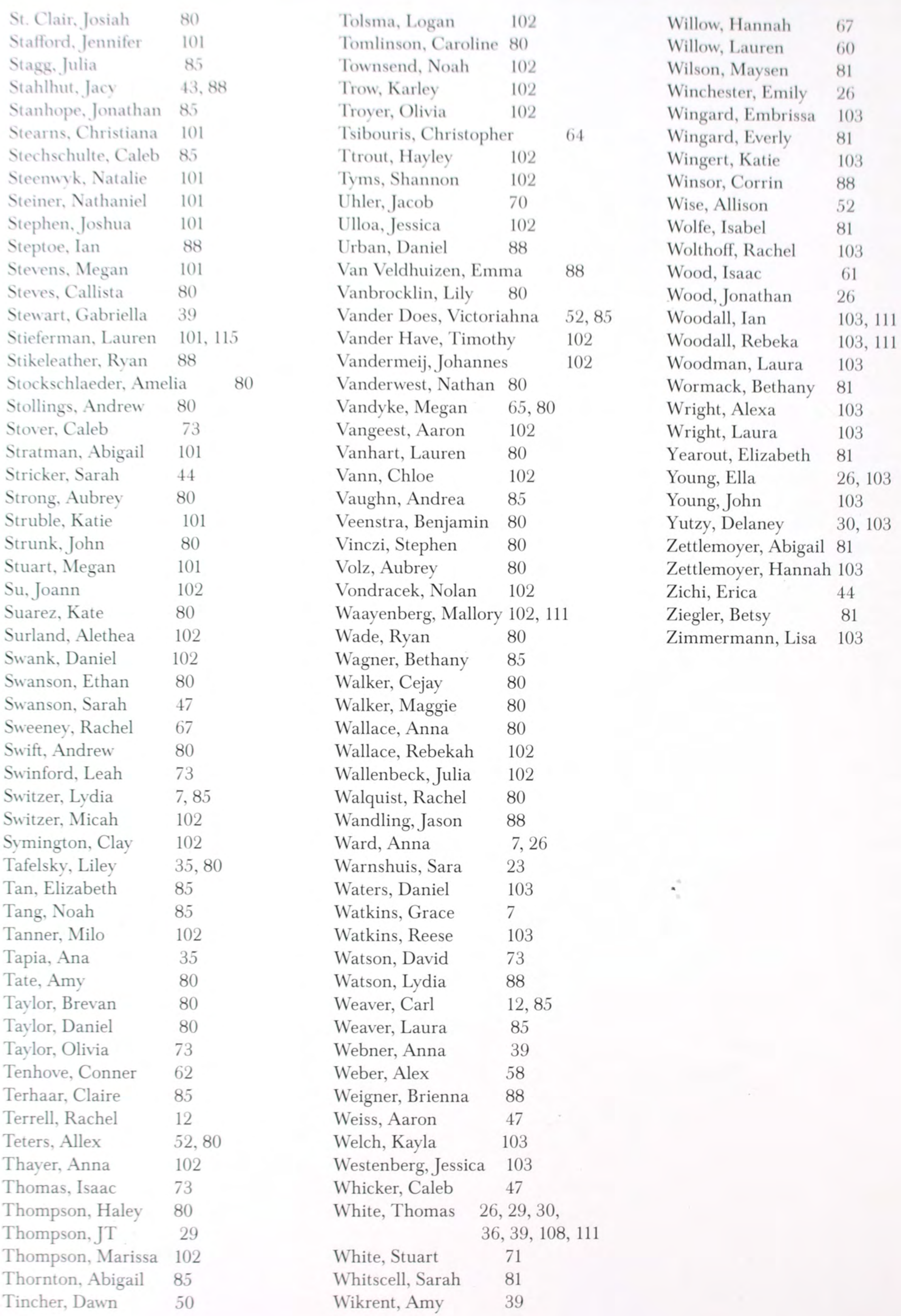









\section{8}

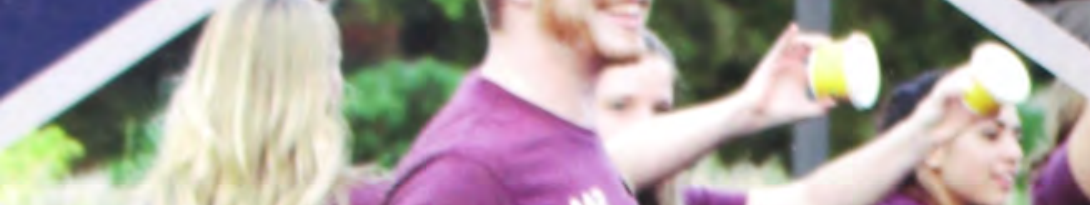

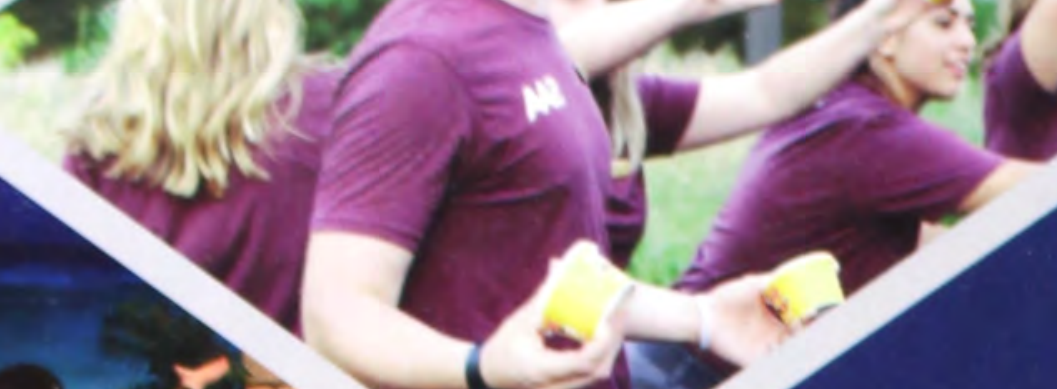

$-20$

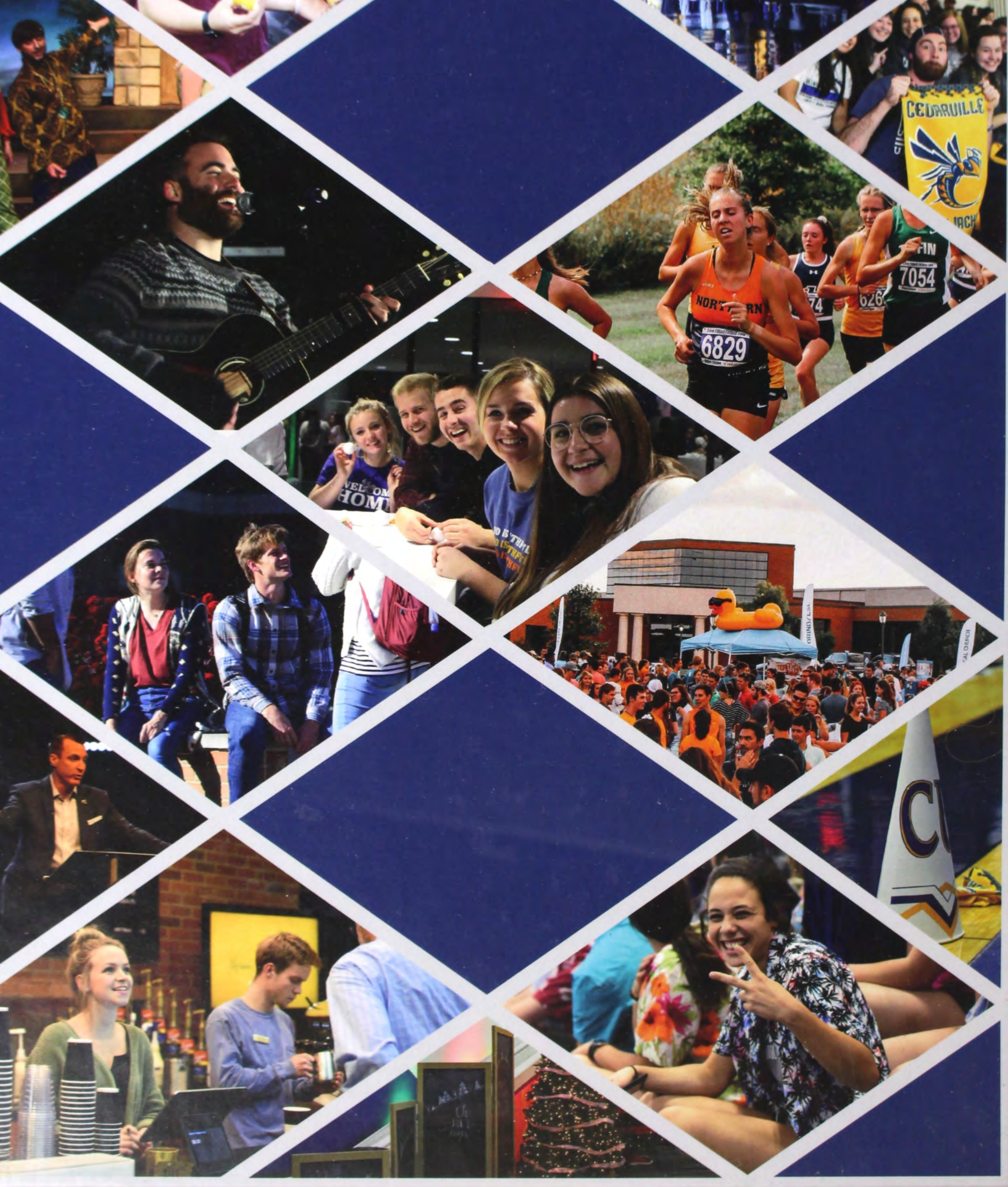

$\rightarrow \cos x^{2} \mathrm{x}^{2}$

\section{0.}

constion

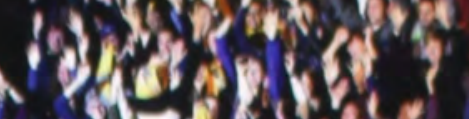
Stent 